\title{
TOXICOLOGICAL PROFILE FOR FUEL OILS
}

\section{U.S. DEPARTMENT OF HEALTH AND HUMAN SERVICES \\ Public Health Service \\ Agency for Toxic Substances and Disease Registry}

June 1995 


\section{DISCLAIMER}

The use of company or product name(s) is for identification only and does not imply endorsement by the Agency for Toxic Substances and Disease Registry. 


\section{UPDATE STATEMENT}

A Toxicological Profile for Fuel Oils was released on November 1993. This edition supersedes any previously released draft or final profile.

Toxicological profiles are revised and republished as necessary, but no less than once every three years. For information regarding the update status of previously released profiles, contact ATSDR at:

Agency for Toxic Substances and Disease Registry

Division of Toxicology/Toxicology Information Branch

1600 Clifton Road NE, E-29

Atlanta, Georgia 30333 


\section{FOREWORD}

This toxicological profile is prepared in accordance with guidelines developed by ATSDR and the Environmental Protection Agency (EPA) and in support of Department of Defense information needs. The original guidelines were published in the Federal Register on April 17, 1987. Each profile will be revised and republished as necessary.

The ATSDR toxicological profile succinctly characterizes the toxicologic and adverse health effects information for the hazardous substance being described. Each profile identifies and reviews the key literature (that has been peer-reviewed) that describes a hazardous substance's toxicologic properties. Other pertinent literature is also presented, but described in less detail than the key studies. The profile is not intended to be an exhaustive document; however, more comprehensive sources of specialty information are referenced.

Each toxicological profile begins with a public health statement, which describes in nontechnical language a substance's relevant toxicological properties. Following the public health statement is information concerning levels of significant human exposure and, when known, significant health effects. The adequacy of information to determine a substance's health effects is described in a health effects summary. Data needs that are significant to protect public health will be identified by ATSDR and the EPA. The focus of the profiles is on health and toxicologic information; therefore, we have included this information in the beginning of the document.

Each profile must include the following:

(A) The examination, summary, and interpretation of available toxicologic information and epidemiologic evaluations on a hazardous substance in order to ascertain the levels of significant human exposure for the substance and the associated acute, subacute, and chronic health effects.

(B) A determination of whether adequate information on the health effects of each substance is available or in the process of development to determine levels of exposure that present a significant risk to human health of acute, subacute, and chronic health effects.

(C) When appropriate, identification of toxicologic testing needed to identify the types or levels of exposure that might present significant risk of adverse health effects in humans.

The principal audiences for the toxicological profiles are health professionals at the federal, state, and local levels, interested private sector organizations and groups, and members of the public.

The toxicological profiles are developed in response to the Superfund Amendments and Reauthorization Act (SARA) of 1986 (Public Law 99-499) which amended the Comprehensive Environmental Response, Compensation, and Liability Act of 1980 (CERCLA or Superfund). Section 211 of SARA also amended Title 10 of the U. S. Code, creating the Defense Environmental Restoration Program. Section 2704(a) of Title 10 of the U. S. Code directs the Secretary of Defense to notify the Secretary of Health and Human Services of not less than 25 of the most commonly found unregulated hazardous substances at defense facilities.

Section 2704(b) of Title 10 of the U. S. Code directs the Administrator of the Agency for Toxic Substances and Disease Registry (ATSDR) to prepare a toxicological profile for each substance on the list provided by the Secretary of Defense under subsection (b). 
Foreword

This profile reflects our assessment of all relevant toxicologic testing and information that has been peer reviewed. It has been reviewed by scientists from ATSDR, the Centers for Disease Control and Prevention (CDC), and other federal agencies. It has also been reviewed by a panel of nongovernment peer reviewers and was made available for public review. Final responsibility for the contents and views expressed in this toxicological profile resides with ATSDR.

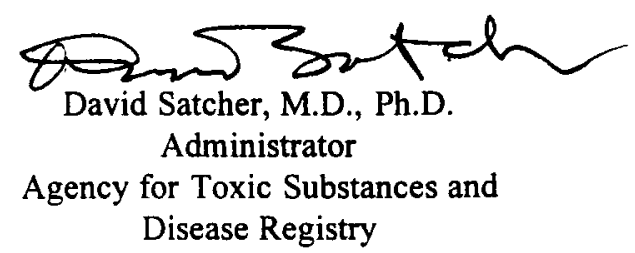




\section{CONTRIBUTORS}

\section{CHEMICAL MANAGER(S)/AUTHOR(S):}

John F. Risher, Ph.D.

ATSDR, Division of Toxicology, Atlanta, GA

Steven W. Rhodes, Ph.D.

Sciences International, Inc., Alexandria, VA

THE PROFILE HAS UNDERGONE THE FOLLOWING ATSDR INTERNAL REVIEWS:

1. Green Border Review. Green Border review assures the consistency with ATSDR policy.

2. Health Effects Review. The Health Effects Review Committee examines the health effects chapter of each profile for consistency and accuracy in interpreting health effects and classifying endpoints.

3. Minimal Risk Level Review. The Minimal Risk Level Workgroup considers issues relevant to substance-specific minimal risk levels (MRLs), reviews the health effects database of each profile, and makes recommendations for derivation of MRLs.

4. Quality Assurance Review. The Quality Assurance Branch of the Division of Toxicology assures that consistency across profiles is maintained, identifies any significant problems in format or content, and establishes that Guidance has been followed. 


\section{PEER REVIEW}

A peer review panel was assembled for fuel oils. The panel consisted of the following members:

1. Dr. Rick Cardwell, Head of Toxicology, Parametrix, Inc., Kirkland, Washington

2. Dr. Charles Ward, Private Consultant, Pittsburgh, Pennsylvania

3. Dr. Laurence M. Holland, Laboratory Associate, Los Alamos National Laboratory, Los Alamos, New Mexico

These experts collectively have knowledge of fuel oils' physical and chemical properties, toxicokinetics, key health end points, mechanisms of action, human and animal exposure, and quantification of risk to humans. All reviewers were selected in conformity with the conditions for peer review specified in Section 104(i)(13) of the Comprehensive Environmental Response, Compensation, and Liability Act, as amended.

Scientists from the Agency for Toxic Substances and Disease Registry (ATSDR) have reviewed the peer reviewers' comments and determined which comments will be included in the profile. A listing of the peer reviewers' comments not incorporated in the profile, with a brief explanation of the rationale for their exclusion, exists as part of the administrative record for this compound. A list of databases reviewed and a list of unpublished documents cited are also included in the administrative record.

The citation of the peer review panel should not be understood to imply its approval of the profile's final content. The responsibility for the content of this profile lies with the ATSDR. 


\section{CONTENTS}

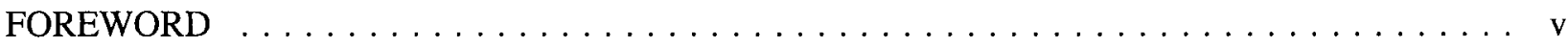

CONTRIBUTORS $\ldots \ldots \ldots \ldots \ldots \ldots \ldots \ldots \ldots \ldots \ldots \ldots \ldots \ldots \ldots \ldots \ldots$ vii

PEER REVIEW $\ldots \ldots \ldots \ldots \ldots \ldots \ldots \ldots \ldots \ldots \ldots \ldots \ldots \ldots \ldots \ldots \ldots \ldots$

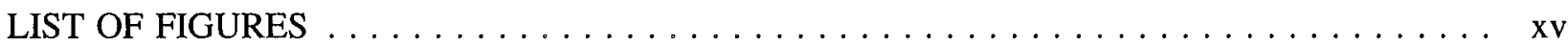

LIST OF TABLES $\ldots \ldots \ldots \ldots \ldots \ldots \ldots \ldots \ldots \ldots \ldots \ldots \ldots \ldots \ldots \ldots \ldots \ldots$

1. PUBLIC HEALTH STATEMENT $\ldots \ldots \ldots \ldots \ldots \ldots \ldots \ldots \ldots \ldots \ldots \ldots \ldots$

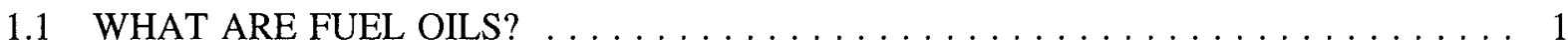

1.2 WHAT HAPPENS TO FUEL OILS WHEN THEY ENTER THE ENVIRONMENT? . . . 3

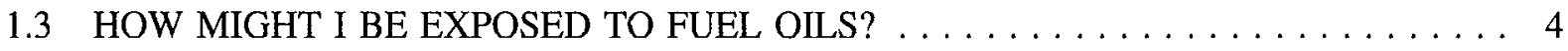

1.4 HOW CAN FUEL OILS ENTER AND LEAVE MY BODY? $\ldots \ldots \ldots \ldots \ldots \ldots \ldots \ldots$

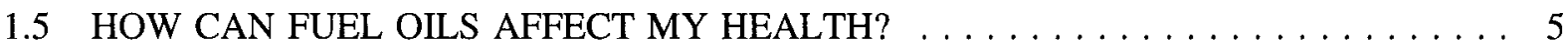

1.6 IS THERE A MEDICAL TEST TO DETERMINE WHETHER I HAVE BEEN

EXPOSED TO FUEL OILS? . . . . . . . . . . . . . . . . . . . . . 6

1.7 WHAT RECOMMENDATIONS HAS THE FEDERAL GOVERNMENT MADE TO

PROTECT HUMAN HEALTH? $\ldots \ldots \ldots \ldots \ldots \ldots \ldots \ldots \ldots \ldots \ldots \ldots$

1.8 WHERE CAN I GET MORE INFORMATION? $\ldots \ldots \ldots \ldots \ldots \ldots \ldots \ldots \ldots \ldots$

2. HEALTH EFFECTS $\ldots \ldots \ldots \ldots \ldots \ldots \ldots \ldots \ldots \ldots \ldots \ldots$

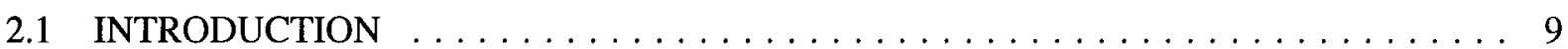

2.2 DISCUSSION OF HEALTH EFFECTS BY ROUTE OF EXPOSURE $\ldots \ldots \ldots \ldots \ldots$

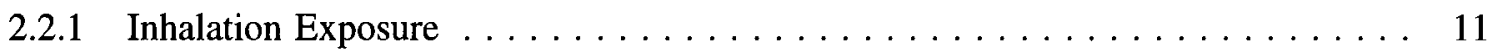

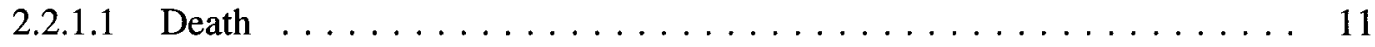

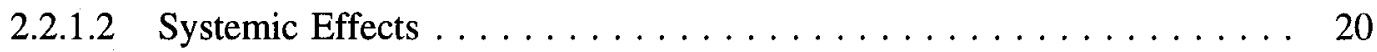

2.2.1.3 Immunological and Lymphoreticular Effects . . . . . . . . . . 28

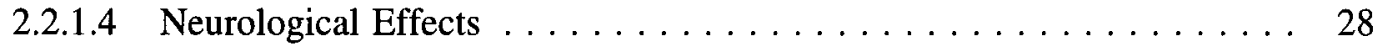

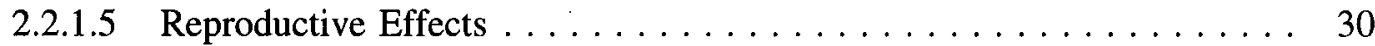

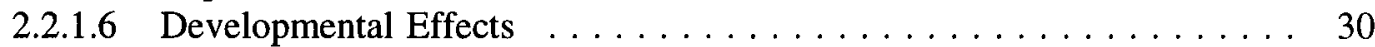

2.2.1.7 Genotoxic Effects . . . . . . . . . . . . . . . . . . . . 30

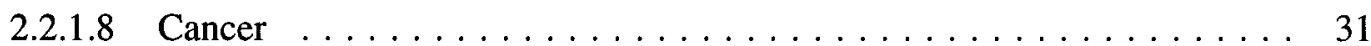

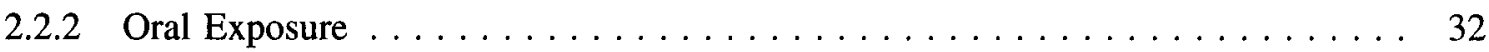

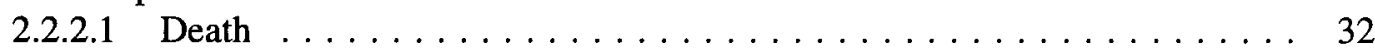

2.2.2.2 Systemic Effects ...................... 33

2.2.2.3 Immunological and Lymphoreticular Effects . . . . . . . . . . . 41

2.2.2.4 Neurological Effects . . . . . . . . . . . . . . . . . . . 41

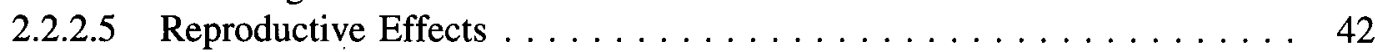

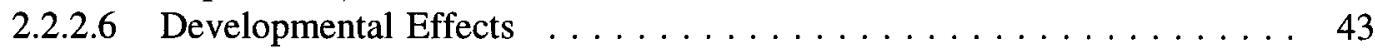

2.2.2.7 Genotoxic Effects . . . . . . . . . . . . . . . . . . . . . 43

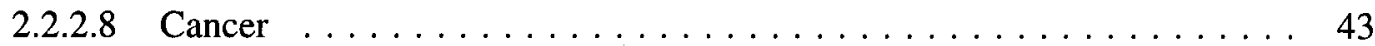

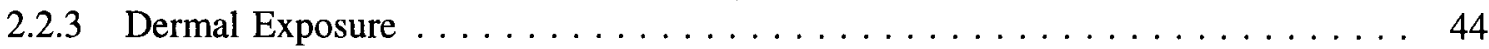

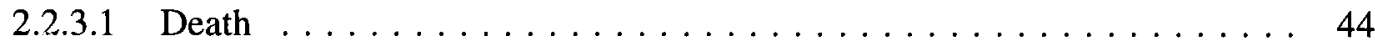

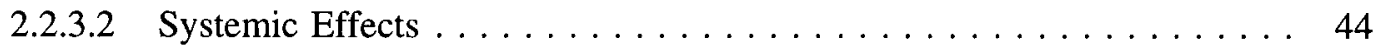


2.2.3.3 Immunological and Lymphoreticular Effects . . . . . . . . . . . . 57

2.2.3.4 Neurological Effects . . . . . . . . . . . . . . . . . . 57

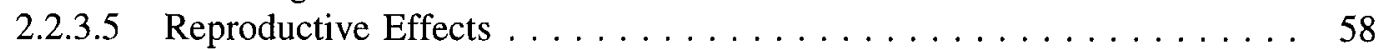

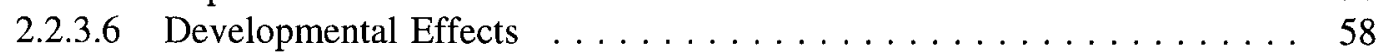

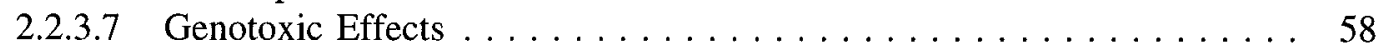

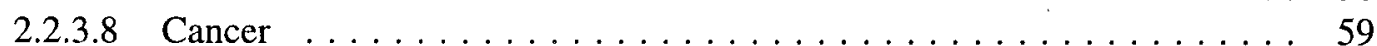

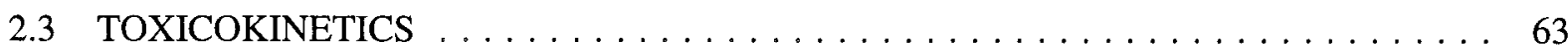

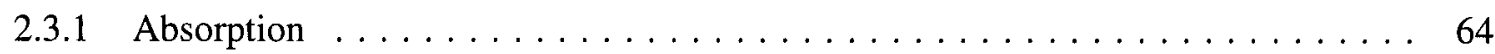

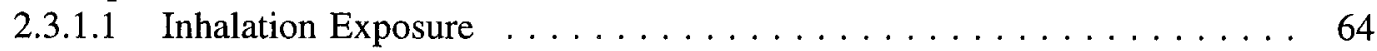

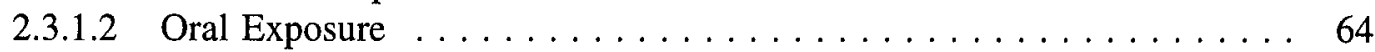

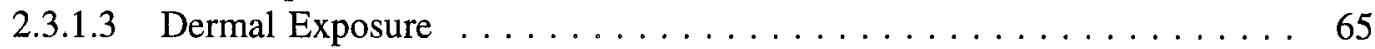

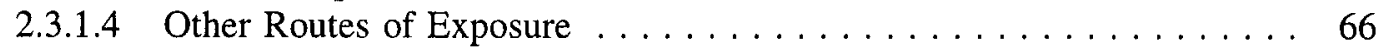

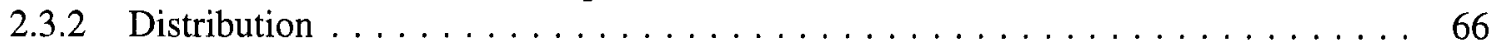

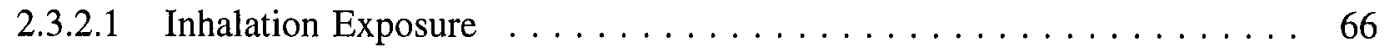

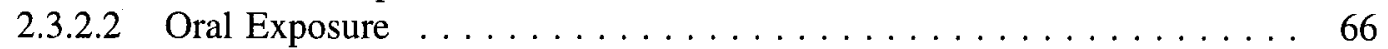

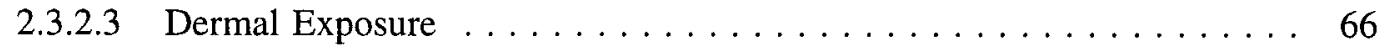

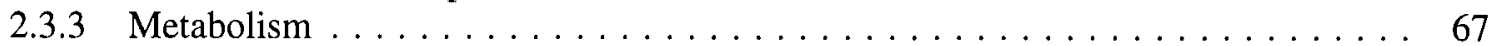

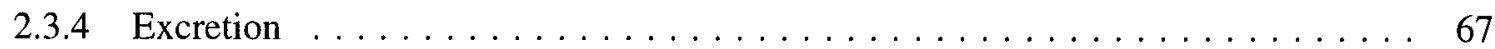

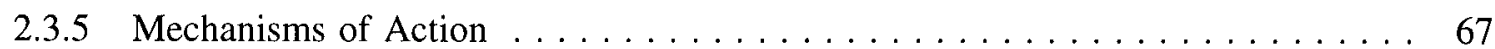

2.4 RELEVANCE TO PUBLIC HEALTH $\ldots \ldots \ldots \ldots \ldots \ldots \ldots \ldots \ldots \ldots$

2.5 BIOMARKERS OF EXPOSURE AND EFFECT $\ldots \ldots \ldots \ldots \ldots \ldots \ldots \ldots$

2.5.1 Biomarkers Used to Identify or Quantify Exposure to Fuel Oils . . . . . . . . . . 90

2.5.2 Biomarkers Used to Characterize Effects Caused by Fuel Oils . . . . . . . . . 90

2.6 INTERACTIONS WITH OTHER CHEMICALS $\ldots \ldots \ldots \ldots \ldots \ldots \ldots \ldots \ldots$

2.7 POPULATIONS THAT ARE UNUSUALLY SUSCEPTIBLE $\ldots \ldots \ldots \ldots \ldots \ldots \ldots$

2.8 METHODS OF REDUCING TOXIC EFFECTS $\ldots \ldots \ldots \ldots \ldots \ldots \ldots \ldots \ldots \ldots$

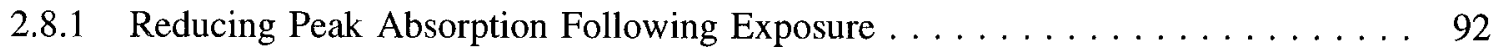

2.8 .2 Reducing Body Burden $\ldots \ldots \ldots \ldots \ldots \ldots \ldots \ldots \ldots \ldots$

2.8.3 Interfering with the Mechanism of Action for Toxic Effects . . . . . . . . . 94

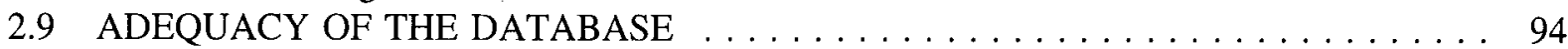

2.9.1 Existing Information on Health Effects of Fuel Oils . . . . . . . . . . . . . . 95

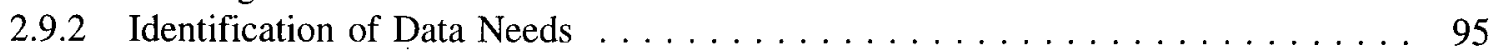

2.9 .3 On-going Studies . . . . . . . . . . . . . . . . . . . . 104

3. CHEMICAL AND PHYSICAL INFORMATION $\ldots \ldots \ldots \ldots \ldots \ldots \ldots \ldots \ldots \ldots$

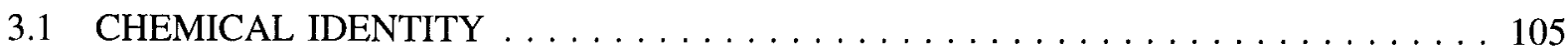

3.2 PHYSICAL AND CHEMICAL PROPERTIES $\ldots \ldots \ldots \ldots \ldots \ldots$

4. PRODUCTION, IMPORT, USE, AND DISPOSAL $\ldots \ldots \ldots \ldots \ldots \ldots \ldots \ldots \ldots$

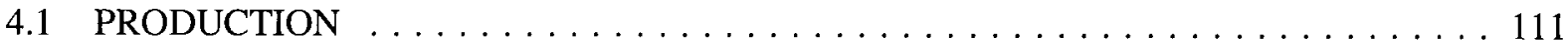

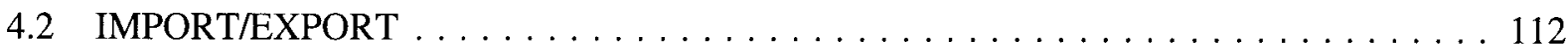

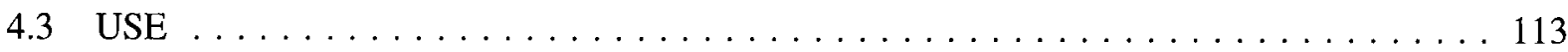

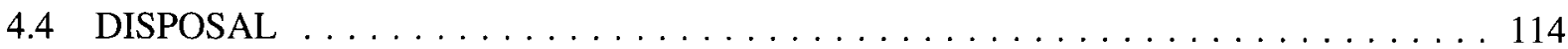

5. POTENTIAL FOR HUMAN EXPOSURE $\ldots \ldots \ldots \ldots \ldots \ldots \ldots \ldots \ldots \ldots \ldots \ldots$

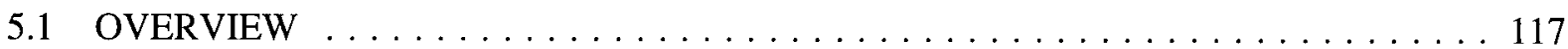

5.2 RELEASES TO THE ENVIRONMENT $\ldots \ldots \ldots \ldots \ldots \ldots \ldots \ldots \ldots \ldots \ldots$

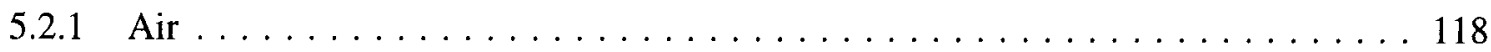

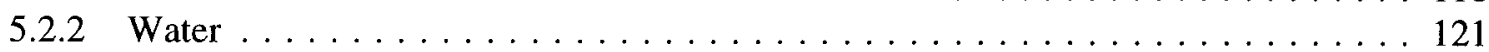




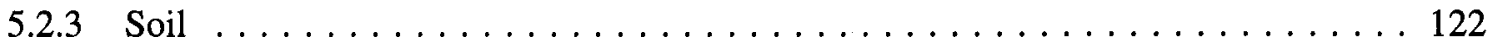

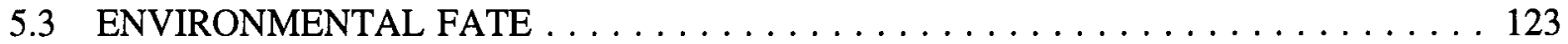

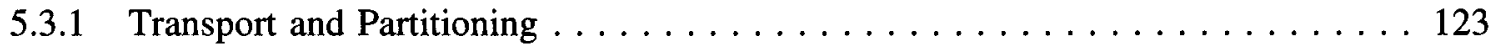

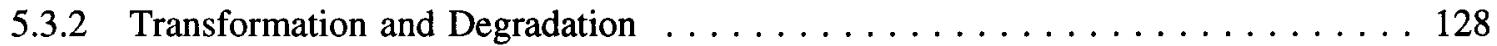

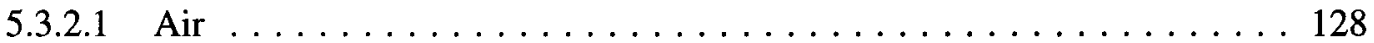

5.3 .2 .2 Water ........................... 128

5.3 .2 .3 Soil . . . . . . . . . . . . . . . . . . . . . 131

5.4 LEVELS MONITORED OR ESTIMATED IN THE ENVIRONMENT $\ldots \ldots \ldots \ldots$

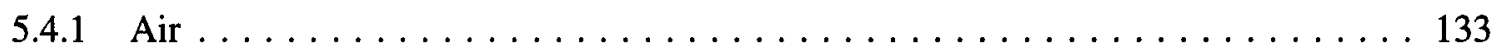

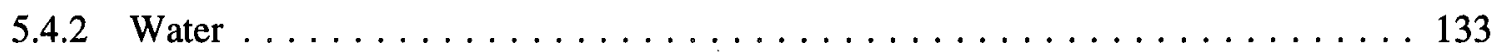

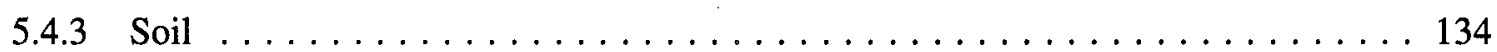

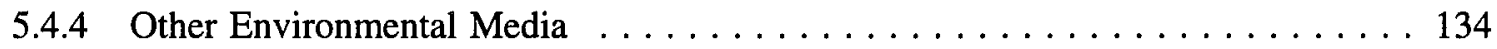

5.5 GENERAL POPULATION AND OCCUPATIONAL EXPOSURE $\ldots \ldots \ldots \ldots \ldots$

5.6 POPULATIONS WITH POTENTIALLY HIGH EXPOSURES $\ldots \ldots \ldots \ldots \ldots \ldots$

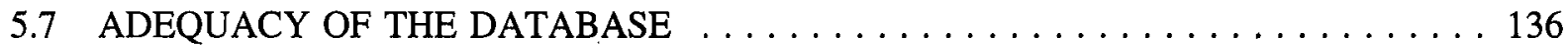

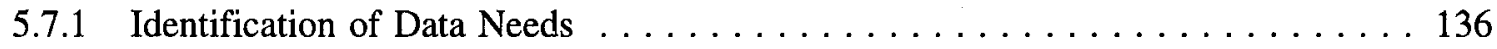

5.7 .2 On-going Studies . . . . . . . . . . . . . . . . . . . . 139

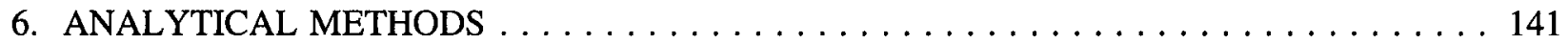

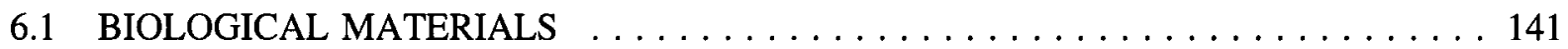

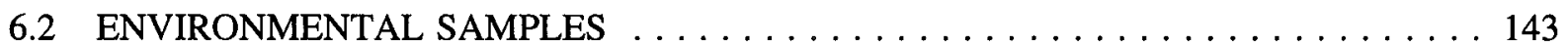

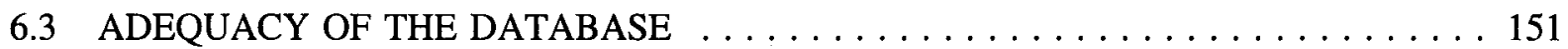

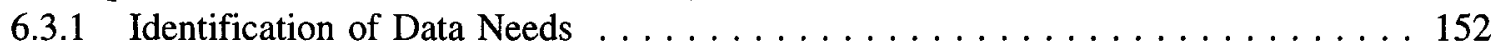

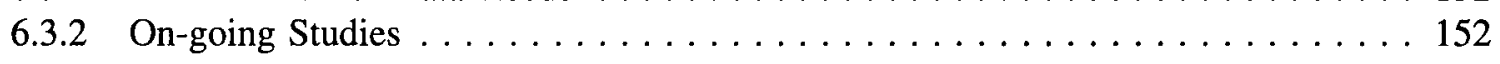

7. REGULATIONS AND ADVISORIES $\ldots \ldots \ldots \ldots \ldots \ldots \ldots \ldots \ldots \ldots \ldots \ldots \ldots$

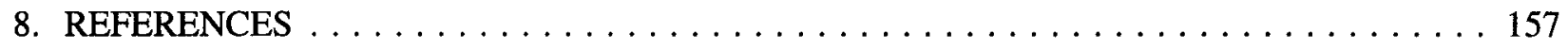

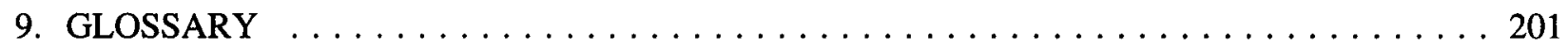
APPENDICES

A. USER'S GUIDE $\ldots \ldots \ldots \ldots \ldots \ldots \ldots \ldots \ldots \ldots \ldots \ldots \ldots \ldots$ A-1

B. ACRONYMS, ABBREVIATIONS, AND SYMBOLS $\ldots \ldots \ldots \ldots \ldots \ldots \ldots$. $\ldots \ldots$ 


\section{LIST OF FIGURES}

2-1. Levels of Significant Exposure to Fuel Oils - Inhalation $(\mathrm{ppm}) \ldots \ldots \ldots \ldots \ldots \ldots$

2-2. Levels of Significant Exposure to Fuel Oils - Inhalation $\left(\mathrm{mg} / \mathrm{m}^{3}\right) \ldots \ldots \ldots \ldots$

2-3. Levels of Significant Exposure to Fuel Oils - Oral $\ldots \ldots \ldots \ldots \ldots \ldots \ldots \ldots$

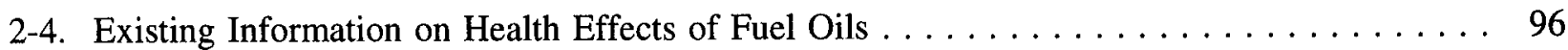

$5-1$. Frequency of NPL Sites with Fuel Oil No. 1 Contamination $\ldots \ldots \ldots \ldots \ldots \ldots \ldots$

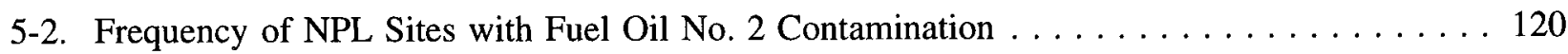




\section{LIST OF TABLES}

2-1. Levels of Significant Exposure to Fuel Oils - Inhalation $\ldots \ldots \ldots \ldots \ldots \ldots$

2-2. Levels of Significant Exposure to Fuel Oils - Oral $\ldots \ldots \ldots \ldots \ldots \ldots \ldots$

2-3. Levels of Significant Exposure to Fuel Oils - Dermal $\ldots \ldots \ldots \ldots \ldots \ldots$

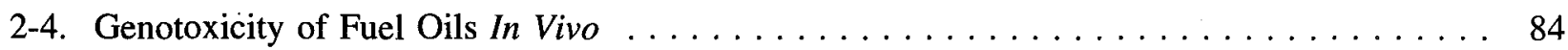

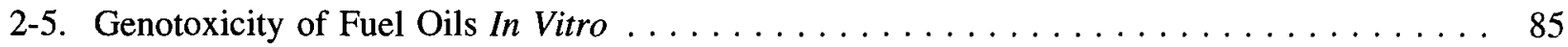

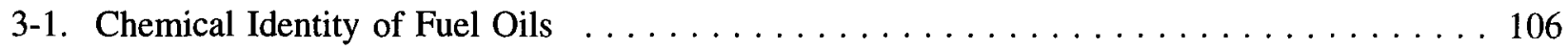

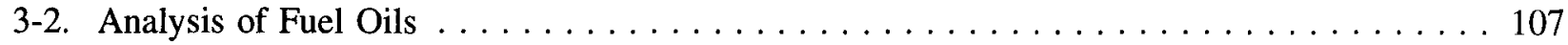

3-3. Physical and Chemical Properties of Fuel Oils $\ldots \ldots \ldots \ldots \ldots \ldots$

6-1. Analytical Methods for Determining Fuel Oils in Biological Materials . . . . . . . . . 142

6-2. Analytical Methods for Determining Fuel Oils in Environmental Samples . . . . . . . . . 144

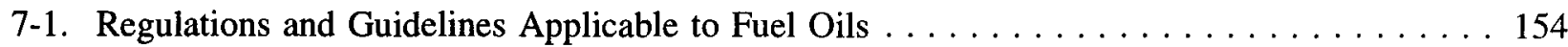




\section{PUBLIC HEALTH STATEMENT}

This Statement was prepared to give you information about fuel oils and to emphasize the human health effects that may result from exposure to them. The Environmental Protection Agency (EPA) has identified 1,397 sites on its National Priorities List (NPL). Fuel oils have been found in $2 \%$ (26 out of the 1,397) of the NPL sites. However, we do not know how many of the 1,397 NPL sites have been evaluated for fuel oils. As EPA evaluates more sites, the number of sites at which fuel oils are found may change. This information is important for you to know because fuel oils may cause harmful health effects and because these sites are potential or actual sources of human exposure to fuel oils.

When a chemical is released from a large area, such as an industrial plant, or from a container, such as a drum or bottle, it enters the environment as a chemical emission. This emission, which is also called a release, does not always lead to exposure. You can be exposed to a chemical only when you come into contact with the chemical. You may be exposed to it in the environment by breathing, eating, or drinking substances containing the chemical or from skin contact with it.

If you are exposed to hazardous chemicals such as fuel oils, several factors will determine whether harmful health effects will occur and what the type and severity of those health effects will be. These factors include the dose (how much), the duration (how long), the route or pathway by which you are exposed (breathing, eating, drinking, or skin contact), the other chemicals to which you are exposed, and your individual characteristics such as age, sex, nutritional status, family traits, lifestyle, and state of health.

\subsection{WHAT ARE FUEL OILS?}

Fuel oils are petroleum products that are used in many types of engines, lamps, heaters, furnaces, stoves, and as solvents. Fuel oils come from crude petroleum and are refined to 
meet specifications for each use. Fuel oils are mixtures of aliphatic (open chain and cyclic compounds that are similar to open chain compounds) and aromatic (benzene and compounds similar to benzene) petroleum hydrocarbons. In addition, they may contain small amounts of nitrogen, sulfur, and other elements as additives. The exact chemical composition (i.e., precise percentage of each constituent) of each of the fuel oils discussed in this profile may vary somewhat, depending on the source and other factors. Fuel oils are distinguished from each other primarily by their boiling point ranges, chemical additives, and uses. In this profile, six fuel oils are discussed. The fuel oils of interest and common synonyms follow:

- fuel oil no. 1 (the most widely used fuel oil)

- kerosene

- straight-run kerosene

- kerosene

- range oil

- Deobase (the trade name of a clear, white, deodorized kerosene)

- coal oil

- JP-5 (jet fuel)

- fuel oil no. 1-D

- diesel fuel

- diesel fuel oil no. 1

- fuel oil no. 2

- home heating oil

- gas oil

- no. 2 burner oil

- fuel oil no. 2-D

- diesel fuel oil no. 2

- diesel fuel no. 2

- diesel oil no. 2

- no. 2 diesel 
- fuel oil no. 4

- diesel fuel oil no. 4

- heavy residual fuel oil

- marine diesel fuel

- residual fuel oil no. 4

- fuel oil UNSP (which is not referred to by any synonyms)

In this profile, a fuel oil is referred to by the name used in the cited study. That is, if one study identifies a fuel oil as fuel oil no. 1, and another study identifies the same fuel oil as kerosene, the names "fuel oil no. 1" and "kerosene" will be used, respectively. All fuel oils are liquids at room temperature, although they can evaporate. The rates at which the various fuel oils will evaporate is dependent on the temperature and the composition of the individual fuel oil. Most fuel oils are yellowish to light brown in color. They generally have a kerosene-like odor, are flammable, and burn at temperatures between $177^{\circ} \mathrm{C}$ and $329^{\circ} \mathrm{C}$.

In this profile, fuel oils are discussed together because of the similarities in their chemical and physical properties. More information on the chemical and physical properties of fuel oils is provided in Chapter 3. More information on the production and use of fuel oils is found in Chapter 4.

\subsection{WHAT HAPPENS TO FUEL OILS WHEN THEY ENTER THE ENVIRONMENT?}

Fuel oils are composed of a large number of different chemicals, and each fuel oil is a slightly different mixture of these chemicals. Some of these chemicals evaporate into the air when fuel oils are spilled onto soils or surface waters (e.g., streams, rivers, lakes, or oceans) or are stored in open containers. Other chemicals in the fuel oils dissolve in water following spills to surface waters or leaks from underground storage tanks. Some of the chemical constituents of fuel oils may slowly move down through the soil to the groundwater. Another group of chemicals in fuel oils can attach to particles in the soil or water and, in water, may sink down into the sediment. The chemicals that evaporate may break down in air by 
reacting with sunlight, e.g., photooxidation, or other chemicals in the air. The chemicals that dissolve in water may also be broken down by organisms (primarily bacteria and fungi) in the soil or water. However, this may take up to a year to occur, if ever, depending on the environmental conditions. Chemicals that attach to soil or other matter (e.g., marsh sediment) may remain in the environment for more than a decade. Benzene, toluene, and xylenes (single-ring aromatic compounds), as well as polycyclic aromatic compounds, are the fuel oil components about which we have the greatest amount of information. You can find this information in the ATSDR toxicological profiles for these specific chemicals. See Chapter 5 for more information on what happens to fuel oils when they enter the environment.

\subsection{HOW MIGHT I BE EXPOSED TO FUEL OILS?}

The most likely way for you to be exposed to fuel oils in the home is if you use a kerosene heater. If you handle fuel oils or use a fuel oil to clean equipment at your job, or if fuel oils are stored at your workplace, you may also be exposed to them through contact with the skin or in the air. Some workers may be exposed to fuel oils through their skin if they come into contact with them without adequate protection, such as gloves, boots, coveralls, or other protective clothing. There are no data on background levels of fuel oils that may be found in the environment or workplace.

You may also be exposed to fuel oils if you swim in waters where fuel oils have been spilled. If fuel oils have leaked from underground storage tanks and entered underground water, you may drink contaminated water from a well containing fuel oils. The vapor (the gas phase) of fuel oils can also move through the soil and enter basements of homes or buildings near areas where leaks have occurred. Children may also be exposed by playing in soil contaminated with fuel oils. A major pathway of exposure is washing one's hands with fuel oils to remove paint, grease, etc. For more information on how you might be exposed to fuel oils, see Chapter 5. 


\subsection{HOW CAN FUEL OILS ENTER AND LEAVE MY BODY?}

Fuel oils can enter and leave your body when you breathe them in the air, when you drink water or eat food containing them, and when your skin comes into contact with them. This can occur in the workplace or if you live near an area where fuel oils have been dumped or spilled. We do not know how much of a fuel oil might be taken up by your body if you inhale fuel oil vapor, drink contaminated water, or come in contact with fuel oils. We have no information on what happens to fuel oils once they enter your body. Kerosene has been found in small amounts in the brain, lung, liver, spleen, and kidney of exposed animals. We do not know if fuel oils are broken down and leave the body in the urine or the feces. For more information on how fuel oils can enter and leave your body, see Chapter 2.

\subsection{HOW CAN FUEL OILS AFFECT MY HEALTH?}

We know very little of the human health effects caused by fuel oils. Daily use of a kerosene stove for cooking should not cause any breathing problems for most people. People who use kerosene stoves to cook do not have more colds than people who have other types of stoves. Breathing moderate amounts of deodorized kerosene (fuel oil no. 1) has been shown to slightly affect the ability to smell and to cause a taste sensation. Numerous case-studies have reported accidental poisoning in children as the result of drinking kerosene. These accidents are probably much more frequent in areas where kerosene is commonly used for cooking and heating. Drinking kerosene may cause vomiting, diarrhea, swelling of the stomach, stomach cramps, coughing, drowsiness, restlessness, irritability, and unconsciousness; also, it may be difficult to breathe, and breathing may be painful. Coughing, pneumonia, and difficult or painful breathing after drinking kerosene suggest that kerosene has entered the lungs. In addition, drinking large amounts of kerosene can put you into a coma, cause convulsions, and may even cause death. When kerosene gets on your skin for short periods, it can make your skin itchy, red, and sore; sometimes blisters may occur and your skin may peel. 
Breathing fuel oil no. 1 vapor for periods as short as 1 hour may make you feel nauseous, increase your blood pressure, be irritating to your eyes, or make your eyes bloodshot. Breathing kerosene or JP-5 vapors can also affect your nervous system. Some of the effects that have been noted in case studies include headache, light-headedness, anorexia (loss of appetite), poor coordination, and difficulty concentrating. Breathing diesel fuel vapors for a long time may damage your kidneys, increase your blood pressure, or lower your blood's ability to clot. Constant skin contact (for example, washing) with diesel fuel may also damage your kidneys.

It appears that repeated contact with fuel oils can cause skin cancer in mice and may cause liver cancer in mice. However, there is some conflicting information. Further, the fuel oils were tested only on mice. We do not know if fuel oils can cause cancer in humans. The International Agency for Research on Cancer (IARC) has determined that residual (heavy) fuel oils and marine diesel fuel are possibly carcinogenic to humans (Group 2B classification). In addition, IARC considers that there is not enough information (Group 3 classification) available to determine if distillate (light) fuel oils or distillate (light) diesel fuels cause cancer. They have also determined that occupational exposures to fuel oils during petroleum refining are probably carcinogenic to humans (Group 2A classification). We do not know if fuel oils can cause birth defects or if they affect reproduction. See Chapter 2 for more information on the health effects of fuel oils.

\subsection{IS THERE A MEDICAL TEST TO DETERMINE WHETHER I HAVE BEEN EXPOSED TO FUEL OILS?}

There is no medical test that shows if you have been exposed to fuel oils. There are methods to determine if your blood contains some fuel oil components such as benzene, toluene, and xylenes; however, the concentrations of these compounds in distilled fuels are so low that if they were detected in your blood, it might not indicate specific or exclusive exposure to fuel oils. For information on tests for measuring exposure to some individual components of fuel oils, see the ATSDR toxicological profiles on benzene, toluene, total xylenes, and polycyclic 
aromatic hydrocarbons. See Chapters 2 and 6 for information on symptoms that suggest exposure to fuel oils.

\subsection{WHAT RECOMMENDATIONS HAS THE FEDERAL GOVERNMENT MADE TO PROTECT HUMAN HEALTH?}

The government has developed regulations and guidelines for fuel oils and some of the chemicals in them. These are designed to protect the public from the possible harmful health effects of these chemicals. The Department of Transportation also regulates the transportation of fuel oils, because they are classified as hazardous materials that are considered to pose a risk to health, safety, or property when transported.

The Occupational Safety and Health Administration (OSHA) and the Air Force Office of Safety and Health (AFOSH) regulate levels of petroleum products in the private sector and Air Force workplaces, respectively. The maximum allowable amount of petroleum products in the workroom air during an \&hour workday, 40-hour workweek, is 400 parts of petroleum distillates (naphtha) per million parts of air, or more simply stated, $400 \mathrm{ppm}$.

\subsection{WHERE CAN I GET MORE INFORMATION?}

If you have any more questions or concerns, please contact your community or state health or environmental quality department or:

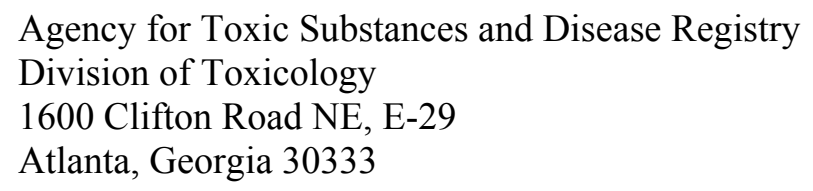

This agency can also provide you with information on the location of the nearest occupational and environmental health clinic. These clinics specialize in the recognition, evaluation, and treatment of illnesses resulting from exposure to hazardous substances. 



\section{HEALTH EFFECTS}

\subsection{INTRODUCTION}

The primary purpose of this chapter is to provide public health officials, physicians, toxicologists, and other interested individuals and groups with an overall perspective of the toxicology of fuel oils and a depiction of significant exposure levels associated with various adverse health effects. It contains descriptions and evaluations of studies and presents levels of significant exposure for fuel oils based on toxicological studies and epidemiological investigations.

\subsection{DISCUSSION OF HEALTH EFFECTS BY ROUTE OF EXPOSURE}

To help public health professionals address the needs of persons living or working near hazardous waste sites, the information in this section is organized first by route of exposure--inhalation, oral, and dermal--and then by health effect--death, systemic, immunological, neurological, developmental, reproductive, genotoxic, and carcinogenic effects. These data are discussed in terms of three exposure periods--acute (14 days or less), intermediate (15-364 days), and chronic (365 days or more).

Levels of significant exposure for each route and duration are presented in tables and illustrated in figures. The points in the figures showing no-observed-adverse-effect levels (NOAELs) or lowest observedadverse-effect levels (LOAELs) reflect the actual doses (levels of exposure) used in the studies, LOAELs have been classified into "less serious" or "serious" effects. These distinctions are intended to help the users of the document identify the levels of exposure at which adverse health effects start to appear. They should also help to determine whether or not the effects vary with dose and/or duration, and place into perspective the possible significance of these effects to human health.

The significance of the exposure levels shown in the tables and figures may differ depending on the user's perspective. For example, physicians concerned with the interpretation of clinical findings in exposed persons may be interested in levels of exposure associated with "serious" effects. Public health officials and project managers concerned with appropriate actions to take at hazardous waste sites may want information on the lowest levels of exposure associated with more subtle effects in humans or animals (LOAEL) or exposure levels below which no adverse effects (NOAEL) have been 
observed. Estimates of levels posing minimal risk to humans (Minimal Risk Levels, MRLs) may be of interest to health professionals and citizens alike.

Levels of exposure associated with the carcinogenic effects of fuel oils are indicated in Table 2-3. Estimates of exposure levels posing minimal risk to humans (MRLs) have been made, where data were believed reliable, for the most sensitive non-cancer effect for each exposure duration. MRLs include adjustments to reflect human variability and extrapolation of data from laboratory animals to humans.

Although methods have been established to derive these levels (Barnes and Dourson 1988; EPA 1990e), uncertainties are associated with these techniques. Furthermore, ATSDR acknowledges additional uncertainties inherent in the application of the procedures to derive less than lifetime MRLs. As an example, acute inhalation MRLs may not be protective for health effects that are delayed in development or are acquired following repeated acute insults, such as hypersensitivity reactions, asthma, or chronic bronchitis. As these kinds of health effects data become available and methods to assess levels of significant human exposure improve, these MRLs may be revised.

Fuel oils are petroleum products whose composition varies with the refinery streams from which they are blended (Air Force 1989). Fuel oils, which have auto-ignition temperatures between $177^{\circ} \mathrm{C}$ and $329^{\circ} \mathrm{C}$ (Coast Guard 1985), are composed primarily of aliphatic hydrocarbons (64\%), aromatic hydrocarbons (35\%), and olefinic hydrocarbons (1-2\%) (Air Force 1989). The aliphatic constituents consist of $n$-alkanes ( $n$-paraffins), branched alkanes (isoparaffins), and cyclic alkanes (cycloparaffins or naphthenes). Aromatic hydrocarbons include benzene and polycyclic hydrocarbons. These petroleum products are used both for residential heating oil and for diesel fuel. Diesel fuels are graded according to the type of engine in which they are used and range from no. 1-D for higher speed and frequent load changes to no. 4-D for low speed engines.

The purpose of this chapter is to discuss the toxicological effects of fuel oils. There are six types of fuel oils discussed in this profile: (1) fuel oil no. 1, (2) fuel oil no. I-D, (3) fuel oil no. 2, (4) fuel oil no. 2-D, (5) fuel oil no. 4, and (6) fuel oil UNSP. However, there are no toxicity data for fuel oils in general; the available toxicity data are specific for particular fuel oils. Therefore, the toxicity of fuel oils will be discussed in this chapter by referring to the following fuel oils for which there are data: (1) fuel oil no. 1, which is also called kerosene, straight-run kerosene, kerosene, range oil, Deobase ${ }$, deodorized kerosene, coal oil, and JP-5 (jet fuel); (2) fuel oil no. 1-D, which is also known as diesel 
fuel and diesel fuel oil no. 1; (3) fuel oil no. 2, which is also called home heating oil, gas oil, and no. 2 burner oil; (4) fuel oil no. 2-D, which is also known as diesel fuel oil no. 2, diesel fuel no. 2 , diesel oil no. 2, and no. 2 diesel; (5) fuel oil no. 4, which is also known as diesel fuel oil no. 4, heavy residual fuel oil, marine diesel fuel, and residual fuel oil no. 4; and (6) fuel oil UNSP. Exposure to individual fuel oil components or combustion products will not be discussed as it is not known whether the components or combustion products behave in a toxicologically similar manner to the fuel oils from which they are derived. For more information regarding the potential toxicity of some fuel oil components, the Air Force document (1989) and previous ATSDR profiles on benzene (ATSDR 1989), toluene (ATSDR 1990a), xylenes (ATSDR 1991a), and polycyclic aromatic hydrocarbons (ATSDR 1991b) can be consulted. Since fuel oils are complex and somewhat variable mixtures, it is not possible to identify the molecular weight for these oils. As such, airborne concentrations of fuel oils are reported as milligrams per cubic meter $\left(\mathrm{mg} / \mathrm{m}^{3}\right)$.

\subsubsection{Inhalation Exposure}

Fuel oils can enter the respiratory system as a vapor or an aerosol; in addition, products formed during the combustion of fuel oils can be inhaled in smoke. A vapor is the gaseous phase of a substance that is a liquid at standard temperature. Fuel oils have a low vapor pressure (e.g., the saturation concentration of kerosene in air is approximately $100 \mathrm{mg} / \mathrm{m}^{3}$ ). An aerosol is the suspension of solid or liquid particles in a gas (usually air), with particles ranging in size from 0.0001 to over $100 \mu \mathrm{m}$. Smoke is an aerosol formed during incomplete combustion. Due to the low volatility of fuel oils, human exposure to vapor concentrations above $100 \mathrm{mg} / \mathrm{m}^{3}$ is unlikely. Higher concentrations can be achieved, however, by increasing the ambient temperature or modifying other physical parameters. Thus, exposure of the general population to high concentrations of airborne fuel oils would probably occur only in unusual situations.

\subsubsection{Death}

No studies were located regarding death in humans after inhalation exposure to fuel oils.

Mortality occurred in 3 of 10 mice exposed by inhalation 8 hours/day for 5 days to diesel fuel no. 2 vapors at a concentration of $204 \mathrm{mg} / \mathrm{m}^{3}$; inhalation of 65 or $135 \mathrm{mg} / \mathrm{m}^{3}$ was not lethal to mice (Kainz and White 1984). Acute inhalation of either 86.9 or 408.8 ppm fuel oil UNSP vapor or 101.8 or 
$401.5 \mathrm{ppm}$ diesel fuel vapor did not induce death in rats (API 1979c, 19798). Inhalation of $8,000-16,000 \mathrm{mg} / \mathrm{m}^{3}$ diesel fuel aerosol for 2 or 4 hours was lethal to rats (Dalbey and Lock 1983). No lethality occurred following single-exposure inhalation of $6,000 \mathrm{mg} / \mathrm{m}^{3}$ diesel fuel aerosol for 4 hours or $2,700 \mathrm{mg} / \mathrm{m}^{3}$ for 6 hours. However, inhalation of $4,000 \mathrm{mg} / \mathrm{m}^{3}$ for 6 hours was lethal (Dalbey and Lock 1983).

No deaths occurred in rats exposed to $5,000 \mathrm{mg} / \mathrm{m} 3$ kerosene (physical form not specified) for 4 hours (Vernot et al. 1990d). This study is limited because only one concentration level was tested. It is useful, however, because the concentration used is very high. Inhalation of diesel fuel aerosol 4 hours/day, 2 days/week, for 13 weeks at concentrations up to $1,500 \mathrm{mg} / \mathrm{m}^{3}$ did not induce mortality in rats (Lock et al. 1984). Intermediate exposures (once per week for 9 weeks or 3 times per week for 3 weeks) to diesel fuel aerosol induced mortality in $6.25 \%$ of the rats exposed to a concentration time product $(\mathrm{Ct})$ of $12,000 \mathrm{mg}$ hour $/ \mathrm{m}^{3}\left(\mathrm{Ct}=\right.$ [airborne concentration of aerosolized diesel fuel in $\mathrm{mg} / \mathrm{m}^{3}$ ] $\mathrm{x}$ [duration of exposure in hours]). However, no rats died at a Ct of 8,000 $\mathrm{mg}$ hour $/ \mathrm{m}^{3}$ (Dalbey et al. 1987). The Ct of $8,000 \mathrm{mg}$ hour $/ \mathrm{m}^{3}$, under these conditions, was based on repeated 2- or 6-hour exposures to 4,000 or $1,330 \mathrm{mg} / \mathrm{m}^{3}$, respectively. The Ct of $12,000 \mathrm{mg}$ hour $/ \mathrm{m}^{3}$ was based on repeated 2- or 6-hour exposures to 6,000 or $2,000 \mathrm{mg} / \mathrm{m}^{3}$, respectively. However, dose-response data were not reported for the individual exposure concentrations used to produce each $\mathrm{Ct}$.

No rats died during 90-day inhalation exposures to 50 or $300 \mathrm{mg} / \mathrm{m}^{3}$ marine diesel fuel vapor (Cowan and Jenkins 1981) or to 150 or $750 \mathrm{mg} / \mathrm{m}^{3} \mathrm{JP}-5$ vapor (Cowan and Jenkins 1981; Gaworski et al. 1984). No mice died during a 90-day inhalation exposure of 150 or $750 \mathrm{mg} / \mathrm{m}^{3} \mathrm{JP}-5$ vapor (Cowan and Jenkins 1981; Gaworski et al. 1984). One rat died of pneumonia out of 25 male rats exposed to $100 \mathrm{mg} / \mathrm{m} 3$ deodorized kerosene vapor (the maximally achievable vapor concentration at standard temperature and pressure) for 6 hours per day, 5 days per week for 13 weeks (Carpenter et al. 1976).

The NOAEL and LOAEL values for death after inhalation exposure to fuel oils are recorded in Table 2-1 and plotted in Figures 2-1 and 2-2. 
TABLE 2-1. Levels of Significant Exposure to Fuel Oils - Inhalation

\begin{tabular}{|c|c|c|c|c|c|c|c|c|c|}
\hline \multirow{2}{*}{$\begin{array}{c}\text { Key } \\
\text { to } \\
\text { figure }\end{array}$} & \multirow[b]{2}{*}{$\begin{array}{l}\text { Species/ } \\
\text { (strain) }\end{array}$} & \multirow{2}{*}{$\begin{array}{l}\text { Exposure/ } \\
\text { duration/ } \\
\text { frequency }\end{array}$} & \multirow[b]{2}{*}{ System } & \multirow[b]{2}{*}{$\begin{array}{l}\text { NOAEL' } \\
(\mathbf{m g} / \mathbf{m} 3)\end{array}$} & & \multicolumn{2}{|r|}{ LOAEL ${ }^{b}$} & \multirow[b]{2}{*}{$\begin{array}{l}\text { Serious } \\
\text { (mg/m3) }\end{array}$} & \multirow[b]{2}{*}{$\begin{array}{l}\text { Referencel } \\
\text { Chemical Form } \\
\end{array}$} \\
\hline & & & & & & \multicolumn{2}{|c|}{$\begin{array}{c}\text { Less serious } \\
\text { (mg/m3) }\end{array}$} & & \\
\hline \multicolumn{10}{|c|}{ ACUTE EXPOSURE } \\
\hline \multicolumn{10}{|c|}{ Death } \\
\hline 1 & $\begin{array}{l}\text { Rat } \\
\text { Sprague- } \\
\text { Dawley }\end{array}$ & $\begin{array}{l}1 \mathrm{~d} \\
6 \mathrm{hr} / \mathrm{d}\end{array}$ & & & & & & $\begin{array}{ll}4000 & \text { (sex not specified, } 30 \% \\
\text { mortality) }\end{array}$ & $\begin{array}{l}\text { Dalbey and Lock } \\
1983 \\
\text { FO5DFU }\end{array}$ \\
\hline 2 & $\begin{array}{l}\text { Mouse } \\
\text { CD-1 }\end{array}$ & $\begin{array}{l}5 \mathrm{~d} \\
8 \mathrm{hr} / \mathrm{d}\end{array}$ & & & & & & 204 M (30\% mortality) & $\begin{array}{l}\text { Kainz and White } \\
1984 \\
\text { FO4DF2 }\end{array}$ \\
\hline \multicolumn{10}{|c|}{ Systemic } \\
\hline 3 & Rat & $\begin{array}{l}10 \mathrm{~d} \\
6 \mathrm{hr} / \mathrm{d}\end{array}$ & Other & $\begin{array}{l}408.8 \\
(\mathrm{ppm})\end{array}$ & $\mathbf{F}$ & & & & $\begin{array}{l}\text { API 1979c } \\
\text { FO5 }\end{array}$ \\
\hline 4 & $\begin{array}{l}\text { Rat } \\
\text { [CRL: } \\
\text { COBS } \\
\text { CD(SD) } \\
\text { BR] }\end{array}$ & $\begin{array}{l}10 \mathrm{~d} \\
6 \mathrm{hr} / \mathrm{d}\end{array}$ & Other & & & $\begin{array}{l}401.5 \\
(p p m)\end{array}$ & $F$ (decreased food intake) & & $\begin{array}{l}\text { API } 1979 g \\
\text { FO5DFU }\end{array}$ \\
\hline 5 & $\begin{array}{l}\text { Rat } \\
\text { NS }\end{array}$ & $\begin{array}{l}10 \mathrm{~d} \\
6 \mathrm{hr} / \mathrm{d}\end{array}$ & Other & $\begin{array}{r}400 \\
(\mathrm{ppm})\end{array}$ & $\mathbf{F}$ & & & & $\begin{array}{l}\text { Beliles and } \\
\text { Mecler } 1983 \\
\text { FO2HHO }\end{array}$ \\
\hline \multirow[t]{2}{*}{6} & $\begin{array}{l}\text { Mouse } \\
\text { CD-1 }\end{array}$ & $\begin{array}{l}5 \mathrm{~d} \\
8 \mathrm{hr} / \mathrm{d}\end{array}$ & Cardio & 65 & M & 135 & M (vasodilation) & & $\begin{array}{l}\text { Kainz and White } \\
1984\end{array}$ \\
\hline & & & $B d W t$ & 135 & $M$ & 204 & $\begin{array}{l}\text { M (decreased water and food } \\
\text { consumption with } \\
\text { subsequent weight loss of } \\
30 \% \text { ) }\end{array}$ & & FO4DF2 \\
\hline \multicolumn{10}{|c|}{ Neurological } \\
\hline 7 & $\begin{array}{l}\text { Mouse } \\
\text { CD-1 }\end{array}$ & $\begin{array}{l}5 \mathrm{~d} \\
8 \mathrm{hr} / \mathrm{d}\end{array}$ & & & & $65^{c}$ & M (ataxia; disturbed gait) & & $\begin{array}{l}\text { Kainz and White } \\
1984 \\
\text { FO4DF2 }\end{array}$ \\
\hline
\end{tabular}


TABLE 2-1. Levels of Significant Exposure to Fuel Oils - Inhalation (continued)

\begin{tabular}{|c|c|c|c|c|c|c|c|}
\hline \multirow{2}{*}{$\begin{array}{c}\text { Key } \\
\text { to } \\
\text { figure }\end{array}$} & \multirow[b]{2}{*}{$\begin{array}{l}\text { Species/ } \\
\text { (strain) }\end{array}$} & \multirow{2}{*}{$\begin{array}{l}\text { Exposure/ } \\
\text { duration' } \\
\text { frequency }\end{array}$} & \multirow[b]{2}{*}{ System } & \multirow[b]{2}{*}{$\begin{array}{l}\text { NOAEL } \\
\text { (mg/m3) }\end{array}$} & \multicolumn{2}{|c|}{ LOAEL' } & \multirow[b]{2}{*}{$\begin{array}{l}\text { Referencel } \\
\text { Chemical Form }\end{array}$} \\
\hline & & & & & $\begin{array}{l}\text { Less serious } \\
\text { (mg/m3) }\end{array}$ & $\begin{array}{l}\text { Serious } \\
\text { (mg/m3) }\end{array}$ & \\
\hline \multicolumn{8}{|c|}{ Developmental } \\
\hline 8 & Rat & $\begin{array}{l}10 \mathrm{~d} \\
6 \mathrm{hr} / \mathrm{d}\end{array}$ & & $\begin{array}{l}408.8 \\
(\mathrm{ppm})\end{array}$ & $F$ & & $\begin{array}{l}\text { API } 1979 c \\
\text { FO5 }\end{array}$ \\
\hline 9 & $\begin{array}{l}\text { Rat } \\
\text { [CRL: } \\
\text { COBS } \\
\text { CD(SD) } \\
\text { BR] }\end{array}$ & $\begin{array}{l}10 \mathrm{~d} \\
6 \mathrm{hr} / \mathrm{d}\end{array}$ & & $\begin{array}{l}401.5 \\
(p p m)\end{array}$ & $F$ & & $\begin{array}{l}\text { API } 1979 g \\
\text { FO1DOK }\end{array}$ \\
\hline 10 & $\begin{array}{l}\text { Rat } \\
\text { NS }\end{array}$ & $\begin{array}{l}10 \mathrm{~d} \\
6 \mathrm{hr} / \mathrm{d}\end{array}$ & & $\begin{array}{r}400 \\
(\mathrm{ppm})\end{array}$ & $F$ & & $\begin{array}{l}\text { Beliles and } \\
\text { Mecler } 1983 \\
\text { FO2HHO }\end{array}$ \\
\hline \multicolumn{8}{|c|}{ INTERMEDIATE EXPOSURE } \\
\hline 11 & $\begin{array}{l}\text { Rat } \\
\text { Albino Harlan } \\
\text { Wistar }\end{array}$ & $\begin{array}{l}13 \text { wk } \\
5 \mathrm{~d} / \mathrm{wk} \\
6 \mathrm{hr} / \mathrm{d}\end{array}$ & Resp & 100 & $M$ & & $\begin{array}{l}\text { Carpenter et al. } \\
1976 \\
\text { FO1DOK }\end{array}$ \\
\hline & & & Cardio & 100 & $M$ & & \\
\hline & & & Gastro & 100 & $M$ & & \\
\hline & & & Hemato & 100 & $M$ & & \\
\hline & & & Musc/skel & 100 & $M$ & & \\
\hline & & & Hepatic & 100 & M & & \\
\hline & & & Renal & 100 & $M$ & & \\
\hline & & & Other & 100 & M & & \\
\hline
\end{tabular}


TABLE 2-1. Levels of Significant Exposure to Fuel Oils - Inhalation (continued)

\begin{tabular}{|c|c|c|c|c|c|c|c|c|}
\hline \multirow{2}{*}{$\begin{array}{l}\text { Key } \\
\text { to } \\
\text { figure }\end{array}$} & \multirow[b]{2}{*}{$\begin{array}{l}\text { Species/ } \\
\text { (strain) }\end{array}$} & \multirow{2}{*}{$\begin{array}{l}\text { Exposure/ } \\
\text { duration/ } \\
\text { frequency }\end{array}$} & \multirow[b]{2}{*}{ System } & \multirow[b]{2}{*}{$\begin{array}{c}\text { NOAEL } \\
(\mathrm{mg} / \mathrm{m} 3)\end{array}$} & & \multicolumn{2}{|r|}{ LOAEL } & \multirow[b]{2}{*}{$\begin{array}{l}\text { Referencel } \\
\text { Chemical Form }\end{array}$} \\
\hline & & & & & & $\begin{array}{l}\text { Less serious } \\
(\mathrm{mg} / \mathrm{m} 3)\end{array}$ & $\begin{array}{l}\text { Serious } \\
(\mathrm{mg} / \mathrm{m} 3)\end{array}$ & \\
\hline \multirow[t]{9}{*}{12} & Rat & $13 \mathrm{wk}$ & Resp & 750 & & 1500 & (increase in relative weight & Lock et al. 1984 \\
\hline & $\begin{array}{l}\text { Sprague- } \\
\text { Dawley }\end{array}$ & $\begin{array}{l}2 \mathrm{~d} / \mathrm{wk} \\
4 \mathrm{hr} / \mathrm{d}\end{array}$ & & & & & of right lobe of lung) & FO5DFU \\
\hline & & & Cardio & 1500 & & & & \\
\hline & & & Gastro & 1500 & & & & \\
\hline & & & Hemato & 1500 & & & & \\
\hline & & & Hepatic & 1500 & & & & \\
\hline & & & Renal & 1500 & & & & \\
\hline & & & Dermal & 1500 & & & & \\
\hline & & & $\mathrm{Bd} \mathrm{Wt}$ & & & 250 & (decreased body weight) & \\
\hline \multirow[t]{3}{*}{13} & $\begin{array}{l}\text { Rat } \\
\text { Wistar }\end{array}$ & $\begin{array}{l}14 \mathrm{wk} \\
6 \mathrm{~d} / \mathrm{wk}\end{array}$ & Hepatic & & & $58^{d} M$ & $\begin{array}{l}\text { (decreased blood glucose } \\
\text { levels) }\end{array}$ & $\begin{array}{l}\text { Starek and } \\
\text { Vojtisek } 1986\end{array}$ \\
\hline & & $6 \mathrm{hr} / \mathrm{d}$ & & & & & & FO-1 \\
\hline & & & Other & & & $231 \mathrm{M}$ & $\begin{array}{l}\text { (decreased metabolism of } \\
\text { phenacetin; decrease in } \\
\text { lactate and pyruvate) }\end{array}$ & \\
\hline \multirow[t]{4}{*}{14} & Mouse & $90 \mathrm{~d}$ & Hepatic & & & 150 & (hepatocellular fatty & Gaworski et al. \\
\hline & C57BL/6 & $24 \mathrm{hr} / \mathrm{d}$ & & & & & changes and vacuolization) & 1984 \\
\hline & & & & & & & & FD1JP5 \\
\hline & & & Other & 750 & $F$ & & & \\
\hline \multirow[t]{9}{*}{15} & $\begin{array}{l}\text { Dog } \\
\text { Beagle }\end{array}$ & $\begin{array}{l}13 w k \\
5 \mathrm{~d} / w \mathrm{k}\end{array}$ & Resp & 100 & $M$ & & & $\begin{array}{l}\text { Carpenter et al. } \\
1976\end{array}$ \\
\hline & & $6 \mathrm{hr} / \mathrm{d}$ & & & & & & FO1DOK \\
\hline & & & Cardio & 100 & $M$ & & & \\
\hline & & & Gastro & 100 & $M$ & & & \\
\hline & & & Hemato & 100 & $M$ & & & \\
\hline & & & Musc/skel & 100 & M & & & \\
\hline & & & Hepatic & 100 & $M$ & & & \\
\hline & & & Renal & 100 & M & & & \\
\hline & & & $B d W t$ & & & $20 M$ & (increased body weight) & \\
\hline
\end{tabular}


TABLE 2-1. Levels of Significant Exposure to Fuel Oils - Inhalation (continued)

\begin{tabular}{|c|c|c|c|c|c|c|c|}
\hline \multirow{2}{*}{$\begin{array}{c}\text { Key } \\
\text { to } \\
\text { figure }\end{array}$} & \multirow[b]{2}{*}{$\begin{array}{l}\text { Speciest } \\
\text { (strain) }\end{array}$} & \multirow{2}{*}{$\begin{array}{l}\text { Exposure/ } \\
\text { duration/ } \\
\text { frequency }\end{array}$} & \multirow[b]{2}{*}{ System } & \multirow[b]{2}{*}{$\begin{array}{l}\text { NOAEL }{ }^{b} \\
(\mathrm{mg} / \mathrm{m} 3)\end{array}$} & \multicolumn{2}{|r|}{ LOAEL $^{\mathrm{b}}$} & \multirow[b]{2}{*}{$\begin{array}{l}\text { Referencel } \\
\text { Chemical Form }\end{array}$} \\
\hline & & & & & $\begin{array}{l}\text { Less serious } \\
(\mathrm{mg} / \mathrm{m} 3)\end{array}$ & $\begin{array}{l}\text { Serious } \\
\text { (mg/m3) }\end{array}$ & \\
\hline \multicolumn{8}{|c|}{ Neurological } \\
\hline 16 & $\begin{array}{l}\text { Rat } \\
\text { Harlan- } \\
\text { Wistar }\end{array}$ & $\begin{array}{l}13 \mathrm{wk} \\
5 \mathrm{~d} / \mathrm{wk} \\
6 \mathrm{hr} / \mathrm{d}\end{array}$ & & 100 & & & $\begin{array}{l}\text { Carpenter et al. } \\
1976 \\
\text { FO1DOK }\end{array}$ \\
\hline 17 & $\begin{array}{l}\text { Rat } \\
\text { Sprague- } \\
\text { Dawley }\end{array}$ & $\begin{array}{l}13 \mathrm{wk} \\
2 \mathrm{~d} / \mathrm{wk} \\
4 \mathrm{hr} / \mathrm{d}\end{array}$ & & & 250 & $\begin{array}{l}\text { (increased response } \\
\text { time/startle reflex assay) }\end{array}$ & $\begin{array}{l}\text { Lock et al. } 1984 \\
\text { FO5DFU }\end{array}$ \\
\hline 18 & $\begin{array}{l}\text { Dog } \\
\text { Beagle }\end{array}$ & $\begin{array}{l}13 \mathrm{wk} \\
5 \mathrm{~d} / \mathrm{wk} \\
6 \mathrm{hr} / \mathrm{d}\end{array}$ & & $100 \mathrm{M}$ & & & $\begin{array}{l}\text { Carpenter et al. } \\
1976 \\
\text { FO1DOK }\end{array}$ \\
\hline \multicolumn{8}{|c|}{ Reproductive } \\
\hline 19 & $\begin{array}{l}\text { Rat } \\
\text { Sprague- } \\
\text { Dawiey }\end{array}$ & $\begin{array}{l}13 \mathrm{wk} \\
2 \mathrm{~d} / \mathrm{wk} \\
4 \mathrm{hr} / \mathrm{d}\end{array}$ & & 1500 & & & $\begin{array}{l}\text { Lock et al. } 1984 \\
\text { FO5DFU }\end{array}$ \\
\hline
\end{tabular}

'The number corresponds to entries in Figures 2-1 or 2-2.

${ }^{b}$ Units are in $\mathrm{mg} / \mathrm{m}^{3}$, unless specified otherwise. In some studies, the units were given in ppm. Since the molecular weight of fuel oils is not known, the ppm units could not be converted to $\mathrm{mg} / \mathrm{m}^{3}$. Data from the studies with exposures in ppm are shown in Figure 2-1; data from studies with exposures in $\mathrm{mg} / \mathrm{m}^{3}$ are shown in Figure 2-2. 'Used to derive an acute inhalation Minimal Risk level (MRL) of $0.02 \mathrm{mg} / \mathrm{m}^{3}$; exposure concentration adjusted for 24 hours per day exposure divided by an uncertainty factor of 1000 ( 10 for interspecies variability, 10 for intraspecies variability, and 10 for use of a LOAEL (less serious effect) for MRL derivation)

${ }^{\mathrm{d}}$ Used to determine an intermediate Minimal Risk Level (MRL) of $0.01 \mathrm{mg} / \mathrm{m}^{3}$; exposure concentration adjusted for 24 hours per day, 7 days per week exposure divided by an uncertainty factor of 1000 (10 for interspecies variability, 10 for intraspecies variability, and 10 for use of a LOAEL (less serious effect) for MRL derivation).

Cardio $=$ cardiovascular; $\mathrm{d}=$ day $(\mathrm{s}) ; \mathrm{F}=$ female; FO-1 $=$ fuel oil no. $1 ; \mathrm{FO} 1 \mathrm{DOK}=$ deodorized kersoene; FO5DFU $=$ unspecified diesel fuel; FO2HHO $=$ home heating oil no. 2; FO1JP5 = JP-5 (jet fuel); FO4DF2 = fuel oil no. 2-D; FO5 = unspecified fuel oil; Gastro = gastrointestinal; Hemato = hematological; hr $=$ hour(s); LOAEL = lowest-observed-adverse-effect level; $\mathrm{M}=$ male; $\mathrm{Musc} / \mathrm{skel}=$ musculoskeletal; $\mathrm{NOAEL}=$ no-observed-adverse-effect level; $\operatorname{Resp}=$ respiratory; wk $=$ week(s) 
Figure 2-1. Levels of Significant Exposure to Fuel Oils - Inhalation

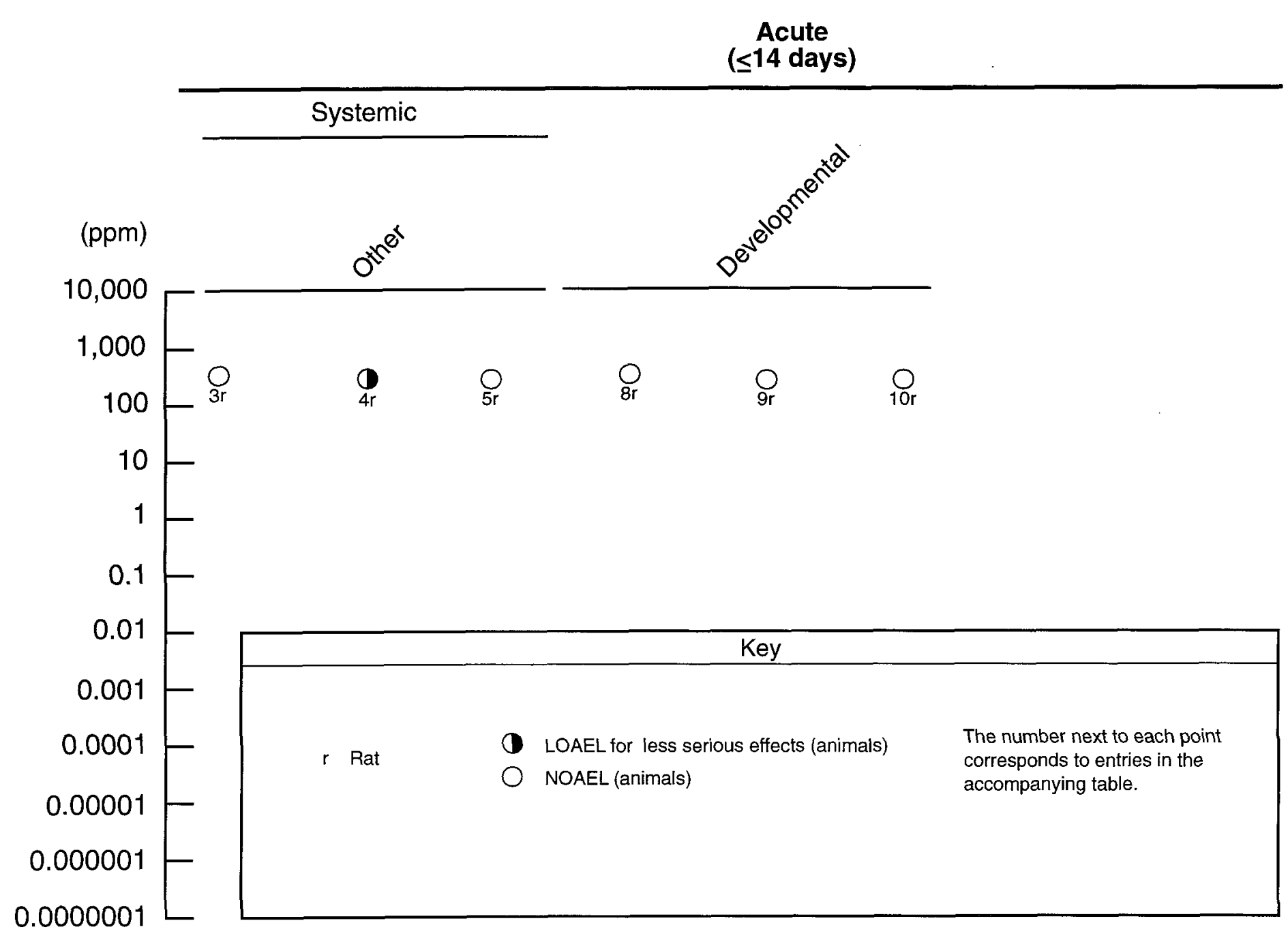


Figure 2-2. Levels of Significant Exposure to Fuel Oils - Inhalation

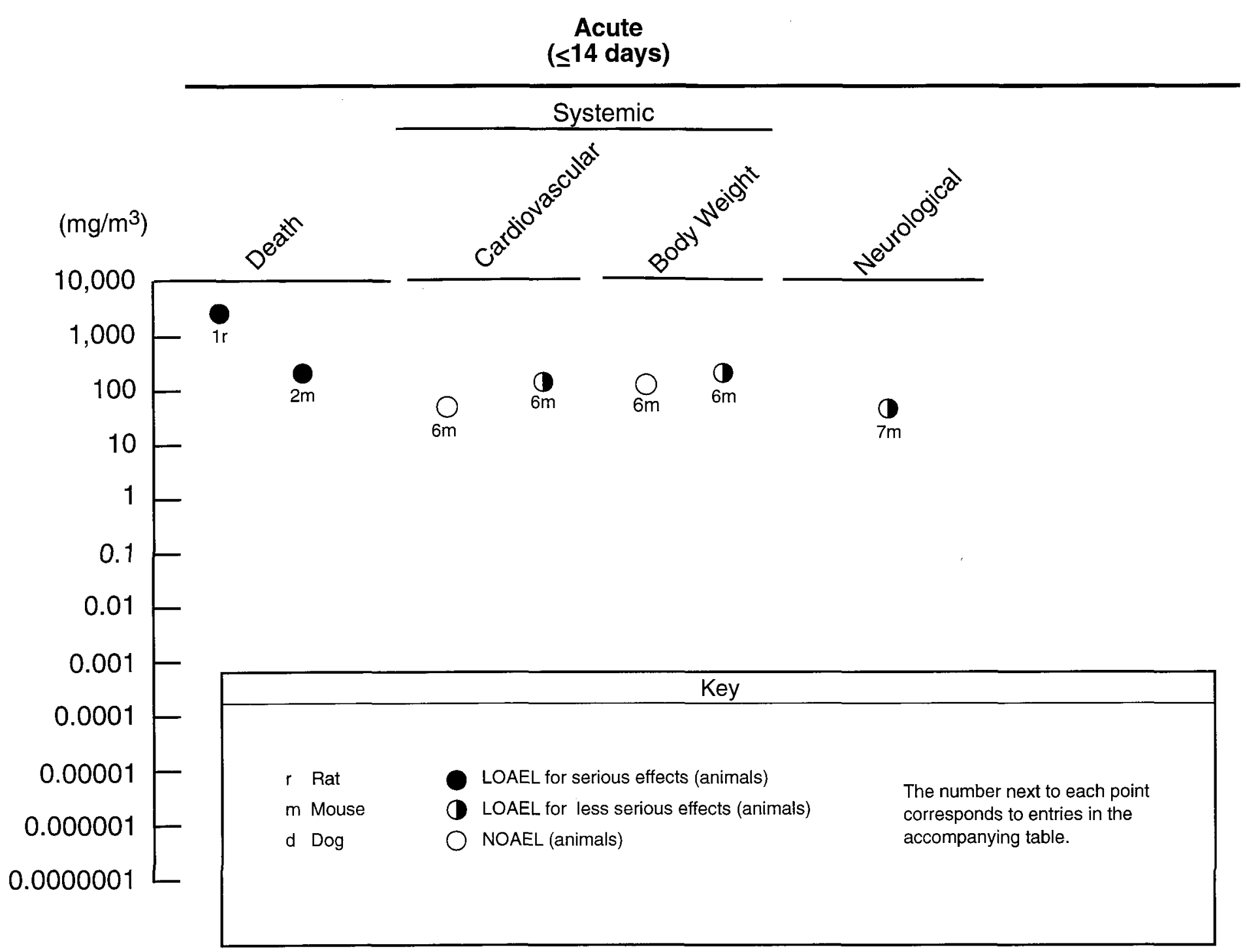


Figure 2-2. Levels of Significant Exposure to Fuel Oils - Inhalation (continued)

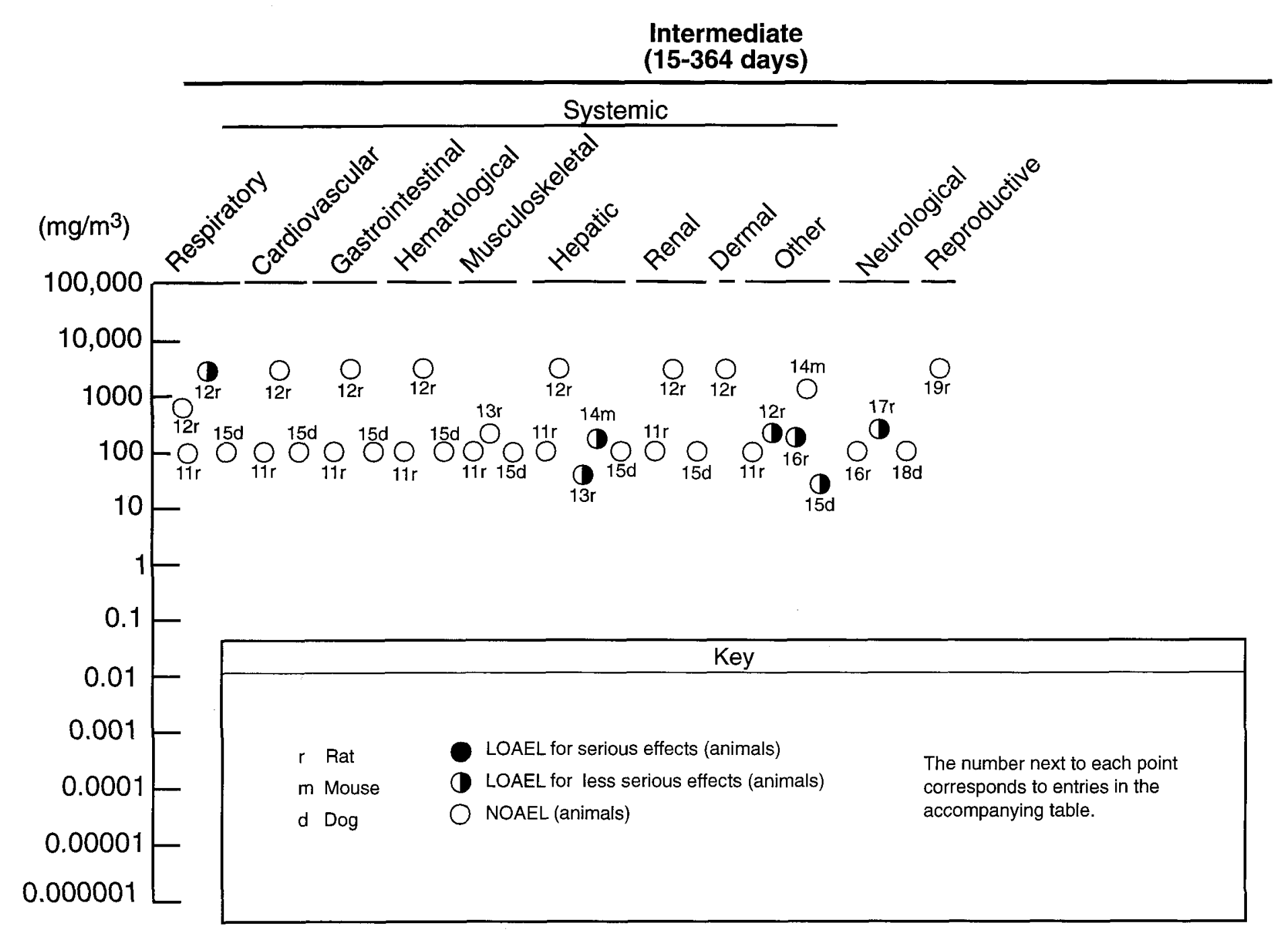




\subsubsection{Systemic Effects}

The highest NOAEL values and all reliable LOAEL values for systemic effects in each species and duration category for inhalation exposure to fuel oils are recorded in Table 2-1 and plotted in Figures 2-1 and 2-2.

Respiratory Effects. Pleural effusions and alveolar infiltrations were noted in a man who had washed his hair with an unknown amount of diesel fuel (Barrientos et al. 1977). The relative contributions from inhalation and dermal exposure could not be distinguished in this case. There was no throat irritation in six volunteers following a 15-minute exposure to a concentration reported to be $140 \mathrm{mg} / \mathrm{m}^{3}$ of deodorized kerosene vapor (Carpenter et al. 1976). The authors used a hot nichrome wire for the volatilization of their test material and reported that the concentration was probably the "highest attainable concentration at which vapor analysis is representative of liquid analysis." The air saturating concentration of kerosene is considered to approximate $100 \mathrm{mg} / \mathrm{m}^{3}$ (room temperature and $760 \mathrm{mmHg}$ ) and is dependent on the constituents of the mixture.

An epidemiological study examined the effects of chronic exposure to jet fuels in factory workers (Knave et al. 1978). This study found a significant increase in a feeling of heaviness in the chests of exposed subjects when compared to unexposed controls from the same factory. The data are limited because the jet fuels were not specified and may not include JP-5, which is the jet fuel of concern in this profile, and the study did not adjust for the presence of other chemicals. Inhalation exposure is likely, since jet fuel vapor was detected by the authors; however, dermal and oral (i.e., from eating contaminated food) exposures cannot be excluded. An estimated time-weighted average of $128-423 \mathrm{mg} / \mathrm{m}^{3}$ was detected in the breathing zones of the workers. However, it is not possible to associate the specific concentrations with specific effects.

Limited epidemiological data suggest that chronic human inhalation exposure to kerosene vapor and/or kerosene combustion products from cooking with kerosene stoves does not induce asthmatic respiratory effects. The presence of kerosene stoves in the homes of Malaysian children was not associated with chronic cough, persistent wheeze, asthma, or chest illness (Azizi and Henry 1991). Asthmatic bronchitis and frequent common colds in 3-year-old Japanese children were not associated with the presence of kerosene stoves in their homes (Tominaga and Itoh 1985). The latter study 
corrected for exposure to passive smoke. These data are of limited usefulness because the duration of exposure was not reported and the levels of kerosene exposure could not be quantified. Finally, it cannot be determined whether actual exposure to kerosene occurred in these individuals because kerosene exposure was assumed to occur if kerosene was used during cooking or if a kerosene stove was present in the home.

Animal data that pertain to respiratory effects following acute exposure to kerosene by inhalation are limited, because only one concentration level was tested in each study. Reductions in tidal volume and dynamic lung compliance, bronchoconstriction, and an increase in pulmonary resistance occurred in rabbits following inhalation of $32,500 \mathrm{mg} / \mathrm{m}^{3}$ kerosene aerosol (Casaco et al. 1982).

Bronchoconstriction was also induced in guinea pigs that were exposed to $20,400 \mathrm{mg} / \mathrm{m}^{3}$ kerosene aerosol (Garcia et al. 1988b).

No histopathological changes were noted in the respiratory system of rats or dogs exposed to up to $100 \mathrm{mg} / \mathrm{m}^{3}$ deodorized kerosene vapor for 13 weeks (Carpenter et al. 1976). Inhalation of diesel fuel aerosol 4 hours/day, 2 days/week, for 13 weeks at concentrations up to $1,500 \mathrm{mg} / \mathrm{m}^{3} \mathrm{did}$ not impair pulmonary function or induce histopathological changes in rats (Lock et al. 1984). However, there was a dose-related increase in the relative weight of the right lobe of the lung, which was only significant at the highest exposure level. Elevated numbers of alveolar macrophages in the low- and high-dose groups were not dose related. Intermediate exposures to diesel fuel aerosol induced damage to the lung parenchyma of rats exposed to a Ct of 8,000 or $12,000 \mathrm{mg}$ hour $/ \mathrm{m}^{3}$ (Dalbey et al. 1987). In general, respiratory effects were more severe after three exposures/week for 3 weeks than one exposure/week for 9 weeks at various exposure levels and durations. Thus, the study found that the respiratory effects were generally more dependent upon the frequency of exposure than the exposure dose or duration. Dose-response data were not reported for the individual exposure concentrations used to produce each concentration time product (see discussion in Section 2.2.1.1).

Cardiovascular Effects. Two case studies were found that reported mild hypertension in humans from acute inhalation exposures to fuel oils. Mild hypertension was noted for 4 days in one of two individuals following a 1-hour exposure to JP-5 vapor while flying a small airplane (Porter 1990). Delayed mild hypertension was also noted in a man who was exposed to diesel fuel vapor for 10 days while driving a truck with a fuel injector leak (Reidenberg et al. 1964). The concentration of vapor was not reported in either study. Palpitations were noted in workers chronically exposed to jet fuel 
according to one epidemiological study (Knave et al. 1978). The limitations of this study are discussed in detail in Section 2.2.1.2 under Respiratory Effects.

Vasodilation was seen in the ear and tail veins of mice exposed via acute inhalation to 204 or $135 \mathrm{mg} / \mathrm{m}^{3}$ diesel fuel no. 2 vapors. The effect was not seen at $65 \mathrm{mg} / \mathrm{m}^{3}$ (Kainz and White 1984). Inhalation of kerosene aerosol for an intermediate duration induced aortic plaques in guinea pigs that resemble those seen in atherosclerosis (Noa and Illnait 1987a). Significant increases in total serum cholesterol and decreases in high-density lipoprotein (HDL) were also noted. Similar effects were induced following exposure to kerosene aerosol or kerosene smoke. This study was limited because only one concentration of kerosene aerosol, within a range of $20,400-34,000 \mathrm{mg} / \mathrm{m}^{3}$, was tested and the actual exposure level of kerosene smoke was not reported. Inhalation of diesel fuel aerosol 4 hours/day, 2 days/week, for 13 weeks at concentrations up to $1,500 \mathrm{mg} / \mathrm{m}^{3}$ did not induce histopathological changes in the cardiovascular system of rats (Lock et al. 1984). However, a statistically significant decrease in blood cholesterol levels was reported in females of the high-dose group immediately after exposure compared to controls. The authors did not consider this effect to be treatment related; no data were presented. No microscopic or histopathological changes were noted in the cardiovascular system of rats or dogs exposed to up to $100 \mathrm{mg} / \mathrm{m}^{3}$ deodorized kerosene vapor for 13 weeks (Carpenter et al. 1976).

Gastrointestinal Effects. Several studies were identified that described gastrointestinal effects in humans after inhalation exposure to unknown quantities of fuel oils. In one case study, one of two individuals that were exposed to JP-5 vapor for approximately 1 hour while flying a small airplane experienced nausea after landing (Porter 1990). This effect subsided within 24 hours. Abdominal cramps, vomiting, and diarrhea occurred in a man who was exposed to diesel fuel vapor for 10 days while driving a truck with a fuel injector leak (Reidenberg et al. 1964). Also, nausea, abdominal cramps, and diarrhea were reported for a man who had washed his hair with a diesel fuel. "On examination" (no further description of the examination was provided), the abdomen was normal (Barrientos et al. 1977). A history of epigastric (upper abdominal) pain was noted in a male subsequent to washing his hands with diesel fuel over several weeks (Crisp et al. 1979). Effects resulting from inhalation versus dermal exposure could not be distinguished in the two latter cases.

No histopathological changes were noted in the gastrointestinal system of rats or dogs exposed to up to $100 \mathrm{mg} / \mathrm{m}^{3}$ deodorized kerosene vapor for 13 weeks (Carpenter et al. 1976). Inhalation of diesel 
fuel aerosol 4 hours/day, 2 days/week, for 13 weeks at concentrations up to $1,500 \mathrm{mg} / \mathrm{m}^{3} \mathrm{did}$ not induce histopathological changes in the gastrointestinal system of rats (Lock et al. 1984).

Hematological Effects. Three case studies were found that addressed possible hematological effects due to acute inhalation exposure to unknown quantities of fuel oils by humans. There were no blood chemistry changes in either of two individuals following a l-hour exposure to JP-5 vapor while flying a small airplane (Porter 1990). Subcutaneous hemorrhage, mild nose bleeds, low platelet counts, and retinal arteriole constriction were reported for a man who was exposed to diesel fuel vapor for 10 days while driving a truck with a fuel injector leak (Reidenberg et al. 1964). The latter effect was delayed, occurring 4 weeks after initial exposure. These effects may be indicative of blood clotting problems. Decreased hemoglobin concentration and an increase in erythrocyte sedimentation rate were noted in one man after washing his hands with diesel fuel over several weeks (Crisp et al. 1979). Effects resulting from inhalation versus dermal exposure cannot be distinguished in this case.

No exposure-related hematological effects were noted in rats or dogs exposed to up to $100 \mathrm{mg} / \mathrm{m}^{3}$ deodorized kerosene vapor for 13 weeks (Carpenter et al. 1976). Inhalation of diesel fuel aerosol (4 hours/day, 2 days/week, for 13 weeks) at concentrations ranging up to $1,500 \mathrm{mg} / \mathrm{m}^{3}$ failed to produce histopathological changes, splenic weight changes, or other hematological effects in rats (Lock et al. 1984). Intermediate exposures to diesel fuel aerosol induced decreases in the mean red blood cell count in rats exposed to a $\mathrm{Ct}$ of 8,000 or $12,000 \mathrm{mg}$ hour $/ \mathrm{m}^{3} 3$ times/week for 3 weeks (Dalbey et al. 1987). However, the statistical significance of this effect was not clearly reported in the study. There was no significant effect on white blood cell count in these rats. Dose-response data were not reported for the individual exposure concentrations used to produce each $\mathrm{Ct}$ (see discussion in Section 2.2.1.1).

Musculoskeletal Effects. No studies were located regarding musculoskeletal effects in humans after inhalation exposure to fuel oils.

No histopathological changes were noted in the musculoskeletal system of rats or dogs exposed to up to $100 \mathrm{mg} / \mathrm{m}^{3}$ deodorized kerosene vapor for 13 weeks (Carpenter et al. 1976). Only one study of this effect was located. 
Hepatic Effects. No studies were located regarding hepatic effects in humans after inhalation exposure to fuel oils.

In a study designed to evaluate the effects of kerosene hydrocarbons on the tissue metabolism of rats after acute and subchronic exposure, Starek and Vojtisek (1986) exposed groups of male Wistar rats (131 total animals for both acute and subchronic studies) to kerosene vapors in average concentrations of 58 (range 33.3-75.0) or 231 (range 181.3-250.2) $\mathrm{mg} / \mathrm{m}^{3}$ for 6 hours/day, 6 days/week for 14 consecutive weeks. Food and water were available $a d$ lib throughout exposure, but animals were fasted for 18 hours prior to post-dosing tests. Twenty hours after termination of exposure, two types of tests were conducted: (1) the effects of kerosene on the rate of biotransformation of hexobarbital and phenacetin were examined by looking at hexobarbital sleeping time and measuring the antipyritic activity of phenacetin in intact animals; and (2) blood, liver, and muscle tissue were obtained for in vitro tests to examine pyruvate, lactate, and glucose activity/levels. In the first experiments, hexabarbital sleeping time remained unchanged in both treatment groups, and the antipyretic activity of phenacetin was significantly prolonged only in the high-dose (concentration) group. In the second group of tests, the blood glucose concentration was found to be decreased in both the $58 \mathrm{mg} / \mathrm{m}^{3}$ and $231 \mathrm{mg} / \mathrm{m}^{3}$ exposure groups, while lactate and pyruvate were found to be increased only in the high concentration group. (This study was used as the basis for derivation of an intermediate MRL for fuel oil no. 1 for the inhalation route of exposure.) The authors suggest that the decreased circulating glucose levels may be associated with both increased glycolysis and the inhibition of gluconeogenesis (kerosene exposure effecting increased glycolysis is supported by the findings of increased concentrations of lactate and pyruvate in the blood and liver, as well as increased lactate dehydrogenase activity in the liver). Further, the authors suggest that the increased glycolysis may be the result of the inhibition of cellular respiration by kerosene, and it was noted that cellular respiration was inhibited in liver and kidney slices subsequent to the addition of kerosene to the incubation solution.

When exposed to up to $100 \mathrm{mg} / \mathrm{m}^{3}$ deodorized kerosene vapor for 13 weeks, no histopathological changes in the liver were noted in rats or dogs, and no liver weight changes were noted in dogs (Carpenter et al. 1976). Inhalation of diesel fuel aerosol 4 hours/day, 2 days/week for 13 weeks at concentrations up to $1,500 \mathrm{mg} / \mathrm{m}^{3}$ did not induce histopathological or organ weight changes in the livers of rats (Lock et al. 1984). 
Renal Effects. Renal effects were tested by urinalysis in two individuals who were exposed to JP-5 vapor for approximately 1 hour while flying a small airplane (Porter 1990). No abnormalities in the urine were reported in this case study for either of these individuals. Acute renal failure was reported in a man who was exposed to diesel fuel vapor for 10 days while driving a truck with a fuel injector leak (Reidenberg et al. 1964). Acute renal failure also occurred in a man after washing his hair with an unknown amount of diesel fuel (Barrientos et al. 1977). In addition, he had oliguria; biopsy revealed mitosis and vacuolization in renal cells, tubular dilation, and some cellular proliferation in the glomerulus. Another man developed acute tubular renal necrosis after washing his hands with an unspecified diesel fuel over several weeks (Crisp et al. 1979). Specifically, patchy degeneration and necrosis of the proximal and distal tubular epithelium with preservation of the basement membranes were noted. Also, increased blood urea and serum creatinine levels were noted in this individual. Effects resulting from inhalation versus dermal exposure could not be distinguished in the two latter cases. Based upon these case studies and the finding of kidney damage in mice dermally exposed to fuel oils (see Section 2.2.3.2 under Renal Effects), it may be possible to absorb fuel oil vapor through the skin. However, no studies were located that tested dermal absorption of fuel oil vapor in humans (see Section 2.3.1.3).

Several studies have identified a hydrocarbon-induced nephropathy in male rats that is associated with exposure to hydrocarbon vapors, including some fuel oils (Bruner 1984; Cowan and Jenkins 1981; Gaworski et al. 1984). This hydrocarbon-induced nephropathy has only been demonstrated in adult male rats and has been linked to a specific protein, $\alpha_{2 \mu}$-globulin, which is produced under hormonal control by the liver (Alden 1986). When male rats are exposed to certain hydrocarbons, including JP-5 and marine diesel fuel, $\alpha_{2 \mu}$,-globulin accumulates in hyaline droplets, which can be visualized in proximal tubule cells. This buildup of $\alpha_{2 \mu}$-globulin-containing hyaline droplets is thought to lead to cell necrosis; the cellular debris accumulates at the corticomedullary junction, causing tubule dilation and mineralization of the tubules. Studies of 90 -day continuous inhalation of 150 or $750 \mathrm{mg} / \mathrm{m}^{3} \mathrm{JP}-5$ vapor (Bruner 1984; Cowan and Jenkins 1981; Gaworski et al. 1984) and 50 or $300 \mathrm{mg} / \mathrm{m}^{3}$ marine diesel fuel vapor (Bruner 1984; Cowan and Jenkins 1981) have shown that a dose-response relationship exists for multifocal tubular atrophy and focal tubular necrosis at the corticomedullary junction in male rats. Granular cysts form from the necrotic debris, which then plug and dilate the proximal tubules, resulting in chronic necrosis. In all cases of JP-5-induced and marine diesel fuel-induced nephropathy, dose-dependent formation of cytoplasmic hyaline droplets of the proximal tubules in the renal cortex is prominent. Increased blood urea nitrogen and creatinine levels were 
found to be associated with this nephropathy in male rats following inhalation of 150 or $750 \mathrm{mg} / \mathrm{m}^{3}$ JP-5 (Cowan and Jenkins 1981). Since humans do not possess $\alpha_{2 \mu}$-globulin, this effect in male rats is not considered germane to human health risk assessment.

This nephropathy has also been identified in male rats exposed to JP- 5 by the oral route (see the discussion of Renal Effects in Section 2.2.2.2). This nephropathy does not appear to be induced by deodorized kerosene or diesel fuel, at least not under subchronic exposure conditions. No histopathological changes were noted in the renal system of rats or dogs exposed to up to $100 \mathrm{mg} / \mathrm{m}^{3}$ deodorized kerosene vapor for 13 weeks (Carpenter et al. 1976). No organ weight or histopathological changes of the renal system were noted in rats following inhalation of diesel fuel aerosol 4 hours/day, 2 days/week, for 13 weeks at concentrations up to $1,500 \mathrm{mg} / \mathrm{m}^{3}$ (Lock et al. 1984). This lesion has not been noted in female rats, female mice (studies conducted on male mice were not located), or dogs of either sex when exposed under similar conditions to either JP-5 or marine diesel fuel vapors (Bruner 1984; Cowan and Jenkins 1981; Gaworski et al. 1984).

Dermal Effects. No studies were located regarding dermal effects in humans after inhalation exposure to fuel oils.

Whole-body inhalation exposure to diesel fuel aerosol 4 hours/day, 2 days/week, for 13 weeks at concentrations up to $1,500 \mathrm{mg} / \mathrm{m}^{3}$ did not induce skin lesions in rats (Lock et al. 1984).

Ocular Effects. One case study describes eye irritation in two individuals exposed to JP-5 vapor for approximately 1 hour while flying a small airplane (Porter 1990). Both individuals experienced a burning sensation in their eyes, and one had itchy, watery eyes 1 day after the exposure. These effects subsided within 24 hours. Hyperemic conjunctiva were also reported for one of the individuals; this effect subsided after 4 days. Another case study describes subconjunctival hemorrhages in a man whom had washed his hair with an unknown amount of diesel fuel (Barrientos et al. 1977). Effects resulting from inhalation versus dermal exposure could not be distinguished in this case. Eye irritation was not induced in six volunteers by a 15 -minute exposure to $140 \mathrm{mg} / \mathrm{m}^{3}$ deodorized kerosene vapor (Carpenter et al. 1976). This study is limited since only one concentration was tested. Eye irritation was also noted in factory workers who were chronically exposed to jet fuel (Knave et al. 1978). The limitations of the study are discussed in detail in Section 2.2.1.2 under Respiratory Effects. 
No studies were located regarding ocular effects in animals after inhalation exposure to fuel oils.

Body Weight Effects. No studies were located regarding body weight effects for humans after inhalation exposure to fuel oils.

There was no change in body weight gain in rats exposed to up to $100 \mathrm{mg} / \mathrm{m}^{3}$ deodorized kerosene vapor for 13 weeks (Carpenter et al. 1976). Inhalation of diesel fuel aerosol 4 hours/day, 2 days/week for 13 weeks at concentrations of $250-1,500 \mathrm{mg} / \mathrm{m}^{3}$ induced reversible body weight loss at all exposure levels and decreased food consumption in rats exposed to the mid- and high-exposure levels (Lock et al. 1984). There were no histopathological or relative adrenal gland weight changes in these animals. Intermediate exposures to diesel fuel aerosol induced decreases in the mean body weights of rats exposed to a Ct of 8,000 or $12,000 \mathrm{mg}$ hour $/ \mathrm{m}^{3}$ (Dalbey et al. 1987). Weight loss was found to be dependent upon exposure concentration, frequency, and duration in this study. Dose-response data were not reported for the individual exposure concentrations used to produce each $\mathrm{Ct}$ (see discussion in Section 2.2.1.1). There was no change in body weight gain in mice or female rats following 90-day inhalation exposure to $750 \mathrm{mg} / \mathrm{m}^{3} \mathrm{JP}-5$ vapor (Gaworski et al. 1984).

Other Systemic Effects. A man exposed to diesel fuel vapor for 10 days while driving a truck with a fuel injector leak exhibited systemic edema (Reidenberg et al. 1964). Edema of the scrotum and ankle were reported in a man who washed his hands with diesel fuel over several weeks (Crisp et al. 1979). Other effects noted in this man were loin pains, thirst, and severe exhaustion. Effects resulting from inhalation versus dermal exposure could not be distinguished in this case. Inhalation of 400 ppm home heating oil no. 2 vapor, 408.8 ppm fuel oil UNSP vapor, or $401.5 \mathrm{ppm}$ diesel fuel vapor by pregnant rats for 10 days did not induce maternal body weight changes (API 1979c, 1979g; Beliles and Mecler 1983). A dose-response relationship was noted for decreased food and water consumption with subsequent weight loss and dehydration in mice following 5-day, 8-hour/day acute inhalation of $204 \mathrm{mg} / \mathrm{m}^{3}$ diesel fuel no. 2 vapors (Kainz and White 1984). These effects were not induced by $135 \mathrm{mg} / \mathrm{m}^{3}$ of the diesel fuel. Decreased food intake was also noted in pregnant rats following inhalation of $401.5 \mathrm{ppm}$ diesel fuel vapor; no effects on maternal food intake were noted following inhalation of $101.8 \mathrm{ppm}$ diesel fuel vapor, 100 or $400 \mathrm{ppm}$ home heating oil vapor, or 86.9 or 408.8 ppm fuel oil UNSP vapor (API 1979c, 1979g; Beliles and Mecler 1983). 


\subsubsection{Immunological and Lymphoreticular Effects}

No studies were located regarding immunological or Lymphoreticular effects in humans or animals after inhalation exposure to fuel oils.

\subsubsection{Neurological Effects}

In one case study, neurological effects in humans resulting from acute exposure to JP-5 vapor were reported (Porter 1990). Coordination and concentration difficulties and fatigue were noted in each of two individuals following a 1-hour exposure to JP-5. Other effects included headache, apparent intoxication, and anorexia. Neither experienced any sensory impairment. The effects subsided within 24 hours for one individual, and within 4 days for the other. Anorexia was also reported in a man who washed his hands with diesel fuel over several weeks (Crisp et al. 1979). Effects resulting from inhalation versus dermal exposure could not be distinguished in this case. A man exposed to diesel fuel vapor for 10 days while driving a truck with a fuel injector leak exhibited severe headaches approximately 4 weeks after exposure (Reidenberg et al. 1964). In a study of six volunteers, slight olfactory fatigue was induced in three, while one reported "tasting something," following a 15-minute exposure to $140 \mathrm{mg} / \mathrm{m} 3$ deodorized kerosene vapor (Carpenter et al. 1976). This study is limited since only one concentration was tested.

An epidemiological study tested the effects of chronic exposure to jet fuel in factory workers (Knave et al. 1978). This study found significant increases in neurasthenia (i.e., fatigue, depressed mood, lack of initiative, dizziness, and sleep disturbances) in the exposed subjects when compared to unexposed controls from the same factory. Also, attention and sensorimotor speed were impaired in the exposed workers, but no effects were found on memory function or manual dexterity. Results of an electroencephalograph (EEG) suggested that the exposed workers may have had instability in the thalamocortical system. The limitations of the study, which include lack of specification of type of jet fuel and no adjustment for other chemicals, were discussed in greater detail in Section 2.2.1.2 under Respiratory Effects.

Kainz and White (1984) exposed (nose only) groups of CD-1 mice to concentrations of 65, 135, or $204 \mathrm{mg}$ diesel vapor/m3 of air for 8 hours/day for 5 consecutive days. General appearance and behavior were observed, as was performance on a series of neurobehavioral tests (square box activity 
test, rotating rod test, inclined plane test, cornea1 reflex test, hot plate test) administered 24 hours before exposure, on each day of exposure, and 24 hours after the last exposure. Results of the square box test revealed increased activity at the lowest concentration, little change at the mid-concentration, and decreased activity (up to 50\%) in the high-concentration exposed animals. The rotating rod test showed decreased performance at the mid- and high-exposures. Results of the hot plate test indicated an increased sensitivity to heat of the mid- and high-concentration groups on day 1 of exposure, but tolerance was reported on day 6 . The corneal reflex and inclined plane tests showed no differences from controls at any air concentration. Some degree of ataxia/disturbed gait was observed in all exposure groups immediately after removal from the exposure chamber, with the severity and duration of the symptom being dose dependent (all mice returned to normal before the next day's exposure). Grooming habits were reported to be poor in the mid- and high-exposure groups. Water consumption was decreased in the high-dose group, which was reported to appear dehydrated on day 3 of exposure, and a $30 \%$ loss in body weight was also observed in this group. Vasodilation of the ear and tail veins was seen in the mid- and high-concentration groups on the third day of the experiment. Tremors were reported in 3 of 10 mice in the mid-exposure group and in 5 of 10 mice in the high-concentration group while in motion, and 3 of the high-exposure animals died before the end of the experiment. The results of the Kainz and White (1984) study indicated a time- and dose-dependent response to diesel vapor, with nonlethal effects all being completely reversible within 24 hours of cessation of exposure. (This study was used to derive an acute inhalation MRL for fuel oil no. 2-D.)

No histopathological changes were noted in the nervous system of rats or dogs exposed to up to $100 \mathrm{mg} / \mathrm{m}^{3}$ deodorized kerosene vapor for 13 weeks (Carpenter et al. 1975, 1976). Inhalation of diesel fuel aerosol 4 hours/day, 2 days/week, for 13 weeks at concentrations up to $1,500 \mathrm{mg} / \mathrm{m}^{3}$ did not induce histopathological changes in the nervous system of rats (Lock et al. 1984). However, peak response time using the startle reflex assay was increased in rats at all exposure levels, but the greatest increase occurred in the high-dose group. Neurotoxicity, as measured using the landing footspread, tail flick, forelimb grip strength, and startle reflex assays, did not occur in rats exposed to a $\mathrm{Ct}$ of 8,000 or $12,000 \mathrm{mg}$ hour $/ \mathrm{m}^{3}$ diesel fuel aerosol for 3 or 9 weeks (Dalbey et al. 1987).

The highest NOAEL and all reliable LOAEL values for neurological effects after inhalation exposure to fuel oils are recorded in Table 2-1 and plotted in Figure 2-2. 


\subsubsection{Reproductive Effects}

No studies were located regarding reproductive effects in humans after inhalation exposure to fuel oils.

Inhalation of diesel fuel aerosol 4 hours/day, 2 days/week, for 13 weeks at concentrations up to $1,500 \mathrm{mg} / \mathrm{m}^{3}$ did not induce relative testes weight changes nor histopathological changes in the reproductive organs of rats (Lock et al. 1984).

The highest NOAEL value for reproductive effects after inhalation exposure to fuel oils is recorded in Table 2-1 and plotted in Figure 2-2.

\subsubsection{Developmental Effects}

No studies were located regarding developmental effects in humans after inhalation exposure to fuel oils.

No developmental effects (soft tissue changes, skeletal abnormalities, inhibition of fetal growth) were noted in the fetuses of female rats exposed to $400 \mathrm{ppm}$ home heating oil no. 2, $408.8 \mathrm{ppm}$ fuel oil UNSP, or 401.5 ppm diesel fuel vapor by inhalation during gestation days 6-15 (API 1979c 1979g; Beliles and Mecler 1983). Only one study was located for each fuel oil for these effects.

The highest NOAEL values for developmental effects after inhalation exposure to fuel oils are recorded in Table 2-1 and plotted in Figure 2-1.

\subsubsection{Genotoxic Effects}

No studies were located regarding genotoxic effects in humans after inhalation exposure to fuel oils.

In the only in vivo animal study located regarding genotoxic effects using inhalation as the route of exposure, male CD-1 mice (12/group) exposed to 100 or $400 \mathrm{ppm}$ diesel fuel vapor (6 hours/day, 5 days/week, for 8 weeks) showed no adverse effects with respect to the frequency of dominant lethal mutations (API 1981). 
Other genotoxicity studies are discussed in Section 2.4.

\subsubsection{Cancer}

There are limited epidemiological data regarding carcinogenicity in humans following chronic inhalation exposure to kerosene. In one case-control study, there was no association between the use of kerosene stoves for cooking and bronchial cancer in nonsmoking women (Chan et al. 1979). In another case-control study, there was no association between renal cell cancer and occupational exposure to fuel oils, including diesel fuel (Partanen et al. 1991). In the first study, it cannot be determined whether the individuals were actually exposed to kerosene vapor. Also, there may be additional or alternative effects resulting from exposure to the combustion products of kerosene, which may be toxicologically different from the kerosene itself. In the latter study, exposure to other chemicals may have affected the results, since fuel oil exposure was based upon occupation. Both studies are limited because they do not quantify the levels of exposure and cannot accurately determine the duration of exposure to fuel oils. In another study, increased risk of laryngeal cancer was associated with self-reported exposure to diesel oil (Ahrens et al. 1991). However, the data were equivocal. Similarly, exposure to "petroleum products," including diesel fuel, has been associated with acute leukemia (Lindquist et al. 1991), but the study was very limited in that type of product exposed to was not described, and included a wide range of product types. A third study associated the use of kerosene stoves and exposure to "petroleum products" with oral and pharyngeal cancer (Zheng et al. 1992), but suffers the same limitations as Lindquist et al., with the addition that use of kerosene stoves involves exposure to both kerosene vapor and combustion products.

In a study conducted on rats, no renal tumors were observed during life-time observation following a 90 -day continuous exposure to $750 \mathrm{mg} / \mathrm{m}^{3} \mathrm{JP}-5$ vapor or to $300 \mathrm{mg} / \mathrm{m}^{3}$ marine diesel fuel vapor (Bruner 1984). Since this study was not designed to test carcinogenicity, these data have limited usefulness. 


\subsubsection{Oral Exposure}

\subsubsection{Death}

Numerous case studies have described death following the accidental ingestion of kerosene by children (usually under the age of 5 but as old 15 years). The deaths are usually attributed to lipoidal pneumonia (Morrison and Sprague 1976; Santhanakrishnan and Chithra 1978; Zucker et al. 1986) that was probably induced by the aspiration of the kerosene. Specific respiratory effects associated with death from kerosene ingestion include pneumothorax (Mahdi 1988; Zucker et al. 1986), emphysema (Mahdi 1988), and pneumonitis (Singh et al. 1981). Cardiac arrhythmia was reported as the cause of death in one child; however, it was suspected that myocarditis and pulmonary edema may have been the cause of the rapid deterioration and death of the child (Dudin et al. 1991).

Estimated ingested doses of kerosene associated with death are as low as $1,890 \mathrm{mg} / \mathrm{kg}$, based on ingestion of $30 \mathrm{~mL}$ of kerosene by children 11 months to 2 years of age (Dudin et al. 1991; Santhanakrishnan and Chithra 1978), and as high as $16,789 \mathrm{mg} / \mathrm{kg}$, based on ingestion of $200 \mathrm{~mL}$ of kerosene by a l-year-old child (Santhanakrishnan and Chithra 1978). No lethality was reported for children from 10 months to 5 years old following ingestion of estimated doses ranging from 120 to $870 \mathrm{mg} / \mathrm{kg}$ and in one instance a dose as high as $1,700 \mathrm{mg} / \mathrm{kg}$ of kerosene (Dudin et al. 1991).

Death in rats occurred after acute oral exposure to $12,000 \mathrm{mg} / \mathrm{kg}$ kerosene but not after exposures to $8,000-11,200 \mathrm{mg} / \mathrm{kg}$ kerosene or 12,150 mg/kg Deobase ${ }^{\circledR}$ (Muralidhara et al. 1982). Oral exposure to $4,000 \mathrm{mg} / \mathrm{kg}$ kerosene was lethal to 10-day-old rats; this dose level was not tested in adult rats (Deichmann et al. 1944). Death occurred in two out of six rats subsequent to a single gavage dose of 47,280 mg/kg JP-5, but none died from single doses of 18,912-29,944 mg/kg JP-5 (Parker et al. 1981). One rat exposed to $37,824 \mathrm{mg} / \mathrm{kg} \mathrm{JP}-5$ died from a gavage accident. There were no other deaths in that treatment group.

The acute oral $\mathrm{LD}_{50}$ values for kerosene in guinea pigs and rabbits have been reported to be 16,320 and $22,720 \mathrm{mg} / \mathrm{kg}$, respectively (Deichmann et al. 1944). In guinea pigs, death occurred following acute oral exposure to 3,760-19,200 mg/kg kerosene. Death in rabbits occurred after acute oral exposure to $12,800-28,800 \mathrm{mg} / \mathrm{kg}$ kerosene but not after exposure to $8,000 \mathrm{mg} / \mathrm{kg}$. These data for guinea pigs and rabbits are limited, because the methodologies and experimental conditions of this 
study were poorly described. Oral gavage of $6,400 \mathrm{mg} / \mathrm{kg} /$ day kerosene, administered for 7-10 days, was lethal to four out of five male calves; only one dose was tested in this study (Rowe et al. 1973). Mortality in rats was induced by acute aspiration of $0.05-0.25 \mathrm{~mL}$ of kerosene; there was a dose response relationship for death in this study (Gerarde 1963). Aspiration is induced by placing the test material into the back of the throat which causes the animal to choke, forcing the test compound into the respiratory tract. The purpose of using aspiration as a route of exposure in animals is to mimic human respiratory exposure which occurs during vomiting after ingestion of kerosene. Mortality in mice was noted following a single exposure to $20 \mu \mathrm{L}$ kerosene by aspiration (Nouri et al. 1983). This latter study is limited because only one dose was tested.

All reliable LOAEL values for death in each species and duration category after oral exposure to fuel oils are recorded in Table 2-2 and plotted in Figure 2-3.

\subsubsection{Systemic Effects}

No studies were located regarding musculoskeletal effects in humans or animals after oral exposure to fuel oils.

The highest NOAEL and all reliable LOAEL values for systemic effects in each species and duration category for oral exposure to fuel oils are recorded in Table 2-2 and plotted in Figure 2-3.

Respiratory Effects. Even if the kerosene is initially ingested (accidental ingestion of fuel oils is most often noted in children under 5 years of age), the respiratory toxicity is usually attributable to the aspiration of kerosene into the lungs during vomiting (Coruh and Inal 1966; Majeed et al. 1981; Nouri and Al-Rahim 1970). Based on those case studies that examined at least 50 cases of kerosene ingestion by children, the respiratory effects that primarily occur from kerosene ingestion are bronchopneumonia, bronchitis, pneumonitis, lung infiltrates and effusions, cough, dyspnea, and tachypnea (Akamaguna and Odita 1983; Aldy et al. 1978; Annobil 1983; Annobil and Ogunbiyi 1991; Mahdi 1988; Santhanakrishnan and Chithra 1978; St. John 1982). Pneumonitis, pulmonary edema, and/or pneumonia were reported for children and adults who had ingested kerosene (Subcommittee on Accidental Poisoning 1962). Hypoxia has also been noted in some cases (Dudin et al. 1991). An epidemiological study found a significant increase in a feeling of heaviness in the chests of workers 
TABLE 2-2. Levels of Significant Exposure to Fuel Oils - Oral

\begin{tabular}{|c|c|c|c|c|c|c|c|}
\hline \multirow{2}{*}{$\begin{array}{l}\text { Key } \\
\text { to } \\
\text { figure }\end{array}$} & \multirow[b]{2}{*}{$\begin{array}{l}\text { Species/ } \\
\text { (Strain) }\end{array}$} & \multirow{2}{*}{$\begin{array}{l}\text { Exposure/ } \\
\text { Duration/ } \\
\text { Frequency } \\
\text { (Specific Route) }\end{array}$} & \multirow[b]{2}{*}{ System } & \multirow[b]{2}{*}{$\begin{array}{c}\text { NOAEL } \\
(\mathrm{mg} / \mathrm{kg} / \text { day })\end{array}$} & \multicolumn{2}{|c|}{ LOAEL } & \multirow[b]{2}{*}{$\begin{array}{l}\text { Referencel } \\
\text { Chemical Form }\end{array}$} \\
\hline & & & & & $\begin{array}{r}\text { Less Serious } \\
(\mathrm{mg} / \mathrm{kg} / \text { day })\end{array}$ & $\begin{array}{l}\text { Serlous } \\
\text { (mg/kg/day) }\end{array}$ & \\
\hline & \multicolumn{7}{|c|}{ ACUTE EXPOSURE } \\
\hline & \multicolumn{7}{|l|}{ Death } \\
\hline 1 & $\begin{array}{l}\text { Rat } \\
\text { Wistar- } \\
\text { CFTRI }\end{array}$ & $\begin{array}{l}1 d \\
(G)\end{array}$ & & & & $\begin{array}{l}12000 \mathrm{~F} \text { (minimum lethal dose; } 33 \% \\
\text { mortality) }\end{array}$ & $\begin{array}{l}\text { Muralidhara et al. } \\
1982 \\
\text { FO-1 }\end{array}$ \\
\hline \multirow[t]{2}{*}{2} & $\begin{array}{l}\text { Rat } \\
\text { Sprague- } \\
\text { Dawley }\end{array}$ & $\begin{array}{l}1 d \\
(G)\end{array}$ & & & & $47280 \mathrm{M}$ (33\% mortality) & $\begin{array}{l}\text { Parker et al. } 1981 \\
\text { FO1JP5 }\end{array}$ \\
\hline & Systemic & & & & & & \\
\hline \multirow[t]{5}{*}{3} & $\begin{array}{l}\text { Rat } \\
\text { Wistar- } \\
\text { CFTRI }\end{array}$ & $\begin{array}{l}1 d \\
(G)\end{array}$ & Cardio & $12000 \mathrm{~F}$ & & & $\begin{array}{l}\text { Muralidhara et al. } \\
1982 \\
\text { FO-1 }\end{array}$ \\
\hline & & & $\begin{array}{l}\text { Gastro } \\
\text { Hemato }\end{array}$ & $\begin{array}{l}12000 \mathrm{~F} \\
12000 \mathrm{~F}\end{array}$ & & & \\
\hline & & & Renal & $12000 \mathrm{~F}$ & $\begin{array}{c}\text { NS F (slightly dilated kidney } \\
\text { tubules) }\end{array}$ & & \\
\hline & & & Hepatic & $12000 F$ & $\begin{array}{l}\text { NS F (cellular vacuolization; } \\
\text { infiltration) }\end{array}$ & & \\
\hline & & & Bd Wt & $12000 \mathrm{~F}$ & $\begin{array}{c}\text { NS F (decreased body weight } \\
\text { and food intake) }\end{array}$ & & \\
\hline
\end{tabular}


TABLE 2-2. Levels of Significant Exposure to Fuel Oils - Oral (continued)

\begin{tabular}{|c|c|c|c|c|c|c|c|}
\hline \multirow{2}{*}{$\begin{array}{l}\text { Key } \\
\text { to } \\
\text { figure }\end{array}$} & \multirow{2}{*}{$\begin{array}{l}\text { Species/ } \\
\text { (Strain) }\end{array}$} & \multirow{2}{*}{$\begin{array}{l}\text { Exposure/ } \\
\text { Duration/ } \\
\text { Frequency } \\
\text { (Specific Route) } \\
\end{array}$} & \multirow[b]{2}{*}{ System } & \multirow[b]{2}{*}{$\begin{array}{c}\text { NOAEL } \\
\text { (mg/kg/day) }\end{array}$} & \multicolumn{2}{|c|}{ LOAEL } & \multirow[b]{2}{*}{$\begin{array}{l}\text { Reference/ } \\
\text { Chemical Form }\end{array}$} \\
\hline & & & & & $\begin{array}{r}\text { Less Serious } \\
(\mathrm{mg} / \mathrm{kg} / \mathrm{day})\end{array}$ & $\begin{array}{l}\text { Serious } \\
\text { (mg/kg/day) }\end{array}$ & \\
\hline \multirow[t]{8}{*}{4} & Rat & $1 \mathrm{~d}$ & Resp & & NS $M$ (congestion of the lung) & & Parker et al. 1981 \\
\hline & $\begin{array}{l}\text { Sprague- } \\
\text { Dawley }\end{array}$ & $(G)$ & & & & & FO1JP5 \\
\hline & & & Cardio & NSM & NS M (epicardium congestion) & & \\
\hline & & & Gastro & $18912 \mathrm{M}$ & $\begin{array}{l}\text { NS M (mottled liver; swollen } \\
\text { liver; hepatocyte } \\
\text { changes) }\end{array}$ & & \\
\hline & & & Hepatic & & 18912 M (hepatocyte necrosis) & & \\
\hline & & & Renal & $37824 \mathrm{M}$ & 47280 M (hyaline droplets) & & \\
\hline & & & Derm & & $\begin{array}{c}\text { NS M (subcutis congestion; } \\
\text { alopecia) }\end{array}$ & & \\
\hline & Neurologic & & & & & & \\
\hline \multirow[t]{2}{*}{5} & $\begin{array}{l}\text { Rat } \\
\text { Wistar-CFTRI }\end{array}$ & $\begin{array}{l}1 \mathrm{~d} \\
(\mathrm{G})\end{array}$ & & $8000 \mathrm{~F}$ & NS F (anorexia) & 9600 F (unsteady gait; drowsiness) & $\begin{array}{l}\text { Muralidhara et al. } \\
1982\end{array}$ \\
\hline & & & & & & & FO-1 \\
\hline
\end{tabular}

${ }^{2}$ The number corresponds to entries in Figure 2-3.

Cardio = cardiovascular; Derm - dermal; $\mathrm{d}=$ day $(\mathrm{s}) ; \mathrm{F}=$ female; FO-1 = fuel oil no. $1 ;$ FO1JP5 = JP-5 (jet fuel); $(\mathrm{G})=$ gavage; Gastro = gastrointestinal; Hemato $=$ hematological; LOAEL = lowest-observed-adverse-effect level; $M=$ male; NOAEL =

no-observed-adverse-effect level; Resp = respiratory 
Figure 2-3. Levels of Significant Exposure to Fuel Oils - Oral

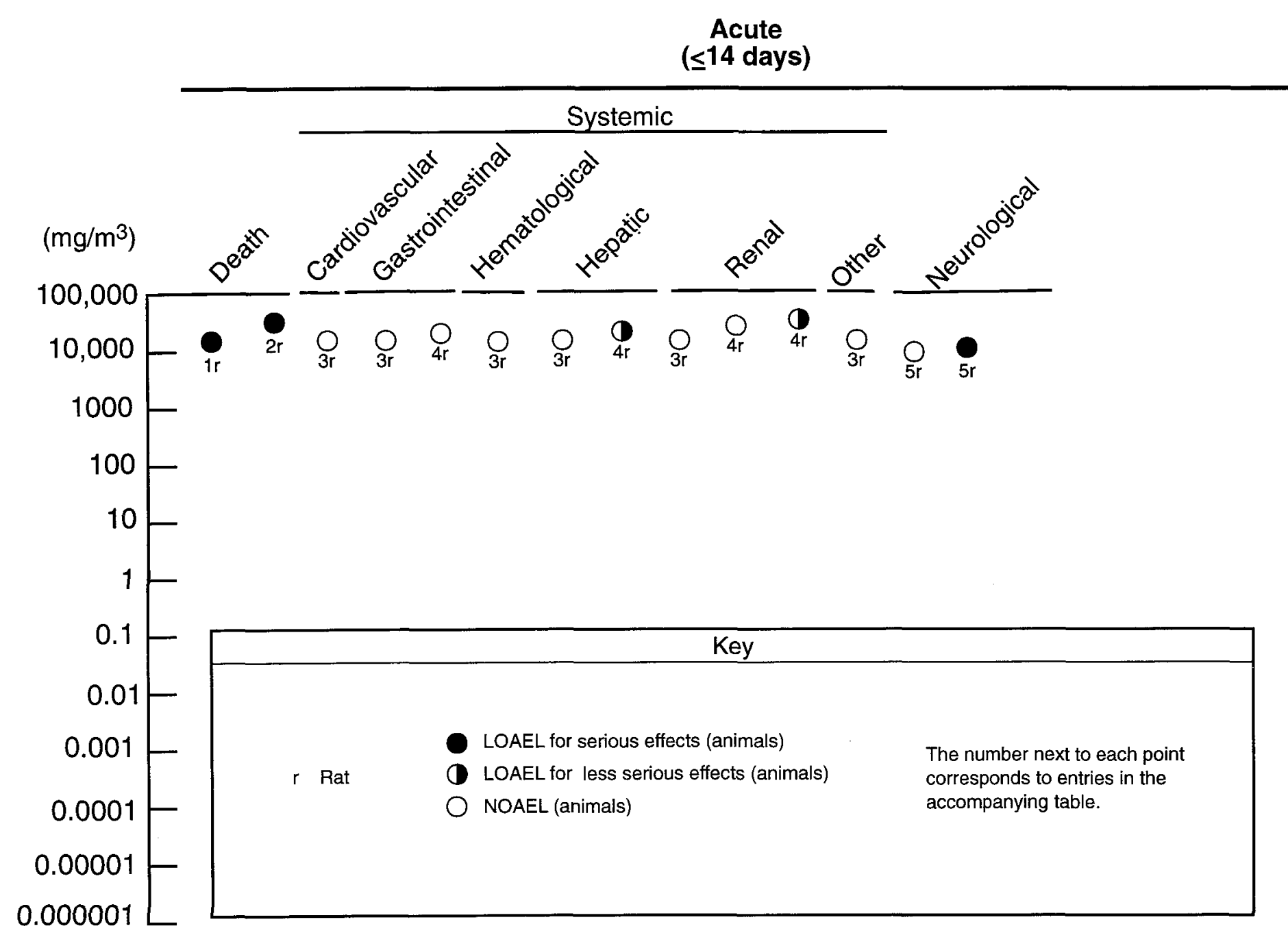


who were chronically exposed to jet fuels by the inhalation, oral, and/or dermal exposure routes (limitations of the study are discussed in detail in Section 2.2.1.2 in Respiratory Effects) (Knave et al. 1978). A follow-up study was conducted on children who 10 years earlier had been diagnosed with pneumonitis due to kerosene ingestion and who had abnormal chest radiographs at the time (Tal et al. 1984).

Researchers found an increase in volume of isoflow, a decrease in change in flow while breathing helium compared to air at 50\% vital capacity, and the continued presence of abnormal chest radiographs. The study suggests that there may be long-term respiratory effects following aspiration of ingested kerosene.

Several studies have reported estimated levels of exposure which are usually based on the finding of an empty container near the poisoned child (Agarwal and Gupta 1974; Akamaguna and Odita 1983; Aldy et al. 1978; Coruh and Inal 1966; Dudin et al. 1991; Nouri and Al-Rahim 1970; Saksena 1969; Santhanakrishnan and Chithra 1978), although the effects associated with specific doses were not reported. The Subcommittee on Accidental Poisoning (1962) estimated that ingestion of 10-30 mL kerosene was associated with pulmonary complications in 11 of the 422 cases studied (the incidence of the effects, ages associated with the effects, and doses were not reported). These effects also occurred at doses beyond this range. An estimated oral dose of less than 5,300 mg/kg kerosene resulted in the death of a 10-month-old girl. Pneumothorax, pneumomediastinum, and death were believed to be the results of respiratory distress from aspiration of kerosene (Zucker et al. 1986). Respiratory distress was reported to have resulted in the deaths of a 2-year-old child and a 1-year-old child after ingestion of $30 \mathrm{~mL}(1,890-1,959 \mathrm{mg} / \mathrm{kg})$ and $200 \mathrm{~mL}(15,340-16,789 \mathrm{mg} / \mathrm{kg})$ of kerosene, respectively (Santhanakrishnan and Chithra 1978).

Not all cases of kerosene ingestion result in toxicity. For instance, as many as $56 \%$ of the cases studied were asymptomatic in two of the study populations (Mahdi 1988; Santhanakrishnan and Chithra 1978). Also, 39\% of one population of children had normal lung x-rays following kerosene ingestion (Annobil and Ogunbiyi 1991). No doses were reported in these cases, although the authors estimated them as small.

Mononuclear and polymorphonuclear cell infiltration and unspecified pathological lesions were noted in the lungs of guinea pigs after gavage administration of 3,200-8,000 $\mathrm{mg} / \mathrm{kg}$ kerosene (Brown et al. 
1974). In mice, aspiration of $20 \mu \mathrm{L}$ of Kerosene induced pulmonary consolidation and hemorrhage, pneumonitis, a decrease in pulmonary clearance of Staphylococcus aureus, and an increase in relative lung weight (Nouri et al. 1983). Dogs exposed to $0.5 \mathrm{~mL} / \mathrm{kg}$ kerosene by aspiration exhibited increases in oxygen utilization, intrapulmonary physiologic shunt fraction, and respiratory rate and decreases in arterial oxygen tension (Goodwin et al 1988). In the aspiration studies, the actual dose entering the lungs cannot be determined.

Cardiovascular Effects. Tachycardia was noted in children following acute ingestion of kerosene (Akamaguna and Odita 1983; Coruh and Inal, 1966). In one case study, cardiomegaly, but not heart failure, occurred in $20 \%$ of the cases of kerosene poisoning (Akamaguna and Odita 1983). An epidemiological study found a significant increase in cardiac palpitations in workers who were chronically exposed to jet fuels by the inhalation, oral, and/or dermal exposure routes (Knave et al. 1978). The limitations of the study are discussed in detail in Section 2.2.1.2 under Respiratory Effects.

There were no histopathological changes and no change in the relative heart weight in rats following exposure by gavage to single doses of up to $12,000 \mathrm{mg} / \mathrm{kg}$ kerosene or $12,150 \mathrm{mg} / \mathrm{kg}$ Deobase ${ }^{\circledR}$ (Muralidhara et al. 1982). Data for Deobase ${ }^{\circledR}$ are limited because effects were reported for only one dose.

In another study, decreases in heart rate and mean arterial blood pressure occurred in dogs following a single exposure to $0.5 \mathrm{~mL} / \mathrm{kg}$ kerosene by aspiration, although these values returned to the control values within 60 minutes ( Goodwin et al. 1988). The actual dose entering the lungs by aspiration cannot be determined. The study is limited, however, because only one dose was tested.

Gatrotestinal Effects. The most commonly reported gastrointerinal effect in children following acute ingestion of kerosene in vomiting (Akamaguna and Odita 1983; Aldy et al. 1978; Mahdi 1988; Majeed et al. 1981; Nouri and Al-Rahim 1970; Saksena 1969; St. Johns 1982), including bloody vomit (Nouri and Al-Rahmin 1970). Other effects noted are abdominal pain and/or distension (Akamaguna and Odita 1983; Mahdi 1988; Majeed et al. 1981; Nouri and Al-Rahim 1970; Sakena 1969), gastroenteritis (Sakena 1969), and diarrhea (Majeed et al. 1981). 
No diarrhea was noted in rats following exposure by gavage to single doses of up to $12,000 \mathrm{mg} / \mathrm{kg}$ kerosene or $12,150 \mathrm{mg} / \mathrm{kg}$ Deobase ${ }^{\circledR}$ (Muralidhara et al. 1982).

Hematological Effects. Several case studies reported hematological effects in children following acute ingestion of kerosene. Increases in leukocyte counts were reported for $37-80 \%$ of the respective study populations (Dudin et al. 1991; Majeed et al. 1981; Nouri and Al-Rahim 1970).

In rats exposed by gavage to single doses of up to $12,000 \mathrm{mg} / \mathrm{kg} /$ kerosene or $12,150 \mathrm{mg} / \mathrm{kg}$ Deobase ${ }^{\circledR}$, there was no change in relative spleen weight and no histopathological changes of the spleen occurred (Muralidhara et al. 1982). Rats had increased hematocrit, decreased white blood cell counts, and increased erythrocyte counts following exposure by gavage to a single dose of 18,912 mg JP-5/kg (Parker et al. 1981).

Hepatic Effects. No studies were located regarding hepatic effects in humans after oral exposure to fuel oils.

There was no change in the relative organ weight of the liver in rats following exposure by gavage to single doses of up to $12,000 \mathrm{mg} / \mathrm{kg}$ kerosene or $12,150 \mathrm{mg} / \mathrm{kg}$ Deobase ${ }^{\circledR}$ (Muralidhara et al. 1982). Histopathological examination revealed slight cellular infiltration and mild vacuolization of the liver, but the kerosene and Deobase exposure levels that induced these effects were not specified. A single exposure to JP-5 induced necrosis in the hepatocytes of rats exposed to $18,912-47,280 \mathrm{mg} / \mathrm{kg}$ by gavage (Parker et al. 1981). In another experiment, a single exposure to $18,912 \mathrm{mg} \mathrm{JP}-5 / \mathrm{kg}$ induced vacuolization of the periportal hepatocytes within 2 days of gavage, as well as statistically significant increases in serum glutamic pyruvic transaminase (SGPT), glutamic oxaloacetic transaminase (SGOT), and lactate dehydrogenase levels, suggesting hepatic damage (Parker et al. 1981).

Renal Effects. Several case studies reported normal urinalysis tests in children following acute ingestion of kerosene (Dudin et al. 1991; Mahdi 1988; Nouri and Al-Rahim 1970), although albuminuria was occasionally noted (Dudin 1991; Nouri and Al-Rahim 1970).

There were no changes in relative kidney weights in rats following exposure by gavage to single doses of up to $12,000 \mathrm{mg} / \mathrm{kg}$ kerosene or $12,150 \mathrm{mg} / \mathrm{kg}$ Deobase ${ }^{\circledR}$ (Muralidhara et al. 1982). Histopathological examination revealed slight cellular infiltration and mild vacuolization in the kidney 
tissues and slight dilation of the kidney tubules, but the kerosene and Deobase ${ }^{\circledR}$ exposure levels that induced these effects were not specified. Only one study was located that tested for kidney weight changes.

In another study, hyaline droplets were detected in the kidneys of two male rats that died 48 hours after a single exposure to $47,280 \mathrm{mg} / \mathrm{kg} \mathrm{JP}-5$ by gavage (Parker et al. 1981). This effect was not apparent in male rats that died within 48 hours of exposure to $47,280 \mathrm{mg} / \mathrm{kg}$ or in rats that survived for 14 days following exposures to $18,912-37,824 \mathrm{mg} / \mathrm{kg}$ JP-5. However, hyaline droplets were apparent in rats that were killed within 2-3 days of exposure to $18,912 \mathrm{mg} / \mathrm{kg}$ JP-5. Thus, the effect appears to be induced within a specific period, between 2 and 14 days, following exposure. A single exposure to $18,912 \mathrm{mg} / \mathrm{kg} \mathrm{JP}-5$ also induced a statistically significant increase in creatinine levels (Parker et al. 1981). These effects are apparently unique to male rats and are not expected to occur in humans (see discussion in Section 2.2.1.2 under Renal Effects).

Dermal Effects. Large blisters, erythema, and peeling skin were reported in two cases of apparent oral exposure to kerosene (Annobil 1988). However, the strong odor of kerosene on one of the individuals and the kerosene-stained clothing of the other indicate that dermal exposure may have also occurred in these cases. Exposure levels were not reported.

Alopecia and congestion of the subcutis were noted in rats following exposure by gavage to single doses of $24 \mathrm{~mL} \mathrm{JP-5/kg} \mathrm{(Parker} \mathrm{et} \mathrm{al.} \mathrm{1981).}$

Ocular Effects. No studies were located regarding ocular effects in humans or animals after oral exposure to fuel oils.

Other Systemic Effects. Fever has been reported in children following ingestion of kerosene (Akamaguna and Odita 1983; Aldy et al. 1978; Dudin et al. 1991; Mahdi 1988; Majeed et al. 1981; Nouri and Al-Rahim 1970; Saksena 1969; St. John 1982). In one study, fever was reported with pulmonary complications for children and adults who had ingested kerosene (Subcommittee on Accidental Poisoning 1962). It is not known whether the fever was secondary to the pulmonary effects. 
There were no histopathological changes and no changes in the relative adrenal gland weights in rats following exposure by gavage to single doses of up to $12,000 \mathrm{mg} / \mathrm{kg}$ kerosene or $12,150 \mathrm{mg} / \mathrm{kg}$ Deobase $^{\circledR}$ (Muralidhara et al. 1982). Only one study was located that tested for these effects.

\subsubsection{Immunological and Lymphoreticular Effects}

No studies were located regarding immunological effects in humans or animals after oral exposure to fuel oils.

\subsubsection{Neurological Effects}

In one study, lethargy, semicoma, and/or coma were reported for children and adults who had ingested kerosene (Subcommittee on Accidental Poisoning 1962). Estimated exposure levels of 10-30 mL kerosene were associated with complications of the central nervous system in 18 of the 422 study participants. However, these effects also occurred at doses beyond this range, but the exact exposure levels are not known. Incidences of the effects and the ages associated with the effects or ingested doses were not reported.

Several case studies reported neurological effects in children following acute ingestion of kerosene. In studies that examined 50-205 kerosene poisoning cases, the neurological effects noted most frequently were unconsciousness or semiconsciousness, drowsiness, restlessness, and irritability (Akamaguna and Odita 1983; Aldy et al. 1978; Coruh and Inal 1966; Dudin et al. 1991; Mahdi 1988; Majeed et al. 1981; Nouri and Al-Rahim 1970; Saksena 1969; Santhanakrishnan and Chithra 1978; St. John 1982). Coma and convulsions were also noted in numerous studies, but were usually evident in only one or two individuals per study population (Coruh and Inal 1966; Dudin et al. 1991; Majeed et al. 1981; Nouri and Al-Rahim 1970; Saksena 1969; Santhanakrishnan and Chithra 1978).

In one study of 78 children known to have ingested kerosene, coma, convulsions, and death were noted in two children (aged 11-48 months) after each ingested a quantity of kerosene estimated to be between $30 \mathrm{~mL}(1,890 \mathrm{mg} / \mathrm{kg}$ ) and $50 \mathrm{~mL}(4,255 \mathrm{mg} / \mathrm{kg})$ (Dudin et al. 1991). The cause of death was not neurological for these children. Neither coma nor convulsions occurred in children that ingested 3-20 $\mathrm{mL}$ of kerosene (equivalent to $126-1,754 \mathrm{mg} / \mathrm{kg}$ in children aged $10 \mathrm{months}$ to 5 years).

However, in the majority of the cases of kerosene ingestion, neurological effects were not associated 
with specific reported quantities. There are limited data that suggest that the central nervous system effects following ingestion of kerosene are due to hypoxia from kerosene-induced respiratory impairment (Majeed et al. 1981).

An epidemiological study found significant increases in neurasthenia (i.e., fatigue, depressed mood, lack of initiative, dizziness, and sleep disturbances) in workers who were chronically exposed to jet fuels by inhalation, oral, and/or dermal exposure (Knave et al. 1978). Also, attention and sensorimotor speed were impaired, but no effects were found on memory function or manual dexterity. EEG results suggest that the exposed workers may have had instability in the thalamocortical system. The limitations of the study are discussed in detail in Section 2.2.1.2 under Respiratory Effects.

Single exposures to $12,000 \mathrm{mg} / \mathrm{kg}$ kerosene and $12,150 \mathrm{mg} / \mathrm{kg}$ Deobase by oral gavage induced unsteady gait and drowsiness in rats; however, no neurological effects occurred from exposure to $8,000 \mathrm{mg} / \mathrm{kg}$ kerosene (Muralidhara et al. 1982). These data are limited since statistical analysis was not conducted and effects in the controls were not described. Also, a dose-response relationship cannot be identified from the Deobase ${ }^{\circledR}$ data, since only one dose was tested.

In another study in which mice were exposed to a single dose of $20 \mu \mathrm{L}$ of kerosene followed by aspiration, drowsiness, lack of coordination, and behavioral changes occurred (Nouri et al. 1983). The study is limited because only one dose was tested. The actual dose entering the lungs by aspiration cannot be determined.

The highest NOAEL and all reliable LOAEL values for neurological effects after oral exposure to fuel oils are recorded in Table 2-2 and plotted in Figure 2-3.

\subsubsection{Reproductive Effects}

No studies were located regarding reproductive effects in humans or animals after oral exposure to fuel oils. 


\section{HEALTH EFFECTS}

\subsubsection{Developmental Effects}

No studies were located regarding developmental effects in humans or animals after oral exposure to fuel oils.

\subsubsection{Genotoxic Effects}

No studies were located regarding genotoxic effects in humans after oral exposure to fuel oils.

Inconclusive evidence that fuel oil no. 2 is clastogenic in rats has been reported (Conaway et al. 1984). Briefly, a bone marrow assay was used in which groups of four Sprague-Dawley rats (sex not specified) received oral doses of 125,417 , or $1,250 \mathrm{mg} / \mathrm{kg} /$ day fuel oil no. 2 for 5 consecutive days. Animals were then sacrificed, and bone marrow cells were examined for abnormal chromosome morphology. Marked, but not dose-related, increases in the percentage of aberrant cells and the percentage of cells with chromatid breaks were seen in all treatment groups. The effect was reported to be significant at the low and high dose, and the greatest yield of aberrant chromosome figures occurred in the animals treated with $125 \mathrm{mg} / \mathrm{kg} /$ day. Alternatively, cyclohexane/DMSO extract and DMSO extract of diesel 1 (CAS no. 8008-20-6) and home heating oil (CAS no. 68476-30-2), administered orally at doses of $1.0,2.0$, and $5.0 \mathrm{~g} / \mathrm{kg}$, did not induce increased frequency of micronuclei in a mouse bone marrow micronucleus assay (McKee et al 1994). It should be noted that the extraction procedure was used to concentrate the aromatic fraction (with particular interest in the polynuclear aromatics) of the fuel oils tested.

Other genotoxicity studies are discussed in Section 2.4.

\subsubsection{Cancer}

No studies were located regarding cancer in humans or animals after oral exposure to fuel oils. 


\subsubsection{Dermal Exposure}

\subsubsection{Death}

No studies were located regarding death in humans after dermal exposure to fuel oils.

Single dermal exposures to $0.5 \mathrm{~mL} / \mathrm{kg}$ home heating oil no. 2 or diesel fuel were not lethal to rabbits (API 1979a, 1980a). Daily dermal exposures for 1 week to $0.1 \mathrm{~mL}$ kerosene were not lethal to male mice (Upreti et al. 1989). Death in mice occurred after acute dermal exposures to 20,000-40,000 mg/kg/day marine diesel fuel and 30,000-40,000 mg/kg/day JP-5, but not after exposures to $2,000-8,000 \mathrm{mg} / \mathrm{kg} /$ day marine diesel fuel or $5,000-20,000 \mathrm{mg} / \mathrm{kg} /$ day JP-5 (NTP/NIH 1986). Intermediate exposures to $2,000-8,000 \mathrm{mg} / \mathrm{kg} / \mathrm{day} \mathrm{JP}-5$ for 13 weeks (NTP/NIH 1986) and to $42.2 \mathrm{mg}$ per application JP-5 or $45.5 \mathrm{mg}$ per application marine diesel fuel 3 times per week for 40 weeks (Schultz et al. 1981), were also lethal to mice. Intermediate exposures (13 weeks) to 500 or $1,000 \mathrm{mg} / \mathrm{kg} /$ day JP-5, or 2504,000 mg/kg/day marine diesel fuel (NTP/NIH 1986), or $21.1 \mathrm{mg}$ per application JP-5 3 times per week for 40 weeks, or $22.9 \mathrm{mg}$ per application marine diesel fuel 3 times per week for 40 weeks (Schultz et al. 1981) were not lethal in mice.

A statistically significant increase in the number of deaths was noted only in female mice following chronic exposure to marine diesel fuel and JP-5 at doses of 250 and $500 \mathrm{mg} / \mathrm{kg} / \mathrm{day}$ for both fuel oils (NTP/NIH 1986). Although the number of deaths in males under these conditions was increased over that of the controls, the effect was not significant. Deaths were observed as early as week 1 of exposure to marine diesel fuel and week 2 of exposure to JP-5. The data are limited for each of these experiments because it was not specified whether the animals were protected against oral exposure and/or removal of the test material.

The highest NOAEL and all reliable LOAEL values for death in each species and duration category after dermal exposure to fuel oils are recorded in Table 2-3.

\subsubsection{Systemic, Effects}

The highest NOAEL and all reliable LOAEL values for systemic effects in each species and duration category for dermal exposure to fuel oils are recorded in Table 2-3. 
TABLE 2-3. Levels of Significant Exposure to Fuel Oils - Dermal

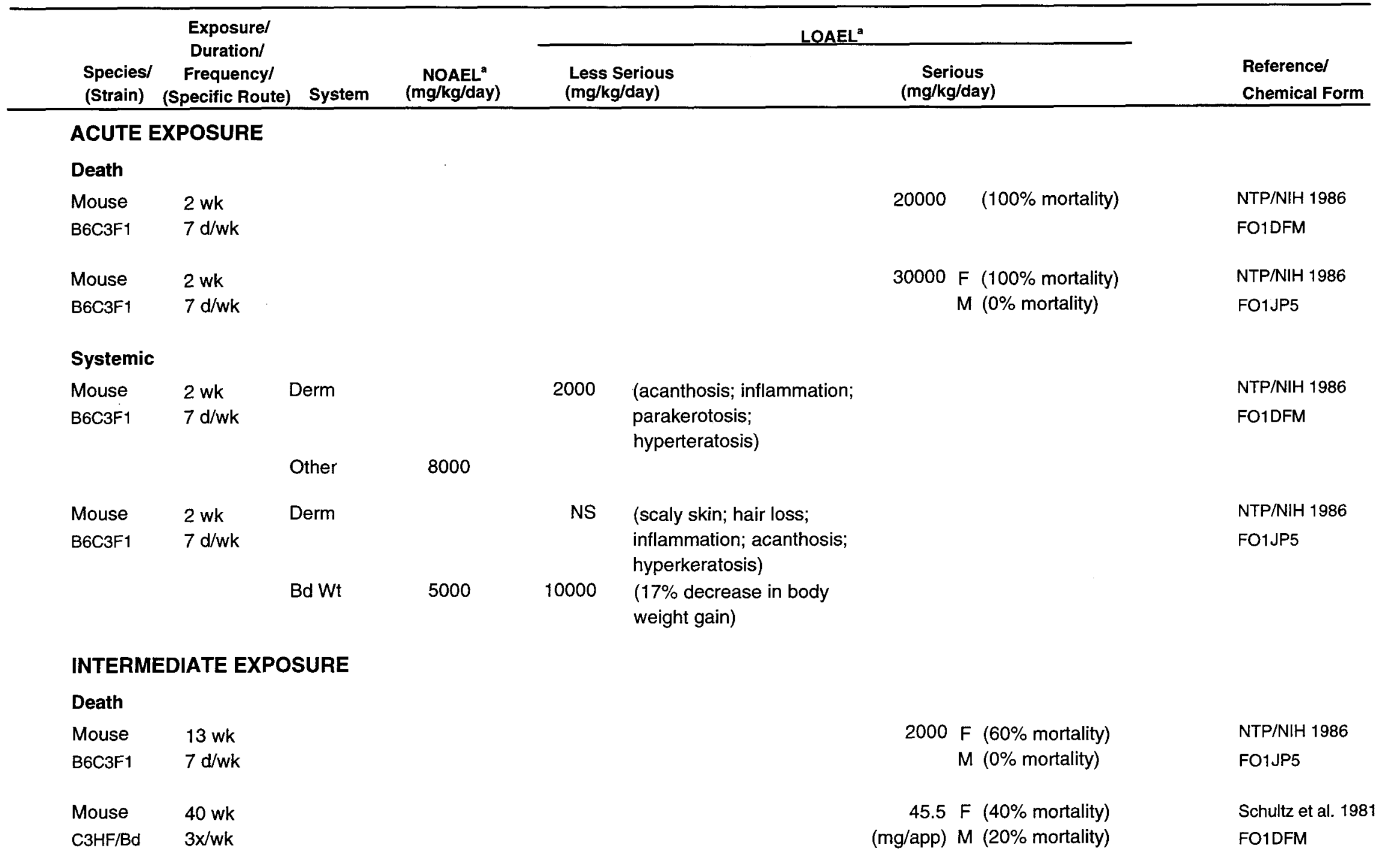


TABLE 2-3. Levels of Significant Exposure to Fuel Oils - Dermal (continued)

\begin{tabular}{|c|c|c|c|c|c|c|}
\hline \multirow[b]{2}{*}{$\begin{array}{l}\text { Species/ } \\
\text { (Strain) }\end{array}$} & \multirow{2}{*}{$\begin{array}{l}\text { Exposure/ } \\
\text { Duration/ } \\
\text { Frequency/ } \\
\text { (Specific Route) }\end{array}$} & \multirow[b]{2}{*}{ System } & \multirow[b]{2}{*}{$\begin{array}{c}\text { NOAEL } \\
\text { (mg/kg/day) }\end{array}$} & \multicolumn{2}{|c|}{ LOAEL } & \multirow[b]{2}{*}{$\begin{array}{l}\text { Reference/ } \\
\text { Chemical Form }\end{array}$} \\
\hline & & & & $\begin{array}{l}\text { Less Serious } \\
\text { (mg/kg/day) }\end{array}$ & $\begin{array}{c}\text { Serious } \\
\text { (mg/kg/day) }\end{array}$ & \\
\hline Mouse & $40 w k$ & & & & $42.2 \mathrm{~F}(40 \%$ mortality $)$ & Schultz et al. 1981 \\
\hline C3HF/Bd & $3 x / w k$ & & & & (mg/app) M (13\% mortality) & F01JP5 \\
\hline \multicolumn{7}{|l|}{ Systemic } \\
\hline Mouse & $13 w k$ & Resp & 8000 & & & NTP/NIH 1986 \\
\hline \multirow[t]{8}{*}{$\mathrm{B} 6 \mathrm{C} 3 \mathrm{~F} 1$} & $7 \mathrm{~d} / \mathrm{wk}$ & & & & & FO1JP5 \\
\hline & & Cardio & 8000 & & & \\
\hline & & Gastro & 8000 & & & \\
\hline & & Hemato & & (splen & & \\
\hline & & Hepatic & & (karyo & & \\
\hline & & Renal & 8000 & & & \\
\hline & & Derm & & $\begin{array}{l}\text { (slight } \\
\text { derma }\end{array}$ & & \\
\hline & & Bd Wt & 2000 & $\begin{array}{ll}0 & \text { (decre } \\
& \text { gain) }\end{array}$ & & \\
\hline Mouse & 13 wk & Resp & 4000 & & & NTP/NIH 1986 \\
\hline \multirow[t]{8}{*}{$\mathrm{B} 6 \mathrm{C} 3 \mathrm{~F} 1$} & $7 \mathrm{~d} / \mathrm{wk}$ & & & & & F01DFM \\
\hline & & Cardio & 4000 & & & \\
\hline & & Gastro & 4000 & & & \\
\hline & & Hemato & 4000 & & & \\
\hline & & Hepatic & 4000 & & & \\
\hline & & Renal & 4000 & & & \\
\hline & & Dermal & 2000 & $\begin{array}{l}\text { (mild } \mathrm{c} \\
\text { derma }\end{array}$ & & \\
\hline & & Bd Wt & $250 \mathrm{M}$ & $\begin{array}{r}500 \text { M (9\% d } \\
\text { weight }\end{array}$ & & \\
\hline
\end{tabular}


TABLE 2-3. Levels of Significant Exposure to Fuel Oils - Dermal (continued)

\begin{tabular}{|c|c|c|c|c|c|c|}
\hline \multirow[b]{2}{*}{$\begin{array}{l}\text { Species/ } \\
\text { (Strain) }\end{array}$} & \multirow{2}{*}{$\begin{array}{c}\text { Exposure/ } \\
\text { Duration/ } \\
\text { Frequency/ } \\
\text { (Specific Route) }\end{array}$} & \multirow[b]{2}{*}{ System } & \multirow[b]{2}{*}{$\begin{array}{c}\text { NOAEL" } \\
\text { (mg/kg/day) }\end{array}$} & \multicolumn{2}{|r|}{ LOAEL" } & \multirow[b]{2}{*}{$\begin{array}{l}\text { Referencel } \\
\text { Chemical Form }\end{array}$} \\
\hline & & & & \multicolumn{2}{|c|}{$\begin{array}{l}\text { Less Serious } \\
\text { (mg/kg/day) }\end{array}$} & \\
\hline \multirow{6}{*}{$\begin{array}{l}\text { Mouse } \\
\text { BALC/C }\end{array}$} & $40 \mathrm{wk}$ & Hemato & & 21.1 & (increased spleen weight) & Schultz et al. 198 \\
\hline & $3 x / w k$ & & & (mg/app) & & F01JP5 \\
\hline & & Hepatic & $\begin{array}{r}42.2 \\
(\mathrm{mg} / \mathrm{app})\end{array}$ & & & \\
\hline & & Renal & & $\begin{array}{r}21.1 \\
\text { (mg/app) }\end{array}$ & F (increased kidney weight) & \\
\hline & & & & $\begin{array}{r}21.1 \\
\text { (mg/app) }\end{array}$ & M (decreased kidney weight) & \\
\hline & & Bd Wt & & $\begin{array}{r}21.1 \\
\text { (mg/app) }\end{array}$ & $\begin{array}{l}\text { (7-11\% decrease in body } \\
\text { weight) }\end{array}$ & \\
\hline \multirow{6}{*}{$\begin{array}{l}\text { Mouse } \\
\text { BALB/C }\end{array}$} & $40 \mathrm{wk}$ & Hemato & & 22.9 & (increased spleen weight) & Schultz et al. 198 \\
\hline & $3 x / w k$ & & & (mg/app) & & FO1DFM \\
\hline & & Hepatic & $\begin{array}{r}45.5 \\
\text { (mg/app) }\end{array}$ & & & \\
\hline & & Renal & & $\begin{array}{r}22.9 \\
\text { (mg/app) }\end{array}$ & F (increased kidney weight) & \\
\hline & & & & $\begin{array}{r}22.9 \\
\text { (mg/app) }\end{array}$ & M (decreased kidney weight) & \\
\hline & & $B d W t$ & & $\begin{array}{r}22.9 \\
\text { (mg/app) }\end{array}$ & $\begin{array}{l}\text { (4-21\% decrease in body } \\
\text { weight) }\end{array}$ & \\
\hline \multicolumn{7}{|c|}{ Neurological } \\
\hline Mouse & 13 wk & & $8000 \mathrm{M}$ & & & NTP/NIH 1986 \\
\hline B6C3F1 & $7 \mathrm{~d} / \mathrm{wk}$ & & & & & FO1JP5 \\
\hline \multicolumn{7}{|c|}{ Reproductive } \\
\hline Mouse & $13 w k$ & & 8000 & & & NTP/NIH 1986 \\
\hline B6C3F1 & $7 \mathrm{~d} / \mathrm{wk}$ & & & & & FO1JP5 \\
\hline
\end{tabular}


TABLE 2-3. Levels of Significant Exposure to Fuel Oils - Dermal (continued)

\begin{tabular}{|c|c|c|c|c|c|c|c|}
\hline \multirow[b]{2}{*}{$\begin{array}{l}\text { Species/ } \\
\text { (Strain) }\end{array}$} & \multirow{2}{*}{$\begin{array}{c}\text { Exposure/ } \\
\text { Duration/ } \\
\text { Frequency/ } \\
\text { (Specific Route) }\end{array}$} & \multirow[b]{2}{*}{ System } & \multirow[b]{2}{*}{$\begin{array}{c}\text { NOAEL } \\
\text { (mg/kg/day) }\end{array}$} & \multicolumn{3}{|c|}{ LOAEL $^{a}$} & \multirow[b]{2}{*}{$\begin{array}{l}\text { Reference/ } \\
\text { Chemical Form }\end{array}$} \\
\hline & & & & \multicolumn{2}{|c|}{$\begin{array}{l}\text { Less Serious } \\
\text { (mg/kg/day) }\end{array}$} & $\begin{array}{c}\text { Serious } \\
\text { (mg/kg/day) }\end{array}$ & \\
\hline \multicolumn{8}{|c|}{ CHRONIC EXPOSURE } \\
\hline \multicolumn{8}{|l|}{ Death } \\
\hline Mouse & $84-103 w k$ & & & & & $250 \mathrm{~F}$ (74\% mortality) & NTP/NIH 1986 \\
\hline $\mathrm{B} 6 \mathrm{C} 3 \mathrm{~F} 1$ & $5 \mathrm{~d} / w \mathrm{k}$ & & & & & 250 M (54\% mortality) & FO1DFM \\
\hline Mouse & $90-103 w k$ & & & & & $250 F(30 \%$ mortality $)$ & NTP/NIH 1986 \\
\hline $\mathrm{B} 6 \mathrm{C} 3 \mathrm{~F} 1$ & $5 \mathrm{~d} / w \mathrm{k}$ & & & & & 250 M (34\% mortality) & F01JP5 \\
\hline \multicolumn{8}{|l|}{ Systemic } \\
\hline Mouse & $90-103$ wk F & Resp & 500 & & & & NTP/NIH 1986 \\
\hline \multirow[t]{9}{*}{$\mathrm{B} 6 \mathrm{C} 3 \mathrm{~F} 1$} & $5 \mathrm{~d} / w \mathrm{k}$ & & & & & & F01JP5 \\
\hline & & Cardio & 500 & & & & \\
\hline & & Gastro & 500 & & & & \\
\hline & & Hemato & 250 & 500 & (amyloid spleen) & & \\
\hline & & Musc/skel & 500 & & & & \\
\hline & & Hepatic & 250 & 500 & (amyloid liver) & & \\
\hline & & Renal & 250 & 500 & (amyloid kidney) & 250 & \\
\hline & & Derm & & & & (ulcers; dermatitis) & \\
\hline & & Bd Wt & 250 & 500 & $\begin{array}{l}\text { (12-25\% decreas } \\
\text { weight gain) }\end{array}$ & & \\
\hline
\end{tabular}


TABLE 2-3. Levels of Significant Exposure to Fuel Oils - Dermal (continued)

\begin{tabular}{|c|c|c|c|c|c|c|c|}
\hline \multirow[b]{2}{*}{$\begin{array}{l}\text { Species/ } \\
\text { (Strain) }\end{array}$} & \multirow{2}{*}{$\begin{array}{c}\text { Exposure/ } \\
\text { Duration/ } \\
\text { Frequency/ } \\
\text { (Specific Route) }\end{array}$} & \multirow[b]{2}{*}{ System } & \multirow[b]{2}{*}{$\begin{array}{c}\text { NOAEL } \\
\text { (mg/kg/day) }\end{array}$} & \multicolumn{3}{|c|}{ LOAEL $^{a}$} & \multirow[b]{2}{*}{$\begin{array}{l}\text { Reference/ } \\
\text { Chemical Form }\end{array}$} \\
\hline & & & & \multicolumn{2}{|c|}{$\begin{array}{l}\text { Less Serious } \\
\text { (mg/kg/day) }\end{array}$} & $\begin{array}{c}\text { Serious } \\
\text { (mg/kg/day) }\end{array}$ & \\
\hline & & & & & & & 1915 \\
\hline $\mathrm{B} 6 \mathrm{C} 3 \mathrm{~F} 1$ & $5 \mathrm{~d} / \mathrm{wk}$ & & & & & & FO1DFM \\
\hline & & Cardio & 500 & & & & \\
\hline & & Gastro & 500 & & & & \\
\hline & & Hemato & & 250 & $\begin{array}{l}\text { (hematopoiesis of spleen } \\
\text { and liver) }\end{array}$ & & \\
\hline & & Musc/skel & 500 & & & & \\
\hline & & Renal & & 250 & $\begin{array}{l}\text { (inflammation of urinary } \\
\text { bladder) }\end{array}$ & 250 & \\
\hline & & Dermal & & & & (ulcers; dermatitis) & \\
\hline & & $B d W t$ & & 250 & $\begin{array}{l}\text { (14-23\% decrease in body } \\
\text { weight gain) }\end{array}$ & & \\
\hline \multicolumn{8}{|c|}{ Immuno/Lymphoret } \\
\hline Mouse & $90-103 w k$ & & 250 & 500 & (granulocyte hyperplasia & & NTP/NIH 1986 \\
\hline $\mathrm{B} 6 \mathrm{C} 3 \mathrm{~F} 1$ & $5 \mathrm{~d} / \mathrm{wk}$ & & & & $\begin{array}{l}\text { in the bone marrow; } \\
\text { hyperplasia in the lymph } \\
\text { nodes) }\end{array}$ & & FO1JP5 \\
\hline Mouse & $84-103 w k$ & & & 250 & (lymph node plasmocyosis) & & NTP/NIH 1986 \\
\hline $\mathrm{B} 6 \mathrm{C} 3 \mathrm{~F} 1$ & $5 \mathrm{~d} / \mathrm{wk}$ & & & & & & FO1DFM \\
\hline \multicolumn{8}{|c|}{ Neurological } \\
\hline Mouse & $90-103 w k$ & & 500 & & & & NTP/NIH 1986 \\
\hline $\mathrm{B} 6 \mathrm{C} 3 \mathrm{~F} 1$ & $5 \mathrm{~d} / \mathrm{wk}$ & & & & & & FO1JP5 \\
\hline Mouse & $84-103 w k$ & & 500 & & & & NTP/NIH 1986 \\
\hline $\mathrm{B} 6 \mathrm{C} 3 \mathrm{~F} 1$ & $5 d / w k$ & & & & & & FO1DFM \\
\hline
\end{tabular}


TABLE 2-3. Levels of Significant Exposure to Fuel Oils - Dermal (continued)

\begin{tabular}{|c|c|c|c|c|c|c|}
\hline \multirow[b]{2}{*}{$\begin{array}{l}\text { Species/ } \\
\text { (Strain) }\end{array}$} & \multirow{2}{*}{$\begin{array}{l}\text { Exposure/ } \\
\text { Duration/ } \\
\text { Frequency/ } \\
\text { (Specific Route) }\end{array}$} & \multirow[b]{2}{*}{ System } & \multirow[b]{2}{*}{$\underset{\text { (mg/kg/day) }}{\text { NOAE }}$} & \multirow{2}{*}{\multicolumn{2}{|c|}{$\begin{array}{l}\text { Less Serious } \\
\text { (mg/kg/day) }\end{array}$}} & \multirow[b]{2}{*}{$\begin{array}{l}\text { Reference/ } \\
\text { Chemical Form }\end{array}$} \\
\hline & & & & & & \\
\hline \multicolumn{7}{|c|}{ Reproductive } \\
\hline Mouse & $84-103 w k$ & & 500 & & & NTP/NIH 1986 \\
\hline $\mathrm{B} 6 \mathrm{C} 3 \mathrm{~F} 1$ & $5 \mathrm{~d} / \mathrm{wk}$ & & & & & F01DFM \\
\hline Mouse & $90-103 w k$ & & 500 & & & NTP/NIH 1986 \\
\hline $\mathrm{B} 6 \mathrm{C} 3 \mathrm{~F} 1$ & $5 \mathrm{~d} / w k$ & & & & & F01JP5 \\
\hline \multicolumn{7}{|l|}{ Cancer } \\
\hline Mouse & $84-103 w k$ & & & & $250 \mathrm{M}$ (hepatocellular adenoma or & NTP/NIH 1986 \\
\hline $\mathrm{B} 6 \mathrm{C} 3 \mathrm{~F} 1$ & $5 \mathrm{~d} / w \mathrm{k}$ & & & & carcinoma) & F01DFM \\
\hline Mouse & $90-103 w k$ & & & & 250 (malignant lymphomas) & NTP/NIH 1986 \\
\hline $\mathrm{B} 6 \mathrm{C} 3 \mathrm{~F} 1$ & $5 \mathrm{~d} / \mathrm{wk}$ & & & & & FO1JP5 \\
\hline
\end{tabular}

${ }^{2}$ Units are in $\mathrm{mg} / \mathrm{kg} /$ day, unless specified otherwise.

Bd Wt $=$ body weight: Cardio = cardiovascular; $\mathrm{d}=$ day $(\mathrm{s}) ;$ Derm $=$ dermal; $\mathrm{F}=$ females; FO1DFM = diesel marine fuel; FO1JP5 = JP-5 (jet fuel); Gastro $=$ gastrointestinal; Hemato = hemotological; Immuno/Lymphoret = immunological/lymphoreticular; LOAEL = lowest-observed-adverse-effect level; $\mathrm{M}=$ males; $\mathrm{mg} / \mathrm{app}=\mathrm{mg}$ per application; Musc/skel = musculoskeletal; NOAEL = no-observed-adverse-effect level; Resp = respiratory; wk = week(s); $\mathrm{x}=$ time(s) 
Respiratory Effects. Effusions and alveolar infiltrations of the lung occurred in a man who had washed his hair with an unknown amount of diesel fuel (Barrientos et al. 1977). Effects resulting from inhalation versus dermal exposure could not be distinguished in this case. An epidemiological study found a significant increase in feelings of "thoracic oppression" (no description provided) in workers who were chronically exposed to jet fuels by the inhalation, oral, and/or dermal exposure routes (Knave et al. 1978). The limitations of the study are discussed in detail in Section 2.2.1.2 under Respiratory Effects.

No histopathological or organ weight changes were noted in the respiratory system of male mice following daily dermal exposures for 1 week to $0.1 \mathrm{~mL}$ kerosene (Upreti et al. 1989); 13-week exposures to $2,000-8,000 \mathrm{mg} / \mathrm{kg} /$ day JP-5; or chronic exposures to 250 or $500 \mathrm{mg} / \mathrm{kg} /$ day of either marine diesel fuel or JP-5 (NTP/NIH 1986).

Cardiovascular Effects. An epidemiological study found a significant increase in heart palpitations in workers who were chronically exposed to jet fuels by inhalation, oral, and/or dermal exposure routes (Knave et al. 1978). The limitations of the study are discussed in detail in Section 2.2.1.2 under Respiratory Effects.

No histopathological changes were noted in the cardiovascular system of mice exposed to 2,000-8,000 mg/kg/day JP-5 for 13 weeks or mice chronically exposed to 250 or $500 \mathrm{mg} / \mathrm{kg} /$ day of either marine diesel fuel or JP-5 (NTP/NIH 1986).

Gastrointestinal Effects. Nausea, abdominal cramps, and diarrhea occurred in a man who had washed his hair with an unknown amount of diesel fuel (Barrientos et al. 1977). Clinical examination revealed a normal abdomen. Another man had epigastric pain after washing his hands with diesel fuel over several weeks (Crisp et al. 1979). Effects resulting from inhalation versus dermal exposure could not be distinguished in these cases.

No histopathological changes were noted in the gastrointestinal system of mice exposed to $2,000-8,000 \mathrm{mg} / \mathrm{kg} /$ day JP-5 for 13 weeks or mice chronically exposed to 250 or $500 \mathrm{mg} / \mathrm{kg} /$ day of either marine diesel fuel or JP-5 (NTP/NIH 1986). 
Hematological Effects. One case study reported that decreased hemoglobin concentration and an increase in erythrocyte sedimentation rate were noted in one man after washing his hands with diesel fuel over several weeks (Crisp et al. 1979). Effects resulting from inhalation versus dermal exposure could not be distinguished in this case.

A decrease in the splenic relative weight, which was not accompanied by histopathological changes, was noted in male mice following daily dermal exposures for 1 week to $0.1 \mathrm{~mL}$ kerosene (Upreti et al. 1989). In addition, decreases in hemoglobin concentration and increases in erythrocyte, white blood cell, and polymorphonuclear leukocyte concentrations were noted. Females were not tested in this study. Hematopoiesis of the spleen (extramedullary hematopoiesis) was noted in mice exposed to $500-8,000 \mathrm{mg} / \mathrm{kg} /$ day JP-5 for 13 weeks (NTP/NIH 1986). This effect was dose related and was found to be secondary to dermatitis in mice chronically exposed to 250 or $500 \mathrm{mg} / \mathrm{kg} /$ day marine diesel fuel (NTP/NIH 1986). The appearance of extramedullary hematopoiesis indicates a response to a hematological change or effect. Hematopoiesis in the liver in female mice was dose dependent and was directly related to chronic exposures to 250 or $500 \mathrm{mg} / \mathrm{kg} /$ day marine diesel fuel (NTP/NIH 1986).

Musculoskeletal Effects. No studies were located regarding musculoskeletal effects in humans after dermal exposure to fuel oils.

No histopathological changes were noted in the musculoskeletal system of mice chronically exposed to 250 or $500 \mathrm{mg} / \mathrm{kg} /$ day of either marine diesel fuel or JP-5 (NTP/NIH 1986).

Hepatic Effects. No studies were located regarding hepatic effects in humans after dermal exposure to fuel oils.

No histopathological or organ weight changes were noted in the livers of male mice following daily dermal exposures for 1 week to $0.1 \mathrm{~mL}$ kerosene (Upreti et al. 1989). Slight hepatic karyomegaly was noted in mice exposed to 500-8,000 mg/kg/day JP-5 for 13 weeks (NTP/NIH 1986). Amyloidosis of the liver occurred in mice chronically exposed to $500 \mathrm{mg} / \mathrm{kg} /$ day JP-5 but not in those exposed to $250 \mathrm{mg} / \mathrm{kg} / \mathrm{day}$. 
Renal Effects. Acute renal failure occurred in a man who washed his hair with an unknown amount of diesel fuel (Barrientos et al. 1977). In addition, he had oliguria; biopsy revealed mitosis and vacuolization in renal cells, tubular dilation, and some cellular proliferation in the glomerulus. Another man developed acute tubular renal necrosis after washing his hands with an unspecified diesel fuel over several weeks (Crisp et al. 1979). Specifically, patchy degeneration and necrosis of the proximal and distal tubular epithelium with preservation of the basement membranes were noted. Also, increased blood urea nitrogen and serum creatinine levels were noted in this individual. Effects resulting from inhalation versus dermal exposure could not be distinguished in these cases.

No histopathological or organ weight changes were noted in the kidneys of male mice following daily dermal exposures for 1 week to $0.1 \mathrm{~mL}$ kerosene (Upreti et al. 1989) nor following exposure to 2,000-8,000 mg/kg/day JP-5 for 13 weeks (NTP/NIH 1986). Renal lesions were produced in at least one sex and at one or both doses levels $(100 \%$ or $50 \%)$ in mice dermally treated three times per week for 60 weeks with JP-5 or marine diesel fuel (Easley et al. 1982). However, the lesions could not be duplicated in mice injected intraperitoneally with $100 \mathrm{mg} / \mathrm{kg}$ (using a corn oil vehicle) for 3 times per week for days or in mice injected intraperitoneally with 25 microliters of JP-5 for 2 to 8 weeks. In contrast to the case study (Barrientos et al. 1977) in which oliguria was manifested as a symptom of acute diesel fuel toxicity, the dermally treated test animals demonstrated increased urine output, increased insensitive water loss, and increased water consumption. The inability to reproduce the lesions and the increased water consumption and loss by intraperitoneal injection led the authors to speculate that dermal application may be the necessary route of exposure to cause the renal toxicity (Easley et al. 1982). It should be noted that only abbreviated results were reported. Intermediate and chronic exposure to petroleum oils was reported to induce a nodular appearance of the kidney as well as induce tubular atrophy of the renal cortex in mice (Schultz et al. 1981). However, it was not reported what petroleum fuels induced the kidney injury, although marine diesel fuel and JP-5 were among those studied. From calculations of the kidney to body weight ratios in mice exposed to 21.1 and $42.2 \mathrm{mg}$ JP-5 or 22.9 and $45.5 \mathrm{mg}$ marine diesel fuel for 40 weeks, dose-related trends were noted in female mice for increased relative kidney weights following JP-5 exposure (right kidney only) and marine diesel fuel (both kidneys) (Schultz et al. 1981). There were no dose-response trends for the decreased relative kidney weights in males exposed to either fuel oil. Statistical analysis was not conducted on the changes in kidney to body weight ratios. Therefore, the significance of the dose-response trends cannot be confirmed. 
Lymphocytic inflammation of the urinary bladder was noted in mice chronically exposed to 250 or $500 \mathrm{mg} / \mathrm{kg} /$ day marine diesel fuel. Amyloidosis of the kidney was found to be secondary to dermatitis in mice chronically exposed to $500 \mathrm{mg} / \mathrm{kg} /$ day JP-5 (NTP/NIH 1986).

Dermal Effects. Experimental data regarding dermal exposure of humans to fuel oils are limited. In one study, there was a dose-dependent increase in dermatitis from acute exposures to $55-85 \%$ solutions of kerosene (Tagami and Ogino 1973). No effects were noted in these subjects from exposure to the $40 \%$ solution of kerosene. This study is limited because no vehicle controls were used. Also, each subject was exposed to all test solutions (i.e., four different concentrations of kerosene), but the chronological spacing of the four treatments is not known. In another study, acute dermal exposure to $1 \mathrm{~mL}$ of kerosene impaired protein synthesis, but not deoxyribonucleic acid (DNA) or collagen synthesis, in the epidermis (Lupulescu and Birmingham 1975). Hyperemia, cellular damage of the epidermis, and mild edema also occurred from acute exposure to $1 \mathrm{~mL}$ kerosene (Lupulescu and Birmingham 1976; Lupulescu et al. 1973). Histological changes included disorganization of the cells, cytolysis, and enlarged intercellular spaces in the stratum corneum and spinous cells of the epidermis (Lupulescu and Birmingham 1976). Effects had subsided within 72 hours in some individuals (Lupulescu et al. 1973). These studies are limited because each tested only one dose.

Dermal effects of fuel oils from known or suspected short-term dermal exposures are described in several case studies. In one study, erythema, bullae, burning, and itching were reported in a 45-year-old man following a 20-minute dermal exposure to kerosene (Mosconi et al. 1988). In another case study, three males (2-15 years old) and 1 female ( 2 years old) exhibited blisters, reddening, flaccid bullae, pustules, soreness, burning, swelling, and denudation of the skin following dermal exposures to unknown volumes of kerosene (Tagami and Ogino 1973). A third study reported large blisters, erythema, and peeling skin in two cases of apparent oral exposure to kerosene (Annobil 1988). However, the strong odor of kerosene on one of the individuals and the kerosene-stained clothing of the other strongly indicate that dermal exposure may have also occurred in these cases. Exposure levels were not specified. Dermatosis and erythema were evident in factory workers who were exposed to kerosene for up to 5 hours daily by handling kerosene-soaked steel parts; exposure levels were not reported (Jee et al. 1985). 
Male mice treated daily for 1 week with $0.1 \mathrm{~mL}$ kerosene had rough skin, edema, and inflammation at the exposure sites (Upreti et al. 1989). Females were not tested in this study. Female mice treated with middle distillates including straight-run kerosene for six weeks developed hyperplasia and necrosis in the epidermis (Ingram et al. 1993) and increased sebocyte counts (Lesnik et al. 1992). Acute dermal exposures to $1 \%$ JP-5 or marine diesel fuel induced mild dermal sensitization in guinea pigs (Cowan and Jenkins 1981). Skin irritation was not induced in male rabbits by acute exposure to $0.5 \mathrm{~mL}$ JP-5 or marine diesel fuel (Schultz et al. 1981). These studies are limited because only one exposure dose was used in each. Acute dermal exposures to 2,000-40,000 mg/kg marine diesel fuel and unspecified concentrations of JP-5-induced dermatitis (acanthosis, scaly skin, hair loss, inflammation, parakeratosis, and/or hyperkeratosis of the skin) in mice (NTP/NIH 1986). This effect also occurred following 13-week exposures to $4,000 \mathrm{mg} / \mathrm{kg}$ /day marine diesel fuel. Intermediate exposure to $500-8,000 \mathrm{mg} / \mathrm{kg} /$ day JP-5 induced slight-to-moderate dermatosis in mice which increased with dose. Dermal sensitization did not occur in guinea pigs that were dermally exposed to 9 or 10 doses of diesel fuel (API 1979f; Schultz et al. 1981) or 9 doses of JP-5 (Schultz et al. 1981) over a 3-week period. Dermal application of three types of no. 2 fuel oils (low-catalytic cracked [10\%], medium-catalytic cracked [30\%], and high-catalytic cracked [50\%]) and diesel fuel did not produce skin sensitization in the guinea pig (Beck et al. 1984), although doses were not reported. Erythema and edema occurred during the induction phase in the animals exposed to diesel fuel (API 1979f).

Chronic exposures to 250 and $500 \mathrm{mg} / \mathrm{kg} /$ day of both marine diesel fuel and JP-5 induced dermatitis and ulcerations of the skin in mice (NTP/NIH 1986). The incidence and severity of dermatitis and the incidence of ulcers induced by marine diesel fuel were dose dependent for the chronic exposures. The severity, but not the incidence, of dermatitis induced by JP-5 was dose dependent for the chronic exposures. Also, the incidence of ulcers was dose dependent in chronic studies with JP-5. Dermatitis was also noted in another study in mice that were chronically exposed to either JP-5 or marine diesel fuel; effective doses were not reported (Easley et al. 1982).

Ocular Effects. Acute exposure to diesel fuel induced ocular effects in one case (Barrientos et al. 1977). Subconjunctival hemorrhages occurred in a man who had washed his hair in an unknown amount of diesel fuel. Effects resulting from inhalation versus dermal exposure could not be distinguished in this case. Eye irritation was also noted in factory workers who were chronically exposed to jet fuel (Knave et al. 1978). The limitations of this study are discussed in detail in Section 2.2.1.2 under Respiratory Effects. 
Ocular irritation was not induced in rabbits by diesel fuel (API 1979b; Beck et al. 1984), marine diesel fuel, JP-5 (Cowan and Jenkins 1981; Schultz et al. 1981), or three types of no. 2 fuel oils (low-catalytic cracked [10\%], medium-catalytic cracked [30\%], an high-catalytic cracked [50\%]) (Beck et al. 1984). Draize scores were not reported in the Cowan and Jenkins (1981) study.

Body Weight Effects. No studies were located regarding body weight effects in humans after dermal exposure to fuel oils.

There was no change in body weight in male mice following daily dermal exposures for 1 week to $0.1 \mathrm{~mL}$ kerosene (Upreti et al. 1989). There was no effect on body weight in mice following acute exposures to 2,000-8,000 mg/kg/day marine diesel fuel (NTP/NIH 1986). Acute exposure to at least $10,000 \mathrm{mg} / \mathrm{kg} /$ day JP-5, but not 5,000 mg/kg/day, induced decreases in body weight in mice. A dose-related trend in decreased body weight gain was noted in male, but not female, mice exposed to 4,000 and $8,000 \mathrm{mg} / \mathrm{kg} /$ day JP-5 and 500-4,000 mg/kg/day marine diesel fuel for 13 weeks. For JP-5 exposure, the changes in weight gain compared to the controls were not large, i.e., 5-7\%, and therefore, the significance of the effect could not be determined (NTP/NIH 1986). Dermal application of total weekly doses of 126.6 and $63.3 \mathrm{mg}$ of JP-5 or 136.5 and $68.2 \mathrm{mg}$ of diesel fuel marine three times per week for 40 weeks produced significant weight reduction in mice (Schultz et al. 1981); however, the authors failed to accurately describe the methods and doses. Chronic exposures to 500 (but not 250) $\mathrm{mg} / \mathrm{kg} /$ day JP-5 and 250 and $500 \mathrm{mg} / \mathrm{kg} /$ day marine diesel fuel induced decreases in body weight relative to controls (NTP/NIH 1986). An increased incidence of amyloid in the adrenal cortex was found to be secondary to dermatitis in mice chronically exposed to $500 \mathrm{mg} / \mathrm{kg} /$ day JP-5 (NTP/NIH 1986).

Other Systemic Effects. Edema of the scrotum and ankle, loin pains, thirst, and severe exhaustion were reported in a man who washed his hands with diesel fuel over several weeks (Crisp et al. 1979). Effects resulting from inhalation versus dermal exposure could not be distinguished in this case.

There were no abnormal clinical signs, no histopathological or organ weight changes in the adrenal glands, and no effects on food or water intake in male mice following daily dermal exposures for 1 week to $0.1 \mathrm{~mL}$ kerosene (Upreti et al. 1989). Amyloidosis of the spleen was found secondary to dermatitis in mice chronically exposed to $500 \mathrm{mg} / \mathrm{kg} /$ day JP-5; this effect was not noted following exposure to $250 \mathrm{mg} / \mathrm{kg} /$ day JP-5 (NTP/NIH 1986). Mice exposed to a 50\% solution of marine diesel 
fuel for 60 weeks had increases in daily water consumption (Easley et al. 1982). This effect also occurred in mice exposed to JP-5, but dose levels were not reported. Similarly, dermal application of JP-5 and diesel marine fuel increased water consumption and urine output (accompanied by a loss in osmolarity) in mice. Easley and coworkers (1982) speculated that the increased water consumption may have been the result of impaired renal function (see Section 2.2.3.2 under Renal Effects) and/or the dehydration of these animals.

\subsubsection{Immunological and Lymphoreticular Effects}

No studies were located regarding immunological effects in humans after dermal exposure to fuel oils.

Decreases in the relative weights of the lymph nodes and thymus were noted in male mice following daily dermal exposures for 1 week to $0.1 \mathrm{~mL}$ kerosene (Upreti et al. 1989). In addition, thymocyte counts, bone marrow nucleated cell counts, thymic cortical lymphocytes, and the cellularity of the thymic lobules were decreased. Increases in the cellular populations of the popliteal lymph nodes and the axial lymph nodes were also present. This study is limited because females were not tested. Chronic exposure to $500 \mathrm{mg} / \mathrm{kg}$ /day JP-5 induced granulocytic hyperplasia in the bone marrow in male and female mice and hyperplasia in the lymph nodes of female mice (NTP/NIH 1986). Plasmacytosis of the lymph nodes was found to be secondary to dermatitis in mice chronically exposed to 250 and $500 \mathrm{mg} / \mathrm{kg} /$ day of marine diesel fuel.

The highest NOAEL and all reliable LOAEL values for immunological effects after dermal exposure to fuel oils are recorded in Table 2-3.

\subsubsection{Neurological Effects}

In one case study, anorexia was reported in a man who washed his hands with diesel fuel over several weeks (Crisp et al. 1979). Effects resulting from inhalation versus dermal exposure could not be distinguished in this case. An epidemiological study found a significant increase in neurasthenia (i.e., fatigue, depressed mood, lack of initiative, dizziness, and sleep disturbances) in workers who were chronically exposed to jet fuels by either inhalation, oral, and/or dermal exposure (Knave et al. 1978). Also, attention and sensorimotor speed were impaired in the exposed workers, but no effects were found on memory function or manual dexterity. Results of EEG tests suggest that the exposed 
workers may have instability in the thalamocortical system. The limitations of the study were discussed in detail in Section 2.2.1.2 under Respiratory Effects.

Increased response to tactile stimuli and hyperactivity occurred in male mice at initiation of daily dermal exposures for 1 week to $0.1 \mathrm{~mL}$ kerosene (Upreti et al. 1989). Females were not tested in this study. No histopathological changes were noted in the nervous system of mice exposed to 2,000-8,000 mg/kg/day JP-5 for 13 weeks or mice chronically exposed to 250 or $500 \mathrm{mg} / \mathrm{kg} / \mathrm{day}$ of either marine diesel fuel or JP-5 (NTP/NIH 1986).

The highest NOAEL values for neurological effects after dermal exposure to fuel oils are recorded in Table 2-3.

\subsubsection{Reproductive Effects}

No studies were located regarding reproductive effects in humans after dermal exposure to fuel oils.

No histological changes were noted in the reproductive system of mice dermally exposed to $2,000-8,000 \mathrm{mg} / \mathrm{kg} /$ day JP-5 for 13 weeks or in mice chronically exposed to 250 or $500 \mathrm{mg} / \mathrm{kg} /$ day of either marine diesel fuel or JP-5 (NTP/NIH 1986).

The highest NOAEL values for reproductive effects after dermal exposure to fuel oils are recorded in Table 2-3.

\subsubsection{Developmental Effects}

No studies were located regarding developmental effects in humans or animals after dermal exposure to fuel oils.

\subsubsection{Genotoxic Effects}

No studies were located regarding genotoxic effects in humans or animals after dermal exposure to fuel oils. 
2. HEALTH EFFECTS

Genotoxicity studies are discussed in Section 2.4.

\subsubsection{Cancer}

No studies were located regarding cancer in humans after dermal exposure to fuel oils.

Unspecified skin tumors were identified in $\mathrm{C} 3 \mathrm{HF} / \mathrm{Bd}$ mice under the following exposure conditions: a 40-week exposure to $22.9 \mathrm{mg}$ (but not $42.2 \mathrm{mg}$ ) JP-5 or 23.8 and $45.5 \mathrm{mg}$ marine diesel fuel; a 60 -week exposure to $5.7-42.2 \mathrm{mg}$ (the highest incidence was at $11.4 \mathrm{mg}$ ) JP-5 or 11.9 and $23.8 \mathrm{mg}$ (but not $45.5 \mathrm{mg}$ ) marine diesel fuel (Schultz et al. 1981). Tumors were more prevalent in females than males for JP-5 exposure. None of the control animals developed skin tumors and statistical analysis was not conducted. The tumor incidence was not dose related, and historical control data for this strain of mouse were not provided.

No skin cancer was reported in $\mathrm{B}_{6} \mathrm{C}_{3} \mathrm{~F}_{1}$ mice chronically exposed to 250 and $500 \mathrm{mg} / \mathrm{kg} / \mathrm{day}$ of JP-5 (NTP/NIH 1986). There was a 2-6\% incidence of squamous cell papilloma and/or carcinoma of the skin in $\mathrm{B}_{6} \mathrm{C} 3 \mathrm{~F}_{1}$ mice chronically exposed to 250 (females only) or 500 (both sexes) $\mathrm{mg} / \mathrm{kg} / \mathrm{day}$ marine diesel fuel. The effect did not occur in the control groups; the statistical significance of these effects was not reported. Hepatocellular adenoma or carcinoma were noted in males exposed to 250 and $500 \mathrm{mg} / \mathrm{kg} /$ day marine diesel fuel. These effects did not occur in female mice at these doses.

Malignant lymphomas were noted in females exposed to $250 \mathrm{mg} / \mathrm{kg} / \mathrm{day}$, but not $500 \mathrm{mg} / \mathrm{kg} / \mathrm{day}$, JP-5; therefore, no dose-response relationship was apparent for this effect. A significant negative trend in the incidence of malignant lymphomas was noted in males of the high-dose group.

The tumorigenic potential of API no. 2 fuel oil was evaluated by dermal application in male and female $\mathrm{C} 3 \mathrm{H} / \mathrm{Bd}_{\mathrm{f}}$ mice (Witschi et al. 1987). Fifty microliters of the fuel oil was applied neat, or as a $50 \%$ or $25 \%$ dilution (w/v, in acetone) three times per week. Negative controls consisted of mice treated with acetone or animals that received no treatment. Positive controls received 50, 25, or $12.5 \mathrm{mg}$ of benzo[a]pyrene dissolved in 50 microliters of acetone. Over all the doses, 15 of the 150 mice developed skin tumors (the first tumor appeared at 75 to 80 weeks), while 299 of the 300 mice treated with benzo[a]pyrene developed skin tumors (first tumor appeared at 19 weeks). Neither of the negative control groups developed neoplastic lesions). 
Similarly, the dermal carcinogenic activity of 6 Commercial no. 2 heating oils with varied boiling ranges, points of origin, and composition have been evaluated (Biles et al 1988). The heating oils were applied neat to male $\mathrm{C} 3 \mathrm{H} / \mathrm{HeJ}$ mice in 25 microliter aliquots, 3 times per week for lifetime or until all mice in the test group developed frank carcinomas. The negative controls received a "highly refined white mineral oil," and the positive controls received four concentrations of catalytically cracked clarified oil (known to produce a positive dermal tumorigenic response) diluted in white mineral oil. None of the negative control mice (140 animals) developed tumors, while all of the positive control groups displayed significantly increased incidence of tumor production. All of the Commercial no. 2 heating oils induced a significantly increased incidence of tumors (an incidence of 5 animals with tumor per 50 animals was statistically significant, and the heating oil incidence ranged from 5 to 11 per 50).

No increase in the incidence of tumor-bearing mice was noted in animals treated with $25 \mathrm{mg}$ of undiluted petroleum diesel three times per week for up to 105 weeks in male and female $\mathrm{C} 3 \mathrm{H} / \mathrm{HeN}$ (diesel-treated had an incidence of 2/27 and mineral oil-treated negative controls did not develop any tumors). Jet A did, however, produce an increased incidence (26\%) of tumors (primarily squamous cell carcinoma and fibrosarcoma) (Clark et al. 1988). It was noted that both types of fuels produced inflammatory and degenerative changes at the application that led to "early mortality" and that the nonneoplastic lesions and their attendant effects were so severe that the application of Jet A was discontinued at week 62 .

Furnace oil (CAS no. 68474-30-2) was evaluated for skin carcinogenicity with both lifetime skinpainting and an initiation/promotion bioassay (Gerhart et al. 1988). Briefly, in the lifetime skinpainting study, 50 microliters of undiluted furnace oil was applied to 50 male $\mathrm{C} 3 \mathrm{H} / \mathrm{HeN}$ mice twice weekly for the lifetime of the animals. A sham negative control group of equal size was run concomitantly. In the initiation portion of the initiation/promotion bioassay, $30 \mathrm{CD}-1$ mice received five treatments of 25 microliters or five treatments of 50 microliters of furnace oil, and both groups were subsequently treated with 50 microliters of $0.1 \mathrm{mg} / \mathrm{mL}$ phorbol-12-myristate-13-acetate (PMA) twice weekly for 25 weeks. Thirty mice received one treatment of 50 microliters of 9,10-dimethyl1,2-benzanthracene (DMBA) or 50 microliters of acetone and subsequently were treated with 50 microliters of furnace oil twice weekly for 25 weeks in the promotion component of the investigation. (Note that Gerhart and coworkers [1988] indicated that the two different strains of mice were used: $\mathrm{C} 3 \mathrm{H}$ mice, which are not commonly used in initiation/promotion studies, and $\mathrm{CD}-1$ mice, 
which are considered to be a sensitive model and used extensively in initiation/promotion studies of carcinogenesis.) In the skin-painting studies, furnace oil produced a significant increase in the incidence (9/43 in furnace oil group and 0/49 in negative controls) of confirmed skin tumors (squamous cell carcinoma and fibrosarcoma). Two of the nine tumor-bearing animals developed squamous cell carcinoma in untreated areas of skin. In contrast, when furnace oil as an initiating agent, no increase in tumor incidence was observed in animals treated with either 25 or 50 microliters. However, a significant increase (12/30 vs 1/30 in acetone initiated) in histologically confirmed tumor incidence (squamous cell carcinoma) was observed in mice that were treated with DMBA as an initiating agent and received furnace oil as the promoting agent.

The tumorigenic activity of no. 2 type fuel oil and hydrodesulfurized kerosene was examined utilizing an initiation/promotion assay with CD-1 mice (API 1989). In the initiation phase of the study, mice received 5-50 microliter consecutive daily applications of the fuel oils and subsequently were treated with PMA $(0.1 \mathrm{mg} / \mathrm{mL})$ twice weekly for 25 weeks. In the promotion phase of the study, mice received a single application of DMBA $(1.0 \mathrm{mg} / \mathrm{mL})$ and were subsequently treated with one of the fuel oils twice weekly for 25 weeks. No significant difference in tumor incidence was noted in those animals treated with either of the fuel oils, when compared to the negative control (initiation with 50 microliters of acetone). However, both the incidence of confirmed tumor (18/30 in animals treated with no. 2 fuel oil as a promoting agent, 22/30 in animals receiving hydrodesulfurized kerosine as a promoting agent, and 0/30 in acetone-promoted negative controls) and the latency period were significantly different than those of the positive controls. The most prevalent tumors were squamous cell papillomas and keratoacanthomas.

The dermal carcinogenicity of mixtures of petroleum products that have a boiling range approximately equal to or greater than $370^{\circ} \mathrm{C}$ has been reported to be primarily related to the polycyclic aromatic hydrocarbon (PAH) content of the material (Biles 1988). The boiling ranges of the various fuel oils are as follows: fuel oil no. $1,175-300^{\circ} \mathrm{C}$; fuel oil no. $1-\mathrm{D}, 193-293^{\circ} \mathrm{C}$; fuel oil no. $2,160-360^{\circ} \mathrm{C}$; fuel oil no. 2-D 282-338 ${ }^{\circ} \mathrm{C}$; fuel oil no. $4,101-588^{\circ} \mathrm{C}$; fuel oil UNSP, $151-588^{\circ} \mathrm{C}$ (see Table 3-3). Whereas some fuel oils contain cracked stocks that are known to contain biologically active PAH, virgin distillate petroleum products (boiling range approximately $177^{\circ} \mathrm{C}$ to $370^{\circ} \mathrm{C}$ ), which include various middle distillate fuel oils, primarily contain saturated species (Biles 1988). Although these virgin petroleum materials contain low concentrations of PAH, repeated application can induce dermal tumors. It has been reported that the tumorigenicity of three petroleum- and four coal-derived liquids 
were not consistent with the PAH content of the test materials (Witschi et al. 1987). Similarly, the dermal carcinogenicity of 10 petroleum-derived fuels (including 6 formulations of no. 2 heating oil) did not appear to be "directly related" to the aromatic content or the presence of PAH in the materials (Biles et al. 1988). Gerhart and colleagues (1988) reported that furnace oil induced tumors through epigenetic or promotional means, even though it contained no detectable concentrations of four- and five-ring aromatics. In a 2-year skin-painting study of four petroleum middle distillates (including jet fuel), the authors suggested aromatic and sulfur heterocycles tested were not the source of tumorigenicity in middle distillates (Freeman et al. 1993). These results suggest that the tumorigenic potential of the middle distillates is not related to their PAH content.

It has been alternatively hypothesized that the carcinogenic activity of fuel oils is a secondary effect associated with dermal irritation (Biles et al. 1988; Clark et al. 1988; McKee et al. 1989). Biles and coworkers (1988) speculated that the irritating properties of middle distillate petroleum fuels played a role in the mechanism of dermal carcinogenesis in a lifetime skin-painting assay, although the data did not demonstrate a relationship. In fact, they noted that the test groups with the most severe "degree of epidermal degeneration and necrosis" demonstrated the lowest tumor yields. Repeated application of four petroleum-derived distillates (including Jet A and diesel) to mouse skin induced severe inflammation and degenerative changes; however, the severity and early onset of inflammation was not always predictive of tumorigenicity (Clark et al. 1988). Similarly, even though dermal application of dewaxed heavy paraffinic distillate led to a greater incidence of confirmed tumors than did furnace oil (26/48 and 9/43, respectively), furnace oil induced a greater incidence of nonneoplastic lesions (37/43 vs. 14/48) (Gerhart et al. 1988). McKee and coworkers (1989) ascribed the weak promotional activity of a lightly refined paraffinic oil to the irritation caused by its repeated application to mouse skin, partially based on findings that the whole oil and various fractions of the oil were negative for both mutagenic activity in bacteria and carcinogenic initiating activity.

The role of chronic acanthosis and inflammation in tumor promotion by a middle distillate has been investigated (Skisak 1991). Briefly, male CD-1 mice received a single dermal treatment of 50 microliters of DMBA (initiation) and subsequently were treated with 25, 50, or 100 microliters (twice weekly for 25 weeks) of hydrodesulfurized kerosine (HK). Dose, washing after treatment, and topical application of dexamethasone were used to control inflammation. The mice treated with 100 microliters of $\mathrm{HK}$ had the greatest tumor incidence (35/53) and the highest degree of acanthosis throughout the study. While the tumor responses of the 25 and 50 microliter treated groups were 
similar (14/54 and 13/54, respectively), the degree of acanthosis was much more pronounced in the mice treated with 50 microliters HK. Application of dexamethasone to animals treated with 50 microliters reduced the tumor incidence to 0 , although acanthosis was still observed. It is interesting to note that washing the mice ( 1 to 2 hours after treatment) with an Ivory soap solution with 50 microliters of HK increased tumor incidence (22/53) compared to the group treated with 50 microliters HK but not washed. The authors concluded that although hyperplasia may play a role in the promoting activity, there are other factors involved.

In a 2-year skin-painting study designed to evaluate the role of skin irritation in the tumorigenicity of middle distillates, 37.5 microliters of jet fuel and steam cracked gas oil were applied two times per week, and jet fuel was also applied in an intermittent fashion (dosing was suspended when irritation was noted in $20 \%$ of the group and resumed when it was resolved in all but 20\%) (Freeman et al. 1993). Intermittent dosing produced irritation that was less severe than dosing two times per week, and only 1/50 intermittently dosed animals developed tumors, compared with 22/50 in the twice-weekly dosed group. Freeman and coworkers (1993) stated that chronic skin irritation was necessary, but insufficient for tumor induction. These data indicate that the irritant properties of fuel oils are not the ultimate cause of dermal carcinogenicity, although the irritation induced by the repeated application may play an important role in the mechanism of tumor formation.

Reliable LOAEL values for cancer effects after dermal exposure to fuel oils are recorded in Table 2-3.

\section{2 . 3 TOXICOKINETICS}

Few data were available concerning the absorption, distribution, metabolism, and excretion of fuel oils. Indirect evidence suggests that some fuel oils may be absorbed through the respiratory tract, the gastrointestinal tract, and percutaneously. Although data concerning the metabolism of fuel oils in humans could not be located, a single animal study suggested that cytochrome P-448 may be involved in the metabolism of fuel oil no. 2 (Rahimtula et al. 1982). No quantitative data were found regarding the excretion of fuel oils. 


\subsubsection{Absorption}

\subsubsection{Inhalation Exposure}

No studies were located regarding the absorption of fuel oils in humans or animals after inhalation exposure. However, indirect evidence of gastrointestinal, cardiovascular, hematological, renal, and/or dermal/ocular effects from case reports in which two pilots were exposed to JP-5 vapor while flying a small airplane and another man was exposed to diesel fuel vapor while driving a truck indicate that these fuel oils can be absorbed following inhalation exposure in humans (Porter 1990; Reidenberg et al. 1964). Effects on animals acutely exposed to fuel oils by inhalation provide indirect evidence for inhalation absorption in animals (Casaco et al. 1985c; Garcia et al. 1988b; Kainz and White 1984).

\subsubsection{Oral Exposure}

No quantitative data were located regarding the absorption of fuel oils in humans after oral exposure. However, there is evidence that absorption from the gastrointestinal tract occurs following ingestion of kerosene by humans (Subcommittee on Accidental Poisoning 1962). In a study of 422 cases, pulmonary complications were noted in 11 individuals, even though gastric lavage was not administered nor was vomiting reported (vomiting and gastric lavage could cause aspiration of the kerosene, thus contributing to the respiratory effects). In this same report, pulmonary complications occurred in a higher percentage of the individuals that did not receive lavage than in those that were treated by gastric lavage. This suggests that pulmonary effects of fuel oils may also be the result of systemic toxicity. Further, administration of gastric lavage within 30 minutes of ingestion further decreased the number of affected individuals, suggesting that removal of kerosene from the stomach may have prevented its absorption and subsequent toxicity in these cases. In this same study, there is also indirect evidence that aspiration from vomiting may induce pulmonary effects since there were more individuals with respiratory complications when vomiting occurred than when it did not, regardless of the administration of gastric lavage. It is possible that both absorption and aspiration contribute to the respiratory effects in these individuals.

Limited animal data and indirect evidence indicate kerosene is poorly absorbed from the gastrointestinal tract. In one study, kerosene labeled with ${ }^{3} \mathrm{H}$-toluene or ${ }^{14} \mathrm{C}$-hexadecane was given to tracheotomized baboons $(15 \mathrm{~mL} / \mathrm{kg}$ ) by nasogastric tube (Mann et al. 1977). The isotopes were 
recovered after 6 hours from the brain, lung, liver, spleen, heart, and kidney; however, the amounts distributed to the tissue were very small, suggesting that gastrointestinal tract absorption was slight. The potential absorption of ingested kerosene into the lungs was tested by comparing respiratory effects from oral exposures in nontracheotomized and tracheotomized monkeys (Wolfsdorf and Kundig 1972). The tracheotomized monkeys who received the kerosene via nasogastric tube could not aspirate the kerosene; thus, the potential for respiratory exposure by aspiration was prevented. Lung lesions were seen in the nontracheotomized monkeys, but no lesions were seen in the tracheotomized monkeys. These data suggest that aspiration of fuel oils, not absorption, is the underlying cause of the respiratory effects. A lack of pulmonary toxicity was reported in dogs in which aspiration was prevented. This study supports the theory that pulmonary toxicity following kerosene ingestion is the result of aspiration of kerosene into the lungs rather than absorption from the gastrointestinal tract (Dice et al. 1982).

\subsubsection{Dermal Exposure}

Studies of effects on animals following acute, intermediate, and chronic dermal exposure to marine diesel fuel and JP-5 fuel provide evidence for dermal absorption (NTP/NIH 1986). Case reports concerning a man who washed his hair with an unknown amount of diesel fuel (Barrientos et al. 1977) and a man who washed his hands with an unspecified diesel fuel over several weeks (Crisp et al. 1979) provide possible evidence for dermal absorption, but effects resulting from inhalation versus dermal exposure could not be distinguished in these cases. No other data on the absorption of fuel oils following dermal exposure in humans or animals were located.

Some case studies suggest that dermal exposure to the vapor of diesel fuel may also result in absorption via the skin. The studies identify one individual with only vapor exposure and two others with vapor and/or direct dermal contact with diesel fuel; individuals developed acute renal failure or renal necrosis (Barrientos et al. 1977; Crisp et al. 1979; Reidenberg et al. 1964). Also, dermal exposures to marine diesel fuel and JP-5 in mice induced renal damage (Easely et al. 1982). No studies were located that directly tested dermal absorption of fuel oil vapor. 


\subsubsection{Other Routes of Exposure}

Dogs that had undergone transection of the esophagus exhibited no respiratory or gastrointestinal effects after injection by syringe of $5,10,20$, or $30 \mathrm{~mL}$ of kerosene $(4-17.9 \mathrm{rnL} / \mathrm{kg}$ ) directly into the stomach. This study provides indirect evidence that kerosene is poorly absorbed from the gastrointestinal tract (Wolfe et al. 1970), or alternatively, kerosene is adsorbed but not grossly toxic unless it is aspirated.

\subsubsection{Distribution}

\subsubsection{Inhalation Exposure}

No studies were located regarding the distribution of fuel oils in humans or animals after inhalation exposure.

\subsubsection{Oral Exposure}

No studies were located regarding the distribution of fuel oils in humans after oral exposure.

Very limited animal data indicate that kerosene is absorbed and distributed to various tissues (Mann et al. 1977). Kerosene, labelled with ${ }^{3} \mathrm{H}$-toluene or ${ }^{14} \mathrm{C}$-hexadecane, was given to tracheotomized baboons $(15 \mathrm{~mL} / \mathrm{kg}$ ) by nasogastric tube (Mann et al. 1977). Radioactivity was recovered from the brain, lung, liver, spleen, heart, and kidney after 6 hours. ${ }^{3} \mathrm{H}$-Toluene was absorbed and taken up by most tissues to a greater extent than was ${ }^{14} \mathrm{C}$-hexadecane; however, the amounts absorbed and distributed were very small (Mann et al. 1977).

\subsubsection{Dermal Exposure}

No studies were located regarding the distribution of fuel oils in humans or animals after dermal exposure. 


\subsubsection{Metabolism}

No studies were located regarding the metabolic pathway of fuel oils in humans. In one animal study, fuel oil no. 2 applied to the skin of rats induced cutaneous aryl hydrocarbon hydroxylase activity in rat skin microsomal preparations by causing a three-fold induction of benzo(a)pyrene (BaP) 3-hydroxylase activity (Rahimtula et al. 1982). In addition, BaP 3-hydroxylase activity was selectively inhibited by $\alpha$-naphthoflavone, but not by metyrapone, suggesting that cytochrome P-448 enzymes are induced and may participate in the metabolism of this fuel oil (Rahimtula et al. 1982).

\subsubsection{Excretion}

There is no quantitative information on the excretion of fuel oils following inhalation, oral, or dermal exposure in humans or animals.

\subsubsection{Mechanisms of Action}

The primary risk from ingestion of kerosene is aspiration during emesis, which may cause pneumonitis. A number of studies have investigated the biochemical mechanism of the lung response to the exposure of large concentrations of aerosolized kerosene (Casaco et al. 1982, 1985b, 1985c). It was suggested that kerosene may induce asthma-like symptoms by acting on the parasympathetic nervous system either through a direct effect on the vagus nerve or by inhibiting acetylcholinesterase, resulting in bronchoconstriction. Garcia and Gonzalez (1985), based on their observations that kerosene caused an "increase in $\mathrm{Ca}^{2+}$-dependent ATP hydrolysis without increase in the rate of net calcium accumulation," concluded that kerosene induced an effect on the membrane of the sarcoplasmic reticulum vesicles and suggested that the mechanism of kerosene-induced bronchoconstriction may involve changes in the ionic flow across the cellular membranes to prolong muscle contraction.

Although generalizations regarding the hematological effects of fuel oils on humans cannot be made, the effect of kerosene on the first two steps of the heme synthetic pathway has been studied in an animal model. Both hepatic $\delta$-aminolevulinic acid ( $\delta$-ALA) dehydratase and $\delta$-ALA synthetase activities were decreased in female rats after intraperitoneal injection of kerosene, while heme oxygenase was unaffected (Rao and Pandya 1980). Since $\delta$-ALA synthetase is the rate-limiting enzyme of the heme biosynthesis pathway, hepatic heme biosynthesis may be inhibited by kerosene. 
It is conceivable that this may be related to the extramedullary hematopoiesis reported in other studies (NTWNIH 1986); however, there are no direct data to support this.

The biochemical mechanism of CNS depression seen with fuel oils and common to many organic solvents has not been elucidated. The mechanism of carcinogenesis associated with various formulations of fuel oils is unknown.

\subsection{RELEVANCE TO PUBLIC HEALTH}

Information regarding health effects of fuel oils in humans and animals is available for the inhalation, oral, and dermal routes of exposure. Most of the information in humans is from cases of accidental ingestion of kerosene that resulted in respiratory, neurotoxic, and to a lesser extent, gastrointestinal effects. In addition, a few case studies have identified these effects as well as cardiovascular, hematological, and renal effects in humans after inhalation and/or dermal exposures to fuel oils. Fuel oils appear to be eye and skin irritants in both animals and humans following direct contact. Animal data exist for most systemic effects; however, the data are inconclusive for many of the endpoints. Further, a number of the animal studies utilized an aerosol for exposure, and it should be noted that the toxicity from an aerosol will typically vary from that of a vapor (the probable form of exposure). The available epidemiological studies are generally inconclusive, since they cannot exclusively associate exposures to fuel oils with the adverse effects reported.

\section{Minimal Risk Levels for Fuel Oils}

\section{Inhalation}

- An MRL of $0.02 \mathrm{mg} / \mathrm{m}^{3}$ has been derived for acute inhalation exposure to diesel fuel (fuel oil no. 2). The MRL is based on dose-related neurobehavioral effects (mild transient ataxia and CNS depression), beginning at $65 \mathrm{mg} / \mathrm{m}^{3}$, in mice exposed to airborne concentrations of fuel oil of 65,135 , and $204 \mathrm{mg} / \mathrm{m}^{3}$.

- An MRL of $0.01 \mathrm{mg} / \mathrm{m}^{3}$ has been derived for the intermediate inhalation exposure to kerosene (also termed fuel oil no. 1). The MRL is based on decreased blood glucose levels noted in male rats subsequent to exposure to airborne concentrations of kerosene averaging 
$58 \mathrm{mg} / \mathrm{m}^{3}$ for 6 hours/day, 6 days/week for 14 weeks. Rats exposed to an airborne concentration of kerosene averaging $231 \mathrm{mg} / \mathrm{m}^{3}$ showed a decrease in blood glucose titers, as well as increased circulating levels of lactate and pyruvate. In addition, mice exposed to 150 or $750 \mathrm{mg} / \mathrm{m}^{3}$ or airborne JP-5 showed hepatocellular fatty changes and vacuolization at the LOAEL of $150 \mathrm{mg} / \mathrm{m}^{3}$ (Gawororski et al. 1984). Finally, no systemic or neurological effects were observed in rats or dogs exposed to a deodorized kerosene concentration of $100 \mathrm{mg} / \mathrm{m}^{3}$ (Carpenter et al. 1976).

No chronic inhalation MRLs were derived for fuel oils because available data were not suitable for MRL derivation. Studies that report lethality or biochemical alterations without attendant pathology cannot be used for MRL determination

\section{Oral}

No acute, intermediate, or chronic oral MRLs were derived for fuel oils because available data were not suitable for MRL derivation. Studies that report lethality at the lowest dose tested cannot be used for MRL determinations. Hepatocyte necrosis reported by Parker et al. (1981) occurred at a dose greater than dose levels at which serious effects occurred in other studies, making these data unsuitable for derivation of an MRL.

Death. No quantitative lethality data for humans were located from inhalation or dermal exposure to fuel oils. Based on case studies reporting deaths in humans following ingestion of kerosene, estimated lethal doses of kerosene range from 1,890 to $16,789 \mathrm{mg} / \mathrm{kg}$ (Dudin et al. 1991; Santhanakrishnan and Chithra 1978). These lethal doses are based upon specific cases in which 30 or $200 \mathrm{~mL}$ of kerosene were ingested by 1- and 2-year-old children. No lethality was reported for children from 10 months to 5 years old following ingestion of 126-877.2 mg/kg or 1,754 mg/kg of kerosene, respectively (Dudin et al. 1991). There are no human data that identify lethal oral doses in adults, and no dose-response data are available for humans; therefore, it is not possible to determine a specific oral dose of kerosene at which lethality in humans would not be expected to occur.

A single 6-hour exposure to $4,000 \mathrm{mg} / \mathrm{m}^{3}$ diesel fuel aerosol (Dalbey and Lock 1983) and repeated exposures (once or three times per week for a total of nine exposures) for 2 hours to $6,000 \mathrm{mg} / \mathrm{m}^{3}$ or 6 hours to $2,000 \mathrm{mg} / \mathrm{m}^{3}$ diesel fuel aerosol (Dalbey et al. 1987) were lethal to rats. However, a single 
4-hour exposure to $6,000 \mathrm{mg} / \mathrm{m}^{3}$ diesel fuel aerosol was not lethal to rats (Dalbey and Lock 1983). The variability of these diesel fuel data appear to indicate that the cumulative dose may be more important than the airborne concentration of fuel oil aerosol, although human exposure to such high concentration of a fuel oil aerosol seems unlikely. Acute and intermediate exposures to moderate through high concentrations of marine diesel fuel, diesel fuel vapor or aerosol, fuel oil UNSP, JP-5, and kerosene (API 1979c, 19798; Cowan and Jenkins 1981; Gaworski et al. 1984; Lock et al. 1984; Vernot et al. 1990d) ranging from $50 \mathrm{mg} / \mathrm{m}^{3}$ marine diesel vapor to $5,000 \mathrm{mg} / \mathrm{m}^{3}$ kerosene were not lethal to rats. Although it appears that fuel oils may be lethal to humans only at vapor concentrations that occur at elevated temperatures or as the result of exposure to an aerosol, these data are not sufficient for such generalizations to be drawn concerning the lethal concentration or cumulative dose of fuel oils.

The acute oral $\mathrm{LD}_{50}$ in guinea pigs and rabbits for kerosene has been reported to be $16,320 \mathrm{mg} / \mathrm{kg}$ and $22,720 \mathrm{mg} / \mathrm{kg}$, respectively (Deichmann et al. 1944). These data suggest that guinea pigs may be more sensitive to kerosene than rabbits. Similarly, a lethal dose of kerosene of $6,400 \mathrm{mg} / \mathrm{kg}$ has been reported in calves (Rowe et al. 1973), but the lethal dose for rats is 12,000 mg/kg (Muralidhara et al. 1982). Comparison of these data is problematic; however, they do suggest that species differences and age sensitivity may exist for oral kerosene toxicity, although such differences have not been established.

For oral exposures, different fuel oils have differing lethality profiles in rats. Acute lethal doses in rats were reported to be $12,000 \mathrm{mg} / \mathrm{kg}$ for kerosene (Muralidhara et al. 1982) and 47,300 mg/kg for JP-5 (Parker et al. 1981). However, an oral dose of $12,200 \mathrm{mg} / \mathrm{kg}$ of Deobase ${ }^{\circledR}$ was not lethal in rats (Muralidhara et al. 1982). Although differences in the oral toxicity of fuel oils and differences in species thresholds of toxicity may exist, the oral toxicity of fuel oils is relatively low. The intestinal absorption of fuel oils is also relatively low, and aspiration, with its resultant pulmonary effects, is the primary risk from the ingestion of fuel oils.

Daily dermal exposures for 1 week to $0.1 \mathrm{~mL}$ kerosene were not lethal to male mice (Upreti et al. 1989). A minimum lethal dose of $30,000 \mathrm{mg} / \mathrm{kg} /$ day was reported for JP-5 from acute dermal exposure in mice, but this dose was decreased to 2,000 and $250 \mathrm{mg} / \mathrm{kg} /$ day following intermediate and chronic exposures, respectively (NTP/NIH 1986). A similar trend was also reported for dermal 
toxicity in mice exposed to marine diesel fuels (NTP/NIH 1986). Conclusions cannot be drawn from the available data regarding dermal exposure by humans to fuel oils near hazardous waste sites.

\section{Systemic Effects}

Respiratory Effects. There are epidemiological data that found no evidence of respiratory toxicity in children from exposure to kerosene vapor and combustion products from kerosene stoves used for cooking (Azizi and Henry 1991; Tominaga and Itoh 1985); however, the importance of such exposures to individuals living near hazardous waste sites or in the workplace is uncertain. Another epidemiological study noted thoracic oppression in workers that were chronically exposed to jet fuel by the inhalation, oral, and/or dermal routes (Knave et al. 1978). However, the jet fuels were not specified in this study, and therefore, these exposures may not necessarily include fuel oils such as JP-5. Only one case study was found that reported effusions and alveolar infiltrations from dermal and/or inhalation exposure to diesel fuel when used as a shampoo (Barrientos et al. 1977). A low concentration of deodorized kerosene vapor was not irritating to the throat in humans (Carpenter et al. 1976). Animal data indicate that functional parameters of the lung may be affected (Casaco et al. 1982) and bronchoconstriction may occur (Casaco et al. 1982; Garcia et al. 1988b) from acute inhalation of kerosene aerosol. In one study, intermediate exposure to diesel fuel aerosol induced damage to the lung parenchyma of rats (Dalbey et al. 1987). This study found that an increase in the frequency of exposure was more likely to induce respiratory effects than the exposure dose or duration. However, in each of these cases of respiratory toxicity, relatively high exposure levels were used. Other animal studies have found no histopathological evidence of respiratory toxicity following relatively low to moderate intermediate inhalation or acute, intermediate, and chronic dermal exposures to various fuel oils (Carpenter et al. 1976; Lock et al. 1984; NTP/NIH 1986; Upreti et al. 1989). These data suggest that bronchoconstriction or respiratory impairment may occur in humans at high inhalation or dermal exposure levels of kerosene or diesel fuel. Relatively low or moderate exposure levels may also affect sensitive members of the population, but this cannot be determined from the data. The data also indicate that humans who are frequently exposed to fuel oils, such as those exposed occupationally, may be at greater risk of developing respiratory lesions than those with single or less frequent exposures.

Ingestion of fuel oils, kerosene in particular, has been shown to induce respiratory effects in humans, although it appears that aspiration is the primary cause of the pulmonary toxicity and the most serious 
feature of ingestion. Numerous studies in animals and humans have evidenced the introduction of kerosene into the lungs during vomitus and subsequent manifestation of deleterious effects in the respiratory tract (Coruh and Inal 1966; Dice et al. 1982; Majeed et al. 1981; Nouri and Al-Rahim 1970; Wolfe et al. 1970; Wolfsdorf and Kundig 1972). However, limited absorption from the gastrointestinal tract into the lungs may also occur (Mann et al. 1977).

Specific effects that have occurred in humans following ingestion of kerosene include bronchopneumonia, bronchitis, pneumonitis, lung infiltrates and effusions, cough, dyspnea, hypoxia, and tachypnea (Akamaguna and Odita 1983; Aldy et al. 1978; Annobil 1983; Annobil and Ogunbiyi 1991; Dudin et al. 1991; Mahdi 1988; Santhanakrishnan and Chithra 1978; St. John 1982). The animal data describing respiratory toxicity are limited but are consistent with the findings in humans. Oral exposure data for humans are only available for kerosene; therefore, no conclusions can be made regarding the respiratory toxicity of other fuel oils. However, the similar composition of the various fuel oils suggests that the effects may also be similar.

A number of studies have investigated the biochemical mechanism of lung response to concentrations of aerosolized kerosene (ranging up to a mean of $32.5 \mathrm{mg} / \mathrm{L}$ ). It was indicated that kerosene may induce asthma-like symptoms by acting on the parasympathetic pathway involving a direct effect on the vagus nerve or by inhibiting acetylcholinesterase, thus increasing the acetylcholine level in the trachea, resulting in bronchoconstriction (Casaco et al. 1982, 1985b, 1985c). It has also been reported that kerosene can affect the calcium pump of the rabbit sarcoplasmic reticulum (Garcia and Gonzalez 1985), suggesting that the mechanism of kerosene-induced bronchoconstriction may involve changes in the ionic flow across the cellular membranes to prolong muscle contraction.

Curdiovasculur Effects. Mild hypertension from acute inhalation of JP-5 vapor (Porter 1990) or diesel fuel vapor (Reidenberg et al. 1964) and palpitations from chronic inhalation, dermal, and/or oral exposures to unspecified jet fuels have been reported in humans (Knave et al. 1978). Tachycardia and cardiomegaly were reported in children following acute ingestion of kerosene (Akamaguna and Odita 1983; Coruh and Inal 1966). Most of the available animal studies found no histopathological changes or organ weight changes in the cardiovascular system of rats and mice following inhalation, oral, or dermal exposures to various fuel oils, including kerosene (Carpenter et al. 1976; Lock et al. 1984; Muralidhara et al. 1982; NTP/NIH 1986). However, there are some limited data regarding cardiac effects. Inhalation of $20,400-34,000 \mathrm{mg} / \mathrm{m}^{3}$ of kerosene vapor induced aortic plaques in guinea pigs. 
Further, significant increases in total serum cholesterol and decreases in HDL were noted (Noa and Illnait 1987a). Vasodilation was reported in mice exposed by inhalation to diesel fuel no. 2 aerosol (Kainz and White 1984). Aspiration of kerosene decreased heart rate and mean arterial blood pressure in dogs (Goodwin et al. 1988). Because most of the toxicity findings are specific for kerosene, it is difficult to draw conclusions regarding the cardiac effects of other fuel oils. However, the similar composition of the various fuel oils suggests that the effects may also be similar. The potential for cardiac effects in humans at hazardous waste sites exists; the risk is increased if the individuals are exposed in confined spaces.

Gastrointestinal Effects. Inhalation of JP-5 vapor induced nausea in one individual. Abdominal cramps, vomiting, and diarrhea occurred in another man who was exposed to diesel fuel vapor for 10 days (Reidenberg et al. 1964). Inhalation and/or dermal exposure to diesel fuel induced epigastric pains in a man who washed his hands with diesel fuel (Crisp et al. 1979) and nausea, abdominal cramps, and diarrhea in another individual who used it as a shampoo (Barrientos et al. 1977). Ingestion of kerosene induces more severe effects: vomiting, abdominal pain and/or distension, gastroenteritis, bleeding, and diarrhea (Akamaguna and Odita 1983; Aldy et al. 1978; Mahdi 1988;

Majeed et al. 1981; Saksena 1969; St. John 1982; Nouri and Al-Rahim 1970). No histopathological changes in the gastrointestinal system were reported in animals exposed to various fuel oils by the inhalation and dermal routes of exposure (Carpenter et al. 1976; Lock et al. 1984; NTP/NIH 1986). Also, acute oral exposure to kerosene or Deobase did not induce diarrhea in rats (Muralidhara et al. 1982). These data, though limited, indicate that species variations may exist between humans and rats following oral exposure to kerosene. Although the data are largely anecdotal, they strongly suggest that gastrointestinal effects are induced in humans by ingestion of kerosene, inhalation of JP-5 or diesel fuel vapor, and dermal contact with or inhalation of diesel fuel. It has not been determined whether these effects would occur as the result of exposure to other fuel oils and if they did at what exposure levels such effects would occur.

Hematological Effects. Subcutaneous hemorrhage, mild nose bleeds, low platelet counts, and retinal arteriole constriction were reported for a man who was exposed to diesel fuel vapor for 10 days (Reidenberg et al. 1964). These effects may be indicative of blood clotting problems. Decreased hemoglobin concentration and an increase in erythrocyte sedimentation rate were noted in one man after washing his hands with diesel fuel over several weeks (Crisp et al. 1979). Of 12 patients admitted to the pediatric intensive care unit of a children's hospital during a 5-year period due to 
respiratory distress associated with hydrocarbon aspiration, 3 showed signs of intravascular hemolysis. A fourth patient, who had ingested kerosene, had clinically insignificant hemolysis (Algren and Rodgers 1992). Increases in leukocyte counts from acute ingestion of kerosene (Dudin et al. 1991; Majeed et al. 1981; Nouri and Al-Rahim 1970) have; also been reported in humans. No hematological effects were noted two individuals exposed to JP-5 for a few hours (Porter 1990).

No hematological or splenic effects were reported in rats following oral exposure to kerosene (Muralidhara et al. 1982), nor were hematological and splenic effects noted in rats and dogs following inhalation of deodorized kerosene (Carpenter et al. 1976), in rats that inhaled diesel fuel (Lock et al. 1984), or in rats following oral administration of Deobase (Muralidhara et al. 1982).

Decreases in hemoglobin concentration and increases in erythrocyte, white blood cell, and polymorphonuclear leukocyte concentrations were noted in mice after acute dermal exposure to kerosene. A decrease in the splenic relative weight, which was not accompanied by histopathological changes, was also noted (Upreti et al. 1989). Oral exposure to JP-5 increased hematocrit levels, decreased white blood cell counts, and increased erythrocyte counts in rats (Parker et al. 1981). However, inhalation of diesel fuel aerosol induced decreases in the mean red blood cell count in rats and had no effect on white blood cells (Dalbey et al. 1987).

The effect of kerosene on the first two steps of the heme synthetic pathway was studied in an animal model and demonstrated that hepatic $\delta$-aminolevulinic acid ( $\delta$-ALA) dehydratase and $\delta$-ALA synthetase activities were decreased in female rats after intraperitoneal injection of kerosene. Further, heme oxygenase was not affected by kerosene under these conditions (Rao and Pandya 1980). Since $\delta$-ALA synthetase is the rate-limiting enzyme of the heme biosynthesis pathway, hepatic heme biosynthesis may be inhibited by kerosene.

Generalizations regarding the hematological effects of fuel oils on humans cannot be made because the available data suggest that each fuel oil may behave differently, that species variation may exist, and that exposure route may play a role. The similar effects in humans and mice exposed to kerosene suggest that kerosene may not be species specific and may act similarly on the hematopoietic system regardless of the exposure route. However, there are not enough data to determine whether these generalizations can be made. The limited data suggest that inhalation or dermal exposure to diesel fuel and ingestion of kerosene can induce hematological effects in some individuals; however, it is not 
known if these effects would occur in most individuals, although Algren and Rodgers suggest that hydrocarbon ingestion may frequently effect intravascular hemolysis.

Musculoskeletal Effects. No studies were located regarding musculoskeletal effects in humans after inhalation, oral, or dermal exposure to fuel oils. No histopathological changes were noted in the musculoskeletal systems of rats and dogs exposed by inhalation to up to $100 \mathrm{mg} / \mathrm{m}^{3}$ deodorized kerosene vapor for 13 weeks (Carpenter et al. 1976). Mice treated dermally with marine diesel fuel and JP-5 (up to $500 \mathrm{mg} / \mathrm{kg} /$ day) also displayed no detectable adverse effects to the musculoskeletal system (NTP/NIH 1986). The limited information available on animals is not sufficient to assess its relevance to human health.

Hepatic Effects. Histopathological examination revealed slight cellular infiltration and mild vacuolization of the livers of rats following gavage with kerosene or Deobase ${ }^{\circledR}$ organ weights were not affected (Muralidhara et al. 1982). Gavage with JP-5 induced increases in serum levels of hepatic enzymes, hepatocyte necrosis, and vacuolization of the periportal hepatocytes in rats (Parker et al. 1981). Inhalation of $231 \mathrm{mg} / \mathrm{m}^{3}$ kerosene vapor induced increases in blood lactate and pyruvate levels; exposure to $58 \mathrm{mg} / \mathrm{m}^{3}$ kerosene vapor induced decreases in blood glucose levels in rats (Starek and Vojtisek 1986). Neither rats nor dogs exhibited histopathological changes in the liver following inhalation exposure to 20,48 , or $100 \mathrm{mg} / \mathrm{m}^{3}$ deodorized kerosene vapor (Carpenter et al. 1976) or following inhalation of up to $1,500 \mathrm{mg} / \mathrm{m}^{3}$ diesel fuel aerosol by rats (Lock et al. 1984). No histopathological changes were noted in the livers of mice following acute dermal exposures to $0.1 \mathrm{~mL}$ kerosene (Upreti et al. 1989). Slight hepatic karyomegaly was noted in mice dermally exposed to $500-8,000 \mathrm{mg} / \mathrm{kg} /$ day JP-5 for 13 weeks (NTP/NIH 1986). These data suggest that fuel oils may be of concern to humans because they affected rats by inhalation and oral exposures and mice by dermal exposures. However, no human data are available for inhalation, oral, or dermal exposures to fuel oils with regard to hepatic toxicity. Therefore, the available information is not sufficient to assess the relevance to human health.

Renal Effects. In one individual, acute renal failure was noted from inhalation and/or dermal exposure to diesel fuel which was used as a shampoo. Biopsy detected tubular dilation, mitosis, and vacuolization in renal cells, and some cellular proliferation in the glomerulus in this individual (Barrientos et al. 1977). Another individual experienced renal failure following inhalation of diesel fuel vapor for 10 days (Reidenberg et al. 1964). Renal necrosis developed in one man after washing 
his hands with diesel fuel over several weeks (Crisp et al. 1979). Urinalysis was normal following inhalation of JP-5 by two individuals or ingestion of kerosene by numerous individuals (Dudin et al. 1991; Mahdi 1988; Nouri and Al-Rahim 1970; Porter 1990).

Renal lesions have been produced in mice by dermal application of JP-5 or marine diesel fuel. The inability to duplicate these lesions with intraperitoneal administration suggested that skin application, in particular the alteration of skin following repeated dermal application, was necessary to produce the renal toxicity, and that the renal effects appeared to be secondary to skin injury (Easley et al. 1982). Lymphocytic inflammation has been induced in the urinary bladder of mice with chronic dermal application of JP-5 or marine diesel fuel (NTP/NIH 1986). However, acute and intermediate dermal exposures to kerosene and JP-5, respectively, were not toxic to the renal system of mice (Upreti et al. 1989; NTP/NIH 1986). Although renal damage has occurred in a few individuals exposed to diesel fuel, it is not known if the general population would exhibit these effects following exposure to these fuel oils. The effects of JP-5 and kerosene on humans is not known.

Inhalation of JP-5 or marine diesel fuel vapors and oral exposure to JP-5 induce a nephropathy that is unique to male rats (Bruner 1984; Cowan and Jenkins 1981; Gaworski et al. 1984; Parker et al. 1981). The progression of this lesion has been noted in several studies, including studies conducted on the hydrocarbon decalin (decahydronaphthalene) (Alden 1986; Bruner 1984; Cowan and Jenkins 1981; Gaworski et al. 1984; Parker et al. 1981). Specifically, hyaline droplets are formed in the cytoplasm of the proximal tubule cells of the cortex. The hyaline droplets contain high concentrations of the protein $\alpha_{2 \mu}$,-globulin. It is believed that this protein accumulates in the cytoplasm of the renal tubule cells because the degradation of $\alpha_{2 \mu}$,-globulin is slowed as a result of to binding with specific substances, such as fuel oils, or their metabolites. The cells die and are sloughed off. The tubules near the corticomedullary junction become dilated and are eventually filled with coarsely granular casts and necrotic debris. This results in nephron obstruction and chronic necrosis.

The nephropathy induced by accumulation of this protein has not been noted in female rats, female mice (studies conducted on male mice were not located), or dogs of either sex when exposed under similar conditions to either JP-5 or marine diesel fuel vapors (Bruner 1984; Cowan and Jenkins 1981; Gaworski et al. 1984). There is no evidence of renal necrosis in humans acutely exposed to JP-5 vapor (Porter 1990). In a case report, one individual exposed to an unspecified diesel fuel for several weeks exhibited acute tubular necrosis (Crisp et al. 1979). However, renal necrosis did not occur in 
two other individuals acutely exposed to diesel fuel vapor (Barrientos et al. 1977; Reidenberg et al. 1964), although they did exhibit acute renal failure. Based on available data, it does not appear that the nephrotoxicity attributable to the $\alpha_{2 \mu}$-globulin syndrome observed in male rats is relevant to humans (Olson et al. 1990).

Dermal Effects. Oral and/or dermal exposure to kerosene induced blisters, erythema, and peeling skin in two cases (Annobil 1988). Dose-related effects in humans from dermal exposures to fuel oils are based upon limited information. Case studies describe numerous effects in or on the skin following dermal exposure to kerosene. These effects are itching, blisters, reddening, flaccid bullae, pustules, soreness, burning, swelling, and denudation (Annobil 1988; Jee et al. 1985; Mosconi et al. 1988; Tagami and Ogino 1973). There are limited data suggesting that epidermal damage may be induced by kerosene by impairing protein synthesis, but not DNA or collagen synthesis, in the epidermis (Lupulescu and Birmingham 1975). However, these data are insufficient to identify the toxic effects that may occur in humans following dermal exposure to kerosene. Also, cellular destruction was noted in humans from dermal exposure to kerosene (Lupulescu and Birmingham 1976; Lupulescu et al. 1973), but the implications of these effects have yet to be determined.

Acute, intermediate, and chronic dermal exposures to marine diesel fuel and JP-5 have induced various degrees of dose-dependent dermatitis in mice (Easley et al. 1982; NTP/NIH 1986). Manifestations of the dermatitis include: acanthosis, inflammation, parakeratosis, and hyperkeratosis (NTP/NIH 1986). Dermal irritation was induced in mice by acute dermal exposure to kerosene (Upreti et al. 1989). It is possible that dermal sensitization by fuel oils occurs only following acute exposures since sensitization was noted in guinea pigs acutely exposed to JP-5 or marine diesel fuel vapors but not following intermediate exposures to JP-5 or diesel fuel vapors (API 1979f; Cowan and Jenkins 1981). However, delayed sensitization was not induced in guinea pigs treated with diesel fuel (Beck et al. 1984), three formulations of No. 2 fuel oil (Beck et al. 1984), JP-5 (Schultz et al. 1981), or diesel fuel marine (Schultz et al. 1981). Diesel fuel marine and JP-5 did induce skin irritation in guinea pigs (API 1979f). No signs of dermal lesions were noted in rats following repeated whole-body inhalation exposure to diesel fuel aerosol (Lock et al. 1984). Whereas dermal exposure to fuel oils (liquid or vapor) would be expected to induce irritation or possibly dermatitis, the data are not adequate to evaluate delayed skin sensitization. Furthermore, the data are insufficient to assess the dermal effects of fuel oils when exposure occurs via the oral or respiratory routes. 
OcularEffects. JP-5 vapor were irritating to the eyes of two individuals and were associated with hyperemic conjunctiva in one case (Porter 1990). Eye irritation was also reported in workers who were chronically exposed to unspecified jet fuels, which may or may not include JP-5 (Knave et al. 1978). Deodorized kerosene vapor were shown to induce eye irritation in some individuals (Carpenter et al. 1976). Dermal exposure to diesel fuel and/or inhalation of its vapor was associated with subconjunctival hemorrhages in an individual who used it as a shampoo (Barrientos et al. 1977). In the only available animal studies, rabbits exposed dermally to diesel fuel (API 1979b), marine diesel fuel, or JP-5 (Cowan and Jenkins 1981; Schultz et al. 1981) showed no signs of ocular irritation. These data suggest that fuel oils, in general, may induce eye irritation in some individuals, although only one or two individuals exhibited ocular or dermal effects from airborne exposures to fuel oils. Irritation is likely to be more severe if exposure occurs in confined spaces.

Body Weight Effects. In mice, dose-dependent decreases in body weight were induced by intermediate and chronic dermal exposures to marine diesel fuel. In addition, dose-dependent decreases in body weight were induced in mice by acute and intermediate dermal exposures to JP-5 (NTP/NIH 1986; Schultz et al. 1981). Both food and water consumption were decreased in mice exposed to diesel fuel no. 2 aerosol for 8 hours/day, 5 consecutive days (Kainz and White 1984); in rats exposed to diesel fuel for 2 or 6 hours, once or 3 times per week (for a total of 9 exposures) (Dalbey et al. 1987); and in rats exposed for 4 hours per day, twice per week for 13 weeks (Lock et al. 1984). None of these effects were noted in mice following acute dermal exposures to kerosene (Upreti et al. 1989). No conclusions can be made regarding human health from the animal data since the significance of decreased body weight and food and water consumption with regard to humans cannot be determined.

Other Systemic Effects. Inhalation and/or dermal exposure to diesel fuel has been associated with edema in two individuals (Crisp et al. 1979; Reidenberg et al. 1964). In one of these cases, loin pains, thirst, and severe exhaustion were also reported (Crisp et al. 1979). Several case studies reported fever in children following acute ingestion of kerosene (Akamaguna and Odita 1983; Aldy et al. 1978; Dudin et al. 1991; Mahdi 1988; Majeed et al. 1981; Nouri and Al-Rahim 1970; Saksena 1969; St. John 1982; Subcommittee on Accidental Poisoning 1962). The effects of oral exposure to kerosene in children cannot be used to predict possible effects in adults or the effects of other fuel oils by this route without additional information. Similarly, it cannot be determined whether the effects of diesel 
fuel noted in humans would occur from exposure to other fuel oils or in the general population since limited information is available.

Immunological and Lymphoreticular Effects. No studies were located regarding immunotoxicity in humans after inhalation, oral, or dermal exposure or in animals following inhalation or oral exposure to fuel oils. Dermal application of JP-5 induced granulocytic hyperplasia in the bone marrow and hyperplasia in the lymph nodes of mice. Dermal treatment of mice with marine diesel fuel induced plasmacytosis in the lymph nodes; this effect was secondary to dermatitis (NTP/NIH 1986). Decreases in the relative weights of the lymph nodes and thymus were noted in mice following dermal exposure to kerosene (Upreti et al. 1989). In addition, thymocyte counts, bone marrow nucleated cell counts, thymic cortical lymphocytes, and the cellularity of the thymic lobules were decreased. Increases in the cellular populations of the popliteal lymph nodes and the cell population of the axial lymph nodes were also present. These studies indicate that fuel oils may have an effect on the immune system of mice, although the toxicological significance of these effects cannot be determined from the data. There are not enough data to determine whether fuel oils would induce immunological effects in humans.

Data regarding changes in white blood cell counts were found; however, it cannot be determined whether these changes indicate hematological or immunological toxicity. Increases in leukocyte counts from acute ingestion of kerosene (Dudin et al. 1991; Majeed et al. 1981; Nouri and Al-Rahim 1970) have been reported in humans. Increases white blood cell and polymorphonuclear leukocyte concentrations were noted in mice after acute dermal exposure to kerosene (Upreti et al. 1989). Oral exposure to JP-5 decreased white blood cell counts in rats (Parker et al. 1981). However, inhalation of diesel fuel aerosol had no effect on white blood cells in rats (Dalbey et al. 1987). The conflicting changes in white blood cell levels may be due to differences in the toxicity of these fuel oils or to differences in exposure route or both. The similar effects in humans and mice exposed to kerosene suggests that kerosene may not be species specific and that this fuel oil affects white blood cells in a similar manner regardless of the exposure route. However, there are not enough data to determine whether these generalizations can be made. 
Neurological Effects. Numerous neurological effects were reported from kerosene ingestion by children: unconsciousness or semiconsciousness, drowsiness, restlessness, irritability, and in fewer cases, coma and convulsions (Akamaguna and Odita 1983; Aldy et al. 1978; Coruh and Inal 1966; Dudin et al. 1991; Mahdi 1988; Majeed et al. 1981; Nouri and Al-Rahim 1970; Saksena 1969; Santhanakrishnan and Chithra 1978; St. John 1982; Subcommittee on Accidental Poisoning 1962). Neither coma nor convulsions occurred in children that ingested $3-20 \mathrm{~mL}$ of kerosene. This dose is equivalent to $126-1,754 \mathrm{mg} / \mathrm{kg}$ in children aged 10 months to 5 years (Dudin et al. 1991). There are limited data that suggest that the central nervous system effects noted from ingestion of kerosene are due to hypoxia which results from kerosene-induced respiratory impairment (Majeed et al. 1981).

Severe headaches occurred in an individual exposed to diesel fuel vapor for 10 days (Reidenberg et al. 1964). Anorexia occurred in a man following dermal and/or inhalation exposure to diesel fuel over several weeks (Crisp et al. 1979). Other neurological effects were reported following inhalation of JP-5 vapor in two individuals who had fatigue and coordination and concentration difficulties; other effects included headache, apparent intoxication, and anorexia. Effects subsided within 24 hours for one individual and within 4 days for the other (Porter 1990). Sensory impairment did not occur in these individuals. However, experimental data indicate that olfactory fatigue and taste sensation may occur in some individuals after a 15 -minute inhalation exposure to $140 \mathrm{mg} / \mathrm{m}^{3}$ deodorized kerosene vapor (Carpenter et al. 1976). These data suggest that the different types of fuel oils may behave differently under inhalation exposure conditions. The effect of deodorized kerosene may also occur at lower doses, but this cannot be determined from these data.

Neurasthenia (i.e., fatigue, depressed mood, lack of initiative, dizziness, sleep disturbances) and impairment of attention and sensorimotor speed were associated with chronic inhalation, oral, and/or dermal exposures to jet fuel by factory workers (Knave et al. 1978). Nevertheless, it is not known to which jet fuels the workers were exposed, and confounding by exposure to other chemicals may have occurred.

Acute inhalation of diesel fuel no. 2 vapor induced dose-dependent ataxia, increased sensitivity to heat, changes in behavior, and tremors in mice. Also, while ataxia occurred, there was no affect on the spinal cord reflex for blink response nor on the integrity of the neuromuscular junction based on responses to the rota rod and inclined plane tests (Kainz and White 1984). In rats, intermediate inhalation of diesel fuel aerosol induced increased peak response time using the startle reflex assay 
(Lock et al. 1984); however, histopathological changes of the nervous system were not noted in these rats. Neurotoxicity was not induced using the landing footspread, tail flick, forelimb grip strength, and startle reflex assays under similar exposure conditions (Dalbey et al. 1987). Oral exposure to kerosene and Deobase ${ }^{\circledR}$ induced ataxia and drowsiness in rats (Muralidhara et al. 1982). Aspiration of kerosene induced drowsiness, lack of muscular coordination, and behavioral changes (Nouri et al. 1983) and dermal exposure induced an increased response to tactile stimuli and hyperactivity (Upreti et al. 1989) in mice. No histopathological changes were noted in the nervous system of mice following dermal exposures to JP-5 or marine diesel fuel (NTP/NIH 1986). The information from human and animal studies indicate that neurotoxicity may occur by all routes of exposure and that all fuel oils may be neurotoxic. As is common with hydrocarbons, the primary acute neurotoxic effect is central nervous depression that may be manifest in a number of symptoms.

Developmental Effects. No studies were located regarding developmental effects in humans after inhalation, oral, or dermal exposure to fuel oils. No developmental effects were noted in rat fetuses after inhalation exposure of the gestating female to home heating oil no. 2, fuel oil UNSP, or diesel fuel vapor (API 1979c, 19798; Beliles and Mecler 1983). Since negative effects were noted for several fuel oils in one species, it is possible that none of the fuel oils induce developmental effects by inhalation. However, additional data are needed to assess whether developmental effects would occur in other species, including humans, and/or by oral and dermal exposures.

Reproductive Effects. No studies were located regarding reproductive effects in humans after inhalation, oral, or dermal exposure to fuel oils. No histological changes were noted in the reproductive system of mice dermally exposed to JP-5 for 13 weeks or chronically exposed to marine diesel fuel or JP-5 (NTP/NIH 1986) or in rats following intermediate-duration inhalation of diesel fuel aerosol (Lock et al. 1984). There is not enough information to assess the human reproductive toxicity to fuel oils by oral, inhalation, or dermal exposures.

Genotoxic Effects. No genotoxicity studies involving human exposure to fuel oils were identified. The results from a study employing a human cell line showed that neither 5 nor 50 ppm petroleumderived JP-5 (PD-JPS) interfered with Snyder-Theilen feline sarcoma virus (ST-FeSV)-directed transformation of human foreskin fibroblastic cells (Blakeslee et al. 1983). Higher concentrations (2100 ppm) were cytotoxic. It was reported that marine diesel fuel failed to inhibit transformation in this assay, but data were not shown. The study authors consider this in vitro assay to be a useful 
predictor of carcinogenesis since several known carcinogens have been shown to suppress transformation in cells infected with the ST-FeSV virus by blocking a specific virus gene function (i.e., transformation); noncarcinogens do not inhibit virus-induced cell transformation in this test system.

Animal models have primarily yielded negative genotoxicity data. Inhalation of 100 to $400 \mathrm{ppm}$ diesel fuel 6 hours/day, 5 days/week for 8 weeks did not increase the frequency of dominant lethal mutations. Cyclohexane/DMSO extract and DMSO extract of diesel 1 (CAS no. 8008-20-6), diesel 2 (CAS no. 64742-47-7), and home heating oil (CAS no. 68476-30-2), administered orally at doses of $1.0,2.0$, and $5.0 \mathrm{~g} / \mathrm{kg}$, did not induce increased frequency of micronuclei in a mouse bone marrow micronucleus assay (McKee et al. 1994). It should be noted that the extraction procedure was used to concentrate the aromatic fraction (with particular interest in the polynuclear aromatics) of the fuel oils tested. Kerosene, administered intraperitoneally, did not increase the frequency of chromosomal aberrations in bone marrow cells harvested from rats following a one-time exposure to $0.04,0.13$, or $0.4 \mathrm{~mL}$ or a 5 -day exposure to $0.02,0.06$, or $0.18 \mathrm{ml} /$ day (Conaway et al. 1984). Since the rationale for selection of $0.4 \mathrm{~mL}(\mathrm{LD}$,$) as the high dose was not provided and there was no information$ regarding toxic effects in the treated animals or cytotoxic effects on the target organ (i.e., bone marrow cells), the findings do not fully support a negative conclusion for kerosene.

Some data has, however, suggested that fuel oils may have genotoxic activity. Evidence that fuel oil no. 2 is clastogenic in rat bone marrow has been reported (Conaway et al. 1984). Significant increases (Wilcoxon rank test) in the percentage of aberrant cells were observed in a rat bone marrow cytogenetic assay in rats receiving single intraperitoneal (i.p.) injections ( 2.0 or $6.0 \mathrm{~mL} / \mathrm{kg}$ diesel fuel $)$ and in rats receiving daily i.p. injections of $6.0 \mathrm{ml} / \mathrm{kg} / \mathrm{day}$ for 5 days, although the response was not dose-related. Similarly, rats that received doses of fuel oil no. 2 (oral gavage; 125, 417, or $1,250 \mathrm{~g} / \mathrm{kg} /$ day) for 5 consecutive days demonstrated nondose-related increases in the percentage of aberrant cells and the percentage of cells with chromatid breaks (Conaway et al. 1984). The effect was significant at the low and high dose, and the greatest yield of aberrant chromosome figures occurred in the rats treated with $125 \mathrm{~g} / \mathrm{kg} / \mathrm{day}$.

The genotoxicity of fuel oil no. 2, kerosene, and diesel fuel was also evaluated with the mouse lymphoma $\mathrm{TK}^{+/-}$forward mutation assay (Conaway et al. 1984). The data reported was insufficient to 
permit a full evaluation of the results; however, the authors considered diesel fuel and kerosene to be negative and fuel oil no. 2 to be positive.

The cyclohexane/DMSO extract and DMSO extract of diesel 1 (CAS no. 8008-20-6), diesel 2 (CAS no. 64742-47-7), and home heating oil (CAS no. 68476-30-2) were evaluated for genotoxicity with the Ames assay (McKee et al. 1994). Diesel 1 extracts did not produce significant increases in revertants. The DMSO extract of diesel 2 produced a significant increase in the number of revertants, although the increase was not dose-related. The cyclohexane/DMSO extract of diesel 2 failed to produce a significant increase in the number of revertants. The DMSO-extract of home heating oil produce a significant increase in revertants, that was dose-dependent, while the cyclohexane/DMSO extract induced a dose-related increase in revertants that was less than two times greater than the control. It should be noted that the modifications to the standard Ames mutagenesis included not only the extraction step but also the use of S9 at eight times the recommended concentration, and the use of the TA98 strain exclusively. Kerosene was mutagenic in S. typhimurium TA98 in the presence of increased concentrations of hamster S9 and nicotinamide adenine dinucleotide phosphate (NADP) in the S9-cofactor mix (Blackburn et al. 1986).

In contrast to the positive results with kerosene, neither JP-5 nor a marine diesel fuel product were mutagenic in the Ames assay when activated with S9 (Arochlor-induced rat liver enzymes) (Schultz et al. 1981). Similarly, neither marine diesel fuel nor JP-5 were mutagenic in well-conducted S. typhimurium preincubation assays (NTP/NIH 1986). Doses of each agent evaluated without S9 activation and with rat or hamster liver fractions ranged from 3 to $333 \mu \mathrm{g} / \mathrm{plate}-\mathrm{S} 9$, from 33 to 3,333 $\mu \mathrm{g} /$ plate $+\mathrm{S} 9$ (marine diesel fuel), and from 100 to 10,000 $\mu \mathrm{g} /$ plate +/-S9 (JP-5). Further, fuel oil no. 2 was not mutagenic up to the limit of solubility (42 mg/plate) in the Salmonella/mammalian microsome mutagenicity assay (Conaway et al. 1984). It was also reported that kerosene (0.001-5 $\mu \mathrm{L} /$ plate $+/-\mathrm{S} 9$ [plate test] and 6.25-50 $\mu \mathrm{L} / \mathrm{mL}+/-\mathrm{S} 9$ [preincubation assay]) and diesel fuel (0.001-5 $\mu \mathrm{L} /$ plate $+/-\mathrm{S} 9$ [plate test] and 3.38-25 $\mu \mathrm{L} / \mathrm{mL}$ [preincubation assay]) were negative in this microbial test system.

The inconsistent data reported for the animal models, the human cell assays, and the Ames tests with the various fuel oils preclude the use of the data for the prediction of genotoxic hazards to humans (refer to Tables 2-4 and 2-5 for a further summary of these studies). 
TABLE 2-4. Genotoxicity of Fuel Oils In Vivo

\begin{tabular}{|c|c|c|c|}
\hline Species (test system) & End point & Results & Reference \\
\hline \multicolumn{4}{|l|}{ Fuel Oil No. 2} \\
\hline $\begin{array}{l}\text { Mammalian cells: } \\
\text { Rat (bone marrow) }\end{array}$ & Chromosome aberrations & $+/-^{a}$ & Conaway et al. 1984 \\
\hline \multicolumn{4}{|l|}{ Diesel Fuel } \\
\hline $\begin{array}{l}\text { Mammalian cells: } \\
\text { Rat (bone marrow) } \\
\text { Mouse (all stages of spermato- } \\
\text { and spermiogenesis) }\end{array}$ & $\begin{array}{l}\text { Chromosome aberrations } \\
\text { Dominant lethal } \\
\text { mutations }\end{array}$ & $\begin{array}{l}+ \\
-{ }^{\mathrm{b}}\end{array}$ & $\begin{array}{l}\text { Conaway et al. } 1984 \\
\text { API } 1981\end{array}$ \\
\hline \multicolumn{4}{|l|}{$\underline{\text { Kerosene }}$} \\
\hline $\begin{array}{l}\text { Mammalian cells: } \\
\quad \text { Rat (bone marrow) } \\
\text { Diesel Fuel No. } 1\end{array}$ & Chromosome aberrations & $-^{c}$ & Conaway et al. 1984 \\
\hline $\begin{array}{l}\text { Mammalian cells: } \\
\text { Rat (bone marrow) }\end{array}$ & Micronucleus increase & - & McKee et al. 1994 \\
\hline \multicolumn{4}{|l|}{ Diesel Fuel No. 2} \\
\hline $\begin{array}{l}\text { Mammalian cells: } \\
\text { Rat (bone marrow) }\end{array}$ & Micronucleus increase & - & McKee et al. 1994 \\
\hline \multicolumn{4}{|l|}{ Home Heating Oil } \\
\hline $\begin{array}{l}\text { Mammalian cells: } \\
\text { Rat (bone marrow) }\end{array}$ & Micronucleus increase & - & McKee et al. 1994 \\
\hline
\end{tabular}

${ }^{2}$ Positive after oral exposure but no dose response

${ }^{b}$ Negative after inhalation exposure

'Negative after intraperitoneal exposure but study was compromised

$+/-=$ inconclusive result, $+=$ positive result; $-=$ negative result 
TABLE 2-5. Genotoxicity of Fuel Oils In Vitro

\begin{tabular}{|c|c|c|c|c|c|}
\hline \multirow[b]{2}{*}{ Species (test system) } & \multirow[b]{2}{*}{ End point } & \multicolumn{2}{|c|}{ Results } & \multirow[b]{2}{*}{ Reference } & \\
\hline & & $\begin{array}{c}\text { With } \\
\text { activation }\end{array}$ & $\begin{array}{l}\text { Without } \\
\text { activation }\end{array}$ & & \\
\hline \multicolumn{6}{|l|}{$\underline{\text { Kerosene }}$} \\
\hline \multicolumn{6}{|l|}{ Prokaryotic organisms: } \\
\hline \multicolumn{6}{|l|}{ Marine Diesel Fuel } \\
\hline $\begin{array}{l}\text { Prokaryotic organisms: } \\
\text { S. typhimurium (TA1535, TA1537, } \\
\text { TA98, TA100) }\end{array}$ & Gene mutation & - & - & NTP/NIH 1986 & n \\
\hline $\begin{array}{l}\text { S. typhimurium (TA98) } \\
\text { Mammalian cells: } \\
\text { ST-FeSV-infected } \\
\text { human foreskin fibroblasts }\end{array}$ & $\begin{array}{l}\text { Inhibition of } \\
\text { morphological } \\
\text { transformation }\end{array}$ & No data & - & $\begin{array}{l}\text { Schultz et al. } 1981 \\
\text { Blakeslee et al. } 1983\end{array}$ & 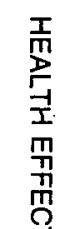 \\
\hline \multicolumn{6}{|l|}{$\underline{\mathrm{JP}-5 \text { Fuel }}$} \\
\hline $\begin{array}{l}\text { Prokaryotic organisms: } \\
\text { S. typhimurium (TA1535, TA97, } \\
\text { TA98, TA100) }\end{array}$ & Gene mutation & - & - & NTP/NIH 1986 & \\
\hline $\begin{array}{l}\text { S. typhimurium (TA98) } \\
\text { Mammalian cells: }\end{array}$ & Gene mutation & - & - & Schultz et al. 1981 & \\
\hline $\begin{array}{l}\text { ST-FeSV-infected } \\
\text { human foreskin fibroblasts }\end{array}$ & $\begin{array}{l}\text { Inhibition of } \\
\text { morphological } \\
\text { transformation }\end{array}$ & No data & - & Blakeslee et al. 1983 & \\
\hline Fuel Oil No. 2 & & & & & \\
\hline $\begin{array}{l}\text { Prokaryotic organisms: } \\
\text { S. typhimurium (TA1535, TA1537, } \\
\text { TA1538, TA98, TA100) }\end{array}$ & Gene mutations & - & - & Conaway et al. 1984 & \\
\hline
\end{tabular}


TABLE 2-5. Genotoxicity of Fuel Oils In Vitro (continued)

\begin{tabular}{lll} 
Species (test system) & Results & With $\begin{array}{c}\text { Without } \\
\text { activation }\end{array}$ \\
\hline
\end{tabular}

Mammalian cells:

Mouse lymphoma (L5178Y)

Gene mutations

Gene mutations

S. typhimurium (TA1535, TA1537, TA1538, TA98, TA100)

Mammalian cells:

Mouse lymphoma (L5178Y)

Diesel Fuel

Prokaryotic organisms:

S. typhimurium (TA1535, TA1537, TA1538, TA98, TA100)

Mammalian cells:

Mouse lymphoma (L5178Y)

Gene mutations

Gene mutations

Gene mutations

Gene mutation

Gene mutation

\section{Diesel Fuel No. 1}

Prokaryotic organisms:

S. typhimurium (TA98)

\section{Diesel Fuel No. 2}

Prokaryotic organisms:

S. typhimurium (TA98)

No data

Conaway et al. 1984

Conaway et al. 1984

Conaway et al. 1984

Conaway et al. 1984

Conaway et al. 1984

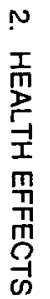


TABLE 2-5. Genotoxicity of Fuel Oils In Vitro (continued)

\begin{tabular}{|c|c|c|c|c|}
\hline \multirow[b]{2}{*}{ Species (test system) } & \multirow[b]{2}{*}{ End point } & \multicolumn{2}{|c|}{ Results } & \multirow[b]{2}{*}{ Reference } \\
\hline & & $\begin{array}{c}\text { With } \\
\text { activation }\end{array}$ & $\begin{array}{l}\text { Without } \\
\text { activation }\end{array}$ & \\
\hline \multicolumn{5}{|l|}{ Home Heating Oil } \\
\hline $\begin{array}{l}\text { Prokaryotic organisms: } \\
\text { S. typhimurium (TA98) }\end{array}$ & Gene mutation & + & No data & McKee et al. 1994 \\
\hline
\end{tabular}

$+=$ positive result; $-=$ negative result $+/-=$ inconclusive result; ST-FeSV $=$ Snyder-Theilen feline sarcoma virus 
Cancer. Human cancer data from epidemiological studies found only equivocal evidence of an association between cancer and exposures to fuel oils. Several studies examined the association between "fuel and oil expenditures for farm purposes" and various forms of cancer in central Canadian farmers (Morrison et al. 1992, 1994; Semenciw et al. 1993). They reported an association between such expenditures and non-Hodgkin's lymphoma and multiple myeloma incidence, but the association was equivocal and not statistically significant. Furthermore, the type of fuels and oils was not specified, nor was the exposure route described. Scherr and colleagues (1992) reported no additional relative risk for non-Hodgkin's lymphoma for subjects occupationally exposed to "gasoline or kerosene." No significant increased relative risk for any type of cancer was noted in Swedish Air Force personnel exposed to military aircraft fuels (including an "unleaded kerosene type jet fuel"). One study (Partanen et al. 1991) suggests that other chemicals could be present in the occupational setting, which could alter fuel oil toxicity, though this same study found no significant association between fuel oil exposure and cancer. Chan and coworkers (1979) examined exposure to kerosene from kerosene cooking stoves, but exposure to kerosene combustion products may have occurred instead of, or in addition to, inhalation of kerosene vapor. Therefore, no firm conclusions may be drawn from this data for human health.

No dermal cancer was noted in $\mathrm{B}_{6} \mathrm{C}_{3} \mathrm{~F}_{1}$ mice following chronic dermal exposure to 250 or 500 $\mathrm{mg} / \mathrm{kg} /$ day JP-5 (NTP/NIH 1986). However, unspecified skin tumors were noted in C3HF/Bd mice, but the tumors were not dose related in most exposure conditions (Schultz et al. 1981). There was an increased incidence of squamous cell papilloma and/or carcinoma in mice chronically exposed to 250 or $500 \mathrm{mg} / \mathrm{kg} /$ day marine diesel fuel (NTP/NIH 1986). Hepatocellular adenoma and carcinoma were noted in male, but not female, mice exposed to 250 or $500 \mathrm{mg} / \mathrm{kg} /$ day marine diesel fuel (NTP/NIH 1986). Although a significant increase in hepatocellular carcinomas were observed in mice dermally treated with middle distillates, the increase was not substantially greater than the incidence noted in "historical" data from negative control groups (Biles et al. 1988). API no. 2 fuel oil demonstrated low tumorigenic activity (15/150) in male and female mice dermally treated with the undiluted material or as a $50 \%$ or $25 \%$ solution in acetone (Witschi et al. 1987). A low, but significant increase in the incidence of dermal tumor was noted in male mice treated with six no. 2 fuel oils that varied in composition (Biles et al. 1988). No increase in tumor incidence occurred in mice receiving dermal applications of diesel fuel; however, dermal application of Jet A induced an increased incidence (26\%) of neoplastic lesions (Clark et al. 1988). An increase in tumor incidence was noted in mice receiving 
DMBA as an initiating agent and furnace oil as a promoting agent; further, furnace oil produced a significant increase in the incidence of confirmed skin tumors in a skin-painting assay (Gerhart et al. 1988). An increase in the incidence of confirmed tumor was also noted in animals receiving DMBA as an initiator and either hydrodesulfurized kerosine or no. 2 fuel oil as a promoting agent (API 1989). These data suggest that fuel oils can act as a skin or liver carcinogen. However, only one species has been investigated, limiting the data. Further investigation utilizing other species is required to more fully elucidate the mechanism of dermal carcinogenesis and the impact of dermal exposure of fuel oils on humans. (See Section 2.2.3.8 for a more complete review of carcinogenesis data.)

\subsection{BIOMARKERS OF EXPOSURE AND EFFECT}

Biomarkers are broadly defined as indicators signaling events in biologic systems or samples. They have been classified as markers of exposure, markers of effect, and markers of susceptibility (NAS/NRC 1989).

A biomarker of exposure is a xenobiotic substance, its metabolite(s), or the product of an interaction between a xenobiotic agent and some target molecule(s) or cell(s) that is measured within a compartment of an organism (NAS/NRC 1989). The preferred biomarkers of exposure are generally the substance itself or substance-specific metabolites in readily obtainable body fluid(s) or excreta. Examples of the types of biomarkers indicated above include blood lead (the xenobiotic), urinary excretion of 2-thiothizolidine-4-carboxylic acid (a metabolite of carbon disulfide), or a DNA adduct (the product of an interaction between an exogenous material and a macromolecule). Several factors can confound the use and interpretation of biomarkers of exposure. The body burden of a substance may be the result of exposures from more than one source. The substance being measured may be a metabolite of another xenobiotic substance (e.g., high urinary levels of phenol can result from exposure to several different aromatic compounds). Depending on the properties of the substance (e.g., biologic half-life) and environmental conditions (e.g., duration and route of exposure), the substance and all of its metabolites may have left the body by the time biologic samples can be taken. It may be difficult to identify individuals exposed to hazardous substances that are commonly found in body tissues and fluids (e.g., essential mineral nutrients such as copper, zinc, and selenium).

Biomarkers of exposure to fuel oils are discussed in Section 2.5.1. 
Biomarkers of effect are defined as any measurable biochemical, physiologic, or other alteration within an organism that, depending on magnitude, can be recognized as an established or potential health impairment or disease (NAS/NRC 1989). This definition encompasses biochemical or cellular signals of tissue dysfunction (e.g., increased liver enzyme activity or pathologic changes in female genital epithelial cells), as well as physiologic signs of dysfunction such as increased blood pressure or decreased lung capacity. Note that these markers are often not substance specific. They also may not be directly adverse, but can indicate potential health impairment (e.g., DNA adducts). Biomarkers of effects caused by fuel oils are discussed in Section 2.5.2.

A biomarker of susceptibility is an indicator of an inherent or acquired limitation of an organism's ability to respond to the challenge of exposure to a specific xenobiotic substance. It can be an intrinsic genetic or other characteristic or a preexisting disease that results in an increase in absorbed dose, a decrease in the biologically effective dose, or a change in target tissue response. If biomarkers of susceptibility exist, they are discussed in Section 2.7, "Populations That Are Unusually Susceptible."

\subsubsection{Biomarkers Used to Identify or Quantify Exposure to Fuel Oils}

No biomarkers of exposure were identified for fuel oils in general. However, there have been suggestions for potential markers for kerosene exposure. These include the odor of kerosene on the breath suggesting ingestion (Annobil 1988; Zucker et al. 1986) and the odor of kerosene on clothing suggesting dermal exposure (Annobil 1988; Tagami and Ogino 1973). The odor of distillate fuels are so similar, however, that the sensitivity and specificity of these markers would be extraordinarily low. Some components of kerosene, other fuel oils, and their metabolites may be detected in the blood and urine, although neither the route of exposure nor the origin can be determined. For information on biomarkers of exposure for some of the constituents of fuel oils, the ATSDR toxicological profiles on benzene, toluene, total xylenes, and polycyclic aromatic hydrocarbons (ATSDR 1989, 1990a, 1991a, 1991b) can be consulted.

\subsubsection{Biomarkers Used to Characterize Effects Caused by Fuel Oils}

No specific, quantitative biomarkers of effect for fuel oils were identified. 


\subsection{INTERACTIONS WITH OTHER CHEMICALS}

Exposures to two or more substances may cause effects that are additive (the combined effect of the mixture is equal to the sum of the effects of the agents), synergistic (causing an effect that is greater than the sum of the effects of the agents), or antagonistic (one substance interferes with the action of another). No information was located regarding the influence of other chemicals on the toxicity of fuel oils. However, kerosene vapor has been shown to increase the effects of hexobarbital (a sleeping agent), following acute exposure, and phenacetin (an antipyretic), following subchronic exposure, in rats (Starek and Vojtisek 1986).

\subsection{POPULATIONS THAT ARE UNUSUALLY SUSCEPTIBLE}

A susceptible population will exhibit a different or enhanced response to fuel oils than will most persons exposed to the same level of fuel oils in the environment. Reasons include genetic make-up, developmental stage, health and nutritional status, and chemical exposure history. These parameters result in decreased function of the detoxification and excretory processes (mainly hepatic and renal) or the pre-existing compromised function of target organs. For these reasons we expect the elderly with declining organ function and the youngest of the population with immature and developing organs will generally be more vulnerable to toxic substances than healthy adults. Populations who are at greater risk due to their unusually high exposure are discussed in Section 5.6, "Populations With Potentially High Exposure."

No information was located regarding the toxicity of fuel oils in susceptible populations. The human data, in general, were based upon case studies that reported ingestion of kerosene by children. Although children were not shown to be particularly susceptible to kerosene in these studies, it was obvious that children are more likely to be exposed to kerosene accidentally than adults. In particular, children that are 5 years old or younger often mistakenly drank kerosene because it was accessible to them.

In one animal study, it was found that younger rats are more susceptible to kerosene toxicity than are older rats. A single oral dose of $22,400 \mathrm{mg} / \mathrm{kg}$ kerosene killed $27 \%$ of the adult rats, $66 \%$ of the 5 -week-old rats, and 100\% of the 10-day-old rats (Deichmann et al. 1944). It is not known whether kerosene would also be more toxic in younger humans as compared to older humans. 


\subsection{METHODS OF REDUCING TOXIC EFFECTS}

This section will describe clinical practice and research concerning methods for reducing toxic effects of exposure to fuel oils. However, because some of the treatments discussed may be experimental and unproven, this section should not be used as a guide for treatment of exposures to fuel oils. When specific exposures have occurred, poison control centers and medical toxicologists should be consulted for medical advice.

\subsubsection{Reducing Peak Absorption Following Exposure}

The mitigation procedures for fuel oils parallel those for hydrocarbon poisoning in general. Inhalation and ingestion appear to be the most serious routes of exposure. In the case of overexposure by inhalation, it is suggested that the patient be moved to an area of fresh air and given basic supportive treatment (CONCAWE 1985; HSDB 1991) including 100\% humidified supplemental oxygen as required (HSDB 1991).

For poisoning by ingestion, the treatment protocol is more complex. As with inhalation, it is recommended that the patient receive prompt supportive medical care (Bronstein and Currance 1988; CONCAWE 1985; Goldfrank et al. 1990; Haddad and Winchester 1990; Stutz and Janusz 1988; Zieserl 1979). The primary concern for the person who has ingested hydrocarbons such as fuel oils or kerosene is hydrocarbon aspiration either during ingestion or during gastric decontamination. Aspiration of the hydrocarbon into the lungs can cause hydrocarbon pneumonitis and secondary infections including pneumonia.

Because of the aspiration risk, a controversy has developed over which (if either) of two gastric decontamination treatments is better: induced vomiting or gastric lavage. In general, the recommendation is that no form of gastric emptying be used if the amount of hydrocarbon ingestion is small (Bronstein and Currance 1988; Ellenhorn and Barceloux 1988; Goldfrank et al. 1990; HSDB 1991; Litovitz and Greene 1988; Shirkey 1971; Zieserl 1979). This is usually the case with accidental poisonings. If unknown or large amounts (volumes greater than $100 \mathrm{~mL}$ ) have been ingested, then the decision of how and/or whether to decontaminate the stomach should be based on the state of the patient, the hydrocarbon's viscosity, and the involvement of other more dangerous chemicals. For conscious patients with operational gag reflexes and without spontaneous emesis, induced vomiting 
seems to be the preferred method of gastric emptying (Ellenhorn and Barceloux 1988; Goldfrank et al. 1990; Ng et al. 1974; Shirkey 1971; Zieserl 1979); otherwise, endotracheal intubation followed by gastric lavage has been suggested (Ellenhorn and Barceloux 1988; Haddad and Winchester 1990).

For ingestion of large amounts (greater than $30 \mathrm{~mL}$ in children) of home or diesel fuel oils, gastric decontamination has been contraindicated since these hydrocarbons have a high viscosity and are poorly absorbed (Ellenhorn and Barceloux 1988). The low viscosity of kerosene, however, has produced conflicting opinions. Some recommend induced emesis to prevent gastrointestinal absorption (Ellenhorn and Barceloux 1988). On the other hand, others suggest that the low viscosity of kerosene increases the risk of aspiration (Gerarde 1959; Litovitz and Greene 1988) and therefore do not recommend gastric decontamination regardless of volume (Bronstein and Currance 1988; CONCAWE 1985; Haddad and Winchester 1990; Litovitz and Greene 1988; Macnamara 1968).

Controversy also exists over whether or not to administer activated charcoal (to bind the hydrocarbon) or cathartics (Ellenhorn and Barceloux 1988; Goldfrank et al. 1990; Haddad and Winchester 1990; HSDB 1991; Litovitz and Greene 1988; Shirkey 1971; Stutz and Janusz 1988; Zieserl 1979). Some question the overall effectiveness of activated charcoal and cathartics (Goldfrank et al. 1990; Litovitz and Greene 1988; Zieserl 1979). In addition, activated charcoal may cause vomiting (HSDB 1991) which may or may not be desired. Most agree, however, that if cathartics are administered, they should be saline cathartics such as magnesium or sodium sulfate or citrate and not oil-based cathartics such as mineral oil (Ellenhorn and Barceloux 1988; Goldfrank et al. 1990; Haddad and Winchester 1990; Stutz and Janusz 1988).

In general, administration of antibiotics and/or corticosteroids does not appear useful in treating hydrocarbon pneumonitis (Brown et al. 1974; Goldfrank et al. 1990; Haddad and Winchester 1990; HSDB 1991; Steele et al. 1972; Wolfsdorf and Kundig 1974; Zieserl 1979). In fact, one study has suggested that steroid administration may increase bacterial colonization in the lungs (Brown et al. 1974). The use of antibiotics is recommended only to treat secondary lung infections (Haddad and Winchester 1990; HSDB 1991; Zieserl 1979).

If the skin is exposed to fuel oils, washing the area of contact with large amounts of soapy water is recommended (CONCAWE 1985; Ellenhorn and Barceloux 1988; Goldfrank et al. 1990; HSDB 1991; Stutz and Janusz 1988). If blistering or skin loss occurs, then the use of sterile water alone is 
suggested (CONCAWE 1985). For ocular exposure, flushing the eyes liberally with water (CONCAWE 1985; HSDB 1991; Stutz and Janusz 1988) and, if necessary, using proparacaine hydrochloride to assist the irrigation (Bronstein and Currance 1988) are the recommended treatment protocols.

\subsubsection{Reducing Body Burden}

Little is known about the toxicokinetics of fuel oils, and there are no known methods for the reduction of body burden.

\subsubsection{Interfering with the Mechanism of Action for Toxic Effects}

Although lung response to aerosolized kerosene and the effect of kerosene on heme biosynthesis have been partially investigated, the toxicities of fuel oils as well as their mechanisms are not well defined. As such, no known therapies are available that disrupt the mechanisms of action.

\subsection{ADEQUACY OF THE DATABASE}

Section 104(i)(5) of CERCLA, as amended, directs the Administrator of ATSDR (in consultation with the Administrator of EPA and agencies and programs of the Public Health Service) to assess whether adequate information on the health effects of fuel oils is available. Where adequate information is not available, ATSDR, in conjunction with the National Toxicology Program (NTP), is required to assure the initiation of a program of research designed to determine the health effects (and techniques for developing methods to determine such health effects) of fuel oils.

The following categories of possible data needs have been identified by a joint team of scientists from ATSDR, NTP, and EPA. They are defined as substance-specific informational needs that, if met, would reduce or eliminate the uncertainties of human health assessment. This definition should not be interpreted to mean that all data needs discussed in this section must be filled. In the future, the identified data needs will be evaluated and prioritized, and a substance-specific research agenda may be proposed. 


\subsubsection{Existing Information on Health Effects of Fuel Oils}

The existing data on health effects of inhalation, oral, and dermal exposure of humans and animals to fuel oils are summarized in Figure 2-4. The purpose of this figure is to illustrate the existing information concerning the health effects of fuel oils. Each dot in the figure indicates that one or more studies provide information associated with that particular effect. The dot does not imply anything about the quality of the study or studies. Gaps in this figure should not be interpreted as "data needs" information (i.e., data gaps that must necessarily be filled).

Information is available on acute, intermediate, and chronic systemic effects, as well as neurological and cancer effects, following inhalation exposure to fuel oils; death, acute systemic, and neurological effects following oral exposure to fuel oils; and acute, intermediate, and chronic systemic and neurological effects following dermal exposure to fuel oils in humans. Information is available on death, and acute and intermediate systemic effects, as well as neurological, developmental, reproductive, genotoxic, and cancer effects following inhalation exposure to fuel oils; death, acute systemic effects, as well as neurological and genotoxic effects following oral exposure to fuel oils; and death, acute, intermediate, and chronic systemic effects, as well as immunological, neurological, reproductive, and cancer effects following dermal exposure to fuel oils in animals. Therefore, as Figure 2-4 shows, the majority of the data on health effects of fuel oils concern inhalation or dermal exposure of animals; however, there are some data for all routes of exposure in both animals and humans.

\subsubsection{Identification of Data Needs}

The following are topical sections that identify gaps in the present state of knowledge concerning the toxicology of fuel oils. Each of the sections identifies specific areas in which additional data are needed to gain a greater understanding of the toxicity of fuel oils and its constituents as well as of the biochemical mechanisms of their toxicity. It must be noted, however, that there are finite monies available for all toxicological research. Hard decisions must be made to determine how (e.g., the material to be studied, the effect to be investigated, whether human study or animal model) these funds would best be invested. 


\section{FIGURE 2-4. Existing Information on Health Effects of Fuel Oils}
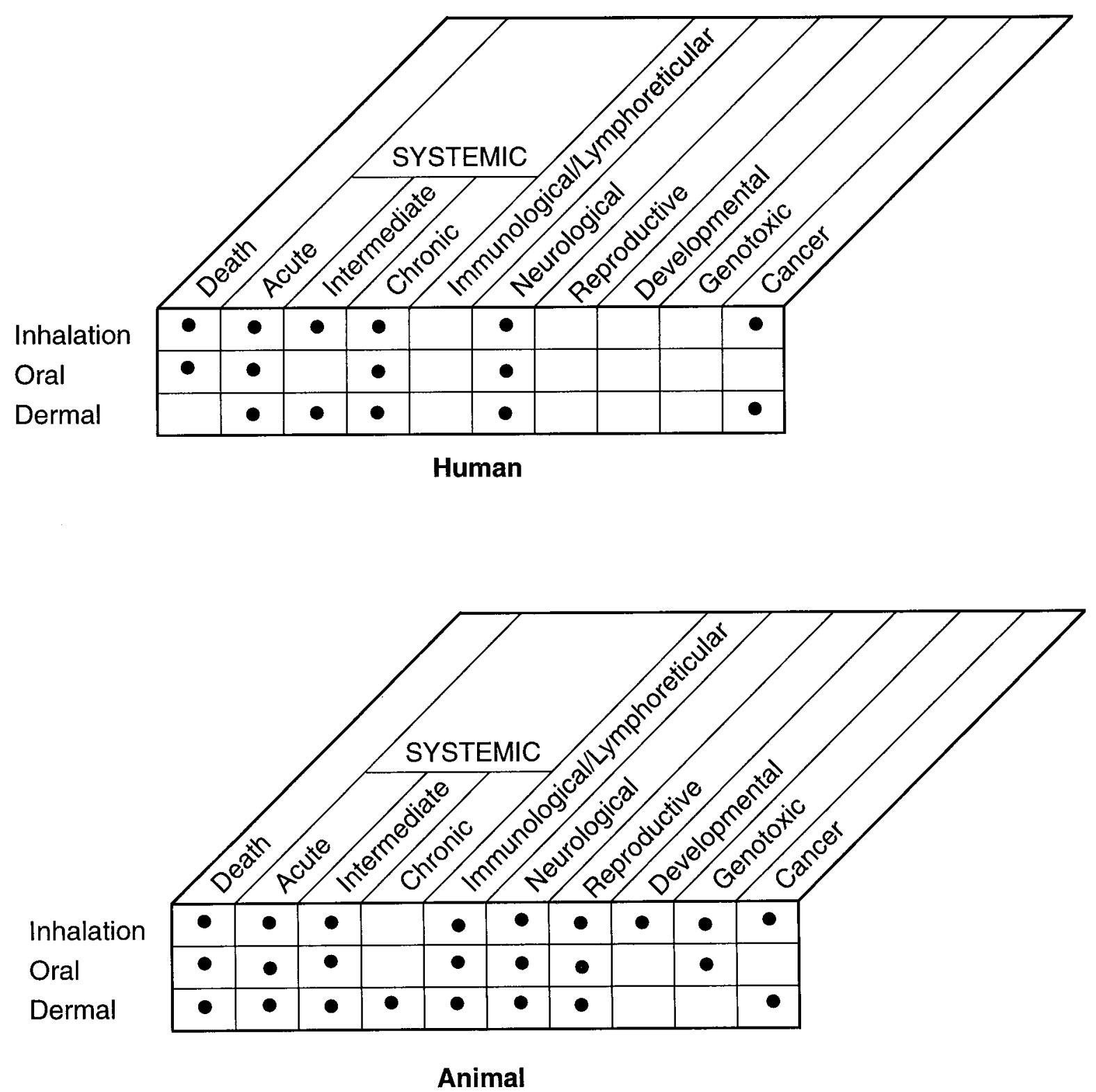

- Existing Studies 
Acute-Duration Exposure. There are many case studies that identify respiratory, neurological, and gastrointestinal effects as the primary effects in humans induced by acute exposures to fuel oils, particularly by the oral route (Akamaguna and Odita 1983; Aldy et al. 1978; Annobil 1983; Annobil and Ogunbiyi 1991; Mahdi 1988; Santhanakrishnan and Chithra 1978; St. John 1982; Subcommittee on Accidental Poisoning 1962) and, to a lesser extent, by inhalation exposure (Barrientos et al. 1977; Porter 1990). Dermal irritation is also well documented for both humans (Annobil 1988; Barrientos et al. 1977; Mosconi et al. 1988; Tagami and Ogino 1973) and animals (NTP/NIH 1986; Upreti et al. 1989) by the dermal route of exposure. A few case studies indicate that cardiovascular, hematological, and renal effects may occur in humans exposed to the vapors of JP-5 or diesel fuel (Barrientos et al. 1977; Porter 1990; Reidenberg et al. 1964). Renal toxicity may also occur following dermal contact with diesel fuel (Barrientos et al. 1977).

Dose-response data are largely lacking for the effects noted in both humans and animals. A few animal studies do contain dose-response data. Decreased food and water consumption, vasodilation, and neurological effects (reduced coordination, increased sensitivity to heat, changes in behavior, tremors) were found to be dose-dependent in mice exposed to diesel fuel no. 2 aerosol (Kainz and White 1984). Dose-response lethality data were found for inhalation exposures to diesel fuel aerosols (Dalbey and Lock 1983). In addition, there was a dose-response relationship following a single exposure to kerosene by oral gavage for death, unsteady gait, and drowsiness in rats (Muralidhara et al. 1982). However, the majority of the animal studies contain negative data (Beliles and Mecler 1983) that have not been verified by more than one study using the same fuel oil, species, and/or route of exposure, or the studies only tested one dose (Brown et al. 1974; Casaco et al. 1982; Garcia et al. 1988b; Goodwin et al. 1988; Nouri et al. 1983; Upreti et al. 1989). Acute oral $\mathrm{LD}_{50}$ data are available for kerosene in guinea pigs and rabbits (Deichmann et al. 1944). Additional data are needed regarding inhalation and dermal exposures in various species to verify the renal toxicity of fuel oils noted in a few individuals.

Intermediate-Duration Exposure. Only one case study was identified that described intermediate exposure in one individual who washed his hands with diesel fuel over several weeks (Crisp et al. 1979). The man exhibited epigastral pain, hematological effects, renal necrosis, edema of the scrotum and ankle, loin pains, thirst, and severe exhaustion. Effects resulting from inhalation versus dermal exposure could not be distinguished in this case. This is the only study found that identifies renal 
necrosis in humans. The renal necrosis described in this individual resembles a renal nephropathy that was previously found only in male rats from vapor inhalation and oral exposure to JP-5 and marine diesel fuel (Bruner 1984; Cowan and Jenkins 1981; Gaworski et al. 1984; Parker et al. 1981). There are data that show the $\alpha_{2 \mu}$-globulin protein, which is responsible for the necrosis in rats, may not exist in humans (Alden 1986). Also, data are needed to determine whether mechanisms of toxicity, other than those involving this protein, may exist for the induction of this lesion in both humans and rats. Also, data from well conducted studies are needed to determine which fuel oils induce this lesion in various species. Finally, in future cases of human exposure to fuel oils, signs of renal toxicity should be carefully monitored and results from histological examinations of renal tissue should be reported, if available.

Animal data are available for intermediate exposures by the inhalation and dermal routes of exposure. No animal data were located by the oral route. Most of these studies found no evidence of toxicity in any of the exposure conditions used in each (Carpenter et al. 1976; Bruner 1984; Lock et al. 1984; NTP/NIH 1986). However, the lack of toxicity in these studies has not been verified by more than one study using the same fuel oil, species, and/or route of exposure. In one aerosol inhalation study (Dalbey et al. 1987) there were positive findings for respiratory, hematological, and body weight effects at higher doses than those used in the studies by Carpenter et al. (vapor) (1979) and Lock et al. (aerosol) (1984). However, MRLs cannot be derived from these data because the Dalbey et al. study was not designed to test for a dose-response relationship, and therefore, the exact LOAEL(s) could not be determined for these effects. In another aerosol study with positive findings, only one concentration level was tested (Noa and Illnait 1987a).

One well-conducted study in mice describes effects (death, hepatic karyomegaly, and dermatitis) from dermal exposures to either JP-5 or marine diesel fuel (NTP/NIH 1986). Another study found dose-dependent increases in blood lactate and pyruvate levels and decreases in blood glucose levels in rats after inhalation of kerosene vapor (Starek and Vojtisek 1986). In a third study, dose-related increases in the relative weight of the right lobe of the lung were noted from inhalation of diesel fuel aerosol (Lock et al. 1984). None of these studies can be used for MRL derivation since the data were obtained by dermal exposures in one study and the biochemical and organ weight effects induced by inhalation of the fuel oils were not supported by pathological changes. More data are needed in animals, and especially in humans, for all routes of exposure to identify the primary toxic effects of fuel oils from intermediate exposures. 
Chronic-Duration Exposure and Cancer. Epidemiological data regarding respiratory and dermal effects from chronic exposures to fuel oils in humans are described elsewhere (see Epidemiological and Human Dosimetry Studies in this section). No other information is available for humans regarding chronic inhalation or oral exposures to fuel oils. A single animal study addressed carcinogenicity in animals via inhalation (Bruner 1984); however, the study did not adequately investigate the subject. Animal model data were available for the carcinogenic effects of chronic dermal exposure. It is apparent that chronic dermal application of fuel oils can induce tumorigenesis; however, both the mechanism of induction and the relevance of fuel oil tumor induction to humans are poorly defined. Equivocal data were available for the induction of hepatic tumors following dermal exposure. The data were so limited that the effect could not be evaluated. As such, further elucidation of the biochemical pathway, the relevance of dermal exposure to humans, and the incidence of induction of systemic tumorigenesis subsequent to dermal exposure would be of value.

The demonstration of renal toxicity in animal models has been considered significant due, at least in part, to case studies reporting such toxicity. However, data exist that appear to associate the renal toxicity with water loss due to skin lesions induced by chronic dermal application of fuel oils rather than systemic toxicity. Data that clarifies this effect would be of interest.

Genotoxicity. No definite conclusions can be reached from the in vitro human cell and whole animal genetic toxicology studies that have been performed with fuel oils. Data from bacterial in vitro assays are inconsistent (see Section 2.4, Genotoxic Effects). A study of the genotoxicity/mutagenicity of commercially available fuel oils and the various component petroleum streams used in their formulation would be of value.

Reproductive Toxicity. No information was found regarding reproductive toxicity in humans from inhalation, oral, or dermal exposures to fuel oils. There were no pathological changes on the reproductive organs of mice following chronic and/or intermediate dermal exposures to marine diesel fuel and JP-5 (NTP/NIH 1986) or in rats following intermediate inhalation of diesel fuel aerosol (Lock et al. 1984). Additional data are needed to identify the toxic potential of fuel oils on the reproductive system by all routes of exposure. 
Developmental Toxicity. No information was found regarding developmental toxicity in humans from inhalation, oral, or dermal exposures to fuel oils. Several studies were identified that tested developmental effects in animals, but only using the inhalation route of exposure. These studies found no developmental effects in the fetuses of female rats that had been exposed to heating oil, fuel oil UNSP, or diesel fuel vapors by inhalation during gestation days 6-15 (API 1979c, 19798; Beliles and Mecler 1983). Additional data are needed to identify the toxic potential of fuel oils regarding developmental effects by all routes of exposure.

Immunotoxicity. No information was found regarding immunotoxicity in humans from inhalation, oral, or dermal exposures to fuel oils. Only two animal studies were identified that tested immunological effects, both using mice. These studies identified cellular effects in the bone marrow, lymph nodes, and/or thymus and decreases in the relative weights of the lymph nodes and thymus from acute dermal exposures to kerosene (Upreti et al. 1989) and chronic dermal exposures to JP-5 and marine diesel fuel (NTP/NIH 1986). However, the toxicological significance of these effects on the immune system cannot be determined from these data. Additional data are needed to identify the toxic potential of fuel oils on the immune system by all routes of exposure and in different animal systems.

Neurotoxicity. Epidemiological data regarding neurological effects from chronic exposures to fuel oils in humans are described elsewhere (see Epidemiological and Human Dosimetry Studies in this section). Neurological effects from oral exposures are well documented in humans by case studies (Akamaguna and Odita 1983; Aldy et al. 1978; Coruh and Inal 1966; Dudin et al. 1991; Mahdi 1988; Majeed et al. 1981; Nouri and Al-Rahim 1970; Saksena 1969; Santhanakrishnan and Chithra 1978; St. John 1982; Subcommittee on Accidental Poisoning 1962). There is limited information in animals regarding neurotoxic effects following oral exposure (Muralidhara et al. 1982) or aspiration (Nouri et al. 1983).

Some information is available to identify neurological effects in humans from inhalation exposures. The available data indicate that coordination and concentration difficulties, headache, intoxication, and/or anorexia may be induced by inhalation of JP-5 vapor (Porter 1990), headaches may be induced by diesel fuel vapor (Reidenberg et al. 1964), and sensory impairment may be induced by deodorized kerosene vapor (Carpenter et al. 1976). In animals, a few studies were found that document neurological effects from inhalation of fuel oils. Acute inhalation of diesel fuel no. 2 vapor produced 
behavioral changes, tremors, ataxia, reduced coordination, and increased sensitivity to heat in mice (Kainz and White 1984). In another study (Lock et al. 1984), peak response time, based on the startle reflex assay, was increased in rats after intermediate inhalation of diesel fuel aerosol, but at higher exposure levels than those used in the Kainz study. These studies conflict with the negative neurotoxicity findings of a second intermediate-duration study in which diesel fuel aerosol was tested in rats at even higher concentrations (Dalbey et al. 1987). Thus, MRLs cannot be derived from these data.

Neurotoxicity in humans from dermal exposures has been reported in 1 case study in which anorexia was noted (Crisp et al. 1979); inhalation exposure may have also occurred. One animal study found no histopathological changes in the organs of the nervous system in mice following chronic and/or intermediate dermal exposures to marine diesel fuel and JP-5 (NTP/NIH 1986). However, increased response to tactile stimuli and hyperactivity occurred in mice from acute dermal exposures to kerosene (Upreti et al. 1989).

In summary, there is much information regarding the specific neurological effects that may be induced by oral exposures to kerosene in humans, but dose-response data are lacking for both animals and humans. More information is needed to identify the inhalation and dermal effects of fuel oils on the nervous system in both animals and humans.

Epidemiological and Human Dosimetry Studies. There were limited data that indicated that the use kerosene stoves in the home is not associated with increased respiratory illness (Azizi and Henry 1991; Tominaga and Itoh 1985), although chronic dermal exposure to kerosene has been related to Dermatosis (Jee et al. 1985). These studies are of limited use, however, since neither exposure nor duration of exposure were reported.

A number of effects have been associated with chronic exposure to jet fuel in factory workers (Knave et al. 1978). These effects included increases in the occurrence of neurasthenia (anxiety and/or mental depression, fatigue, depressed mood, lack of initiative, dizziness, palpitations, thoracic oppression, sleep disturbances) and eye irritation. Psychological tests found that attention and sensorimotor speed were impaired in exposed workers, but there were no effects on memory functions or manual dexterity. EEG tests suggested that there may have been instability in the thalamocortical system in the exposed group. However, the type of jet fuels were not noted nor was there a control for exposure to other 
compounds. Inhalation exposure is likely since jet fuel vapor was detected by the study authors; however, dermal and oral (i.e., eating with contaminated hands) exposures may also be possible.

Limited epidemiological information exists for carcinogenicity in humans following inhalation exposure to kerosene (vapor) (Chan et al. 1979) and other fuel oils such as diesel fuel (vapor) (Partanen et al. 1991). These studies either test kerosene exposure by use of kerosene stoves, and so are limited for the same reasons as the respiratory studies described above, or measure fuel oil exposures according to occupation. In the latter case, confounding from exposure to other chemicals, such as gasoline, exists. Both studies are limited since the duration and level of fuel oil exposure were not identified. Other available data are also reported to be inadequate to assess the carcinogenic potential of fuel oils (IARC 1989; Lam and Du 1988).

Exposures to fuel oils generally occur in the occupational setting. For this reason, it is difficult to control for confounding by other chemicals and to identify levels and durations of exposure to specific fuel oils. Exposure to kerosene may occur in the general population through the use of kerosene stoves and kerosene heaters. Aside from accidental poisonings in children, however, quantitative exposures to kerosene are difficult to determine because exposures are likely to be by inhalation or dermal routes. Also, there is much variability in the ventilation systems, cooking patterns, and smoking habits in individual homes of the general population, which makes determination of the level of exposure difficult. Finally, it is not possible to control for confounding by combustion products of kerosene when testing the effects of kerosene by the inhalation route. Therefore, if future studies are going to yield useful data concerning the toxicity of fuel oils in humans, rigorous controls must be planned for any confounding factors.

Biomarkers of Exposure and Effect. No biomarkers of exposure or effect were identified for fuel oils. Although no standard procedures exist for identifying and quantifying exposure to fuel oils in general, procedures do exist for identifying and quantifying the hydrocarbon components of fuel oils, specifically kerosene, in blood, urine, and stomach contents (Hara et al. 1988; Kimura et al. 1988, 1991; Yamaguchi et al. 1992). Another potential biomarker of exposure to kerosene is the distinct odor of kerosene on the breath or clothing (Annobil 1988; Tagami and Ogino 1973; Zucker et al. 1986). Studies delineating the metabolism and excretion of fuel oils are needed to identify potential biomarkers of exposure. 
Although not specific for kerosene, aminolevulinic acid (ALA) could potentially be used as an adjunct or supplemental biomarker for kerosene exposure. Kerosene may affect heme metabolism by decreasing the activities of enzymes in the heme biosynthetic pathway (hepatic $\delta$-ALA dehydratase and $\delta$-ALA synthetase) (Rao and Pandya 1980). Therefore, it may be possible that this effect would generate increased ALA in the urine of exposed individuals. Additional studies of acute, intermediate, and chronic exposure are needed to identify biomarkers of effects for specific target organs following exposure to fuel oils.

Absorption, Distribution, Metabolism, and Excretion. No quantitative data were located regarding the absorption, distribution, metabolism, or excretion of fuel oils following inhalation, oral, or dermal exposure in humans. No quantitative data were located regarding absorption and distribution of fuel oils following inhalation or dermal exposure in animals. Very limited data indicate that kerosene is poorly absorbed from the gastrointestinal tract and is distributed to various tissues, although accumulation is low (Mann et al. 1977). Another study in humans suggests that respiratory toxicity may result from both aspiration from vomiting and gastrointestinal absorption (Subcommittee on Accidental Poisoning 1962). However, aspiration is the primary concern following ingestion. There is also some suggestion from case studies that renal toxicity may occur in humans following exposure to diesel fuel vapor (Barrientos et al. 1977; Reidenberg et al 1964), although this possibility appears remote. Renal toxicity may occur following dermal contact with diesel fuel (Barrientos et al. 1977; Easely et al. 1982). No data were located regarding the metabolism or excretion of fuel oils following any of the three routes of exposure. Acute, intermediate, and chronic data are needed to assess the relative rates and extent of absorption, distribution, and excretion of fuel oils with respect to all three routes of exposure, as well as with respect to time or dose. Also, data are needed to determine whether dermal absorption of diesel fuel vapor can occur to induce renal toxicity.

Comparative Toxicokinetics. Limited data are available regarding comparative toxicokinetics.

The acute oral $\mathrm{LD}_{50}$ values in guinea pigs and rabbits for kerosene has been reported to be $16,320 \mathrm{mg} / \mathrm{kg}$ and 22,720 mg/kg, respectively (Deichmann et al. 1944). These data suggest that there may be species differences in the oral toxicity of kerosene; however, more data would be needed to thoroughly examine species variation in toxicokinetics. This information would be useful to identify similar target organs and to adequately assess which animals can serve as the best models for humans, as well as to define mechanisms of action. 
Methods for Reducing Toxic Effects. The mitigation procedures for fuel oils parallel those for hydrocarbon poisoning. Several treatments for hydrocarbon poisoning have been considered controversial: gastric decontamination, induced emesis versus gastric lavage, and administration of activated charcoal, cathartics, antibiotics, and corticosteroids. Most studies indicate that antibiotics and corticosteroids are not effective treatments for hydrocarbon-induced, and specifically kerosene-induced, pneumonitis (Brown et al. 1974; Goldfrank et al. 1990; Haddad and Winchester 1990; HSDB 1991; Steele et al. 1972; Wolfsdorf and Kundig 1974; Zieserl 1979). However, more research regarding the usefulness of cathartics and activated charcoal is needed. In addition, elucidating kerosene's toxicokinetic properties of absorption in the gastrointestinal tract would help determine whether gastric decontamination is worth the risk of pulmonary aspiration. Related to gastric decontamination is the question of whether induced emesis is safer than gastric lavage. Since there are presently no known antidotes for hydrocarbon poisoning, research in this area would be beneficial as well.

\subsubsection{On-going Studies}

No on-going studies evaluating the health effects or toxicokinetics of fuel oils were located. 


\section{CHEMICAL AND PHYSICAL INFORMATION}

\subsection{CHEMICAL IDENTITY}

Information regarding the chemical identity of fuel oils is located in Table 3-1. Information on the composition of selected fuel oils, specifically fuel oil no. 2 and kerosene, is presented in Table 3-2.

All of the fuel oil classes discussed in this Profile are refined from crude petroleum and may be categorized as either a distillate fuel or a residual fuel depending on the method of production. Fuel oils no. 1 and no. 2 are distillate fuels which consist of distilled process streams. Residual fuel oils such as fuel oil no. 4 are residues remaining after distillation or cracking, or blends of such residues with distillates (IARC 1989). Diesel fuels are approximately similar to fuel oils used for heating (fuel oils no. 1, no. 2, and no. 4). All fuel oils consist of complex mixtures of aliphatic and aromatic hydrocarbons. The aliphatic alkanes (paraffins) and cycloalkanes (naphthenes) are hydrogen saturated and compose approximately $80-90 \%$ of the fuel oils. Aromatics (e.g., benzene) and olefins (e.g., styrene and indene) compose $10-20 \%$ and $1 \%$, respectively, of the fuel oils. Fuel oil no. 1 (straightrun kerosene) is a light distillate which consists primarily of hydrocarbons in the $\mathrm{C}_{9}-\mathrm{C}_{16}$ range; fuel oil no. 2 is a heavier, usually blended, distillate with hydrocarbons in the $\mathrm{C}_{11}-\mathrm{C}_{20}$ range. Straight-run distillates may also be used to produce fuel oil no. 1 and diesel fuel oil no. 1. Diesel fuel no. 1 and no. 2 are similar in chemical composition to fuel oil no. 1 and fuel oil no. 2 , respectively, with the exception of the additives. Diesel fuels predominantly contain a mixture of $\mathrm{C}_{10}$ through $\mathrm{C}_{19}$ hydrocarbons, which include approximately $64 \%$ aliphatic hydrocarbons, $1-2 \%$ olefinic hydrocarbons, and 35\% aromatic hydrocarbons (Air Force 1989). Jet fuels are based primarily on straight-run kerosene, as well as additives. All of the above fuel oils contain less than 5\% polycyclic aromatic hydrocarbons. Fuel no. 4 (marine diesel fuel) is less volatile than diesel fuel no. 2 and may contain up to $15 \%$ residual process streams, in addition to more than $5 \%$ polycyclic aromatic hydrocarbons (IARC 1989). Residual fuel oils are generally more complex in composition and impurities than distillate fuel oils; therefore, a specific composition cannot be determined (Air Force 1989). Sulfur content in residual fuel oils has been reported to be from $0.18 \%$ to $4.36 \%$ by weight. 
TABLE 3-1. Chemical Identity of Fuel Oils

\begin{tabular}{|c|c|c|c|c|c|c|}
\hline Characteristic & Fuel oil no. 1 & Fuel oil no. 1-D & Fuel oil no. 2 & Fuel oil no. 2-D & Fuel oil no. 4 & Fuel oil UNSP \\
\hline Synonym(s) & $\begin{array}{l}\text { Kerosene; coal } \\
\text { oil; kerosine; } \\
\text { range oil; } \\
\text { straight run } \\
\text { kerosene; distil- } \\
\text { late fuel oils, } \\
\text { light; furnace } \\
\text { oil no. 1; } \\
\text { Deobase }{ }^{\mathbb{B}} \text {; JP-5; } \\
\text { JP-1; range oilab,c }\end{array}$ & $\begin{array}{l}\text { Diesel fuel; } \\
\text { diesel fuel oil no. 1; } \\
\text { diesel oil no. 1; no. } 1 \\
\text { diesel; diesel oil } \\
\text { (light); Arctic } \\
\text { diesel }^{\text {ld, }, e}\end{array}$ & $\begin{array}{l}\text { API no. } 2 \text { fuel } \\
\text { oil; gas oil; } \\
\text { home heating } \\
\text { oil no. } 2 \text {; } \\
\text { number } 2 \text { burner } \\
\text { oil; diesel } \\
\text { fuel; furnace oil } \\
\text { no. } 2^{\text {b }}\end{array}$ & $\begin{array}{l}\text { Diesel fuel; } \\
\text { diesel fuel oil } \\
\text { no. } 2 \text {; diesel } \\
\text { oil no. } 2 \text {; } \\
\text { no. } 2 \text { diesel; diesel } \\
\text { oil (medium) a,de }\end{array}$ & $\begin{array}{l}\text { Oil, fuel, no. 4; } \\
\text { residual fuel } \\
\text { oil no. } 4 \text {; no. } \\
4 \text { fuel oil; residual } \\
\text { fuel oil; marine } \\
\text { boiler fuel; marine } \\
\text { diesel fuel; diesel } \\
\text { fuel no. } 4 \text {; grade } 4^{\text {ad,e }}\end{array}$ & No data \\
\hline Registered trade name(s) & Deobase $\AA^{c}$ & No data & No data & No data & No data & No data \\
\hline Chemical formula ${ }^{\mathrm{r}}$ & No data & No data & No data & No data & No data & No data \\
\hline Chemical structure $^{\mathrm{f}}$ & No data & No data & No data & No data & No data & No data \\
\hline CAS registry & $8008-20-6^{6} / 70892-10-3^{e}$ & No data & $68476-30-2^{\mathrm{d}}$ & $68476-34-6^{a}$ & $68476-31-3^{b}$ & No data \\
\hline NIOSH RTECS & OA5500000 & No data & $\mathrm{HZ} 1800000^{\mathrm{d}}$ & No data & No data & LS $8950000^{d}$ \\
\hline EPA hazardous waste & No data & No data & No data & No data & No data & No data \\
\hline OHM/TADS & $7217063^{\mathrm{e}}$ & No data & No data & No data & $7217065^{e}$ & No data \\
\hline $\begin{array}{l}\text { DOT/UN/NA/IMCO } \\
\text { shipping }\end{array}$ & UN 1223; IMO 3.3 & No data & No data & No data & No data & No data \\
\hline HSDB & $632^{c}$ & No data & No data & No data & No data & No data \\
\hline $\mathrm{NCI}$ & No data & No data & C54795 & No data & No data & No data \\
\hline
\end{tabular}

${ }^{\mathrm{a}}$ IARC 1989

${ }^{\mathrm{b}} \mathrm{RTECS} 1991$

${ }^{\mathrm{c} H S D B} 1991$

dAir Force 1989

${ }^{\mathrm{e} O H M / T A D S} 1985$

${ }^{\mathrm{f}}$ Fuel oils are mixtures of various hydrocarbons designed to meet specifications set forth by the American Society for Testing and Materials (IARC 1989); therefore,

chemical structure, chemical formula and molecular weight cannot be determined.

${ }^{8}$ Sax and Lewis 1989

CAS = Chemical Abstracts Services; DOT/UN/NA/IMCO = Department of Transportation/United Nations/North America/International Maritime Dangerous Goods Code; EPA = Environmental Protection Agency; HSDB = Hazardous Substances Data Bank; NCI = National Cancer Institute; NIOSH = National Institute for Occupational Safety and Health; OHM/TADS = Oil and Hazardous Materials/Technical Assistance Data System; RTECS = Registry of Toxic Effects of Chemical Substances 
TABLE 3-2. Analysis of Fuel Oils ${ }^{a}$

\begin{tabular}{llc}
\hline & \multicolumn{2}{c}{ Volume \% } \\
\cline { 2 - 3 } Hydrocarbon type & Fuel oil no. 1 & Fuel oil no. 2 \\
\hline & & \\
Paraffins ( $n$ - and iso-) & 52.4 & 41.3 \\
Monocycloparaffins & 21.3 & 22.1 \\
Bicycloparaffins & 5.1 & 9.6 \\
Tricycloparaffins & 0.8 & 2.3 \\
Total saturated hydrocarbons & 79.7 & 75.3 \\
Olefins & No data & No data \\
Alkylbenzenes & 13.5 & 5.9 \\
Indans/tetralins & 3.3 & 4.1 \\
Dinaphthenobenzenes/indenes & 0.9 & 1.8 \\
Naphthalenes & 2.8 & 8.2 \\
Biphenyls/acenaphthenes & 0.4 & 2.6 \\
Fluorenes/acenaphthylenes & No data & 1.4 \\
Phenanthrenes & No data & 0.7 \\
Total aromatic hydrocarbons & 23.6 & 24.7 \\
\end{tabular}

${ }^{a}$ Derived from IARC 1989; provided by the American Petroleum Institute 
CHEMICAL AND PHYSICAL INFORMATION

\subsection{PHYSICAL AND CHEMICAL PROPERTIES}

Information regarding the physical and chemical properties of fuel oils is located in Table 3-3. 
TABLE 3-3. Physical and Chemical Properties of Fuel Oils ${ }^{a}$

\begin{tabular}{|c|c|c|c|c|c|c|}
\hline Characteristic & Fuel oil no. 1 & Fuel oil no. 1-D & Fuel oil no. 2 & Fuel oil no. 2-D & Fuel oil no. 4 & Fuel oil no. UNSP \\
\hline Molecular weight & No data & No data & No data & No data & No data & No data \\
\hline Color & $\begin{array}{l}\text { Pale yellow; } \\
\text { Colorless to brown }{ }^{\mathrm{c}, \mathrm{d}}\end{array}$ & Colorless to brown ${ }^{c}$ & Colorless to brown ${ }^{\mathrm{c}}$ & Colorless to brown ${ }^{c}$ & Colorless to brown ${ }^{\mathrm{c}}$ & Colorless to brown ${ }^{\mathrm{c}}$ \\
\hline Physical state & Liquid $^{c}$ & Liquid $^{\mathrm{c}}$ & Liquid $^{\mathbf{c}}$ & Liquid $^{c}$ & Liquid $^{\complement}$ & Liquid $^{c}$ \\
\hline Melting point & $-45.6^{\circ} \mathrm{C}^{\mathrm{d}}$ & $-34^{\circ} \mathrm{C}^{d}$ & $-29^{\circ} \mathrm{C}^{\mathrm{d}}$ & $18^{\circ} \mathrm{C}^{\mathrm{d}}$ & $-29^{\circ} \mathrm{C}$ to $-9^{\circ} \mathrm{C}^{\mathrm{d}} ;-46^{\circ} \mathrm{C}^{\mathrm{e}}$ & $-48^{\circ} \mathrm{C}-18^{\circ} \mathrm{C}^{\mathrm{c}}$ \\
\hline Boiling point & $\begin{array}{c}175-325^{\circ} \mathrm{C}^{\mathrm{b}} \\
200-260^{\circ} \mathrm{C}^{\mathrm{d}}\end{array}$ & $193-293^{\circ} \mathrm{C}^{\mathrm{d}}$ & $\begin{array}{l}160-360^{\circ} \mathrm{C}^{\mathrm{f}} \\
282-338^{\circ} \mathrm{C}^{d}\end{array}$ & $282-338^{\circ} \mathrm{C}^{\mathrm{d}}$ & $101-588^{\circ} \mathrm{C}^{\mathrm{d}}$ & $151->588^{\circ} \mathrm{C}^{\mathrm{c}}$ \\
\hline \multicolumn{7}{|l|}{ Density: } \\
\hline At $15^{\circ} \mathrm{C}$ & $0.810-0.9360 \mathrm{~g} / \mathrm{mL}^{\mathrm{c}}$ & $0.810-0.9360 \mathrm{~g} / \mathrm{mL}^{\mathrm{c}}$ & No data & No data & $0.810-0.9360 \mathrm{~g} / \mathrm{mL}^{\mathrm{c}}$ & No data \\
\hline At $20^{\circ} \mathrm{C}$ & $0.80 \mathrm{~g} / \mathrm{mL}^{\mathrm{e}, \mathrm{f}}$ & No data & $0.8700-0.9500^{c}$ & $0.8700-0.9500 \mathrm{~g} / \mathrm{mL}^{c}$ & $1 \mathrm{~g} / \mathrm{mL}^{\mathrm{e}}$ & No data \\
\hline Odor & Kerosene-like $^{c}$ & Kerosene-like $^{c}$ & Kerosene-like $^{c}$ & Kerosene-like $^{\mathfrak{c}}$ & Kerosene-like $^{c}$ & Kerosene-like $^{c}$ \\
\hline Odor threshold (ppm) & $0.082^{\mathrm{f}} ; 1^{\mathrm{d}}$ & $0.7^{\mathrm{d}}$ & No data & No data & $0.5^{\mathrm{c}}$ & No data \\
\hline \multicolumn{7}{|l|}{ Solubility } \\
\hline Water at $20^{\circ} \mathrm{C}$ & $\approx 5 \mathrm{mg} / \mathrm{L}^{\mathrm{c}}$ & $\Rightarrow 5 \mathrm{mg} / \mathrm{L}^{\mathrm{c}}$ & $\Rightarrow 5 \mathrm{mg} / \mathrm{L}^{\mathrm{c}}$ & $\approx 5 \mathrm{mg} / \mathrm{L}^{\mathrm{c}}$ & $\approx 5 \mathrm{mg} / \mathrm{L}^{\mathrm{c}}$ & $\approx 5 \mathrm{mg} / \mathrm{L}^{\mathrm{c}}$ \\
\hline Organic solvent(s) & $\begin{array}{l}\text { Miscible with other } \\
\text { petroleum } \\
\text { solvents }\end{array}$ & No data & No data & No data & No data & No data \\
\hline \multicolumn{7}{|l|}{ Partition coefficients: } \\
\hline $\log K_{o w}$ & $3.3-7.06^{\mathrm{c}}$ & $3.3-7.06^{c}$ & $3.3-7.06^{\mathrm{c}}$ & $3.3-7.06^{\mathrm{c}}$ & $3.3-7.06^{\mathrm{c}}$ & $3.3-7.06^{\mathrm{c}}$ \\
\hline $\log K_{o c}$ & $3.0-6.7^{c}$ & $3.0-6.7^{c}$ & $3.0-5.7^{\mathrm{c}}$ & $3.0-6.7^{\mathrm{c}}$ & $3.0-6.7^{\mathrm{c}}$ & $3.0-6.7^{c}$ \\
\hline Vapor pressure at $21^{\circ} \mathrm{C}$ & $2.12-26.4 \mathrm{mmHg}^{\mathrm{c}}$ & $2.12-26.4 \mathrm{mmHg}^{\mathrm{c}}$ & $2.12-26.4 \mathrm{mmHg}^{\mathrm{c}}$ & $2.12-26.4 \mathrm{mmHg}^{\mathrm{c}}$ & $2.12-26.4 \mathrm{mmHg}^{\mathrm{c}}$ & $2.12-26.4 \mathrm{mmHg}^{\mathrm{c}}$ \\
\hline \multicolumn{7}{|l|}{ Henry's law constant } \\
\hline Autoignition temperature & $229^{\circ} \mathrm{C}^{\mathrm{d}}$ & $177.0-329.0^{\circ} \mathrm{C}^{\mathrm{d}}$ & $257^{\circ} \mathrm{C}^{\mathrm{d}}$ & $254-285^{\circ} \mathrm{C}^{\mathrm{d}}$ & $263^{\circ} \mathrm{C}^{\mathrm{d}}$ & $\begin{array}{l}3.9 \times 10-1.4 \\
\text { No data }\end{array}$ \\
\hline Flashpoint (close cup) & $38^{\circ} \mathrm{C}^{\mathrm{c}, \mathrm{d}}$ & $38^{\circ} \mathrm{C}^{\mathrm{d}, f}$ & $58^{\circ} \mathrm{C}^{\mathrm{d}}$ & $52^{\circ} \mathrm{C}^{\mathrm{d}, \mathrm{f}}$ & $55^{\circ} \mathrm{C}^{\mathrm{f}}>>54^{\circ} \mathrm{C}^{\mathrm{d}}$ & No data \\
\hline \multicolumn{7}{|l|}{ Flammability limits } \\
\hline Conversion factors & No data & No data & No data & No data & No data & No data \\
\hline Explosive limits & $0.7 \%-5 \%^{\mathrm{b}}$ & No data & No data & No data & No data & No data \\
\hline
\end{tabular}

${ }^{a}$ Values listed are specifications required or general characteristics of each class of fuel oils.

bHSDB 1991

cAir Force 1989

'OHM/TADs 1985

${ }^{\mathrm{d}}$ Coast Guard 1985

IARC 1989 


\section{PRODUCTION, IMPORT, USE, AND DISPOSAL}

\subsection{PRODUCTION}

Fuel oils are produced from refined crude petroleum to meet specifications for a particular use (Air Force 1989; IARC 1989). These specifications are designated by the American Society for Testing and Materials (ASTM) (IARC 1989). Light fuel oils such as fuel oil no. 1 and no. 2 are manufactured from straight distillation of crude oil, or distillation of crude oil in the presence of a catalyst, and are chemically enhanced with antioxidants, dispersants, or corrosion inhibitors to meet the requirements for a specific application. Fuel oil no. 1 is a product of the straight-run distillation of crude petroleum (HSDB 1991). It consists of a mixture of petroleum hydrocarbons, chiefly of the methane series, which typically have from 10 to 16 carbon atoms per molecule (HSDB 1991; IARC 1989). The typical components of the end product of fuel oil no. 1 include paraffins ( $n-$, iso-, monocycle-, bicycle- and tricycle-), olefins, aromatics, and nitrogen and sulfur impurities (Air Force 1989; IARC 1989). Fuel oil no. 2 is manufactured from the blending of straight-run and catalytically cracked distillates (IARC 1989). The types of each stream and the proportioned amounts in the resulting fuel oil depend on the quality of the crude petroleum used for the distillations.

The distillate manufacturing processes of diesel fuel oils, such as fuel oil 1-D and fuel oil 2-D, are similar to those of fuel oil no. 1 and fuel oil no. 2, respectively (IARC 1989). Fuel oil no. 1-D is manufactured from a straight-run distillate process. Diesel fuel oil (1-D, 2-D) is defined as the fraction of petroleum that distills after kerosene (Air Force 1989). Fuel oil no. 2-D is also made from mixing of straight-run and catalytically cracked distillates (IARC 1989).

Residual fuel oils, such as fuel oil no. 4, are manufactured by the addition of blending stocks to distillation residues in order to meet viscosity specifications set by ASTM (IARC 1989). No data were located for the manufacturing process of fuel oil UNSP.

Although most facilities that refine crude petroleum in the United States produce a fuel oil. no. 1 fraction (HSDB 1991), only producers that market fuel oil no. 1 as an end product are listed as commercial manufacturers. These manufacturers include Claiborne Gasoline Company (Claiborne and Union Parish, Louisiana), Continental Oil Company (Acadia Parish, Louisiana), Sun Production 
Company (Starr County, Texas), Exxon Corporation (Pledger County, Texas), Atlantic Richfield Company (New York, New York), and Shell Oil Company (Houston, Texas) (HSDB 1991). Since fuel oils nos. 1, 1D, 2, 2-D, and 4, and fuel oil UNSP are not required to be reported under SARA Section 313, there are no data for these fuel oils in the 1990 Toxics Release Inventory (TRI90 1992).

Between 1970 and 1980, distillate fuel production, which includes the production of diesel fuels, increased steadily (IARC 1989). The total production volume in 1970 was 2,460,000 barrels, which increased to 3,167,000 barrels in 1979; however, between 1980 and 1986, distillate fuel production volumes fluctuated. After 1986, production volume of distillate fuels steadily increased to a maximum to 3,167,000 barrels in 1990 (API 1991).

Production of kerosene has steadily decreased since 1970 (API 1991). The supply of kerosene produced in 1970 was $95,600,000$ barrels. By 1975, production volume had dropped to 55,500,000 barrels. As of 1990, only 16,400,000 barrels of kerosene were produced. Production volumes of residual fuel oils showed a sharp increase between 1970 and 1980 and a sharp decline between 1980 and 1985 (IARC 1989). The total production volume of residual fuels in 1970 was 262,000,000 barrels, which increased to $456,000,000$ barrels in $1975,605,000,000$ barrels in 1980 , decreased to $321,000,000$ barrels in 1985, and increased slightly to 346,000,000 barrels in 1990 (API 1991). No data were located for production volumes of fuel oil UNSP.

\subsection{IMPORT/EXPORT}

Imports of distillate fuels have varied from year to year since the 1970s. Since 1975, imports of distillate fuel oils such as fuel oils no. 1 and no. 2 into the United States have been low compared to the amount of distillate fuel oils produced in the United States (API 1991). Annual import volumes fluctuated between 57,000,000 barrels in 1975 and 64,000,000 barrels in 1983 with a maximum of 91,250,000 barrels in 1977. From 1984 to 1989, imports of distillate fuels steadily increased from $99,439,000$ barrels in 1984 to $111,000,000$ barrels in 1989. Imports of kerosene fluctuated between 1975 and 1984 and then showed a steady increase from 1985 to 1987, attaining an annual maximum of 6,935,000 barrels in 1987. From 1988 to 1990, imports of kerosene deceased to a low of 1,825,000 barrels in 1990 (API 1991). 
4. PRODUCTION, IMPORT, USE, AND DISPOSAL

Imports of residual fuel oils such as fuel oil no. 4 generally decreased in the period between 1975 and 1989 (API 1991). In 1975, total imports of residual fuel oil were 447,000,000 barrels; however, imports gradually decreased over this 15 -year period to $230,000,000$ barrels in 1985 . No information was located regarding diesel fuel imports or unspecified fuel oil imports.

Exports of fuel oil no. 1 between 1972 and 1975 ranged from 14,000 tons in 1972 to 98,000 tons in 1975 (HSDB 1991). Exports of distillate fuel oils (which include fuel oil no. 1, fuel oil no. 2, diesel fuel, and fuel oil no. 4) increased almost 100-fold between 1975 and 1990 (API 1991). In 1975, a yearly average of 365,000 barrels of distillate fuel oils were exported out of the United States. By 1990, exports had increased to an average of 3,900,000 barrels. Little kerosene has been exported from the United States since the 1970s. In 1971, approximately 365,000 barrels were exported from the United States. The next 2 years for which export volumes were reported for kerosene were 1983 and 1984, when 365,000 barrels were exported each year. However, between 1986 and 1990, export volumes doubled from 730,000 barrels in 1986 to 1,820,000 barrels in 1990 (API 1991).

Comprehensive export data for kerosene prior to 1986 are not available. Kerosene exportation between 1987 and 1989 remained relatively constant with a yearly export average of approximately 547,500 barrels. However, by 1990, the annual export of kerosene was 2,190,000 barrels (API 1991), an increase of approximately $400 \%$. Residual fuel oil exports also increased, from a daily average of 15,000 barrels in 1975 to 215,000 barrels in 1989 (API 1990).

\subsection{USE}

Fuel oils have many commercial and military uses. Kerosene, a type of fuel oil no. 1, was chosen as a jet fuel during the development of the first jet engines, largely because gasoline was in short supply during wartime (IARC 1989). Fuels that are used currently in jet engines, such as JP-5, are very similar to kerosene, and are also included in the fuel oil no. 1 designation. At present, fuel oil no. 1 is used almost exclusively for domestic heating (Air Force 1989) with burners of the vaporizing type (IARC 1989); although fuel oil no. 1 was used as a jet fuel in the first jet engines (IARC 1989). In the petroleum industry, fuel oil no. 1 has also been used as an illuminating fuel, a motor fuel, and a heating fuel (HSDB 1991). In the pesticide industry, fuel oil no. 1 has been used as a vehicle for insecticides and fungicides (HSDB 1991). Fuel oil no. 1 is also used in kerosene lamps, flares, and stoves. Fuel oil no. 2 has been primarily used as a home heating oil and as an industrial heating oil 
4. PRODUCTION, IMPORT, USE, AND DISPOSAL

(IARC 1989). Fuel oil no. 2 is also reported to be used in atomizing-type burners (Air Force 1989; IARC 1989).

Diesel fuels are most commonly used as transportation fuels for diesel engines (Air Force 1989; IARC 1989). Fuel oil no. 1-D is used in engines that require frequent load and speed changes (Air Force 1989). Fuel oil no. 2-D has been used for engines that are in industrial or heavy mobile service (Air Force 1989). Diesel fuels have been used in stationary gas turbines to generate electric power (IARC 1989).

In electric utilities, residual fuel oils, such as no. 4, have been used to process steam for electric plants (IARC 1989). Fuel oil no. 4 has been used in commercial and industrial burner installations that are not equipped with preheating facilities (Air Force 1989). In other industries, such as the maritime industry, plants and factories, and the petroleum industry, residual fuel oils have been used for space and water heating, pipeline pumping, and gas compression, as well as in road oils, and in the manufacture.

U.S. consumption of distillate fuels used for heating decreased gradually between 1979 and 1983 (IARC 1989). The annual domestic demand for distillate fuel oils was approximately 1,214,355,000 barrels in 1979, decreasing to $981,850,000$ barrels in 1983. The U.S. demand for distillate fuels subsequently rose from 1984 to 1989, reaching an annual maximum of 1,248,700,000 barrels in 1989 (API 1991). The annual domestic demand for residual fuel oils also decreased between 1979 (1,034,800,000 barrels) and 1985 (475,600,000 barrels). After 1985, the demand varied from an annual average of 561,000,000 barrels in 1986 to 486,180,000 barrels in 1990 (API 1991). Finally, the average annual domestic demand for kerosene decreased from 68,990,000 barrels in 1979 to $16,790,000$ barrels in 1990 (API 1991).

\subsection{DISPOSAL}

Incineration is one method of disposal proposed for fuel oils no. 1 and no. 2 (OHM/TADS 1985). Other methods may be used to disposal of oil spills, including absorption (straw, polyurethane foam, activated carbon, and peat have been used as absorbents), gelling agents, combustion promoters, dispersants, and mechanical systems (OHM/TADS 1985). Biodegradation has also been suggested as a means of disposal for spills onto soil (OHM/TADS 1985). Hydrocarbon-degrading bacteria have been 
FUEL OILS

\section{PRODUCTION, IMPORT, USE, AND DISPOSAL}

shown to degrade petroleum products into smaller units and eventually into nonseparable particles

(Butt et al. 1988). Soil contaminated with fuel oil no. 1 was found to have a growth response of $10 \mathrm{E}+6$ colony forming units per $\mathrm{mL}$ in 7 out of 21 types of bacteria isolated for sample study (Butt et al. 1988). For more information on biodegradation, refer to Chapter 5. 



\section{POTENTIAL FOR HUMAN EXPOSURE}

\subsection{OVERVIEW}

Fuel oils are complex mixtures of aliphatic and aromatic hydrocarbons whose exposure potentials are based on the environmental fate of the individual components of the mixtures, particularly n-alkanes, branched alkanes, benzene and alkylbenzenes, naphthalenes, and PAHs.

Fuel oils may enter the water or soil environment as a result of spills during use or transportation or from leaking storage facilities or pipelines. The more volatile components of fuel oils (low molecular weight alkanes) will evaporate from the soil or water and enter the atmosphere where they will be degraded. The higher molecular weight aliphatic components $\left(>C_{20}\right)$ of fuel oils have very low water solubility and will not volatilize from soils or surface waters. Consequently, these heavier compounds will remain on the soil or in the water column where they may be adsorbed to particulate organic matter in water or soil and, in water, will settle to the sediment. They will eventually be biodegraded by microorganisms in the soils and sediments. The rate and extent of biodegradation are dependent on the ambient temperature, the presence of a sufficient number of microorganisms capable of metabolizing these hydrocarbons, the amount of aromatic species in a given oil, and the concentration of fuel oil. The aromatic components (benzene and alkylbenzenes) of fuel oils tend to partition into the polar phase of the environment and migrate through the soil to the groundwater. However, these components of fuel oil are also the most biodegradable.

The National Occupational Exposure Survey conducted by NIOSH between 1980 and 1983 estimated that 96,345 employees were exposed to fuel oil no. 2, 1,526 workers were exposed to fuel oil no. 4, and 1,076,518 employees (including 96,255 females) were exposed to kerosene in the workplace. Worker exposure was most likely in industries associated with machinery and special trade contractors. General population exposure is potentially the greatest for persons living near an area where fuel oils have been dumped and have migrated into the groundwater or when fuel oil vapor has penetrated the soil and may enter basements of buildings.

Fuel oil no. 1 has been identified in 23 of the 1,397 hazardous waste sites that have been proposed for inclusion on the EPA National Priorities List (NPL), and fuel oil no. 2 has been identified in at least 4 
of the NPL sites (HAZDAT 1991). The frequency of these sites within the United States can be seen in Figures 5-1 and 5-2.

\subsection{RELEASES TO THE ENVIRONMENT}

Releases of fuel oils are not required to be reported under SARA Section 313; consequently, there are no data for these compounds in the 1990 Toxics Release Inventory (TR190 1992).

\subsubsection{Air}

Fuel oils may be released to air as fugitive emissions from storage facilities or as a result of their use as fuel for combustion engines; in stoves, lamps, and furnaces; and as solvents. Atmospheric emissions of a fuel oil may be determined primarily by detection of its volatile hydrocarbon components. Atmospheric releases of fuel oil no. 1 (kerosene) may be expected as a result of its use as a solvent for insecticides and fungicides and by evaporation from open containers when used as a fuel. Indoors, unvented kerosene heaters are a source of sulfur dioxide, nitrogen dioxide, carbon monoxide, respirable suspended particulate matter, and acids in the vapor and particulate phase (Koutrakis et al. 1992; WHO 1991). In mobile homes in particular, use of kerosene heaters resulted in an increase in $\mathrm{CO}$ and airborne unburned kerosene fuel, an increase in mutagenicity of particle-phase organics, and little mutagenicity in the semivolatile organics (Mumford et al. 1991). Emission rates of carbon monoxide from unvented kerosene heaters in mobile homes were measured to be 10 to $272 \mu \mathrm{g} / \mathrm{kJ}$ for convective heaters, and 57 to $264 \mu \mathrm{g} / \mathrm{kJ}$ for radiant heaters; concentrations of CO averaged $7.4 \mathrm{ppm}$ with a peak of $11.5 \mathrm{ppm}$. Hydrocarbon emissions detected at fixed-roof fuel oil and low vapor pressure distillate storage tanks were only $8 \%$ of the emissions estimated for these facilities using the equations developed by the American Petroleum Institute (Wilson et al. 1978). The relationships have been quantified between the components in diesel fuel blends, the variables of the emissions when the fuel is burned, and their biological effects (Westerholm and Egerback 1991). Combustion from kerosene heaters contributes to the radon progeny particle size distribution in particles in the size range of 0.02-0.08 $\mu \mathrm{m}$ (Tu et al. 1991). Fuel oil combustion was determined to be a negligible contributor to atmospheric aerosol particles in the Toyama Prefecture of Japan (Toriyama et al. 1991). For residential oil furnaces, the mutagenicity of emissions in revertants per megajoule increases as particulate emissions increase, and emissions are up to 3 orders of magnitude 
FIGURE 5-1. FREQUENCY OF NPL SITES WITH FUEL OIL NO. 1 CONTAMINATION *

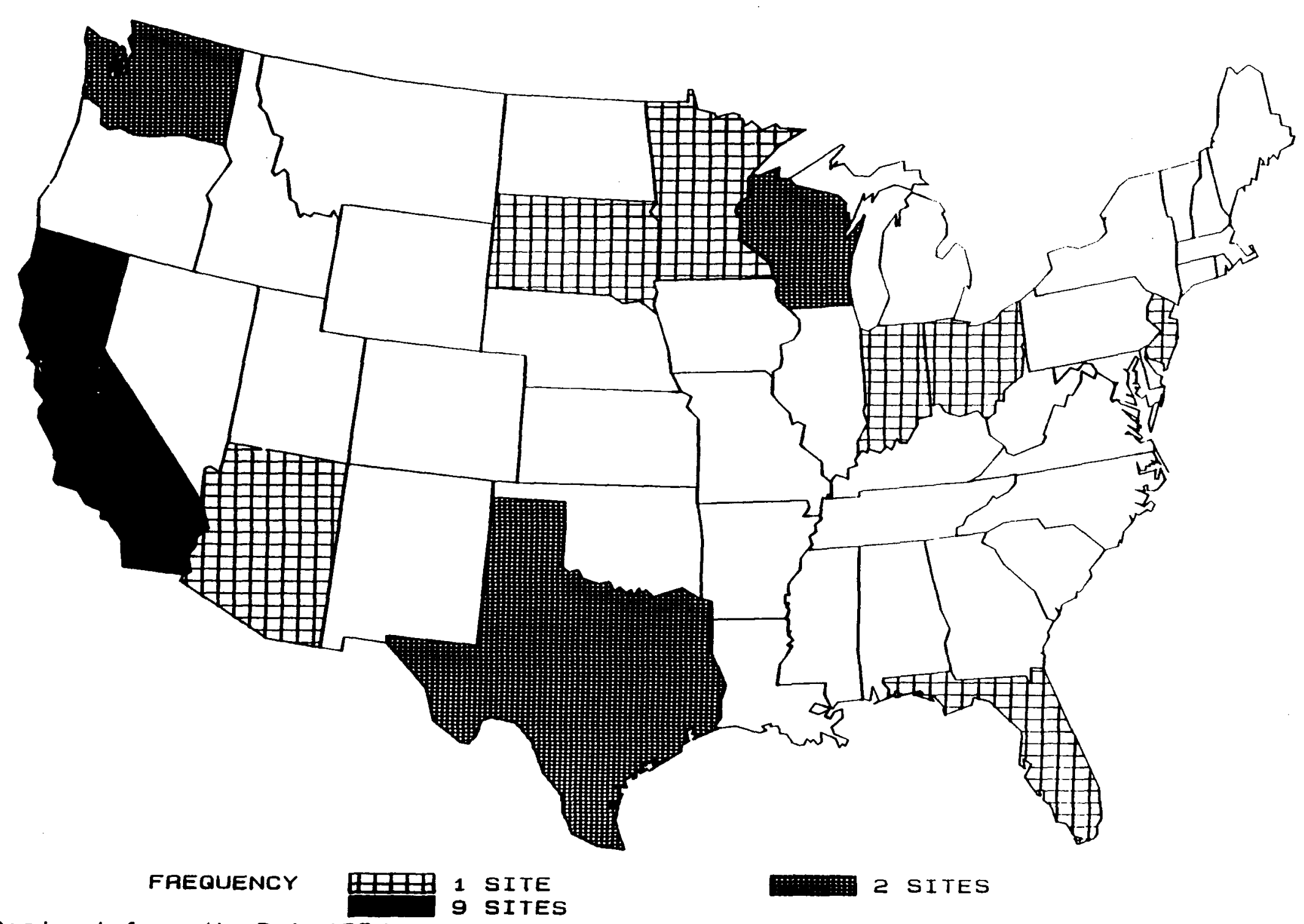


FIGURE 5-2. FREQUENCY OF NPL SITES WITH FUEL OIL NO. 2 CONTAMINATION *

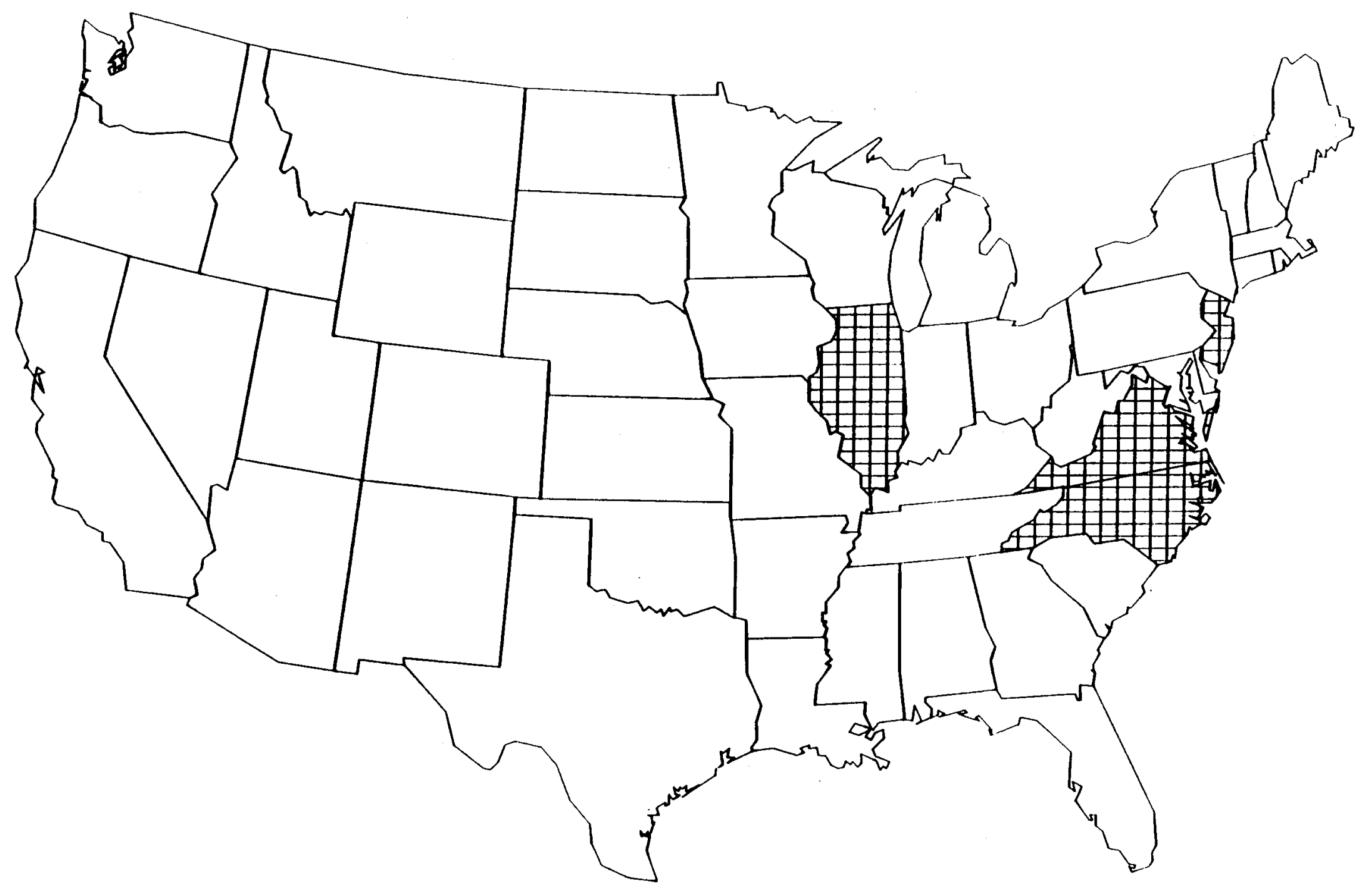

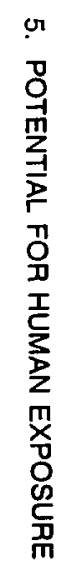

*Derived from HazDat 1994 FREQUENCY 1 SITE

$\vec{\nabla}$ 


\section{POTENTIAL FOR HUMAN EXPOSURE}

less mutagenic than wood smoke from conventional, uncontrolled woodstoves on a per unit of fuel energy value (EPA 1992).

Fuel oils are released to the atmosphere as vapor when used as smoke screens or fogs by the U.S. Army; concentrations may range from 13 to $2,000 \mathrm{mg} / \mathrm{m}^{3}$. Deposition of these particles to soil and water may result in fallout concentrations of 6-60 g/ $/ \mathrm{m}^{2}$ (Army 1986).

\subsubsection{Water}

Fuel oils may be released to surface waters as a result of fuel spills from transport vessels or from facilities located adjacent to surface waters, in runoff from industrial facilities where they are used as fuels or solvents, or from the intentional disposal of excess fuel oils down drains. Kerosene may enter surface and groundwater as a result of leaking aboveground and underground storage tanks, including those found at disposal facilities for spent nuclear fuel reprocessing operations (DOE 1989c). In 1988, a rupture of an aboveground storage tank outside of Pittsburgh, Pennsylvania, released more than 1,000,000 gallons of fuel oil no. 2 into the Monongahela and Ohio Rivers and disrupted local drinking water supplies (MacKerron and Kiesche 1988). Fuel oils may enter the marine ecosystem as a result of accidental spills from transport vessels, such as occurred when an oil barge released more than 650,000 liters of fuel oil no. 2 into Buzzards Bay, Massachusetts, in 1969 (EPA 1981); a second spill occurred in this area in 1974 (Bums and Teal 1979; Teal et al. 1978). Since 1915, ships and barges containing fuel or oil have sunk in Puget Sound or adjacent waters. Nine of these vessels have been classified as posing a potential hazard to human health or the aquatic environment because they have not been salvaged and contain large known reservoirs of fuel or oil, some which may have been discharged after sinking (EPA 1991d). Between 1986 and 1991, 4.6 million gallons of fuel oil no. 2 and 12.6 million gallons of fuel oil no. 6 were reported released into Newark Bay, New Jersey (Gunster et al 1993a). A significant source of petroleum to the bay appears to be municipal and industrial wastewater treatment facilities; over 600,000 gallons of petroleum products have been discharged since 1982 (Gunster et al 1993b). Approximately 170,000 gallons of diesel fuel arctic entered the marine ecosystem surrounding Arthur Harbor on the Antarctic Peninsula in 1989 when an Argentine resupply/tourist ship sank (Karl 1992), and in 1988, 230,000 gallons of Bunker C fuel oil was released from a barge off the Washington coast (Strand et al 1992). 


\section{POTENTIAL FOR HUMAN EXPOSURE}

Fuel oils that are accidentally released to inland waters are reported to the Emergency Response Notification System (ERNS). Total spill volumes of fuel oils released in 1991 were as follows (ERNS 1992):

\begin{tabular}{lrr} 
Fuel oil & No. of notifications & Gallons released \\
\cline { 2 - 3 } No. 1 & 8 & 43,190 \\
No. 1-D & 20 & 3,292 \\
No. 2 & 916 & $14,558,313$ \\
No. 2-D & 28 & 2,769 \\
No. 4 & 35 & 12,239
\end{tabular}

Storm runoff from an industrial site in Rhode Island used by oil distributors, scrap metal dealers, and metal finishers contained a hydrocarbon product resembling fuel oil no. 2. This product comprised $4 \%$ of the total petroleum hydrocarbons detected in the runoff, most of which were associated with crankcase oil (Latimer et al. 1990). Two freighters collided off the coast of South Africa in 1992; the freighter transporting 160 tons of marine fuel oil and 53 tons of gas oil sank(Molden 1992).

\subsubsection{Soil}

Fuel oils may be released to soil as a result of accidental spills (Strayer et al. 1983; Rosenblatt and Montemagno 1992) and leaking from underground storage tanks or pipelines. Hydrocarbon contamination (due to diesel fuel spillage and leakage related to ship and boating activities) has been measured in sediment samples in Arthur Harbor on the Antarctic Peninsula (Kennicutt et al. Also, approximately 200,000 gallons of liquid hydrocarbons were released into the underlying soil at a fuel-storage terminal in northern Virginia. The soil vapor above the resultant hydrocarbon plume and the groundwater below were analyzed for total and individual petroleum hydrocarbons (Mushrush et al. 1994). 


\subsection{ENVIRONMENTAL FATE}

\subsubsection{Transport and Partitioning}

The transport and dispersion of fuel oils are dependent on the water solubility and volatility of the aliphatic and aromatic hydrocarbon fractions. Lower molecular weight hydrocarbons such as $n$-alkanes may volatilize relatively quickly from both water and soil, while larger aliphatics (greater than $\mathrm{C}_{9}$ chain length) may be sorbed to organic particles in water or soil. Aromatic hydrocarbons will be dissolved in the aqueous phase in both soil and water and may undergo some volatilization.

Aerosol oil particles of SGF-1, a distillate oil chemically similar to fuel oil no. 2, used by the military to generate oil fogs (particle diameter of 0.5-1.2 $\mu \mathrm{m}$ ) may remain aloft for approximately 1 hour, may be transported 1-10 km (average of $5 \mathrm{~km}$ ) downwind during this time, and, with the exception of evaporative losses, will be deposited to soil or surface waters (Army 1986; Liss-Suter et al. 1978).

The solubility of fuel oil no. 2, particularly the alkane and isoprenoid fractions, in seawater is increased by the presence of fulvic acid, although the solubilities of phenanthrene or anthracene, both polycyclic aromatic hydrocarbons, are unaffected by the presence of humic materials (Boehm and Quinn 1973). Unfiltered Narragansett Bay water was able to dissolve 1,560 $\mu \mathrm{g} / \mathrm{L}$ of fuel oil no. 2, although removal of dissolved organic material from the water reduced the solubility by $33-60 \%$ (Boehm and Quinn 1974). The water-dissolved fraction of JP-5 fuel was stable for 24 days (Edgerton et al. 1987).

The microlayer at the air-water interface may be composed of different fuel oil hydrocarbons than the subsurface waters. When fuel oil no. 2 was added below the surface of a marine ecosystem, the microlayer was enriched for both saturated and aromatic hydrocarbons compared with the subsurface water, with a significantly greater proportion of total saturates compared with aromatics. The hydrocarbons in the microlayer were predominantly higher molecular weight hydrocarbons, greater than $\mathrm{C}_{18}$ for saturates and phenanthrene $\left(\mathrm{F}_{2}\right)$ for aromatics. This indicates that there is transport of all the hydrocarbons from the water column to the microlayer and weathering of the hydrocarbons by evaporation once in the microlayer (Gearing and Gearing 1982b). Weathering of fuel oil spills on water surfaces is dependent on the vapor pressures of the hydrocarbon components and can be correlated with the evaporation rates of the alkanes present in the fuel oil mixture. Components with 


\section{POTENTIAL FOR HUMAN EXPOSURE}

vapor pressures higher than n-octane rapidly evaporate from the surface of the fuel oil spill while those with vapor pressures lower than n-octadecane persist and may result in a more viscous residue, eventually retarding the evaporation of other components (Regnier and Scott 1975.

Addition of fuel oil no. 2 to a laboratory marine ecosystem showed that the insoluble, saturated hydrocarbons in the oil were slowly transported to the sediment on suspended particulate material. The particulate material contained $40-50 \%$ of the total amount of aliphatics added to the system and only $3-21 \%$ of the aromatic fraction (Oviatt et al. 1982). This indicates that most aromatic hydrocarbons are dissolved in the water (Coleman et al. 1984), whereas the aliphatic hydrocarbons are not (Gearing et al, 1980; Oviatt et al. 1982). In a similar experiment, when fuel oil no. 2 was added continuously to a marine ecosystem for 24 weeks, oil concentrations in the sediment remained low until 135 days after the additions began, but then increased dramatically to levels that were $9 \%$ of the total fuel oil added (108 g/tank) and $12 \%$ of the total fuel oil saturated hydrocarbons. The fuel oil concentrations in the sediment began to decrease quite rapidly after the maximum levels were reached. The highest sediment concentrations of saturated hydrocarbons $(106-527 \mu \mathrm{g} / \mathrm{g})$ were found in the surface flocculent layer, with concentrations decreasing with sediment depth from $22 \mu \mathrm{g} / \mathrm{g}$ to not detectable at 2-3 cm below the sediment surface. Fuel oil was being transported to the sediments adsorbed to suspended material in the water column with smaller particles $(<45 \mu \mathrm{m})$ containing 2.2 times more fuel oil than larger particles $(>45 \mu \mathrm{m})$ (Wade and Quinn 1980). Although biodegradation may remove many of the soluble, aromatic hydrocarbons, a residue of $10-20 \%$ of the total added oil, composed primarily of branched alkanes, cycloalkanes, and aromatics, may remain in the top $2 \mathrm{~cm}$ of the sediment for over a year (Gearing et al. 1980; Oviatt et al. 1982). A spill of fuel oil no. 2 to waters off Massachusetts showed that the oil was detected at distant monitoring locations 46 months after the spill, although the concentration in the sediments remained the greatest in the vicinity of the original spill. Oil continued to move in pulses from more polluted areas to less polluted areas for several years after the spill, with much of the oil being exhumed from sediments in the shallower waters as a result of storm action (EPA 1981). Movement of the oil to adjacent salt marshes indicated that the oil was sorbed to the anoxic sediments where it persisted (Bums and Teal 1979).

The partitioning of fuel oil no. 2 and kerosene into drinking water after 17 hours of incubation resulted in only $1.0 \%$ of the fuel oil and $0.7 \%$ of the kerosene being dissolved in the water. Further analysis of these fuels indicated that although each compound contains approximately $50 \%$ aliphatic 
5. POTENTIAL FOR HUMAN EXPOSURE

hydrocarbons (by weight percent), the water-soluble fractions contained primarily aromatic constituents (>93\%) including benzenes and naphthalenes as shown below (Coleman et al. 1984):

\section{Water-soluble fraction}

Whole product $^{*} \quad \underline{1 / 2 \text { hour }} \quad \underline{17 \text { hours }}$

Kerosene

Alkanes + cycloalkanes
Benzene + substituted
benzenes
Naphthalene + substituted
naphthalenes

Fuel oil no. 2
Alkanes + cycloalkanes
Benzene + substituted benzenes
Naphthalene + substituted naphthalenes

$\begin{array}{rrr}68.6 & 4.5 & 0.5 \\ 13.7 & 63.5 & 53.2 \\ 5.7 & 29.6 & 44.8 \\ 48.0 & <0.5 & <0.5 \\ 4.5 & 25.8 & 19.4 \\ 32.4 & 73.4 & 79.7\end{array}$

"Estimated weight percent

Partitioning of eight PAHs between four diesel fuels and water can be described using Raoult's law for activity coefficients (Lee et al. 1992).

A coal-liquid spill resulted in soil penetration to a depth of 8 meters; the soil was described as crushed stone mixed with glacial outwash sand and gravel. Soil columns collected 6 months after the spill were leached with a synthetic rain solution, and the leachates were collected and analyzed for total phenolics. Over the 12-month leaching period, the phenol fraction of the residual coal-derived fuel decreased by $98 \%$, primarily by dissolution. Groundwater monitoring down-gradient from the spill detected phenols even though the surface of the spill had been sealed to prevent leaching of watersoluble components by precipitation (Strayer et al. 1983).

The movement of a synthetic kerosene through soil was found to be dependent on the moisture content of the soil. The greater the moisture content (i.e., $4 \%$ compared with $0.8 \%$ ) of the soil, the less the adsorption of the more volatile components of the kerosene and the greater and the more rapid the penetration of the liquid component through the soil. Conversely, the upward mobility of both the liquid and vapor phases of kerosene through soil decreased with increased moisture content, and at field capacity, the upward capillary movement of the kerosene was completely inhibited (Acher et al. 


\section{POTENTIAL FOR HUMAN EXPOSURE}

1989). Desorption of a simulated kerosene applied to three types of soil, each with a moisture content at $70 \%$ of field capacity, was found to be complete after 30 days of exposure to the atmosphere with the slowest desorption from the soil having the greatest organic content (Yaron et al. 1989). Kerosene loss from a dune sand, a loamy sand, and a silty loam soil after 50 days showed that volatilization of all kerosene components was greatest from the dune sand and loamy sand soils. The larger pore size of these types of soil compared with the silty loam soil was thought to be the reason for the increased volatilization (Galin et al. 1990a). Movement of kerosene through three grades of sand was affected mainly by volatilization of the $\mathrm{C}_{9}-\mathrm{C}_{13}$ components with a subsequent increase in the viscosity of the remaining kerosene residue and a decrease in the infiltration rate through the inert porous media (Galin et al. 1990b).

The movement of kerosene through various types of soil over a 12 hour period was studied. Upward, downward, and lateral movement was greatest in soil of the mica/kaolinite type ( $11 \%$ clay content) 40, 102, and $45 \mathrm{~cm}$, respectively. Movement through soils that were primarily kaolinite (clay content of 26-52\%), regardless of the direction, ranged between 20 and $33 \mathrm{~cm}$ (EPA 1986b). Application of herbicides such as $S$-ethyl dibutylthiocarbamate to a field using kerosene or fuel oil no. 2 as solvents (up to a volume of 40 gallons per acre) increased the inactivation of the herbicide on soil, whereas acetone, benzene, or xylene did not. The accelerated inactivation possibly resulted from a change in surface tension that facilitated the volatilization of the herbicide from the soil (Danielson and Gentner 1970).

Studies on the permeability of compacted micaceous soil used as a potential liner for landfills found that the permeability of the soil to kerosene and diesel fuel was 3-4 orders of magnitude greater for kerosene and 1-1..5 orders greater for diesel fuel compared with water (EPA 1984).

Aquatic organisms are known to bioconcentrate hydrocarbons. Addition of fuel oil no. 2 (containing $38 \%$ aromatics) to a commercial shrimp pond gave an initial concentration of approximately $0.03 \mathrm{ppm}$ for total naphthalenes. The concentration of total naphthalenes (toxic components of fuel oil) peaked at approximately $0.3 \mathrm{ppm}$ in the water after 48 hours and slowly decreased to background levels after 38 days. Sediment concentrations of the total naphthalenes rose from 0 ppm at 6 hours after the application of the fuel oil to $2 \mathrm{ppm}$ at day 1, peaked at 14 days (9 ppm), and slowly declined to $1.5 \mathrm{ppm}$ at 296 days. The concentrations of total naphthalenes in shrimp, clams, and oysters peaked at 24,48 , and 72 hours, respectively, with maximum concentrations in each organism exceeding the 
naphthalene concentrations in the ambient water. When the contaminated organisms were placed in clean water after 38 days of exposure in the shrimp pond, depuration (to background levels) was complete after 10 days for shrimp and after 47 days for oysters, indicating that the concentrations in marine organisms are more closely correlated with water concentrations than with sediment concentrations of aromatic hydrocarbons (Cox et al. 1975). Lobsters exposed to a pulse of fuel oil no. 2, which simulated a small spill, were found to bioconcentrate PAHs (components of the fuel oil) in the hepatopancreas and muscle tissue within 34 days after exposure. PAH levels continued to be elevated at days 10 and 11; however, depuration to control levels occurred by day 20-21 (Williams et al. 1989, 1991).

Mussels (Mytilis edulis) exposed to a small spill (approximately 6,000 liters) of fuel oil no. 2 were followed for 86 days post-spill to assess the uptake and retention of the fuel oil components. Alkanes, cycloalkanes, and aromatic concentrations increased significantly in the mussel tissue the 1st day; however, by day 5 post-spill, the $n$-alkanes were barely detectable, and by day 21 , the concentration of the unresolved complex mixture of alkanes-cycloalkanes was $30 \%$ of the day 1 concentrations. Concentrations of lower molecular weight aromatics (e.g., naphthalenes) decreased before the higher molecular weight aromatics (e.g., phenanthrenes). The biological half-lives of some fuel oil no. 2

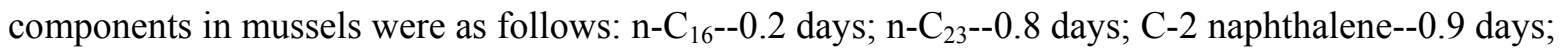
C-3 naphthalene--1.5 days; phenanthrene--2.1 days; and unresolved complex mixture--2.8-3.9 days (Farrington et al. 1982a). Similar results were found in sea scallops (Aequipecten irrudians), which showed a gradual depletion of straight chain and branched chain hydrocarbons after exposure to fuel oil no. 2. However, the more toxic aromatic hydrocarbons were retained in scallop tissue for several months after exposure (Blumer et al. 1970). Sea mullet exposed to $5 \mathrm{ppm}$ kerosene in sea water had a kerosene-like taint after 24 hours of exposure. In another study, oysters exposed to fuel oil no. 2 at $400 \mathrm{ppm}$ for 8 hours accumulated $312 \mathrm{ppm}$ of PAHs and 8.7-21.8 ppm of naphthalenes in their tissues; however, over $90 \%$ of the $n$-paraffins were released within 24 hours when the oysters were returned to oil-free water. Depuration of the aromatic hydrocarbons was much slower. When shrimp, clams, and fish were exposed to the water-soluble fraction of fuel oil no. 2, shrimp rapidly accumulated total naphthalenes for an hour then released them, clams accumulated the naphthalenes at a slower but constant rate for 24 hours, and the fish accumulated the naphthalenes very rapidly during 2 hours of exposure; all three species rapidly released the accumulated naphthalenes when placed in oil-free water with low or undetectable levels at 14 days (Anderson and Neff 1977). 


\subsubsection{Transformation and Degradation}

The fate of four petroleum mixtures has been evaluated using three approaches-evaluating the fate of (1) indicator chemicals, (2) the mixture of the whole with a surrogate, and (3) the hydrocarbon mixture as a whole. The four mixtures were crude oil, JP-5, mineral spirits, and diesel. The choice of approach requires the consideration of availability and quality of data on the mixture, the mobility and toxicity of the mixture, and the availability of site data (Custance et al. 1992).

\subsubsection{Air}

No studies on the transformation or degradation of fuel oils in the atmosphere were located. However, volatile components of fuel oils such as benzene, toluene, xylenes, and PAHs may be expected to enter the atmosphere where they are subjected to degradation processes. Further information on the atmospheric degradation of selected volatile hydrocarbons are presented in the ATSDR toxicological profiles for these chemicals (ATSDR 1989, 1990a, 1991a, 1991b).

\subsubsection{Water}

The photooxidation of fuel oil no. 2 in water is quite rapid in sunlight. The rate is four times that of coal liquids, producing two photooxidant pools with reaction rate constants of 0.58 /minute and $0.037 /$ minute. The faster reacting photooxidant was tentatively identified as hydrogen peroxide and the slower reacting pool as a mixture of indane and tetralin hydroperoxides (Herbes and Whitley 1983). Two mechanisms appear to result in the formation of the peroxides: (1) reaction of free radicals with triplet oxygen to produce peroxy radicals and hydroperoxides, which in turn continue the chain reaction; and (2) formation of hydroperoxides by direct addition of excited singlet oxygen to reactive acceptors in the oil such as olefins. These reactions reached a maximum after approximately 90 hours of irradiation. Other photodegradation products of fuel oil exposed to ultraviolet radiation include phenols (linear increase in concentration during 165 hours of irradiation), naphthols, and carboxylic acids (Larson et al. 1977, 1979).

Biodegradation of fuel oils is dependent on the degradation of the various hydrocarbon fractions present in the oils. The relative order for biodegradation of the hydrocarbon fractions from the mostreadily degraded to the least is as follows: $n$-alkanes, iso-alkanes, olefins, low molecular weight 


\section{POTENTIAL FOR HUMAN EXPOSURE}

aromatics (at low, non-toxic concentrations), PAHs, and cycloalkanes (Bartha and Atlas 1977; Edgerton et al. 1987).

Water and sediment samples taken from Muddy Creek in the Rhode River of Chesapeake Bay were inoculated with $0.1 \%$ (volume/volume) of fuel oil no. 2 and incubated for 28 days. Growth of aerobic bacteria and fungi was enhanced by the addition of the fuel oil, although growth of yeast was inhibited (Walker and Colwell 1975). A mixed culture of estuarine bacteria was observed to degrade fuel oil no. 2 by 55\% in 28 days with the primary microorganisms being Bacillus and Pseudomonas.

Degradation of aromatic components was significantly greater than the n-alkanes (Walker et al. 1976).

Microorganisms readily able to degrade hydrocarbons were found in the Neuse River estuary in North Carolina. Although the estuary was relatively free of hydrocarbon contamination, $63 \%$ of the bacteria and $71 \%$ of the fungi isolated from surface water samples were able to utilize kerosene as the sole carbon source (Buckley et al. 1976). Weathered kerosene (volatile components were allowed to escape prior to testing) was spiked with four marker hydrocarbons, and the degradation of the markers was monitored. All four markers were degraded by a water-sediment mixture from an "oiled arm" of an Ohio lake; more rapid degradation was associated with mixtures taken from relatively polluted areas of the lake (Cooney et al. 1985), suggesting that biodegradation is enhanced by the presence of acclimated microorganisms. Marine bacteria capable of using fuel oil nos. 1, 2, and 4 were isolated from Narragansett Bay, Rhode Island. Most of the bacteria were found to utilize the aliphatic components of the fuel oils, primarily hexadecane, while only a few of the bacteria were able to degrade the aromatic components. The bacteria were able to degrade the hexadecane at $0^{\circ} \mathrm{C}$ but degradation was significantly improved when the incubation temperature was increased to $8^{\circ} \mathrm{C}$ and $16^{\circ} \mathrm{C}$; similar but not such dramatic effects were seen in the degradation of naphthalene with increased temperature (Cundell and Traxler 1976).

The degradation of hydrocarbons fractions of fuel oil no. 2 was studied using a marine microcosm under different temperature, light, and biological activity regimes. Initial fuel oil concentrations ranging from 151 to $189 \mu \mathrm{g} / \mathrm{L}$ were found to decrease exponentially under all regimes, with temperature having the greatest effect on the half-lives of the component hydrocarbons. In cold water $\left(0-2{ }^{\circ} \mathrm{C}\right)$, the half-life for total hydrocarbons was greater than 10 days, while in warmer water $\left(17-21^{\circ} \mathrm{C}\right)$ the half-life decreased to approximately 30 hours. In cold water, saturated hydrocarbons were removed more rapidly than aromatic hydrocarbons, but in warmer water the half-lives of the 


\section{POTENTIAL FOR HUMAN EXPOSURE}

fractions were similar. For the saturated hydrocarbons, the half-life increased with increasing molecular weight or with branched or cyclic moieties, i.e., small $n$-alkanes (C-12) had the shortest half-life in both warm and cold water. Poisoning the microcosm to eliminate biodegradation had no effect on the degradation of saturated hydrocarbons other than $n$-alkanes, but decreased the rate of aromatic degradation by half, indicating that biodegradation is a significant removal process for both $n$-alkanes and aromatics. Saturated hydrocarbons other than $n$-alkanes are most likely to be removed by adsorption to particulate material in the water followed by sedimentation or the formation of a micelle, which may rise to the surface of the water and evaporate. In cold water, aromatics are most likely to be removed by volatilization, whereas in warmer water, biodegradation is the more important removal process. Photooxidation did not appear to be a significant removal process for either hydrocarbon fraction (Gearing and Gearing 1982a).

Fuel oil no. 2 (average water column concentration $182 \mu \mathrm{g} / \mathrm{L}$ ) was added to the Marine Ecosystems Research Laboratory (MERL) system for 5.5 months with a 2-month recovery period. Hydrocarbon concentrations were then measured in the sediment and benthic organisms (Glyceru americana, a carnivorous polychaete, and Crepidulu sp., the common slipper shell). The alkane-cycloalkane and aromatic fractions in the benthic organisms were suggestive of partially degraded fuel oil no. 2, and for the aromatic hydrocarbons, were at least an order of magnitude greater than in the control tank. Phenanthrenes, although present at lower concentrations in fuel oil no. 2 than naphthalenes, were present at greater concentrations in the benthic organisms, suggesting that there is a bioaccumulation potential for these compounds. Organism-specific differences show that organisms in close contact with the sediment had relatively higher concentrations of lower molecular weight naphthalenes, as these compounds are more readily retained in the sediment than the water column. Similarly, organisms that live in the water column contained fewer naphthalenes. These results indicate that fuel oil no. 2 degradation products are taken up by benthic organisms, that they may be selectively retained in both sediments and aquatic organisms, and may thus enter the food chain (Farrington et al. 1982b). After 3 months of exposure in a marine intertidal zone, the concentration of fuel oil no. 2 in the mean lower low water (MLLW) area and 2 feet above the MLLW area had decreased by $30 \%$ and 53\%, respectively (NOAA 1982). Straight-chain alkanes degrade more readily than branched alkanes with a ratio of 1.67 ( $n-\mathrm{C}_{17} /$ pristine), although this ratio will decrease as biodegradation of the n-alkanes progresses (Blumer et al. 1970; EPA 1981). Following spills of fuel oil no. 2 into Buzzards Bay, Massachusetts, the concentrations of aromatic hydrocarbons decreased by a factor of 5 within 6 months of the spills with lighter molecular weight compounds decreasing at a faster rate than the 


\section{POTENTIAL FOR HUMAN EXPOSURE}

heavier molecular weight compounds. Aromatics such as naphthalenes and phenanthrenes were still present in the marsh sediments at concentrations above background, 6.5 years after the spills (Teal et al. 1978). The oil was sorbed to the anoxic marsh sediments, although biodegradation and dissipation resulted in the decrease of $n$ - and branched alkanes from the surface sediment within 4 years. Even 8 years after the spill, some sediments contained over 1,200 ppm petroleum hydrocarbons, with naphthalene and heavier aromatics expected to persist for many more years (Burns and Teal 1979). Twenty years after the spill, some sediments contained trace amounts of biodegraded fuel oil (Teal et al. 1992).

Petroleum residues were measured in the northern Arabian Sea to assess the contamination following the oil spills resulting from the Gulf War in 1991. Little change in variables related to oil pollution took place in any compartment of the marine environment-water, plankton, fish, and sediments (Sengupta et al. 1993).

Groundwater contamination by fuel oil no. 2 and gasoline was detected in wells of a residential area of Rhode Island. While the total hydrocarbon content of the groundwater samples taken at one particular well decreased from 2,350 to $1,580 \mu \mathrm{g} / \mathrm{L}$ over a 19-month period and the percentage of hydrocarbons associated with gasoline also decreased from $58 \%$ to $22 \%$, the percentage of hydrocarbons attributable to fuel oil no. 2 increased from $42 \%$ to $78 \%$ These data indicate that the gasoline hydrocarbons are more readily removed compared with the higher molecular weight hydrocarbons from fuel oils (Zheng and Quinn 1988).

\subsubsection{Soil}

Microbial degradation in soils is greatest for the aromatic fractions of fuel oils, while the biodegradation of the aliphatic hydrocarbons decreases with increasing carbon chain length. Evaporation is the primary fate process for these aliphatics (Air Force 1989).

A single application of approximately 21,14 , or $13 \mathrm{~g} / \mathrm{kg}$ soil of home heating oil no. 2 to outdoor plots in Pennsylvania (silt loam), Oklahoma (sandy loam), and Texas (clay loam) was degraded by $86 \%, 90 \%$, and $86 \%$, respectively, after 1 year, with degradation being independent of temperature differences. Very little oil was present in runoff and leachate water from the sites; however, analysis of ether-extractable compounds in the leachate at the plots suggested that incomplete degradation of 


\section{POTENTIAL FOR HUMAN EXPOSURE}

some individual components in the oils was taking place. Of the six oils tested, no. 2 home heating oil resulted in the largest increase in the number of hydrocarbon-utilizing microorganisms in the plots, and it was the most lethal to soil nematodes (Raymond et al. 1975, 1976). The degradation of kerosene in soil was further studied when a pipeline ruptured and showered a wheat field with kerosene. After 6 months, the kerosene concentration began to decrease in the upper $30 \mathrm{~cm}$ of soil (with $\mathrm{C} 13-\mathrm{Cl} 7 n$-alkanes disappearing more rapidly compared with $\mathrm{C} 10-\mathrm{C} 12 n$-alkanes) and at 21 months was reduced to trace amounts; however, kerosene was still detected at soil depths of $30-45+\mathrm{cm}$. The authors interpreted this as indicating reduced aerobic biodegradation at this depth, especially since the compounds disappeared in the order of their preferential microbial utilization. Seed germination studies using the contaminated soil 1 year after the spill $(0.34 \%$ kerosene concentrations) showed that kerosene delayed seed germination but that the percent germination was unaffected (Dibble and Bartha 1979). Landfarming techniques (tillage of soil using agricultural implements), developed in the Netherlands to enhance biodegradation of contaminants, demonstrated that after one growing season, kerosene (initial concentration of 1,000-10,000 mg/kg dry matter) was significantly degraded (final concentration of $500 \mathrm{mg} / \mathrm{kg}$ dry matter) in $40 \mathrm{~cm}$ of soil (Soczo and Staps 1988).

Application of diesel oil or fuel oil (type unspecified) to soil at $1 \%$ or $10 \%$ showed that, based on carbon dioxide evolution, degradation did occur. After 12 weeks, the applications of $1 \%$ diesel oil and fuel oil were degraded by $45 \%$ and $23 \%$, respectively, whereas the $10 \%$ applications showed that only $10 \%$ of each oil was degraded in this time. Carbon dioxide evolution did not increase with increasing time, indicating that microbial populations were not increasing (Flowers et al. 1984). Addition of nitrogen (as urea) to the soil increases the biodegradation potential of diesel oil and kerosene; however, both oils were found to inhibit the urease activity of soil microbes by up to $47 \%$ and $35 \%$, respectively, suggesting that sources of nitrogen other than urea should be used (Frankenberger 1988).

The bacterial species in the genera Achromobacter, Pseudomonas, and Alcaligenes, isolated from the soil of an active oil field in Louisiana, were able to aerobically degrade kerosene as determined by oxygen uptake (Cooper and Hedrick 1976). Soil Pseudomonas were able to degrade kerosene to a greater extent than were Enterobacterwith stationary phases occurring after 10 days and 8 days, respectively (Butt et al. 1988). Seven years after the dumping of sludge containing kerosene at two sites, vegetation at each site showed little recovery. Although the bacterial biomass had declined at 
both sites, microbial activity, as determined by carbon dioxide evolution, was greater at the site that had received more precipitation and had the more aerated soil (Jones 1977).

Oxidation of kerosene (fuel oil no. 1) and diesel fuel (fuel oil no. 2) by soil microbes, as determined by dehydrogenase activity, increased with increasing loading rates for both fuel oils (up to $60 \% \mathrm{w} / \mathrm{w}$ oil/dry soil) for up to 7 days of incubation but decreased thereafter. Dehydrogenase activity in soil treated with diesel fuel was almost twice that of soils treated with kerosene (56 and $32 \mathrm{pg}$ formazan/g soil/24 hours, respectively) (Frankenberger and Johanson 1982).

Biodegradation of fuel oils in sediments is inhibited under anaerobic conditions (Bartha and Atlas 1977). Under anaerobic conditions, some soil microorganisms are capable of nitrate reduction using fuel oils as the carbon source, although nitrite may be an unwanted by-product. However, the addition of a small amount of oxygen ( 0.2 volume percent oxygen) to the medium can accelerate the degradation of the oil without the concomitant production of nitrite (Riss and Schweisfurth 1987). Thirteen months after the spill in 1988 of 230,000 gallons of Bunker C fuel oil off the Washington coast, only trace levels of oil were found in surface sediments (Strand et al. 1992).

\subsection{LEVELS MONITORED OR ESTIMATED IN THE ENVIRONMENT}

\subsubsection{Air}

No data were located on concentrations of fuel oils in workplace or ambient air.

\subsubsection{Water}

Analysis of drinking water from Cincinnati, Ohio, in February of 1980, showed the presence of numerous hydrocarbons associated with petroleum products at concentrations ranging from $5 \mathrm{ng} / \mathrm{L}$, for naphthalene to $843 \mathrm{ng} / \mathrm{L}$ for benzene (Coleman et al. 1984).

Kerosene was detected at monitoring wells (concentrations were not reported) located at the perimeter of a spent nuclear fuel processing plant in western New York State in 1983. The kerosene had been used as an extractant during plant operations from 1966 to 1972 (DOE 1989c). 
Groundwater samples taken from monitoring wells at gasoline stations undergoing remediation in Florida contained both kerosene and fuel oil at unspecified concentrations (Thomas and Delfino 1991a).

Fuel oil no. 2 was detected along with gasoline in groundwater wells in Tiverton, Rhode Island. Over a 19-month period, total hydrocarbon concentrations in the water from one well decreased from 2,350 to $1,580 \mu \mathrm{g} / \mathrm{L}$ during which time the proportion of hydrocarbons associated with fuel oil increased from $42 \%(987 \mu \mathrm{g} / \mathrm{L})$ to $78 \%(1,232 \mu \mathrm{g} / \mathrm{L})$, probably as a result of the more rapid degradation of the gasoline (Zheng and Quinn 1988).

Kerosene was detected in a whole water sample from monitoring wells for municipal intakes in California in the $\mu \mathrm{g} / \mathrm{L}$ range (STORET 1992).

Background concentrations of total hydrocarbons in Narragansett Bay, Rhode Island, ranged from 0.7 to $4.0 \mu \mathrm{g} / \mathrm{L}$ (Gearing and Gearing 1982a).

\subsubsection{Soil}

No data were located on levels of fuel oils detected in soils.

\subsubsection{Other Environmental Media}

Shellfish taken from unpolluted waters have been found to contain between 1 and $12 \mu \mathrm{g} / \mathrm{g}$ wet weight of total hydrocarbons while fish have been found to contain between 4 and $14 \mu \mathrm{g} / \mathrm{g}$ total hydrocarbons (steam distillables) (Connell and Miller 1980). Following a spill of fuel oil no. 2 in the Cape Cod Canal in Massachusetts, edible mussels (Mytilus edulis) contained average concentrations of various hydrocarbons up to $4.69 \mu \mathrm{g} / \mathrm{g}$ dry weight on day 1 of the spill; background hydrocarbon levels in the controls did not exceed $0.29 \mu \mathrm{g} / \mathrm{g}$ (Farrington et al. 1982a). Limpets in close proximity to onshore accumulations of hydrocarbon contaminants caused by diesel fuel spillage and leakage related to ship and boating activities in Arthur Harbor on the Antarctic Peninsula have incorporated PAHs into their tissues (Kennicutt et al. 1992b). However, 2 years after the release of 150,000 gallons of diesel fuel in the harbor, little spill-related contamination could be detected in intertidal limpets (Kennicutt and Sweet 1992). 


\section{POTENTIAL FOR HUMAN EXPOSURE}

No data were located that discussed concentrations of fuel oils in other environmental media such as food or terrestrial plants and animals.

\subsection{GENERAL POPULATION AND OCCUPATIONAL EXPOSURE}

The National Occupational Exposure Survey, conducted by NIOSH between 1980 and 1983, estimated that 96,345 employees (including 590 females) were exposed to fuel oil no. 2, 1,526 employees were exposed to fuel oil no. 4 and 1,076,518 employees were exposed to kerosene in the workplace (NOES 1992). Most exposure to fuel oil no. 2 was in the electric, gas, and sanitary services industries; exposure to fuel oil no. 4 was greatest in the primary metal industries, and exposure to kerosene was greatest for machinists.

Exposure of the general population to fuel oils is most likely to occur as a result of the use of kerosene and other fuel oils in heaters, furnaces, and combustion engines. Spills of number 2 fuel oil in residential basements can pose a significant health risk; a spill of 21 gallons would present a risk for 8 days or longer (Kaplan et al. 1993). Unintentional exposure to fuel oils may occur as a result of groundwater contamination from spilled fuel oils or contact with soils that have been contaminated with fuel oils.

\subsection{POPULATIONS WITH POTENTIALLY HIGH EXPOSURES}

The extent of potential high exposures to various segments of the population appears to be largely unknown. Workers in the petroleum industry may receive intermittent skin exposure to kerosene and other fuel oils during the refining process. Exposure is most likely to occur during the distillation of crude oil, when monitoring and servicing of equipment are carried out, or when sampling must be done (Runion 1988).

The use of kerosene as a solvent in paints and insecticides increases the likelihood of exposure by painters, particularly when spray applicators are used (Fidler et al. 1987), and in exterminators. Use of a respirator, alternate application methods (brush or roller), and increased ventilation can all reduce worker exposure to the solvent vapor. 
Workers in a ball-bearing manufacturing plant in Taiwan had severe dermatitis as a result of exposure to kerosene that was used as a degreasing agent. Eczema and erythema were also prevalent among the workers (Jee et al. 1985).

\subsection{ADEQUACY OF THE DATABASE}

Section 104(i)(5) of CERCLA, as amended, directs the Administrator of ATSDR (in consultation with the Administrator of EPA and agencies and programs of the Public Health Service) to assess whether adequate information on the health effects of fuel oils is available. Where adequate information is not available, ATSDR, in conjunction with NTP, is required to assure the initiation of a program of research designed to determine the health effects (and techniques for developing methods to determine such health effects) of fuel oils.

The following categories of possible data needs have been identified by a joint team of scientists from ATSDR, NTP, and EPA. They are defined as substance-specific informational needs that, if met, would reduce or eliminate the uncertainties of human health assessment. This definition should not be interpreted to mean that all data needs discussed in this section must be filled. In the future, the identified data needs will be evaluated and prioritized, and a substance-specific research agenda may be proposed.

\subsubsection{Identification of Data Needs}

Physical and Chemical PropertieS.he physical and chemical properties of some fuel oils and their primary component chemicals, specifically kerosene and fuel oil no. 2, are well defined and can be used to estimate the fate of these fuel oils following release to the environment (Air Force 1989; IARC 1989). However, the physical and chemical properties of other fuel oils such as no. 1-D, no. 2-D, and no. 4, are not well defined, and data should be gathered in order to estimate the fate of these oils in the environment. Data needs associated with specific compounds that are components of fuel oils (e.g., benzene, toluene, xylene, and PAHs) are presented in the ATSDR toxicological profiles for these chemicals (ATSDR 1989, 1990a, 1991a, 1991b). 


\section{POTENTIAL FOR HUMAN EXPOSURE}

Production, Import/Export, Use, and Release and Disposal. Fuel oils are used primarily as heating oils and in engines (Air Force 1989). Most releases of fuel oils are the result of spills either on land or water (EPA 1981; Strayer et al. 1983). Few data are available on current production volumes for specific fuel oils such as fuel oil no. 4. Further information on the production volumes for each fuel oil, environmental releases, and disposal of fuel oils would aid in assessing the potential for human exposure as a result of accidental or intentional release.

Environmental Fate. The environmental fate of fuel oils is based on the environmental partitioning of the major hydrocarbon fractions. For aliphatic hydrocarbons, volatilization of lower molecular weight alkanes and sorption to organic matter for larger aliphatics, followed by photooxidation and biodegradation, respectively, are the primary degradation processes (Gearing et al. 1980; Oviatt et al. 1982). Aromatic components are most susceptible to biodegradation in warm water or soil, although some volatilization may occur in colder waters (Walker et al. 1976; Gearing and Gearing 1982a). Aromatics, however, are also water soluble and therefore are the most likely fuel oil components to leach through soil into groundwater (Strayer et al. 1983). Aliphatics that sediment out of the water column may persist for over a year (Oviatt et al. 1982). Photooxidation may also be a significant degradation process for fuel oils in surface waters (Larson et al. 1977, 1979). The movement and persistence of fuel oils in water and soils is well studied. Further data on the atmospheric reactions of fuel oils would be helpful in determining the transport of fuel oils through air.

Bioavailability from Environmental Media. The extent of absorption of fuel oils by inhalation, oral, and/or dermal routes is unknown. However, toxicity data are available for humans exposed to various fuel oils by each of these routes (Porter 1990; Reidenberg et al. 1964; Subcommittee on Accidental Poisoning 1962). These data indicate that absorption does occur. The extent of absorption by these routes depends on the volatility, solubility, lipophilicity, and other properties of the specific fuel oil components. Several of these component compounds have been discussed in their individual ATSDR toxicological profiles (e.g., benzene, toluene, xylene, PAHs, and lead), which should be consulted for further information (ATSDR 1989, 1990a, 1990b, 1991a, 1991b). More data linking exposure levels of fuel oils with biological levels of component chemicals would be useful in determining which chemicals in the mixture are most likely to be absorbed and by which routes. This information would aid in determining daily human exposure levels and more accurately assessing the risk associated with exposure to fuel oils. 
Food Chain Bioaccumulation. Studies of the accidental and intentional release of fuel oils to the aquatic environment indicate that aquatic organisms are able to bioaccumulate some hydrocarbon fractions, particularly PAHs (Farrington et al. 1982b); however, depuration does occur if the source of the contamination is removed (Cox et al. 1975; Williams et al. 1989). Further studies are needed to determine the biomagnification potential of the hydrocarbon components of fuel oils, particularly PAHs, up the food chain within aquatic and terrestrial ecosystems. Specific research needs are presented in the individual ATSDR toxicological profiles on specific hydrocarbon components such as benzene, toluene, total xylenes, and polycyclic aromatic hydrocarbons (ATSDR 1989, 1990a, 1991a, 1991b). Research on the biomagnification of fuel oils as actual mixtures would not be useful because they are not available to the food chain as mixtures.

Exposure Levels in Environmental Media. There is limited information available on the levels of fuel oils found in soil or water where fuel oils are used or stored. Most monitoring studies have been conducted in the aquatic environment following an accidental spill (EPA 1981; Teal et al. 1978). More data on levels of fuel oils or their components in the air, water, and soil around facilities where fuel oils are produced, stored, and used would be useful. Data on levels in contaminated surface water, groundwater, and soil are needed to assess the potential risk from these likely sources of exposure.

Exposure Levels in Humans. Workers who use fuel oils in manufacturing and those involved in their transfer may experience increased dermal and inhalation exposures. Workers in the petroleum refining industry, particularly those involved with monitoring and servicing unit equipment, including fuel oil storage tanks, are known to have increased exposure to fuel oils such as kerosene (Runion 1988). Further information is needed to assess the approximate levels of exposure for these populations.

Exposure Registries. No exposure registries for fuel oils were located. These substances are not currently compounds for which a subregistry has been established in the National Exposure Registry. These substances will be considered in the future when chemical selection is made for subregistries to be established. The information that is amassed in the National Exposure Registry facilitates the epidemiological research needed to assess adverse health outcomes that may be related to the exposure to these substances. 
FUEL OILS

\section{POTENTIAL FOR HUMAN EXPOSURE}

A registry does exist for benzene, a component of fuel oils. More information on the benzene exposure registry can be found in the ATSDR toxicological profile for benzene (ATSDR 1989).

\subsubsection{On-going Studies}

No on-going studies on the exposure or environmental fate of fuel oils were located. 



\section{ANALYTICAL METHODS}

The purpose of this chapter is to describe the analytical methods that are available for detecting and/or measuring and monitoring fuel oils in environmental media and in biological samples. The intention is not to provide an exhaustive list of analytical methods that could be used to detect and quantify fuel oils. Rather, the intent is to identify well-established methods that are used as the standard methods of analysis. Many of the analytical methods used to detect fuel oils in environmental samples are the methods approved by federal organizations such as EPA and the National Institute for Occupational Safety and Health (NIOSH). Other methods presented in this chapter are those that are approved by groups such as the Association of Official Analytical Chemists (AOAC) and the American Public Health Association (APHA). Additionally, analytical methods are included that refine previously used methods to obtain lower detection limits, and/or to improve accuracy and precision.

\subsection{BIOLOGICAL MATERIALS}

Fuel oils are mixtures of aliphatic and aromatic hydrocarbons (Air Force 1989). Most analytical methods for detecting fuel oils in biological media focus on the detection of kerosene components, as this is a commonly used fuel for residential heaters. Analytical methods for detecting other fuel oils in biological media were not located. See Table 6-1 for a summary of the analytical methods most commonly used to measure kerosene in biological materials. For more analytical methods information, see the previous profiles on some of the individual components of fuel oils (e.g., benzene, toluene, total xylenes, and PAHs) (ATSDR 1989, 1990a, 1991a, 1991b).

The primary method for detecting kerosene in biological materials such as blood is gas chromatography (GC). GC may be combined with mass spectroscopy (MS) for peak identification with the gas chromatograph in the electron impact mode (Kimura et al. 1988, 1991). Quantification methods include the use of mass fragmentography (Kimura et al. 1988). Hydrocarbon components of kerosene are determined based on analysis of headspace gas above the sample (Kimura et al. 1991). This method is useful for distinguishing between kerosene intoxication and gasoline intoxication as kerosene gives a high toluene peak and has a pseudocumene-to-toluene ratio only half that of gasoline. Capillary columns are used, with either Porapak, Chromosorb ${ }^{\circledR}$, or Chemipak ${ }^{\circledR}$, giving acceptable results (Kimura et al. 1988). The percent recoveries of these methods were not provided. Wide-bore 
TABLE 6-1. Analytical Methods for Determining Fuel Oils in Biological Materials

\begin{tabular}{|c|c|c|c|c|c|}
\hline Sample matrix & Preparation method & Analytical method & $\begin{array}{r}\text { Sample } \\
\text { detection } \\
\text { limit }\end{array}$ & $\begin{array}{l}\text { Percent } \\
\text { recovery }\end{array}$ & Reference \\
\hline Blood & $\begin{array}{l}\text { Add internal standard; } \\
\text { extract with } n \text {-pentane; } \\
\text { centrifuge; freeze; decant } \\
\text { solvent; concentrate; } \\
\text { inject to GC }\end{array}$ & GC/MS & $50 \mathrm{pg}$ & NR & Kimura et al. 1988 \\
\hline Blood & $\begin{array}{l}\text { Mix sample with internal } \\
\text { standard; add salt } \\
\text { solution; equilibrate; } \\
\text { aspirate headspace vapor } \\
\text { and inject to GC }\end{array}$ & GC/MS & $\begin{array}{l}50 \mathrm{pg} \\
\text { (toluene) }\end{array}$ & NR & Kimura et al. 1991 \\
\hline $\begin{array}{l}\text { Stomach contents, } \\
\text { blood, urine }\end{array}$ & $\begin{array}{l}\text { Extract sample with ethyl } \\
\text { acetate; condense; inject } \\
\text { to GC }\end{array}$ & GC/FID/MS & $0.2 \mu \mathrm{g} / \mathrm{mL}$ & $93-100$ & Hara et al. 1988 \\
\hline
\end{tabular}

FID = flame ionization detector; $\mathrm{GC}=$ gas chromatography; $\mathrm{MS}=$ mass spectrometry; $\mathrm{NR}=$ not reported 
6. ANALYTICAL METHODS

capillary columns have also been used (Hara et al. 1988) for GC/MS analysis combined with flame ionization detectors (FID). This method determined levels of $m$ - and $o$-xylene (components of kerosene) in the blood, urine, and stomach contents. The sensitivity and precision of this method was generally good (93-100\% recovery).

No analytical methods studies were located for detecting fuel oils in biological samples other than blood, urine, or stomach contents.

\subsection{ENVIRONMENTAL SAMPLES}

Because fuel oils are composed of a mixture of hydrocarbons, there are few methods for the environmental analysis of fuel oils as a whole, but methods are reported for the analysis of their component hydrocarbons. The methods most commonly used to detect the major hydrocarbon components of fuel oils in environmental samples are GC/FID and GC/MS. See Table 6-2 for a summary of the analytical methods used to determine fuel oils in environmental samples. Several of the components of fuel oils have been discussed in detail in their individual toxicological profiles (e.g., benzene, toluene, total xylenes, and PAHs), which should be consulted for more information on analytical methods (ATSDR 1989, 1990a, 1991a, 1991b).

GC is the most commonly used method to selectively detect, identify, and quantify the volatile hydrocarbon components of fuel oils in air (Andrasko 1983; Baldwin 1977; NIOSH 1994). Air samples may be collected on adsorbent tubes such as charcoal, Florisil ${ }^{\circledR}$, Tenax ${ }^{\circledR}$, Porapak $^{\circledR}$, or Chromosorb $^{\circledR}$. Active carbons wires have also been used (Andrasko 1983). The hydrocarbons are extracted from the tubes by thermal desorption or with a liquid solvent such as carbon disulfide and analyzed on the gas chromatograph. Precision is good (relative standard deviation $=0.052$ ) using the charcoal tubes (NIOSH 1994); recovery data were not reported for the other types of adsorption tubes, although desorption from the active carbon wires ranged between $90 \%$ and $99 \%$ recovery, with a detection limit in the ppb range. A Tenax-TA ${ }^{\circledR}$ sorbent trap has been used with subsequent thermal desorption (Andrasko 1983). Combining sample concentration with the headspace method allows for sampling of smaller air volumes and for other environmental samples, such as kerosene combustion debris, that have undergone significant evaporation; the headspace method requires concentrating the sample prior to analysis (Andrasko 1983; Baldwin 1977). An exploratory study indicates that, with 
TABLE 6-2. Analytical Methods for Determining Fuel Oils in Environmental Samples

\begin{tabular}{|c|c|c|c|c|c|}
\hline Sample matrix & Preparation method & Analytical method & $\begin{array}{r}\text { Sample } \\
\text { detection } \\
\text { limit }\end{array}$ & $\begin{array}{l}\text { Percent } \\
\text { recovery }\end{array}$ & Reference \\
\hline Air & $\begin{array}{l}\text { Adsorb to solid sorbent } \\
\text { tube (e.g., charcoal); } \\
\text { desorb in } \mathrm{CS}_{2} \text {; equili- } \\
\text { brate; inject aliquot to } \\
\text { GC }\end{array}$ & GC/FID & $\begin{array}{l}0.1 \mathrm{mg} / \\
5-10 \mathrm{~mL} \\
\text { sample }\end{array}$ & $96-106$ & NIOSH 1994 \\
\hline Air & Adsorb to quartz filter & Evolved Gas Analysis & $10 \mu \mathrm{g}$ & NR & $\begin{array}{l}\text { Daisey and Gundel } \\
1991\end{array}$ \\
\hline Air & $\begin{array}{l}\text { Adsorb to Florisil filter; } \\
\text { elute with } \mathrm{CS}_{2} \text {; evaporate } \\
\text { under vacuum }\end{array}$ & GC & NR & NR & Baldwin 1977 \\
\hline Water & $\begin{array}{l}\text { Strip sample in sparger } \\
\text { with helium; adsorb } \\
\text { effluent gas to adsorption } \\
\text { tube; thermally desorb to } \\
\text { GC }\end{array}$ & GC/FID/MS & $10 \mu \mathrm{g} / \mathrm{L}$ & $89.7-95.7$ & Bianchi et al. 1991 \\
\hline Water & $\begin{array}{l}\text { Acidify sample; extract } \\
\text { with hexane; dry solvent } \\
\text { phase; inject to GC }\end{array}$ & GC/FID & $0.25 \mu \mathrm{L} / \mathrm{L}$ & NR & $\begin{array}{l}\text { Dell' Acqua and Bush } \\
1973\end{array}$ \\
\hline $\begin{array}{l}\text { Water } \\
\text { (purgeable } \\
\text { aromatics) }\end{array}$ & $\begin{array}{l}\text { Purge sample with inert } \\
\text { gas; adsorb vapor in trap; } \\
\text { heat trap; backflush to } \\
\text { GC }\end{array}$ & GC/PID & $0.2 \mu \mathrm{g} / \mathrm{L}$ & $92-96$ & EPA $1991 \mathrm{c}$ \\
\hline
\end{tabular}


TABLE 6-2. Analytical Methods for Determining Fuel Oils in Environmental Samples (continued)

\begin{tabular}{|c|c|c|c|c|c|}
\hline Sample matrix & Preparation method & Analytical method & $\begin{array}{r}\text { Sample } \\
\text { detection } \\
\text { limit }\end{array}$ & $\begin{array}{l}\text { Percent } \\
\text { recovery }\end{array}$ & Reference \\
\hline Water & $\begin{array}{l}\text { Purge sample with heli- } \\
\text { um; collect vapor on ad- } \\
\text { sorption tube; thermally } \\
\text { desorb; concentrate; back- } \\
\text { flush to GC }\end{array}$ & GC/FID & $10 \mu \mathrm{g} / \mathrm{L}$ & $\begin{array}{l}99-114 \\
\text { (fuel oil } \\
\text { no. } 2) ; \\
91-112 \\
\text { (kerosene) }\end{array}$ & $\begin{array}{l}\text { Belkin and Esposito } \\
1986\end{array}$ \\
\hline Water & $\begin{array}{l}\text { Purge sample with ambi- } \\
\text { ent air, adsorb to charcoal } \\
\text { filter; extract filter with } \\
\mathrm{CS}_{2} \text {; inject to GC }\end{array}$ & GC/MS & $5 \mathrm{ng} / \mathrm{L}$ & $\begin{array}{l}0.4-89 \\
(75 \% \\
\text { average) }\end{array}$ & Coleman et al. 1981 \\
\hline Water & $\begin{array}{l}\text { Extract aqueous sample } \\
\text { with pentane; equilibrate; } \\
\text { inject to GC }\end{array}$ & GC/MS & NR & NR & Coleman et al. 1984 \\
\hline $\begin{array}{l}\text { Water (base/ } \\
\text { neutral and acids) }\end{array}$ & $\begin{array}{l}\text { Adjust sample } \mathrm{pH} \text { to }>11 \text {; } \\
\text { extract sample with } \\
\mathrm{CH}_{2} \mathrm{Cl}_{2} \text { solvent; adjust } \mathrm{pH} \\
\text { to }<2 \text {; reextract; dry; } \\
\text { concentrate; inject to } \mathrm{GC}\end{array}$ & GC/MS & $\begin{array}{l}1.5-7.8 \mu \mathrm{g} / \mathrm{L} \\
\text { (varies with } \\
\text { actual } \\
\text { compound) }\end{array}$ & NR & EPA $1991 \mathrm{c}$ \\
\hline Seawater & $\begin{array}{l}\text { Extract aqueous phase of } \\
\text { sample with pentane; } \\
\text { evaporate; inject to GC }\end{array}$ & GC/MS & NR & NR & Boylan and Tripp 1971 \\
\hline $\begin{array}{l}\text { Soil } \\
\text { (other solid } \\
\text { materials) }\end{array}$ & $\begin{array}{l}\text { Extract sample with } \mathrm{CCl}_{4} \text {; } \\
\text { inject extract }\end{array}$ & GLC & NR & NR & $\begin{array}{l}\text { Midkiff and Washington } \\
1972\end{array}$ \\
\hline
\end{tabular}


TABLE 6-2. Analytical Methods for Determining Fuel Oils in Environmental Samples (continued)

\begin{tabular}{|c|c|c|c|c|c|}
\hline Sample matrix & Preparation method & Analytical method & $\begin{array}{l}\text { Sample } \\
\text { detection } \\
\text { limit }\end{array}$ & $\begin{array}{l}\text { Percent } \\
\text { recovery }\end{array}$ & Reference \\
\hline Soil & $\begin{array}{l}\text { Extract sample with } \mathrm{CCl}_{4} \text {; } \\
\text { centrifuge; remove water } \\
\text { and humic materials with } \\
\mathrm{Na}_{2} \mathrm{SO}_{4} \text { and } \mathrm{Al}_{2} \mathrm{O}_{3} \text {; inject } \\
\text { extract }\end{array}$ & GC/FID & NR & NR & Galin et al. $1990 \mathrm{a}$ \\
\hline Soil & $\begin{array}{l}\text { Purge at elevated } \\
\text { temperatures; heat trap to } \\
\text { desorb material into GC } \\
\text { column }\end{array}$ & $\mathrm{GC}$ & NR & NR & Chang et al. 1990 \\
\hline Soil & $\begin{array}{l}\text { Sample added to substrate } \\
\text { and placed in cup } \\
\text { mounted on optical fiber }\end{array}$ & Fluorescence Spectroscopy & NR & NR & Apitz et al. 1993 \\
\hline Soil & $\begin{array}{l}\text { Sample extracted using } \\
\text { water and cyclohexane }\end{array}$ & $\begin{array}{l}\text { Synchronous Scanning } \\
\text { Fluorescence Spectroscopy }\end{array}$ & NR & NR & Pharr et al. 1992 \\
\hline Sediment & $\begin{array}{l}\text { Add internal sample to } \\
\text { sample; extract with } \\
\text { KOH in methanol; parti- } \\
\text { tion into petroleum ether; } \\
\text { concentrate; purify and } \\
\text { isolate hydrocarbon } \\
\text { fractions using TLC or } \\
\text { column chromatography }\end{array}$ & GLC/FID & NR & NR & Gearing et al. 1980 \\
\hline $\begin{array}{l}\text { Shellfish tissue } \\
\text { (mussel) }\end{array}$ & $\begin{array}{l}\text { Extract with } \mathrm{NaOH} \text {; } \\
\text { isolate fractions with } \\
\text { column chromatography; } \\
\text { inject fractions to } \mathrm{GC}\end{array}$ & GC or GC/MS & NR & $\begin{array}{l}34-120 \\
\text { (GC); } \\
36-87 \\
\text { (GC/MS) }\end{array}$ & Farrington et al. 1982a \\
\hline
\end{tabular}


TABLE 6-2. Analytical Methods for Determining Fuel Oils in Environmental Samples (continued)

\begin{tabular}{|c|c|c|c|c|c|}
\hline Sample matrix & Preparation method & Analytical method & $\begin{array}{l}\text { Sample } \\
\text { detection } \\
\text { limit }\end{array}$ & $\begin{array}{l}\text { Percent } \\
\text { recovery }\end{array}$ & Reference \\
\hline Shellfish tissue & $\begin{array}{l}\text { Extract with methanol } \\
\text { then pentane; dry; con- } \\
\text { centrate; inject to GC }\end{array}$ & GC & NR & NR & Blumer et al. 1970 \\
\hline
\end{tabular}

$\mathrm{Al}_{2} \mathrm{O}_{3}=$ aluminum oxide; $\mathrm{CCl}_{4}=$ carbon tetrachloride; $\mathrm{CH}_{2} \mathrm{Cl}_{2}=$ dichloromethane (methylene chloride); $\mathrm{CS}_{2}=$ carbon disulfide; FID = flame ionization detector; $\mathrm{GC}=$ gas chromatography; $\mathrm{GLC}=$ gas liquid chromatography; $\mathrm{KOH}=$ potassium hydroxide; $\mathrm{MS}=$ mass spectrometry; $\mathrm{Na}_{2} \mathrm{SO}_{4}=$ sodium sulfate; $\mathrm{NaOH}=$ sodium hydroxide; $\mathrm{NR}=$ not reported $; \mathrm{PID}=$ photoionization detector; $\mathrm{TLC}=$ thin-layer chromatography 
additional research, the microanalytical evolved gas analysis technique (EGA) can be further developed to measure kerosene soot in indoor aerosols (Daisey and Gundel 1991).

GC/FID and GC/MS have been used to measure the water-soluble components of fuel oils, particularly kerosene, in industrial effluents and estuarine water (Bianchi et al. 1991), sea water (Boyland and Tripp 1971), drinking water (Coleman et al. 1984; Dell'Acqua and Bush 1973), and groundwater (Thomas and Delfino 1991a). Purge-and-trap sample preparation methods have been used to determine purgeable (volatile) aromatic components of fuel oils. This method requires a trap with a Tenax $^{\circledR} /$ Chromosorb $^{\circledR}$ absorbent and the use of a gas chromatograph with a photoionization detector (PID) (EPA 1991c), an ion trap detector (ITD), or FID (Thomas and Delfino 1991a). A modification of the purge-and-trap method uses ambient temperatures, has the advantage of being applicable to a variety of waters, requires virtually no sample preparation (no solvents are required), and has an analysis time of approximately 30 minutes (Bianchi et al. 1991). While this method may be used for determining the presence of petroleum contaminants in water, it cannot distinguish between various sources of this contamination, e.g., between gasoline, kerosene, and diesel oil.

Distinctions between water-soluble fractions of mixed hydrocarbons may be made by using solvent extraction of the water-soluble base/neutral and acid fractions with methylene chloride (EPA 1991c; Thomas and Delfino 1991a). This separation of base/neutral and acid fractions will permit the GC resolution of the type of water soluble hydrocarbons present in the aqueous phase. Hexane has also been used as a solvent (Dell'Acqua and Bush 1973), as has pentane (Coleman et al. 1984).

A dynamic thermal stripper has also been used to detect low levels (ppb range) of fuel oil no. 2 and kerosene present in water samples (Belkin and Esposito 1986). This method traps the fuels on an adsorption tube using helium gas for purging. The fuel is then thermally desorbed and backflushed to a gas chromatograph with FID. This method also does not require any solvent and needs only a $15 \mathrm{~mL}$ sample. Recovery for this method is good (91-114\%) with precision ranging from 6.4 to $14.3 \%$ relative standard deviation. A modified Grob closed-loop-stripping method, which uses a wall-coated open tubular glass capillary column combined with GC/MS, has been used to extract and quantify low levels (ppt) of hydrocarbons in water samples. The method continually recirculates an ambient air stream through the 3.8-liter water sample for approximately 2 hours and collects the vapor on an activated carbon filter, followed by extraction with carbon disulfide and analysis (Coleman et al. 1981). An optical fiber fluorescence spectroscopy system has been used for real-time in situ 
measurements of low levels (at ppb of diesel fuel marine equivalent) of petroleum hydrocarbons in seawater, showing temporal and spatial variability (Lieberman et al 1993).

A qualitative method for determining diesel oil in water has been proposed that is based on changes in the internal reflection of an optical fiber coated with an organophilic compound caused by the presence of hydrocarbons. The method does not require any sample preparation but is limited to relatively high concentrations of contaminants, e.g., $17 \mathrm{mg} / \mathrm{L}$ for diesel oil (Kawahara et al. 1983). An alternative method uses a Fourier transform infrared spectrometer (FTIR). This method has the advantage of no sample preparation, a short analysis time (20-30 seconds), and good accuracy ( $\pm 20 \%)$. A detection limit of $0.5 \mathrm{ppb}$ has been determined for a 1-liter sample of sea water; $10 \mathrm{~mL}$ is sufficient if a detection limit of $0.05 \mathrm{ppm}$ is acceptable. The FTIR may be coupled with a GC or liquid chromatography for the analysis of complex mixtures (Mille et al. 1985).

GC/FID (Galin et al. 1990a), gas liquid chromatography (GLC) with FID (Midkiff and Washington 1972), and elevated temperature purge and trap with GC (Chang et al. 1990) have been used to measure fuel oils in soils. An enzyme immunoassay has been developed using a monoclonal antibody reagent that detects gasoline and diesel fuel in soil; commercialization of this assay will offer significant advantages over current testing methods of gasoline and fuel contamination levels in soil (Allen et al. 1992b). GLC has also been used to determine fuel oils in marine sediments (Gearing et al. 1980) and other environmental samples such as paper, cloth, and wood (Midkiff and Washington 1972). Extraction is used to concentrate the sample because fuel oils do not provide sufficient vapors to allow the use of a headspace sampling method. Carbon tetrachloride is the recommended solvent as it causes less interference with the chromatographic peaks of the fuel oils (Galin et al. 1990a; Midkiff and Washington 1972). Quantification of fuel oil hydrocarbons from sediments is a more elaborate process. Following extraction, the saturated and olefinic hydrocarbon fraction is separated from the aromatic hydrocarbon fraction using thin-layer chromatography or column chromatography. Fractions are subsequently analyzed by GLC (Gearing et al. 1980). Recovery, sensitivity, and levels of detection data were not reported. Quantification of oils and grease, by gross weight only, in soils and sludges may be accomplished by extraction with a Soxhlet apparatus using either trichlorotrifluoroethane (APHA 1985) or methylene chloride (Martin et al. 1991) as the solvent, although this method may not be used to identify the specific type of oil or grease present in the soil sample. Synchronous scanning fluorescence spectroscopy can be used to identify kerosene, fuel oil number 2, fuel oil number 5, and other aromatic-containing products in groundwater and soil samples. This analytical method is more 
efficient than chromatographic methods, and its spectra are easier to interpret for identification purposes (Pharr et al. 1992). Fluorescence spectroscopy has been used for in situ detection of petroleum hydrocarbon plumes in soil; this technique allows for measurements in soils before monitoring wells are drilled and is thus independent of the fractionation and transport problems inherent when sampling well fluids (Apitz et al. 1992).

The age of diesel oil in the subsurface soil environment can be determined by utilizing the fact that the composition of the diesel oil (the ratio between $n$-alkanes and isoprenoids) changes due to biodegradation. In one study, the ratio of $\mathrm{C}_{17}$ to pristane was highly correlated with the residence time of diesel fuel at 12 test locations (Christensen et al 1993).

A set of neural networks has been trained to identify seven classes of petroleum hydrocarbon based fuels from their fluorescence emission spectra; this technique correctly identified at least $90 \%$ of the test spectra (Andrews and Lieberman 1994).

High-performance liquid chromatography (HPLC), followed by GC/MS, has been used to fractionate and then quantitate the aliphatic and aromatic hydrocarbons present in liquid fuel precursors in order to determine the fuel potential of the compounds. Kerosene had the advantage of not requiring any sample preparation. Other light fuel oils may require the use of methylene chloride as a solvent prior to HPLC analysis (Lamey et al. 1991). The sensitivity, precision, and recovery of this method were not reported. An alternative method for fractionating and purifying petroleum hydrocarbons prior to GC or HPLC separation has been developed (Theobald 1988). The method uses small, prepacked, silica or $\mathrm{C}_{18}$ columns that offer the advantage of rapid separation (approximately I5 minutes for a run); good recovery of hydrocarbons ( $85 \%$ for the $\mathrm{C}_{18}$ column and $92 \%$ for the silica column); reusability of the columns; and for the silica column in particular, good separation of hydrocarbon from nonhydrocarbon matrices as may occur with environmental samples. Infrared analysis and ultraviolet spectroscopy were used to analyze the aromatic content in diesel fuels; these methods are relatively inexpensive and faster than other available methods, such as mass spectrometry, supercritical fluid chromatography, and nuclear magnetic resonance (Bailey and Kohl 1991).

Due to the tendency of hydrocarbons in the soil to undergo subsurface oxidation, measuring $\mathrm{CO}_{2}$ levels in the soil gas could be used as a cost-effective field screening tool. In one soil-gas survey, $\mathrm{CO}_{2}$ levels in soil gas correlated well with petroleum hydrocarbons in the soil (Diem et al. 1988). 
A two-dimensional supercritical fluid chromatography (SFC) system has been developed for the determination of saturates, alkenes, and mono-, di-, and tri-aromatics in diesel fuel. This technique results in a short analysis time (less than 8 minutes) and good relative standard deviations at low alkene content (Andersson et al. 1992).

The principal method for detecting kerosene or its components in biota is GC (Blamer et al. 1970; Farrington et al. 1982a; Newton et al. 1991). Aliphatic and aromatic hydrocarbon components of fuel oils taken up by shellfish (whole mussels without shells) were isolated by column chromatography following extraction. Both the alka.ne/cycloalkane and alkene/aromatic fractions were analyzed by GC with recoveries in the range of $67-100 \%$ for alkanes and $71-78 \%$ for some aromatics; these aromatics were also analyzed using GC/MS with recoveries between 49\% and 74\% (Farrington et al. 1982a). Determination of hydrocarbons may also be accomplished by fractionating the hydrocarbon components. Extraction of hydrocarbons from contaminated shellfish may be accomplished using Soxhlet extraction with methanol followed by reextraction with pentane. The extracts are then dried and concentrated prior to injection into the GC (Blumer et al. 1970). Other data on detection limits and precision were not provided.

\subsection{ADEQUACY OF THE DATABASE}

Section 104(i)(5) of CERCLA, as amended, directs the Administrator of ATSDR (in consultation with the Administrator of EPA and agencies and programs of the Public Health Service) to assess whether adequate information on the health effects of fuel oils is available. Where adequate information is not available, ATSDR, in conjunction with NTP, is required to assure the initiation of a program of research designed to determine the health effects (and techniques for developing methods to determine such health effects) of fuel oils.

The following categories of possible data needs have been identified by a joint team of scientists from ATSDR, NTP, and EPA. They are defined as substance-specific informational needs that, if met, would reduce or eliminate the uncertainties of human health assessment. This definition should not be interpreted to mean that all data needs discussed in this section must be filled. In the future, the identified data needs will be evaluated and prioritized, and a substance-specific research agenda may be proposed. 


\subsubsection{Identification of Data Needs}

Methods for Determining Biomarkers of Exposure and Effect. No biomarkers of exposure were identified for fuel oils because, while standard procedures exist for identifying or quantifying exposure to fuel oils based on hydrocarbon components in blood, urine, and stomach contents (Hara et al. 1988; Kimura et al. 1988, 1991), none of these are applicable solely to fuel oils. These methods are sensitive enough to measure the levels at which health effects occur and may be adequate for determining background levels in the population; however, they cannot distinguish between exposure to different fuel oils or other types of hydrocarbon mixtures. Analytical methods are needed for measuring the hydrocarbon components of fuel oils in lungs. Biomonitoring studies are needed to adequately assess exposure to fuel oils.

No biomarkers of effects were identified for fuel oils because the effects associated with exposure to fuel oils are not unique for them, i.e., the effects may be caused by other chemicals or hydrocarbon mixtures. Analytical methods do exist for determining angiotensin-converting enzyme activity in the lungs. This enzyme may be used to determine the lung damage caused by a fuel oil. Analytical methods are needed to determine whether the tissue damage is specific to fuel oils and the target organs.

\section{Methods for Determining Parent Compounds and Degradation Products in}

Environmental Media. Methods exist to detect major hydrocarbon components of fuel oils in air (Andrasko 1983; Baldwin 1977; NIOSH 1994), water (Bianchi et al. 1991; Boyland and Tripp 1971; Dell'Acqua and Bush 1973; EPA 1991c), sediment (Gearing et al. 1980), and soil (Galin et al. 1990a; Midkiff and Washington 1972). The most commonly used methods are GC/FID and GC/MS. These methods are relatively sensitive, selective, and reliable, and can be used to detect the levels of the various components of fuel oils found in the environment and levels at which health effects occur.

\subsubsection{On-going Studies}

No on-going analytical methods studies were located. 


\section{REGULATIONS AND ADVISORIES}

The international, national, and state regulations and guidelines regarding fuel oils in air, water, and other media are summarized in Table 7-1. There are only a few regulations that are specific to a particular fuel oil and these are indicated in the table.

An acute inhalation MRL of $0.02 \mathrm{mg} / \mathrm{m}^{3}$ was derived for fuel oil no. 2. The MRL is based on a LOAEL value of $65 \mathrm{mg} / \mathrm{m}^{3}$ for neurobehavioral effects (mild transient ataxia and CNS depression) in mice exposed to airborne concentrations of fuel oil no. 2 .

An intermediate inhalation MRL of $0.01 \mathrm{mg} / \mathrm{m}^{3}$ was derived for fuel oil no. 1 . The MRL is based on decreased blood glucose levels in male rats exposed to airborne concentrations of kerosene averaging $58 \mathrm{mg} / \mathrm{m} 3$ for 6 hours/day, 6 days/week for 14 weeks. Rats exposed to airborne concentrations of kerosene averaging $231 \mathrm{mg} / \mathrm{m}^{3}$ showed a decrease in blood glucose titers, as well as increased circulating levels of lactate and pyruvate.

The EPA has no oral reference dose (RfD) or inhalation reference concentration (RfC) for any of the fuel oils.

Under the Hazardous Materials Transportation Act, fuel oils are designated as hazardous substances subject to special requirements for packaging, labeling, and transportation (DOT 1989a, 1989b). 
FUEL OILS

7. REGULATIONS AND ADVISORIES

TABLE 7-1. Regulations and Guidelines Applicable to Fuel Oils

\begin{tabular}{llll}
\hline Agency & Description & Information & References \\
\hline
\end{tabular}

\section{INTERNATIONAL}

IARC

Carcinogenic classification
for occupational exposures
in petroleum refining
Carcinogenic classification
marine diesel fuel
residual (heavy) fuel oils
jet fuels
distillate (light) diesel fuels

IARC 1989

Group $2 A^{a}$

Group 2B

Group 2B

Group $3^{\mathrm{c}}$

Group 3

NATIONAL

Regulations:

a. Air:

AFOSH

PEL TWA

Petroleum distillates (naphtha)

STEL (15 minutes)

Petroleum distillates (naphtha)

NIOSH

TWA

Petroleum distillates (naphtha)

Ceiling REL (15 minutes)

Petroleum distillates (naphtha)

IDLH

Petroleum distillates (naphtha)

PEL TWA

Petroleum distillates (naphtha)

$\begin{array}{ll} & \text { Air Force } 1989 \\ 500 \mathrm{ppm} & \\ 500 \mathrm{ppm} & \\ & \\ 85 \mathrm{ppm}\left(350 \mathrm{mg} / \mathrm{m}^{3}\right) & \text { NIOSH } 1992 \\ & \\ 438 \mathrm{ppm}\left(1,800 \mathrm{mg} / \mathrm{m}^{3}\right) & \\ & \\ 10,000 \mathrm{ppm} & \text { NIOSH 1990 } \\ & \text { OSHA 1989a (29 CFR } \\ 400 \mathrm{ppm} & 1910.1000) ; \text { OSHA } \\ & 1989 \mathrm{~b} \\ & \\ \text { Yes } & \text { DOT 1989a (49 CFR } \\ & 172.101 \\ & \text { Appendix A); DOT } \\ & 1989 \mathrm{~b} \\ & \text { EPA 1991a (40 CFR } \\ \text { Yes } & 799.2175) ; \text { EPA } \\ & 1987 \mathrm{c}\end{array}$

b. Other:

DOT

Hazardous Material Transportation Act:

Fuel oils are designated as

hazardous materials which are subject

to requirements for packaging, shipping, and transporting

EPA

Toxic Substances Control Act: Manufacturers and processors of the $C_{9}$ aromatic hydrocarbon fraction must test this fraction for the

following: neurotoxicity, mutagenicity, developmental toxicity, reproductive effects, and oncogenicity

EPA

Marine Protection Research and Sanctuaries Act: Ocean dumping of organohalogen compounds or oils of any kind which are known or suspected carcinogens, mutagens, or teratogens is prohibited except when they are present as trace contaminants

Guidelines:

a. Other:

EPA

Domestic water supply must be virtually free from oil and grease, particularly from the tastes and odors that emanate from petroleum products

For aquatic life, levels must be $\leq 0.01$ of the lowest continuous flow $96-\mathrm{h} \mathrm{LC}_{50}$ 
TABLE 7-1. Regulations and Guidelines Applicable to Fuel Oils (continued)

Agency Description Information Reference

NATIONAL (Cont.)

Clean Water Act: Oil and grease are designated as conventional pollutants. Effluent limitations for oil and grease (polynuclear aromatic hydrocarbons) exist for almost all point sources under the general pretreatment standards for new and existing sources

Pesticide subject to registration and/or reregistration (kerosene)

Yes

EPA 1988b (40 CFR 403.2); EPA 1988c

Yes

EPA 1989 c (40 CFR 152.146); EPA $1989 \mathrm{~b}$

\section{STATE}

Regulations and Guidelines:

a. Air:

Connecticut

Maryland

Oklahoma

Texas

Texas

Connecticut

Kansas

Wisconsin

Alabama

Arizona

Florida

Maine

Maryland

Michigan

New Jersey

South Carolina

Virginia

Texas

Washington, DC

Maine

Texas

b. Water:

Alaska
Acceptable ambient air concentrations (Navy Fuels JP-5)

(8 hour)

(24 hour)

(30 minutes)

(annual)

Regulations on hydrocarbon emissions (kerosene, petroleum distillates, diesel, fuel oil)

Regulations on volatile organic carbon emissions (VOC)
NATICH 1991

$2.00 \times 10^{3} \mu \mathrm{g} / \mathrm{m}^{3}$

0.00

$1.00 \times 10^{4} \mu \mathrm{g} / \mathrm{m}^{3}$

$1.00 \times 10^{3} \mu \mathrm{g} / \mathrm{m}^{3}$

$1.00 \times 10^{2} \mu \mathrm{g} / \mathrm{m}^{3}$

Yes

CELDS 1991

Yes

CELDS 1991
Regulations on the open burning of fuel oils (kerosene)

Regulations for gas processing plants

Aquatic life criterion for total hydrocarbons in marine and surface waters

Aquatic life criterion for aromatic hydrocarbons in marine and surface waters

$\begin{array}{ll}\text { Yes } & \text { CELDS } 1991 \\ \text { Yes } & \text { CELDS } 1991\end{array}$

$15 \mu \mathrm{g} / \mathrm{L}$

State of Alaska 1989

$10 \mu \mathrm{g} / \mathrm{L}$

State of Alaska 1989 
TABLE 7-1. Regulations and Guidelines Applicable to Fuel Oils (continued)

Agency Description $\quad$ Information $\quad$ References

STATE (Cont.)

\begin{tabular}{|c|c|c|c|}
\hline Arkansas & $\begin{array}{l}\text { Average or maximum allowable quantity } \\
\text { of oil or grease discharged into surface } \\
\text { waters }\end{array}$ & $\begin{array}{l}10 \mathrm{mg} / \mathrm{L} \text { (average) } \\
15 \mathrm{mg} / \mathrm{L} \text { (maximum) }\end{array}$ & $\begin{array}{l}\text { State of Arkansas } \\
\quad 1991\end{array}$ \\
\hline \multirow[t]{2}{*}{ Florida } & $\begin{array}{l}\text { Average or maximum allowable quantity of } \\
\text { oil or grease discharged Class V waters } \\
\text { (navigation, industrial use) }\end{array}$ & $10 \mathrm{mg} / \mathrm{L}$ & $\begin{array}{l}\text { State of Florida } \\
\quad 1992\end{array}$ \\
\hline & $\begin{array}{l}\text { Average or maximum allowable quantity of } \\
\text { oil or grease discharged into all other } \\
\text { surface waters }\end{array}$ & $5 \mathrm{mg} / \mathrm{L}$ & $\begin{array}{l}\text { State of Florida } \\
\quad 1992\end{array}$ \\
\hline Maine & $\begin{array}{l}\text { Drinking water quality guidelines and } \\
\text { standards (fuel oil no. 2) }\end{array}$ & $100 \mu \mathrm{g} / \mathrm{L}$ & FSTRAC 1988 \\
\hline Massachusetts & $\begin{array}{l}\text { Maximum discharge concentration of oil } \\
\text { or grease of petroleum origin in } \\
\text { surface waters }\end{array}$ & $15 \mathrm{mg} / \mathrm{L}$ & $\begin{array}{l}\text { Commonwealth of } \\
\text { Massachusetts } 1988\end{array}$ \\
\hline Nebraska & $\begin{array}{l}\text { Maximum petroleum oil concentration in } \\
\text { surface waters }\end{array}$ & $10 \mathrm{mg} / \mathrm{L}$ & $\begin{array}{l}\text { State of Nebraska } \\
1991\end{array}$ \\
\hline New York & $\begin{array}{l}\text { Maximum contaminant level of kerosone in } \\
\text { drinking water }\end{array}$ & $50 \mu \mathrm{g} / \mathrm{mL}$ & $\begin{array}{l}\text { State of New York } \\
1989\end{array}$ \\
\hline South Dakota & $\begin{array}{l}\text { Water quality standard for all petroleum } \\
\text { products in surface waters }\end{array}$ & $10 \mathrm{mg} / \mathrm{L}$ & $\begin{array}{l}\text { State of South } \\
\text { Dakota } 1989\end{array}$ \\
\hline Virginia & $\begin{array}{l}\text { Water quality standard for petroleum } \\
\text { hydrocarbons in ground water }\end{array}$ & $1 \mathrm{mg} / \mathrm{L}$ & $\begin{array}{l}\text { Commonwealth of } \\
\text { Virginia } 1988\end{array}$ \\
\hline Wyoming & $\begin{array}{l}\text { Water quality standard for all surface waters } \\
\text { classes }\end{array}$ & $10 \mathrm{mg} / \mathrm{L}$ & $\begin{array}{l}\text { State of Wyoming } \\
1990\end{array}$ \\
\hline Other: & $\begin{array}{l}\text { Regulations on the transport } \\
\text { of flammable/hazardous liquids } \\
\text { (petroleum distillates or VOC) }\end{array}$ & Yes & CELDS 1991 \\
\hline $\begin{array}{l}\text { Colorado } \\
\text { Maryland } \\
\text { Massachusetts } \\
\text { Wisconsin }\end{array}$ & & & \\
\hline Maine & $\begin{array}{l}\text { Regulations on the disposal of } \\
\text { special wastes including diesel } \\
\text { fuels }\end{array}$ & Yes & CELDS 1991 \\
\hline California & $\begin{array}{l}\text { Regulations on leaking underground } \\
\text { fuel tanks }\end{array}$ & Yes & CELDS 1991 \\
\hline Wyoming & $\begin{array}{l}\text { Regulations on well drilling for } \\
\text { oil }\end{array}$ & Yes & CELDS 1991 \\
\hline Rhode Island & Regulations on oil pollution & Yes & CELDS 1991 \\
\hline
\end{tabular}

${ }^{a}$ Group 2A = Probably carcinogenic to humans. This classification is not specified for the fuel oils discussed in this profile, nor for exposure to fuel oils by the general population; rather, this classification applies only to occupational exposures in petroleum refining.

${ }^{\mathrm{b}}$ Group $2 \mathrm{~B}=$ Possibly carcinogenic to humans

${ }^{\circ}$ Group $3=$ Not classifiable as to its carcinogenicity to humans

AFOSH = Air Force Office of Health and Safety; CELDS = Computer-Environmental Legislative Data System; DOT = Department of Transportation; EPA = Environmental Protection Agency; IARC = International Agency for Research on Cancer; IDLH = Immediately Dangerous to Life or Health; NATICH = National Air Toxics Information Clearinghouse; NIOSH = National Institute for Occupational Safety and Health; OSHA = Occupational Safety and Health Administration; PEL = Permissible Exposure Limit; REL $=$ Recommended Exposure Limit; STEL $=$ Short Term Exposure Limit; TWA $=$ Time-Weighted Average; VOC $=$ Volatile Organic Compounds 


\section{REFERENCES}

Acher AJ, Boderie P, Yaron B. 1989. Soil pollution by petroleum products: 1. Multiphase migration of kerosene components in soil columns, Journal of Contaminated Hydrology 4(4):333-345.

Adachi K. 1981. Mass fragmentographic determination of polymethylbiphenyl in foods contaminated with petroleum products. Bull Environ Contam Toxicol 26(6):737-744.

*Agarwal V, Gupta A. 1974. Accidental poisonings in children. Indian Pediatr 11(9):617-621.

Ahlberg M, Berghem L, Nordberg G, et al. 1983. Chemical and biological characterization of emissions from coal- and oil-fired power plants. Environ Health Perspect 47:85-102.

*Ahrens W, Jockel K, Patzak W, et al. 1991. Alcohol, smoking, and occupational factors in cancer of the larynx: A case control study. Am J Ind Med 20:477-493.

* Air Force. 1989. The installation restoration program toxicology guide: Volume 4. Contract no. 1891-A076-Al. Wright Patterson Air Force Base, OH: Harry G. Armstrong Aerospace Medical Research Laboratory, Aerospace Medical Division, Air Force Systems Command. DOE interagency agreement no. 1891-A076-Al.

*Akamaguna AI, Odita JC. 1983. Radiology of kerosene poisoning in young children. Ann Trop Paediatr 3(2):85-88.

Akhtar S, Zahid S, Khan M. 1992. Risk-factors associated with hydropericardium syndrome in broiler flocks. Veterinary Record 131(21):481-484.

*Alden CL. 1986. A review of unique male rat hydrocarbon nephropathy. Toxicol Pathol 14(1): 109111.

*Aldy D, Siregar R, Siregar H. 1978. Accidental poisoning in children with special reference to kerosene poisoning. Paediatr Indones 18( 1-2):45-50.

*Algren J, Rodgers G, JR. 1992. Intravascular hemolysis associated with hydrocarbon poisoning, Pediatric Emergency Care 8( 1):34-35.

Al-Saad H, Al-Timari A. 1993. Sources of hydrocarbons and fatty acids in sediment from Hor AlHammar. Marine Pollution Bulletin 26(10):559.

Allen RL, Manning W, McKenzie KD, et al. 1992a. Development of a monoclonal antibody immunoassay for the detection of gasoline and diesel fuel in the environment. Assoc Am Railroads Contaminated Soils-Diesel Fuel Contamination Research Triangle Park NC.

*Cited in text 
*Allen R, Manning W, McKenzie K, et al. 1992b. A rapid and sensitive immunoassay for the detection of gasoline and diesel fuel in contaminated soil. Journal of Soil Contamination 1(3):227.

Almaguer D, Wilcox T. 1993. Indoor environmental quality "from the ground up." Applied Occupational and Environmental Hygiene 8(8):677-680.

*Ames BN, McCann J, Yamasaki E. 1975. Methods for detecting carcinogens and mutagens with the Salmonella/mammalian-microsome mutagenicity test. Mutat Res 3 1:347-364.

Amitai I, Mogle P, Godfrey S, et al. 1983. Pneumatocele in infants and children: Report of 12 cases. Clin Pediatr (Phila) 22(6):420-422.

Amoozegar A, Warrick AW, Fuller WH. 1986. Movement of selected organic liquids into dry soils. Hazardous Waste and Hazardous Materials 3:29-41.

*Anderson JW, Neff JM. 1977. Accumulation and release of petroleum hydrocarbons by edible marine animals. Proceedings of the International Symposium on recent advances in the assessment of the health effects of environmental pollution, Paris, June 24-28, 1974. Vol. 3:1461-1469.

*Andersson P, Demirbuker M, Blomberg L. 1992. Quantitative hydrocarbon group- analysis of gasoline and diesel fuel by supercritical fluid chromatography. Journal of Chromatography 595(12):301-311.

*Andrasko J. 1983. The collection and detection of accelerant vapors using porous polymers and Curie point pyrolysis wires coated with active carbon. J Forensic Sci 28(2):330-344.

*Andrews J, Lieberman S. 1994. Neutral-network approach to qualitative identification of fuels and oils from laser-induced fluorescence-spectra. Analytica Chimica Acta 285(1-2):237-246.

Andrews GE, Abbass MK, Williams PT, et al. 1989. Factors influencing the composition of the organic fraction of diesel particulates. Journal of Aerosol Science 20(8):1373-1376.

*Annobil SH. 1983. Chest radiographic patterns following kerosene poisoning in Ghanaian children. Clin Radio1 34(6):643-646.

*Annobil SH. 1988. Skin bullae following kerosene poisoning. Ann Trop Pediatr 8(1):45-47.

*Annobil SH, Ogunbiyi OA. 1991. Pulmonary radiology changes in kerosene poisoning in the Asir region of Saudi Arabia. Ann Trop Paediatr 11(4):391-395.

Anonymous. 1980. A recommended standard for occupational exposure to refined petroleum products. Cincinnati, OH: Robert A. Taft Laboratories. Document no. HRP-0030436/O.

Anonymous. 1982. Mutagenicity, teratogenicity, and carcinogenicity. In: Selected petroleum products. Environ Health Criteria 20:50-61.

*APHA. 1985. Standard methods for the examination of water and wastewater. 16th ed. Washington, DC: American Public Health Association. 
*API. 1979a. Acute dermal toxicity: API \#78-3: \#2 home heating oil (10\% cat). Washington, DC: American Petroleum Institute. Project no. 1443-D.

*API. 1979b. Primary eye irritation: API \#79-6: Diesel fuel (marketplace sample). Washington, DC: American Petroleum Institute. Project no. 1443-B.

*API. 1979c. Inhalation/teratology study in rats: Fuel oil. Washington, DC: American Petroleum Institute. Document no. FYI-AX-0183-0230.

API. 1979d. Rat acute oral toxicity study: API \#78-3: \#2 Home heating oil (10\% cat). Washington, DC: American Petroleum Institute. Project no. 1443-E.

API. 1979e. Rat acute oral toxicity study: API \#79-6: Diesel fuel (marketplace sample). Washington, DC: American Petroleum Institute. Project no. 1443-E.

*API. 1979f. Skin sensitization: API \#79-6: Diesel fuel (marketplace sample). Washington, DC: American Petroleum Institute. Project no. 1443-C.

*API. 19798. Teratology study in rats: Diesel fuel. Washington, DC: American Petroleum Institute. Document no. FYI-AX-0183-0230.

*API. 1980a. Acute dermal toxicity: API \#79-6: Diesel fuel (marketplace sample). Washington, DC: American Petroleum Institute. Project no. 1443-D.

API. 1980b. Primary skin irritation: API \#78-3: \#2 Home heating oil (10\% cat). Washington, DC: American Petroleum Institute. Project no. 1443-A.

*API. 1981. Mutagenicity evaluation of diesel fuel in the mouse dominant lethal assay. Washington, DC: American Petroleum Institute.

*API. 1989. Short-term dermal tumorigenesis study of selected petroleum hydrocarbons in male CD-1 mice. Initiation and promotion phases: Final Report API\#36-32643. American Petroleum Institute Washington DC.

*API. 1990. Basic petroleum data book: Petroleum industry statistics. Washington, DC: American Petroleum Institute 10(3):Section VII.

*API. 1991. Basic petroleum data book: Petroleum industry statistics. Washington, DC: American Petroleum Institute 1 1(3):Section VII.

*Apitz S, Borbridge L, Bracchi K, et al. 1992. Fluorescent response of fuels in soils: Insights into fuel-soil interactions. Naval Command, Control and Ocean Surveillance Center, San Diego, CA Jun. 92:9.

Apte MG, Traynor GW, Froehlich DA, et al. 1989. The impact of add-on catalytic devices on pollutant emissions from unvented kerosene heaters. JAPCA 39(9):1228-1230.

Arif JM, Khan SG, Aslam M, et al. 1991. Early biochemical changes in kerosene exposed rat lungs. Chemosphere 22(8):705-712. 
Arif J, Khan S, Aslam M, et al. 1992. Diminution in kerosene-mediated induction of drug metabolizing enzymes by asbestos in rat lungs. Pharmacology and Toxicology 71(1):37-40.

*Army. 1986. Literature survey and data base assessment: Microbial fate of diesel fuel and fog oils. Project no. 3E162720A835. Frederick, MD: U.S. Army Bioengineering Research and Development Laboratory, Fort Detrick. Document no. PC A03/MFAOl.

Arthur M, O’Brien G, Marsh S, et al. 1992. Evaluation of innovative approaches to simulate degradation of jet fuels in subsoils and groundwater. Battelee Columbus Labs, OH Jun. 92:35.

Ashkenazi AE, Berman SE. 1961. Experimental kerosene poisoning in rats: Use of ${ }^{14} \mathrm{C}$ labelled hendecane as indicator of absorption. Pediatrics 28:642-649.

ASTM. 1992. Standard specifications for fuel oils. American Society for Testing and Materials. Philadelphia, PA.

ASTM. 1994a. Standard specification for aviation turbine fuel. American Society for Testing and Materials. Philadelphia, PA.

ASTM. 1994b. Standard specification for diesel fuel oils. American Society for Testing and Materials, Philadelphia, PA.

Athens W, Jockel K, Patzak W, et al. 1991. Alcohol, smoking, and occupational factors in cancer of the larynx: A case-control study. American Journal of Industrial Medicine 20(4):477-493.

*ATSDR. 1989. Toxicological profile for benzene. Atlanta, GA: U.S. Department of Health and Human Services, Public Health Service, Agency for Toxic Substances and Disease Registry.

*ATSDR. 1990a. Toxicological profile for toluene. Atlanta, GA: U.S. Department of Health and Human Services, Public Health Service, Agency for Toxic Substances and Disease Registry.

*ATSDR. 1990b. Toxicological profile for lead. Atlanta, GA: U.S. Department of Health and Human Services, Public Health Service, Agency for Toxic Substances and Disease Registry.

*ATSDR. 1991 a. Toxicological profile for total xylenes. Atlanta, GA: U.S. Department of Health and Human Services, Public Health Service, Agency for Toxic Substances and Disease Registry.

*ATSDR. 1991b. Toxicological profile for polycyclic aromatic hydrocarbons. Atlanta, GA: US. Department of Health and Human Services, Public Health Service, Agency for Toxic Substances and Disease Registry.

Azizi BHO, Henry RL. 1990. Effects of indoor air pollution on lung function of primary school children in Kuala Lumpur. Pediatr Pulmonol 9(1):24-29.

*Azizi BHO, Henry RL. 1991. The effects of indoor environmental factors on respiratory illness in primary school children in Kuala Lumpur. Int J Epidemiol 20(1):144-150.

*Bailey B, Kohl K. 1991. Chemical analysis of aromatics in diesel fuels. Southwest Research inst, San Antonio, TX. 
Bakatubia M, Talleyrand D. 1978. [Infant pneumopathy from kerosene ingestion.] Ann Sot Belg Med Trop 58(3):251-253. (French)

Baldachin BJ, Malmed PM. 1964. Clinical and therapeutic aspects of kerosene poisoning: A series of 200 cases. Br Med J 2:28-30.

*Baldwin RE. 1977. Adsorption-elution technique for concentration of hydrocarbon vapors. Arson Anal News1 1(6):9-12.

Barbari TA, King CJ. 1982. Equilibrium distribution coefficients for extraction of chlorinated hydrocarbons and aromatics from water into undecane. Environ Sci Technol 16(9):624-627.

Barber DM, Cousin DA, Seawtight D. 1987. An episode of kerosene poisoning in dairy heifers. Vet Ret 120(19):462-463.

Barnard K, Gordon D. 1991. Sunken vessels and aircraft containing hazardous materials in Puget Sound. Environmental Protection Agency. Seattle, WA.

*Barnes DG, Dourson M. 1988. Reference dose (RfD): Description and use in health risk estimates. Regul Toxicol Pharmacol 8:471-486.

*Barrientos A, Ortuno MT, Morales JM, et al. 1977. Acute renal failure after use of diesel fuel as shampoo. Arch Intern Med 137:1217.

Barter RA, Byrne MJ, Carter RF. 1966. Pulmonary hyaline membrane: Late results of injury to the lung linings. Arch Dis Child 41(219):489-495.

Bartha R. 1990. Bioremediation of hydrocarbon-contaminated soil: A feasibility study. New

Brunswick, NJ: Rutgers University, Department of Biochemistry and Microbiology.

*Bartha R. Atlas RM. 1977. The microbiology of oil spills. Adv Appl Microbial 22:225-266.

Beamon RF, Siegel CH, Landers G, et al. 1976. Hydrocarbon ingestion in children: A six-year retrospective study. JACEP 5(10):771-775.

Bechtold WE, Dutcher JS, Brooks AL, et al. 1985. Contribution of primary aromatic amines to the mutagenicity of gasifer tars and coal oils. Mutat Res 155:7-16.

Beck LS, Hepler DI, Hansen SL. 1983. The acute toxicology of selected petroleum hydrocarbons. In: MacFarland HN, ed. Proceedings of the Symposium on the toxicology of petroleum hydrocarbons, Washington, DC, May 1982. Washington, DC: American Petroleum Institute, 1-12.

*Beck LS, Hepler DL, Hansen KL. 1984. The acute toxicology of selected petroleum hydrocarbons. In: MacFarland HN, Holdsworth CE, MacGregor JA, et al., eds. Advances in modern environmental toxicology. Volume VI: Applied toxicology of petroleum hydrocarbons. Princeton, NJ: Princeton Scientific Publishers, Inc.

Behera D, Jindel SK. 1991. Respiratory symptoms in Indian women using domestic cooking fuels. Chest 100(2):355-358. 
*Beliles RP, Mecler FJ. 1983. Inhalation teratology of jet fuel A, fuel oil and petroleum naphtha in rats. In: MacFarland HN, ed. Proceedings of the Symposium on the toxicology of petroleum hydrocarbons, Washington, DC, May 1982. Washington, DC: American Petroleum Institute, 233-238.

*Belkin F, Esposito GG. 1986. Dynamic thermal stripping procedure for the analysis of fuel oil no. 2 and kerosene in water. J Chromatogr Sci 24:216-219.

Benestad C, Moeller M, Osvik A, et al. 1985. Air pollution from biomass heated boilers compared with that from waste incineration and oil combustion. Energy Biomass 1985:819-821.

Benz RD, Beltz PA. 1980. Cytogenic toxicologic testing with dogs. Environ Mutagen 2:312-313.

*Berwick M, Leaderer BP, Stowijk JA, et al. 1989. Lower respiratory symptoms in children exposed to nitrogen dioxide from unvented combustion sources. Environment International 15( 1-6):369-373.

*Bianchi AP, Varney MS, Phillips J. 1991. Analysis of industrial solvent mixtures in water using a miniature purge-and-trap device with thermal desorption and capillary gas chromatography-mass spectrometry. J Chromatogr 557(1-2):429-439.

Bieri R. 1974. Identification of hydrocarbons in and extract from estuarine water accommodated No. 2 fuel oil. International Marine Pollution Monitoring (Petroleum) Symposium Gaithersburg, Md.

Biles RW. 1984. Summary of results of skin painting bioassays of mid-distillates. Submitted by RW

Biles, Exxon Corporation, NJ to CA Halder, Standard Oil Company, Chicago, IL, October 22, 1984.

Biles RW, McKee RH. 1983. Toxicological testing for hazard identification in synthetic fuel technology. Dev Toxicol Environ Sci 11:13-21.

*Biles R, McKee R, Lewis S, et al. 1988. Dermal carcinogenic activity of petroleum-derived middle distillate fuels. Toxicology 53:301-314.

Birmingham DJ. 1988. Contact dermatitis and related dermatoses associated with petroleum recovery and use. Occupational Medicine: State of the Art Reviews 3(3):511-523.

Blackburn GR, Deitch RA, Schreiner CA, et al. 1984. Estimation of the dermal carcinogenic activity of petroleum fractions using a modified Ames assay. Cell Biol Toxicol 1:67-80.

*Blackburn GR, Deitch RA, Schreiner CA, et al. 1986. Predicting carcinogenicity of petroleum distillation fractions using a modified Sulmonella mutagenicity assay. Cell Biol Toxicol 2:63-84.

Blackbum G, Deitch R, Schreiner C, et al. 1987. Testing of petroleum middle distillates in a modified Ames assay. Environmental Mutagenesis 9:15.

*Blakeslee JR, Elliot AM, Carter LJ. 1983. In vitro effects of polynuclear aromatic hydrocarbons on FeSV transformation of human cells. In: Cooke M, Dennis AJ, eds. Proceedings of the Seventh International Symposium on polynuclear aromatic hydrocarbons: Formation, metabolism, and measurement. Columbus, OH: Battelle Press, 123-133. 
*Blumer M, Souza G, Sass J. 1970. Hydrocarbon pollution of edible shellfish by an oil spill. Marine Biology 5: 195-202.

Bobra AM, Brown JR, Clark AG. 1978. Bacterial degradation of crude oil and oil compounds in pure and mixed culture systems. In: Afghan BK, MacKay D, eds. Hydrocarbons and halogenated hydrocarbons in the aquatic environment. New York, NY: Plenum Press, 521-530.

*Boehm PD, Quinn JG. 1973. Solubilization of hydrocarbons by the dissolved organic matter in sea water. Geochima et Cosmochimica Acta 37( 11):2459-2477.

*Boehm PD, Quinn JG. 1974. The solubility behavior of no. 2 fuel oil in sea water. Mar Pollut Bull 5(7):101-105.

Boffetta P, Cardis E, Vainio H, et al. 1991. Cancer risks related to electricity production. European J Cancer 27(11):1504-1519.

*Boylan DB, Tripp BW. 1971. Determination of hydrocarbons in seawater extracts of crude oil and crude oil fractions. Nature 230(5288):44-47.

Bracher V, Neuschaefer A, Allen W. 1991. The effect of intrauterine infusion of kerosene on the endometrium of mares. Journal of Reproduction an Fertility S44:706-707.

Brambley MR, Darby WP. 1984. Portable kerosene heaters and indoor air quality. In: Pibazari M, Devinny JS, eds. Environmental engineering: Proceedings of the 1984 Specialty Conference, University of Southern California, June 25-27, 1984. New York, NY: American Society of Civil Engineers, 155-160.

Bratton L. 1975. Ingestion of charcoal lighter fluid. J Pediatr 87:633-637.

Braun AG, Nichinson BB, Horowitz PB. 1982. Inhibition of tumor cell attachment to concanavalin A-coated surfaces as an assay for teratogenic agents: Approaches to validation. Teratogenesis Carcinog Mutagen 2(3-4):343-354.

Braun AG, Busby WF, Liber HL, et al. 1987. Chemical and toxicological characterization of residential oil burner emissions: 2. Mutagenic, tumorigenic, and potential teratogenic activity. Environ Health Perspect 73:235-246.

*Bronstein AC, Currance PL. 1988. Emergency care for hazardous materials exposure. Washington, DC: The C.V. Mosby Company, 175-176.

*Brown J III, Burke B, Dajani AS. 1974. Experimental kerosene pneumonia: Evaluation of some therapeutic regimens. J Pediatr 84(3):396-401.

*Bruner RH. 1984. Pathologic findings in laboratory animals exposed to hydrocarbon fuels of military interest. In: Mehlman MA, Hemstreet GP III, Thorpe JJ, et al., eds. Advances in modern environmental toxicology. Volume VII: Renal effects of petroleum hydrocarbons. Princeton, NJ: Princeton Scientific Publishers, 133-140. 
Bruner RH, Pitts LL. 1983. Nephrotoxicity of hydrocarbon propellants to male, Fischer-344 rats. Proceedings of the 13th Conference on environmental toxicology, University of California, Irvine, CA, November 1982. Dayton, OH: Overlook Branch, 337-363.

*Brtinner S, Rovsing J, Wulf H. 1964. Roentgenographic changes in the lungs of children with kerosene poisoning. Am Rev Respir Dis 89:250-254.

Brunner R. 1983. Nephrotoxicity of hydrocarbon propellents to male Fishcehr-344 rats. Proceedings of the 13th Conference on environmental toxicology, University of California, Irvine, November 1982. Dayton, OH: Overlook Branch, p. 337-363.

Buch N, Ahmed K, Sethi A. 1991. Poisoning in children. Indian Pediatr 28(5):521-524.

*Buckley EN, Jonas RB, Pfaender FK. 1976. Characterization of microbial isolates from an estuarine ecosystem: Relationship of hydrocarbon utilization to ambient hydrocarbon concentrations. Appl Environ Microbial 32(2):232-237.

*Budavari S, O’Neil MJ, Smith A, et al. 1989. The Merck index: An encyclopedia of chemicals, drugs, and biologicals. Rahway, NJ: Merck and Co., 834.

Buetzer P. 1985. [Handling of toxic substances: Experience and hazard: A vapor hazard index for substances.] Swiss Chem 7(9):25-26, 28. (German)

Burley S, Huber G. 1971. The effect of toxic agents commonly ingested by children in antibacterial defenses in the lungs [Abstract]. Pediatr Res 5:405

*Burns KA, Teal JM. 1979. The West Falmouth oil spill: Hydrocarbons in the salt marsh ecosystem. Estuarine and Coastal Marine Science 8(4):349-360.

Butcher BT, Salvaggio JE. 1986. Occupational asthma. J Allergy Clin Immunol 78(4 Part 1):547-556.

*Butt AI, Riazuddin S, Shakoori AR, et al. 1988. Isolation and identification of petroleum hydrocarbon degrading bacteria from the local environments. Pak J Zoo1 20(4):391-399.

Bwibo NO. 1969. Accidental poisoning in children in Uganda. Br Med J 4(683):601-602.

Caceres T, Soto H, Lissi E, et al. 1983. Indoor house pollution: Appliance emissions and indoor ambient concentrations. Atmos Environ 17(5):1009-1013.

Cain PM. 1975. Comparison of kerosenes using capillary gas liquid chromatography. J Forensic Sci 15(4):301-308.

Cain D, Helsel DR, Ragone SE. 1989. Preliminary evaluations of regional ground-water quality in relation to land use. Ground Water 27(2):230-244.

Calkins WH, Deye JF, Hartgrove RW, et al. 1981. Synthetic crude oils from coal: Mutagenicity and tumor-initiation screening tests. Department of Energy Symposium Series 54:462-470. 
Carmichael P, Pfau W, Ni She M, et al. 1991. Formation of DNA-adducts in human and mouse skin following treatment with used engine oil and elucidation of some of the contributing PAHs by 32P-poslabeling (meeting abstract). Proc Annu Meet Am Assoc Cancer Res; 32:A582.

*Carpenter CP, Geary DL, Myers RC, et al. 1976. Petroleum hydrocarbon toxicity studies: XI. Animal and human response to vapors of deodorized kerosene. Toxicol Appl Pharmacol 36(3):443-456.

*Carpenter CP, Kinkead ER, Geary DL Jr, et al. 1975. Petroleum hydrocarbon toxicity studies: I. Methodology. Toxicol Appl Pharmacol 32:246-262.

*Casaco A, Gonzalez R, Arruzazabala L, et al. 1982. Studies on the effects of kerosine aerosol on airways of rabbits. Allergol Immunopathol 10(5):361-366.

Casaco A, Gonzalez R, Arruzazabala L, et al. 1983. Effects of kerosine on the airways of experimental animals. Rev Cubana Med 22(5):490-500.

Casaco A, Carvajal D, Noa M, et al. 1985a. Effects of kerosene on airway sensitization to egg albumin in guinea pig. Allergol Immunopathol 13(3):235-239.

*Casaco A, Garcia M, Gonzalez R, et al. 1985b. Induction of acetylcholinesterase inhibition in the guinea pig trachea by kerosene. Respiration 48( 1):46-49.

*Casaco A, Gonzalez R, Arruzazabala L, et al. 1985c. Kerosene aerosol induces guinea pig airway hyperreactivity to acetylcholine. Respiration 47(3):190- 195.

Casaco A, Gonzalez R, Arruzazabala L, et al. 1989. Effect of cooking emissions on airways of rabbits. Revista Cubana de Ciencias Biologicas

*CELDS. 1991. Computer-Environmental Legislative Data Systems. University of Illinois, Urbana, IL. June 20, 1991.

*Chan WC, Colbourne MJ, Fung SC, et al. 1979. Bronchial cancer in Hong Kong 1976-1977. Br J Cancer 39(2):182-192.

Chandra RK. 1968. Kerosene swallowing [Editorial]. J Trop Pediatr 14(1):1-2.

Chang D, Lopez I. 1992. Determination of Kerosene and \#2 diesel in soil by purge and trap vs. extraction procedure. Journal of Soil Contamination 1(3):239.

Chawla SC, Nehta SP. 1973. A study of host and environment factors in cases of accidental poisoning admitted in Irwin hospital. Indian J Med Res 61(5):724-731.

Chemical Regulation Reporter. 1987. Furnace oil promotes, not initiates, skin cancer, AMOCO report says in risk notice. The Bureau of National Affairs, Inc. (November 27, 1987), 1516-1517.

Chen T, Lam W, Raymond R. 1992. Novel Diesel-fueled engine for microclimate cooling for the individual soldier. Tecogen, Inc Waltham, MA. 
Chet I, Mitchell R. 1976. Petroleum hydrocarbons inhibit decomposition of organic matter in sea water. Nature 261(5558):308-309.

Chlobowska Z, Madej A. 1978. [Use of gas chromatography for identification of hydrocarbon products in contaminated water and other materials: II.] Z Zagdnien Kryminal 13:103-112. (Polish).

*Christensen LB, Larsen TH. 1993. Method for determining the age of diesel oil spills in the soil. Ground Water Monitor Remediation 13(4): 142.

Chu TC, Chu EJ. 1966. Thin-layer chromatography of methyl esters of porphyrins, chlorins, and related compounds with Eastman "chromagram.” J Chromatogr 21(1):46-51.

*Clark C, Walter M, Ferguson P, et al. 1988. Comparative dermal carcinogenesis of shale and petroleum derived distillates. Toxicology and Industrial Health 4:11-22.

Clarkson SG, Tom BL, Babcock AJ, et al. 1984. Results of testing unvented kerosene heaters in a house: Gas emissions, surface temperatures and fuel consumption rates. In: Proceedings of the 77th Annual Meeting of the Air Pollution Control Association, San Francisco, CA, June 24-29, 1984, Vol. 2. Pittsburgh, PA: APCA.

CLPSD. 1990. Contract Laboratories Program Statistical Database. Washington, DC: U.S. Environmental Protection Agency. January, 1990.

Coast Guard. 1985. Chemical Hazard Response Information System (CHRIS): Hazard assessment handbook. Washington, DC: U.S. Department of Transportation, U.S. Coast Guard. Commandant Instruction M.16465.12A.

*Coleman WE, Melton RG, Slater RW, et al. 1981. Determination of organic contaminants by the Grob closed-loop-stripping technique. J Am Water Works Assoc 71: 119-125.

*Coleman WE, Munch JW, Streicher RP, et al. 1984. The identification and measurement of components in gasoline, kerosene, and no. 2 fuel oil that partition into the aqueous phase after mixing. Arch Environ Contam Toxicol 13:171-178.

Comar CL, Nelson N. 1975. Health effects of fossil fuel combustion products: Report of a workshop. Environ Health Perspect 12: 149-170.

*Commonwealth of Massachusetts. 1983. Massachusetts Water Quality Standards. Boston, MA: Massachusetts Surface Water Quality Standards. Massachusetts 314 CMR 4.00.

*Commonwealth of Virginia. 1988. Commonwealth of Virginia State Water Control Board Regulations. Richmond, VA: Commonwealth of Virginia State Water Control Board Regulations, Water Quality Standards.

* Conaway CC, Schreiner CA, Cragg ST. 1984. Mutagenicity evaluation of petroleum hydrocarbons. In: Mac Farland HN, Holdsworth CE, MacGregor JA, et al., eds. Advances in modem toxicology. Volume VI: Applied toxicology of petroleum hydrocarbons. Princeton, NJ: Princeton Scientific Publishers, 89-107. 
*CONCAWE. 1985. Health aspects of petroleum fuels - general principles. Report no. 2/85. Oil Companies' European Organization for Environmental and Health Protection. The Hague, Netherlands, p. 3-19. Document no. PB85-230480.

*Connell DW, Miller GJ. 1980. Petroleum hydrocarbons in aquatic ecosystems: Behavior and effects of sublethal concentrations: Part 1. Crit Rev Environ Control 11(1):37-104.

Connell DW, Miller GJ. 1981. Petroleum hydrocarbons in aquatic ecosystems: Behavior and effects of sublethal concentrations: Part 2. Crit Rev Environ Control 11(2):105-162.

Cookson D, Smith B. 1992. Observed and predicted properties of jet and diesel fuels formulated from coal-liquefaction and fischer-tropsch feedstocks. Energy and Fuels 6(5):581-585.

*Cooney JJ, Silver SA, Beck EA. 1985. Factors influencing hydrocarbon degradation in three freshwater lakes. Microb Ecol 11(2):127-137.

Cooper J, Mattie D. 1993. Developmental toxicity of JP-8 jet fuel in the rat. Toxicologist 13(1):78.

Cooper KR, Alberti RR. 1984. Effect of kerosene heater emissions on indoor air quality and pulmonary function. Am Rev Respir Dis 129(4):629-631.

*Cooper RE, Hedrick HG. 1976. Activity of soil bacteria on petroleum waste adjacent to an active oil well. Soil Sci 122(6):331-338.

Corapcioglu MY, Hossain MA. 1990. Theoretical modeling of biodegradation and biotransformation of hydrocarbons in subsurface environments. J Theor Biol 142(4):503-516.

*Coruh M, Inal H. 1966. Kerosene poisoning in children with special reference to lung complication. Turk J Pediatr 8(1):36-42.

*Cowan MJ, Jenkins LJ Jr. 1981. Navy toxicity study of shale and petroleum JP-5 aviation fuel and diesel fuel marine. In: Griest WH, Guerin MR, Coffin DL, eds. Health effects investigation of oil shale development. Ann Arbor, MI: Ann Arbor Science Publishers, Inc., 129-139.

*Cox BA, Anderson JW, Parker JC. 1975. An experimental oil spill: The distribution of aromatic hydrocarbons in the water, sediment, and animal tissues within a shrimp pond. In: Proceeding of the Conference on the Prevention and Control of Oil Pollution, p. 607-612.

*Crisp AJ, Bhalla AK, Hoffhrand BJ. 1979. Acute tubular necrosis after exposure to diesel fuel. Br Med J 2:177.

*Cundell AM, Traxler RW. 1976. Psychrophilic hydrocarbon-degrading bacteria from Narragansett Bay, Rhode Island, U.S.A. Material und Organismen 11(1):1-17.

*Custance SR, McCaw PA, Kopf AC, et al. 1992. Environmental fate of the chemical Mixtures: Crude oil, JP-5, mineral spirits, and diesel fuel. Journal of Soil Contamination 1(4):379.

Daffner RH, Jimenez JP. 1973. The double gastric fluid level in kerosene poisoning. Radiology 106(2):383-384. 
Dahlgran JR. 1981. Simultaneous detection of total and halogenated hydrocarbons in complex environmental samples. Journal of High Resolution Chromatography and Chromatography Communications 4(8):393-397.

*Daisey J, Gundel L. 1991. Tracing the sources of indoor aerosols using evolved gas-analysis. Aerosol Science and Technology 14(1):25-32.

Daisey JM, Hershman RJ, Kneip TJ. 1982. Ambient levels of particulate organic matter in New York City, USA, in winter and summer. Atmos Environ 16(9):2162-2168.

Dalbey W, Lock S, Garfinkel S, et al. 1982. Inhalation exposures of rats to aerosolized diesel fuel. In: MacFarland HN, Holdsworth CE, MacGregor JA, et al., eds. The toxicology of petroleum hydrocarbons. Washington, DC: American Petroleum Institute, 13-25.

*Dalbey W, Lock S. 1983. Chemical characterization and toxicological evaluation of airborne mixtures: Inhalation toxicology of diesel fuel obscurant aerosol in Sprague-Dawley rats: Final report, phase 2: Acute exposures. Oak Ridge, TN: Oak Ridge National Laboratory. ORN/TM-8867.

* Dalbey W, Henry M, Holmberg R, et al. 1987. Role of exposure parameters in toxicity of aerosolized diesel fuel in the rat. J Appl Toxicol 7(4):265-275.

*Danielson LL, Gentner WA. 1970. Effect of solvent composition on inactivation of several phenyl and thio carbamate herbicides in soil. Proceedings of the Northeastern Weed Control Conference 24:308-312. deAraufo CR, Flores H. 1978. Improved spectrophotometric vitamin A assay. Clin Chem 24(2):386.

*Deichmann WB, Kitzmiller KV, Witherup BS, et al. 1944. Kerosene intoxication. Ann Intern Med 21:803-823.

De la Lande Cremer CN, Van der Veen L, Douwes HT. 1978. [Effect of petroleum products on the development of spring wheat.] Rapp Inst Bodemvruchtbaarheid 12: 1-22. (Dutch)

*Dell'acqua R, Bush B. 1973. Microdetermination of gasoline in potable waters by gas chromatography. Int J Environ Anal Chem 3:141-146.

DeMaria MJ, Arola L, Alemany M. 1989. Effect of the percutaneous administration of hexadecane, 2,4-dinitrophenol, gas oil, and fuel oil on weight changes in mice. Toxicol Environ Chem 19(1-2):3545 .

Demarini DM, Brimer PA, Hsie AW. 1984. Cytotoxicity and mutagenicity of coal oils in the CHO/HGPRT assay. Environ Mutagen 6(4):517-527.

*Dibble JT, Bartha R. 1979. Rehabilitation of oil-inundated agricultural land: A case history. Soil Sci 128( 1):56-60.

*Dice WH, Ward G, Kelley J, et al. 1982. Pulmonary toxicity following gastrointestinal ingestion of kerosene. Ann Emerg Med 11: 138-142. 
DiCicco G, Naviglio A, Spinazzola A. 1986. [Characterization of emissions produced by thermoelectric power plants fired with fuel oil and coal: Evaluation of the relative health and carcinogenic hazards associated with them.] Acqua Aria 7:667-674. (Italian)

*Diem D, Kerfoot H, Ross B. 1988. Field evaluation of a soil-gas analysis method for detection of subsurface diesel fuel contamination: Second national outdoor action conference on aquifer restoration, ground water monitoring and geophysical methods. National Water Well Association Dublin, OH.

DOE. 1978. Embryo culture in teratological surveillance and serum proteins in development. Contract no. EY-76S-02-3139. Washington, DC: U.S. Department of Energy. Document no. C00-3139-31.

DOE. 1980. Health effects of coal technologies: Research needs. Washington, DC: U.S. Department of Energy. Report no. MTR-79W15902.

DOE. 1982. Exploratory research on mutagenic activity of coal-related materials. Contract no. DOE/PC/42692T2. Washington, DC: U.S. Department of Energy. Document no. DE83012791.

DOE. 1986a. Comparative toxicity of crude and refined coal liquids and analogous petroleum products: I. Chronic dermal toxicity in mice. Contract no. DE-AC05-84OR21400. Washington, DC: U.S. Department of Energy. Document no. DE86004762.

DOE. 1986b. Comparison of pollutant emission rates from unvented kerosene and gas space heaters. Washington, DC: U.S. Department of Energy. Document no. DE86015133.

DOE. 1986c. Effects of coal rank on the chemical composition and toxicological activity of coal liquefaction materials. Contract no. DE-AC06-76RLO-1830. Washington, DC: U.S. Department of Energy. Document no. DE86011015.

DOE. 1986d. Evaluation of occupational health and environmental hazards associated with storage and processing of fossil fuels. Washington, DC: U.S. Department of Energy. Document no. DOE/LC/10924-2168.

DOE. 1986e. Sources of nitrogen oxide pollution in the indoor environment. Contract no. BNL-39209. Washington, DC: U.S. Department of Energy. Document no. DE87006742.

DOE. 1988a. Indoor air quality in 300 homes in Kingston/Harriman, Tennessee. Contract no. DE-AC0584OR21400. Washington, DC: U.S. Department of Energy. Document no. ORNL-6401.

DOE. 1988b. Use of medium scale experiments to determine smoke characteristics. Washington, DC: U.S. Department of Energy. Document no. DE89008333.

DOE. 1989a. Impact of kerosene heater usage on indoor $\mathrm{NO}_{2}$ exposures in 50 East Tennessee homes. Washington, DC: U.S. Department of Energy, in cooperation with Harvard University School of Public Health, Boston, MA.

DOE. 1989b. Tracing the sources of indoor aerosols using evolved gas analysis. Washington, DC: U.S. Department of Energy. Document no. DE90000182. 
DOE. 1989c. West Valley demonstration project: Implementation of the kerosene mitigation plan. Contract no. DE-AC07-81NE 44139. Washington, DC: U.S. Department of Energy, Assistant Secretary for Nuclear Energy. Document no. DE 88015385.

DOE. 1993. Petroleum supply monthly, February 1993. Department of Energy Office of Oil and Gas. Washington DC.

DOE/ EIA 1993a. Winter fuels report, week ending April 2, 1993. Department of Energy Office of Oil and Gas. Washington DC.

DOE/ EIA 1993b. Winter fuels report, week ending November 26, 1993. Department of Energy, Office of Oil and Gas. Washington DC.

DOE/HHS/EPA. 1980. Health effects of coal technologies: Research needs. Washington, DC: Department of Energy/Department of Health and Human Services/Environmental Protection Agency, Federal Interagency Committee on the Health and Environmental Effects of Energy Technologies. Document no. PB81-118796.

Dong JI, Bozzelli JW. 1989. Benzo-a-pyrene levels in several indoor environments with kerosene heaters and wood-burning fireplaces. Chemosphere 18(9-10):1829-1836.

DOT. 1984. Emergency response book. Washington, DC: Department of Transportation, U.S. Government Printing Office.

*DOT. 1989a. Hazardous materials table. US. Department of Transportation. Code of Federal Regulations. 49 CFR 172.101 Appendix A.

*DOT. 1989b. List of hazardous substances and reportable quantities. U.S. Department of Transportation. Federal Register 54 (185): 39501-39505.

*Dudin AA, Rambaud-Cousson A, Thalji A, et al. 1991. Accidental kerosene ingestion: A three-year prospective study. Ann Trop Paediatr 11(2):155-161.

Eade NR, Taussig LM, Marks MI. 1974. Hydrocarbon pneumonitis. Pediatrics 54(3):351-357.

*Easley JR, Holland JM, Gipson LC, et al. 1982. Renal toxicity of middle distillates of shale oil and petroleum in mice. Toxicol Appl Pharmacol 65:84-91.

Ebert AG, Schleifer CR, Hess SM. 1966. Absorption, disposition, and excretion of ${ }^{3} \mathrm{H}$-mineral oil in rats. J Pharm Sci 55:923-929.

Eckardt RE. 1983. Petroleum and petroleum products. Encyclopaedia of Occupational Health and Safety 2:1649-1652.

Edelfors S, Raven-Jonsen A. 1992. Effect of organic solvents on nervous cell membrane as measured by changes in the calcium magnesium ATPase activity and fluidity of synaptosomal membrane. Pharmacology and Toxicology 70(3): 181- 187. 
*Edgerton SA, Coutant RW, Henley MV. 1987. Hydrocarbon fuel spill dispersion on water: A literature review. Chemosphere 16(7):1475-1487.

el-Habashi A, Fahin A, Kamel A. 1969. Toxi-pathological studies on kerosene. J Egypt Med Assoc 52(5):421-426.

*Ellenhorn MJ, Barceloux DG. 1988. Medical toxicology: Diagnosis and treatment of human poisoning. New York, NY: Elsevier Publishing, 944-945.

Ellenton JA, Hallett DJ. 1981. Mutagenicity and chemical analysis of aliphatic and aromatic fractions of Prudhoe Bay crude oil and fuel oil no. 2. J Toxicol Environ Health 8(5-6):959-972.

Elmgren R, Hansson S, Larsson U, et al. 1983. The "Tsesis" oil spill: Acute and long-term impact on the benthos. Mar Biol (Berlin) 73(1):51-65.

Emmelin A, Nyskrom L, Wall S. 1993. Diesel exhaust exposure and smoking - A case-referent study of lung-cancer among Swedish dock workers. Epidemiology 4(3):237-244.

*EPA. 1977. Criteria for the evaluation of permit applications for ocean dumping of material. Washington, DC: U.S. Environmental Protection Agency. Federal Register 42(7):2476-2482.

EPA. 1978. Combustion research on characterization of particulate organic matter in flames. Research Triangle Park, NC: U.S. Environmental Protection Agency, Industrial Environmental Research Laboratory.

EPA. 1980a. Characterization of kerosene heater emissions inside two mobile homes. Contract no. EPA-600-D-90-115. Research Triangle Park, NC: U.S. Environmental Protection Agency, Atmospheric Research and Exposure Assessment Laboratory, Harvard School of Public Health, Boston, MA. Document no. PB90-263013.

EPA. 1980b. Substantial risk report EPA number 8EHQ-0879-0301. Environmental Protection Agency. Washington DC.

*EPA. 1981. Long term effects of the barge FLORIDA oil spill. Contract no. EPA-R-801001-02. Cincinnati, OH: U.S. Environmental Protection Agency, Office of Research and Development, Municipal Environmental Research Laboratory. Report no. EPA-600/2-81-012.

EPA. 1983. Summary of preliminary results from lifetime skin-painting study. TSCA Chem-in-Prog Bull 4 \#3:10 May 1983. Environmental Protection Agency. Washington DC.

*EPA. 1984. Permeability of compacted soils to solvents mixtures and petroleum products. In: Proceedings of the Tenth Annual Research Symposium for land disposal of hazardous waste, Ft. Mitchell, Kentucky, April 3-5, 1984. Cincinnati, OH: U.S. Environmental Protection Agency, Office of Research and Development, Municipal Environmental Research Laboratory, 124- 137. Contract no. 6803-3131.

EPA. 1985. Literature survey of environmental concerns associated with in situ coal/oil shale operations. Research Triangle Park, NC: U.S. Environmental Protection Agency, Air and Engineering Research Laboratory. Document no. EPA-68-02-3994. 
*EPA. 1986a. Literature survey of environmental concerns associated with in situ coal/oil shale operations. Contract no. 68-02-3994. Research Triangle Park, NC: U.S. Environmental Protection Agency, Office of Research and Development, Air and Energy Engineering Research Laboratory. EPA report no. EPA/600/7-86/022.

*EPA. 1986b. Movement of selected organic liquids into dry soils. Ada, OK: U.S. Environmental Protection Agency, Office of Research and Development, Robert S. Kerr Environmental Research Laboratory. EPA report no. EPA/600/J-86052.

*EPA. 1986c. Quality criteria for water. Washington, DC: U.S. Environmental Protection Agency. EPA 440/5-86-001.

EPA. 1987a. U.S. EPA evaluation of volumetric UST leak detection methods. In: Proceedings of the 13th Annual Research Symposium, Cincinnati, OH, May 6-8, 1987. Cincinnati, OH: U.S. Environmental Protection Agency, 164- 171.

EPA. 1987b. Human exposure to mutagens from indoor combustion sources. Research Triangle Park, NC: U.S. Environmental Protection Agency, Health Effects Research Laboratory. Report no. EPA/600/D-87/144.

*EPA. 1987c. Identification and listing of hazardous waste. Washington, DC: U.S. Environmental Protection Agency. Federal Register 52(15):2522-2528.

EPA. 1988a. Evaluating sources of indoor air pollution. Research Triangle Park, NC: U.S.

Environmental Protection Agency, Office of Research and Development, Air and Energy Engineering Research Laboratory. EPA report no. EPA/600/D-88/086.

*EPA. 1988b. General pretreatment regulations for existing and new sources of pollution. Washington, DC: U.S. Environmental Protection Agency. Code of Federal Regulations. 403.2 Appendix B.

*EPA. 1988c. General pretreatment regulations for existing and new sources. Washington, DC: U.S. Environmental Protection Agency. Federal Register 53(200):40610-40616.

EPA. 1988d. Integrated approach to the characterization of particle and organic emissions from unvented kerosene space heaters. Research Triangle Park, NC: U.S. Environmental Protection Agency, Office of Research and Development, Air and Energy Engineering Research Laboratory. EPA report no. EPA/600/D-88-25 1.

EPA. 1988e. Laboratory studies of vacuum-assisted steam stripping of organic contaminants from soil. In: Proceedings of the Fourteenth Annual Research Symposium for land disposal, remedial action, incineration, and treatment of hazardous wastes, Cincinnati, Ohio, May 9-1 1, 1988. Cincinnati, OH: U.S. Environmental Protection Agency, Office of Research and Development, Risk Reduction Engineering Laboratory, 65-92.

EPA. 1988f. Review and evaluation of the influence of chemicals on the conductivity of soil clays. Contract no. EPA-R-808824. Cincinnati, OH: U.S. Environmental Protection Agency, Office of Research and Development, Hazardous Waste Engineering Research Laboratory. EPA report no. EPA/600/2-88/016. 
EPA. 19888. Preliminary results of chronic skin-painting studies on mice. TSCA Chem-in Prog Bull 9 \#2:5 m=Mar 1988. Environmental Protection Agency. Washington DC.

EPA. 1989a. Case study: Multipollutant indoor air quality study of 300 homes in Kingston/Harriman, Tennessee. Research Triangle Park, NC: U.S. Environmental Protection Agency, Health Effects Research Laboratory. Contract no. EPA-R-81 1650.

*EPA. 1989b. Pesticides required to be reregistered: List C. U.S. Environmental Protection Agency. Federal Register 54 (104): 30846-30855.

*EPA. 1989c. Reregistration. U.S. Environmental Protection Agency. Code of Federal Regulations. 40 CFR 152.146.

EPA. 1990a. Case study: Multipollutant indoor air quality study of 300 homes in Kingston/Harriman, Tennessee. Research Triangle Park, NC: U.S. Environmental Protection Agency, Health Effects Research Laboratory. EPA report no. EPA/600/D-901126.

EPA. 1990b. Characterization of kerosene heater emissions inside two mobile homes. Research Triangle Park, NC: U.S. Environmental Protection Agency, Office of Research and Development, Atmospheric Research and Exposure Assessment Laboratory. EPA report no. EPA/600/09.

EPA. 1990c. Characterizations of population and usage of unvented kerosene space heaters. Contract no. 68-02-4284. Washington, DC: U.S. Environmental Protection Agency. EPA report no. EPA/600/790/004.

EPA. 1990d. Evaluating sources of indoor air pollution. Research Triangle Park, NC: U.S.

Environmental Protection Agency, Office of Research and Development, Air and Energy Engineering Research Laboratory. EPA report no. EPA/600/13.

*EPA. 1990e. Interim methods for development of inhalation reference concentrations. Research Triangle Park, NC: U.S. Environmental Protection Agency. EPA/600/8-88/066F.

EPA. 1990f. Unvented kerosene heater emissions from mobile homes: Studies on indoor air particles, semi-volatile organics, carbon monoxide, and mutagenicity. Research Triangle Park, NC: U.S. Environmental Protection Agency, Health Effects Research Laboratory. Report no. EPA/600/D-90022.

*EPA 1991a. $\mathrm{C}_{9}$ aromatic hydrocarbon fraction. Washington, DC: U.S. Environmental Protection Agency. Code of Federal Regulations. 40 CFR 799.2175.

*EPA. 1991b. Constituents prohibited as other than trace contaminants. Washington, DC: U.S. Environmental Protection Agency. Code of Federal Regulations. 40 CFR 227.6.

*EPA. 1991c. Method 602 - Purgeable aromatics; Method 610-Polynuclear aromatic hydrocarbons; Method 625 - Base/neutrals and acids. U.S. Environmental Protection Agency. Code of Federal Regulations. 40 CFR 136, Appendix A.

*EPA. 1992. Analysis of emissions from residential oil furnaces. EPA Office of Research and Development, Air and Energy Engineering Research Laboratory. Research Triangle Park, North Carolina. EPA/600/A-92/136. 
Eppley Z. 1992. Assessing indirect effects of oil in the presence of natural variation: The problem of reproductive failure in South Polar Skuas during the Bahla Paraisa oil spill. Marine Pollution Bulletin 25(9-12):307-312.

*ERNS. 1992. Emergency Response Notification System. Washington, DC: US. Environmental Protection Agency, Office of Solid Waste and Emergency Response.

Ewisman MP, Swindoll S. 1991. Determination of petroleum hydrocarbon toxicity with microtox. Bulletin of Environmental Contamination Toxicology 47(6):811.

Fagbule D, Joiner K. 1992. Kerosene poisoning in childhood: a 6-year prospective study at the University of Ilorin Teaching Hospital. West African Journal of Medicine 11(2):116-121.

*Farrington JW, Davis AC, Frew NM, et al. 1982a. No. 2 fuel oil components in Mytilis edulis: Retention and release after an oil spill. Mar Biol 66:15-26.

*Farrington JW, Tripp BW, Teal JM, et al. 1982b. Biogeochemistry of aromatic hydrocarbons in the benthos of microcosms. Toxicol Environ Chem 5(3-4):331-346.

Felsenstein WC, Staiff DC, Miller GC. 1976. Acute demeton poisoning in a child. Arch Environ Health 31(5):266-269.

*Fidler AT, Baker EL, Letz RE. 1987. Estimation of long term exposure to mixed solvents from questionnaire data: A tool for epidemiological investigations. Br J Ind Med 44(2):133-141.

*Flowers TH, Pulford ID, Duncan HJ. 1984. Studies on the breakdown of oil in soil. Environmental Pollution (Ser B) 8(1):71-82.

Foley JC, Dreyer NB, Bradley SA, et al. 1954. Kerosene poisoning in young children. Radiology 62:817-829.

*Frankenberger WT Jr. 1988. Use of urea as a nitrogen fertilizer in bioreclamation of petroleum hydrocarbons in soil. Bull Environ Contam Toxicol 40( 1):66-68.

*Frankenberger WT Jr, Johanson JB. 1982. Influence of crude oil and refined petroleum products on soil dehydrogenase activity. J Environ Qua1 11(4):602-607.

*Freeman J, Federici T, McKee R. 1993. Evaluation of the contribution of chromic skin irritation and selected compositional parameter to the tumorigenicity of petroleum middle distillates in mouse skin. Toxicology 38:103-112.

Frommer U, Ullrich V, Staudinger H, et al. 1972. The monooxygenation of n-heptane by rat liver microsomes. Biochimica Biophysics Acta 280:487-494.

Frosch PJ, Wissing C. 1982. Cutaneous sensitivity to ultraviolet light and chemical irritants. Arch Dermatol Res 272(3-4):269-278. 
*FSTRAC. 1988. Summary of state and federal drinking water standards and guidelines. Chemical Communication Subcommittee, Federal-State Toxicology and Regulatory Alliance Committee. Washington, DC: U.S. Environmental Protection Agency.

*Galin T, Gerstl Z, Yaron B. 1990a. Soil pollution by petroleum products: III. Kerosene stability in soil columns as affected by volatilization. J Contam Hydrol 5(4):375-385.

*Galin T, McDowell C, Yaron B. 1990b. The effect of volatilization on the mass flow of a nonaqueous pollutant liquid mixture in an inert porous medium: Experiments with kerosene. J Soil Sci 41(4):631-641.

Gallagher J, George M, Kohan M, et al. 1993. Detection and comparison of DNA adducts after in vitro and in vivo diesel emission exposures. Environmental Health Perspectives 99:225-228.

Gallagher J, Phillips D, Pojinsky B, et al. 1992. Formation of adducts in rat lungs over time following inhalation to organic diesel emissions and inorganic carbon black, and TIO2 particles [abst]. Proc Annu Meet Am Assoc Cancer Res 33:A884.

*Garcia M, Gonzalez R. 1985. Uncoupling of the calcium pump of the sarcoplasmic reticulum by kerosene. Toxicol Lett 28(1):59-64.

Garcia M, Gonzalez R, Casaco A. 1988a. Biochemical mechanisms in the effects of kerosene on airways of experimental animals. Allergol Immunopathol 16(5):363-367.

*Garcia M Casaco A, Arruzazabala L, et al. 1988b. Role of chemical mediators in bronchoconstriction induced by kerosene. Allergol Immunopathol 16(6):421-423.

*Gaworski CL, MacEwen JD, Vernot EH, et al. 1984. Comparison of the subchronic inhalation toxicity of petroleum and oil shale JP-5 jet fuels. In: MacFarland HN, Holdsworth CE, MacGregor JA, et al., eds. Advances in modern environmental toxicology. Volume VI: Applied toxicology of petroleum hydrocarbons. Princeton, NJ: Princeton Scientific Publishers, 33-47.

*Gearing PJ, Gearing JN. 1982a. Behavior of no. 2 fuel oil in the water column of controlled ecosystems. Marine Environmental Research 6(2): 115-132.

*Gearing PJ, Gearing JN. 1982b. Transport of no. 2 fuel oil between water column, surface microlayer and atmosphere in controlled ecosystems. Marine Environmental Research 6(2):133-143.

*Gearing PJ, Gearing JN, Pruell RJ, et al. 1980. Partitioning of no. 2 fuel oil in controlled estuarine ecosystems: Sediments and suspended particulate matter. Environ Sci Technol 14(9):1129-1 136.

*Gerarde HW. 1959. Toxicological studies on hydrocarbons: V. Kerosene. Toxicol Appl Pharmacol $1: 462-474$.

*Gerarde HW. 1963. Toxicological studies on hydrocarbons: IX. The aspiration hazard and toxicity of hydrocarbons and hydrocarbon mixtures. Arch Environ Health 6:329-341.

*Gerhart JM, Hatoum NS, Halder CA, et al. 1988. Tumor initiation and promotion effects of petroleum streams in mouse skin. Fundam Appl Toxicol 11:76-90. 
Giammona ST. 1967. Effects of furniture polish on pulmonary surfactant. Am J Dis Child 113:658663.

Gleason NN, Gosselin RE, Hodge HC. 1963. Clinical toxicology of commercial products: Acute poisoning (home and farm). Baltimore, MD: The Williams and Wilkins Co, p. 90-94.

*Goldfrank LR, Weisman RS, Flomenbaum NE, et al. 1990. Goldfrank's toxicologic emergencies. 4th ed. Norwalk, CT: Appleton and Lange, 760-768.

Gollhausen R, Klingman AM. 1985. Effects of pressure on contact dermatitis. Am J Ind Med 8(45):323-328.

*Goodwin SR, Berman LS, Tabeling BB, et al. 1988. Kerosene aspiration: Immediate and early pulmonary and cardiovascular effects. Vet Human Toxicol 30(6):521-524.

Gordon DC Jr, Prouse NJ. 1973. The effects of three soils on marine phytoplankton photosynthesis. Mar Biol (Berlin) 22(4):329-333.

Green DO. 1977. Intravenous energine: A case report. Clin Toxicol 10(3):283-286.

Griest WH, Ho CH, Guerin MR, et al. 1986. Comparative toxicity of crude and refined coal liquids and analogous petroleum products: II. Chemical characterization. Prepared Papers of the American Chemical Society, Division of Fuel Chemistry 31(2)189-195.

Griffin JW. 1954. Hydrocarbon pneumonia following furniture polish ingestion. J Pediatr 45:13-26.

*Gunster DG, Bonnevie NL, Gillis CA, et al. 1993a. Assessment of chemical loadings to Newark Bay, New Jersey from petroleum and hazardous chemical accidents occurring from 1986 to 1991. Ecotoxicol Environ Saf 25(2):202-213.

*Gunster DG, Gillis CA, Bonnevie NL, et al. 1993b. Petroleum and hazardous chemical spills in Newark Bay, New Jersey, USA from 1982 to 1991. Environ Pollut 82(3):245-253.

Gupta P, Singh R, Murali M, et al. 1992b. Kerosene oil poisoning. A childhood menace. Indian Pediatric 29(8):979-984.

Gupta P, Singh R, Murali M, et al. 1992b. Prognostic score for kerosene oil poisoning. Indian Pediatric 29(9):1109-1 112.

Gustavsson P, Evanoff B, Hogstedt C. 1993. Increased risk of esophageal cancer among workers exposed to combustion products. Arch Environ Health 48(4):243-245.

Haas JW, Buchanan MV, Wise MB. 1988. Differentiation of polycyclic aromatic hydrocarbons using a multimode ionization gas chromatographic detector. J Chromatogr Sci 26(2):49-54.

*Haddad LM, Winchester JF. 1990. Clinical management of poisoning and drug overdose. 2nd ed. Philadelphia, PA: WB Saunders Company, Harcourt Brace Jovanovich, Inc., 1182-1185. 
Hadder G, RM D. 1991. Navy mobility fuels forecasting system report: Navy fuel production in the year 2000. Oak Ridge National Lab Department of Energy, Washington DC.

Haley TJ. 1987. Solvents and chemical intermediates. In: Haley TJ, Berndt WO, eds. Handbook of toxicology. Washington, DC: Hemisphere Publishing Corporation, 504-554.

Hammerle RH, Pierson WR. 1974. Elemental composition of the aerosol in Pasadena, California. Prepared Papers of the American Chemical Society, Division of Environmental Chemistry, National Meeting, Los Angeles, CA, March 30-April 5, 1974, 14(1):285-286.

Hammond SK, Shatkin J. 1990. The use of a laser light scattering detector to determine the mass extractable in organic solvents [Abstract]. Abs Pap Am Chem Sot 199(1-2):123.

*Hara K, Kageura M, Hieda Y, et al. 1988. Application of wide-bore capillary gas chromatography to analyze volatile compounds in body fluids. Jpn J Legal Med 42(2):142-146.

Haraprasad V, Dave JM. 1989. Emission patterns of unvented combustion devices burning liquid and gaseous fuels. In: Proceedings of the ASHRAE/SOEH Conference San Diego California, April 17-20, 1989. Atlanta, GA: American Society of Heating, Refrigerating, and Air-Conditioning Engineers, Inc., 255-262.

Harris VJ, Brown R. 1975. Pneumatoceles as a complication of chemical pneumonia after hydrocarbon ingestion. An J Roentgenol Radium Ther Nucl Med 125(3):531-537.

Hart L, Cobaugh D, Sean B, et al. 1991. Successful use of extracorporeal membrane oxygenation ecmo in the treatment of refractory respiratory failure secondary to hydrocarbon. Vet Hum Toxicol 33(4):361.

Hase A, Lin PH, Hites RA. 1976. Analysis of complex polycyclic aromatic hydrocarbon mixtures by computerized GC-MS. In: Freudenthal R, Jones PW, eds. Carcinogenesis: A comprehensive survey. Volume 1: Polynuclear aromatic hydrocarbon chemistry, metabolites, and carcinogenesis. New York, NY: Raven Press, 435-442.

Hass U, Ladefoged 0. 1985. [Deodorized kerosene: Nordic expert group for documentation of occupational exposure limits.] Arbete och Halsa 24:1-40. (Swedish).

Hawthorne AR, Gammage RB, Dudney CS, et al. 1985. Indoor air quality of forty East Tennessee homes. Washington, DC: Tennessee University, Knoxville Department of Energy.

*HAZDAT. 1992. Agency for Toxic Substances and Disease Registry (ATSDR), Atlanta, GA. February 1992.

Heath JS, and Koblis K. 1993. Review of chemical physical and toxicological properties of components of total petroleum hydrocarbons. Journal of Soil Contamination 2(1): 125.

Henderson TR, Li AP, Royer RE, et al. 1981. Increased cytotoxicity and mutagenicity of diesel fuel after reaction with $\mathrm{NO}_{2}$. Environ Mutagen 3:211-220. 
*Herbes SE, Whitley TA. 1983. Characterization and toxicity of water-soluble photooxidants produced during irradiation of coal liquids by sunlight. Environmental Pollution (Ser B) 6(3):221-240.

Hersh S, Piper BF, Mormile DJ, et al. 1981. Emission characterization of SRC-II fuel oil fired in a utility boiler. In: Proceedings of Governor's Conference on expanding the use of coal in New York State: Problems and issues, Albany, New York, May 21-22, 1981. New York, NY: Research Foundation of the State University of New York, 323-329.

Hirota Y, Tadeshita S, Kataoka K, et al. 1992. Individual and environmental characteristics related to influenza-like illness among children: A school-based case-control study. Nippon Eiseigaku Zasshi 47(2):587-599.

Holland JM, Rahn RO, Smith LH, et al. 1979. Skin carcinogenicity of synthetic and natural petroleums. J Occup Med 21(9):614-618.

Holland JM, Larimer FW, Rao TK, et al. 1984. The distribution of dermal tumorigens in coal liquids: Relationship of tumorigenicity and microbial mutagenicity. J Appl Toxicol 4( 3): 117-123.

Honickey RE, Osborne JS, Akpom CA. 1985. Symptoms of respiratory illness in young children and the use of wood-burning stoves for indoor heating. Pediatrics 75(3):587-593.

*HSDB. 1991. Hazardous Substances Data Bank. National Library of Medicine, National Toxicology Information Program. October 1, 1991.

Huff JE, McConnell EE, Haseman JK, et al, 1988. Carcinogenesis studies results of 398 experiments on 104 chemicals from the U.S. National Toxicology Program. In: Maltoni C, Selikoff IJ, eds. Annals of the New York Academy of Sciences, Volume 534. Living in a chemical world: Occupational and environmental significance of industrial carcinogens. New York, NY: New York Academy of Sciences, $1-30$.

Huxtable KA. 1964. Experimental furniture polish pneumonia in rats. Pediatrics 34:228-235.

Hyatsu H, Adashi M. 1991. Mutagenicity of tetranitromethane a case difficult to obtain reproducible results in the ames test. Mutation Research 252(1):88.

*IARC. 1989. IARC monographs on the evaluation of carcinogenic risks to humans. Vol. 45: Occupational exposures in petroleum refining: Crude oil and major petroleum fuels. Lyon, France: World Health Organization, International Agency for Research on Cancer.

*Ingram A, King D, Grasso P, et al. 1993. The early changes in mouseskin following topical application of a range of middle distillate oil products. Journal of Applied Toxicology 13(4):247-257.

Jacobziner H, Raybin HW. 1963. Accidental chemical poisonings: Kerosene and other petroleum distillate poisonings. NY State J Med 63:3428-3430.

Jaeger RW, DeCastro F, Blair J, et al. 1978. The brain in hydrocarbon intoxication. Vet Hum Toxicol 20(2):103 
Jayaraman V, Ramakrishnan K, Davies M. 1993. Burns in madras india: An analysis of 1368 patients in 1 year. Burns 19(4):339-344.

*Jee SH, Wang JD, Sun CC, et al. 1985. Prevalence of probable kerosene dermatoses among ballbearing factory workers. Stand J Work Environ Health 12(1):61-65.

Johnson F, Sinha S. 1993. Deliberate self-harm by means of kerosene fire by women in Papua New Guinea. Papua New Guinea Medical Journal 36(1):16-21.

*Jones JG. 1977. The long term effects of kerosine pollution on the microflora of a moorland soil. J Appl Bacterial 43(1):123-128.

Jones JG, Knight M, Byrom JA. 1970. Effect of gross pollution by kerosine hydrocarbons on the microflora of a moorland soil. Nature 227(263):1166.

Joubert PH. 1990. Poisoning admissions of black South Africans. J Toxicol Clin Toxicol 28(1):85-94.

*Kainz RJ, White LE. 1984. Depressant effects associated with the inhalation of uncombusted diesel vapor. In: MacFarland HN, Holdsworth CE, MacGregor JA, et al., eds. Advances in modern environmental toxicology. Volume VI: Applied toxicology of petroleum hydrocarbons. Princeton, NJ: Princeton Scientific Publishers, Inc.

Kamamoto T, Matsumo K, Arashidani K, et al. 1993. Personal exposure to nitrogen dioxide from indoor heaters and cooking stoves, Arch Environ Contam Toxicol 25(4):534-533.

Kamat S, Patil J, Gregart J, et al. 1992. Air pollution related respiratory morbidity in central and north -eastern Bombay. J Assoc Physicians India 40(9):588-593.

Kaminski M, Starek A, Plewa A. 1988. [Protective effect of phenobarbital in liver injury by kerosine hydrocarbons in rats.] Folia Med Cracov 29(1-2):87-98. (Polish)

*Kaplan R, Brandt-Rauf P, Azley J, et al. 1993. Residential releases of number 2 fuel oil a contributor to indoor air pollution. American Journal of Public Health 83(1):84-88

*Karl D. 1992. The grounding of the bahia paraiso microbial ecology of the 1989 Antarctic oil spill. Microbial Ecology 24( 1):77-89.

*Kawahara FK, Fiutem RA, Silvus HS, et al. 1983. Development of a novel method for monitoring oils in water. Anal Chim Acta 151(2):315-327

Kawai A, Goto S, Endo O, et al. 1991. Mutagenicity test for gaseous and vaporous components of combustion exhausts. Mutation Research 252(1):93.

Keen TEB. 1968. The effect of petroleum distillates on lung surfactant. Aust Paediat J 4(4):229-235.

Keenan RR, Cole SB. 1982. A sampling and analytical procedure for skin-contamination evaluation. Am Ind Hyg Assoc J 43(7):473-476. 
Kennicutt M, Sweet S. 1992. Hydrocarbon contamination of the antarctic peninsula III. The bahia paraiso two years after the spill. Marine Pollution Bulletin 25(9-12):303-306.

*Kennicutt M, McDonald T, Denoux G, et al. 1992a. Hydrocarbon contamination of the antarctic peninsula 1. Arthur harbor subtidal sediments. Marine Pollution Bulletin 24( 10):499-506.

*Kennicutt M, McDonald T, Denoux G, et al. 1992b. Hydrocarbon contamination of the antarctic peninsula 2. Arthur harbor intertidal and subtidal limpets (nicella-concinna). Marine Pollution Bulletin 24(10):506-511.

Kilmar V. 1991. Accidental poisoning in southwest Maharashtra India. Indian Pediatr 28(7):731-735.

*Kimura K, Nagata T, Hara K, et al. 1988. Gasoline and kerosene components in blood: A forensic analysis. Hum Toxicol 7(4):299-305.

*Kimura K, Nagata T, Kudo K, et al. 1991. Determination of kerosine and light oil components in blood. Biol Mass Spectrom 20(8):493-497.

Kinetic Labs, Inc. 1992. Study of Recovery from oil spill on the rocky intertidal coast of Washington. KLI-R-92-14^OCS/MMS-92/0072 Minerals Management Service, Camarillo, CA Pacific OCS Region.

Kinnes G, Kawamoto M. 1992. Health hazard evaluation report HETA 89-374-2197, Exxon baytown refinery Baytown, Texas. National Institute for Occupational Safety and Health, Cincinnati, MAR 92:17.

Kinouchi T, Nishifuji K, Tsutsui H, et al. 1988. Mutagenicity and nitropyrene concentration of indoor air particulates exhausted from a kerosene heater. Jpn J Cancer Res 79(1):32-41.

Kissoon N, Vidyasagar D. 1991. Poisoning. Indian Journal of Pediatrics 58(4):431-438.

Kitto M. 1993. Trace-element patterns in fuel oils and gasolines for use in source apportionment. Air \& Waste 43(10):1381-1388.

Kleinmen M, Bhalla D, McClure B. 1993. Effects of inhaled fine particles and ozone on pulmonary macrophages and epithelia. Inhal Toxicol 5(4):371.

Knave B, Mindus P, Struwe G. 1979. Neurasthenic symptoms in workers occupationally exposed to jet fuel. Acta Psychiatr Stand 60:39-49.

*Knave B, Olson BA, Elofson S, et al. 1978. Long term exposure to jet fuel: II. A cross-sectional epidemiologic investigation on occupationally exposed industrial workers with special reference to the nervous system. Stand J Work Environ Health 4:19-45.

Koch EMW, Ott R, Koehler CO. 1986. [Age-related differences in pharmacological activities of corticosteroid tropicals.] Arzneim-Forsch 36(2):1540-1544. (German)

Koo LC, Lee N, Ho JH. 1983. Do cooking fuels pose a risk for lung cancer?: A case-control study of women in Hong Kong. Ecol Dis 2(4):255-265. 
*Koutrakis P, Briggs S, Leaderer B. 1992. Source apportionment of indoor aerosols in Suffolk and onondaga counties new York. Environ Sci Technol 26(3):521-527.

Krahn M, Ylitalo G, Buzitis J, et ul. 1993. Rapid high-performance liquid-chromatographic methods that screen for aromatic-compounds in environmental-samples. Journal of Chromatography 642( 1-2): 1532.

Kryuchkov V. 1991a. Extreme anthropogenic loads and the state of ecosystems in the north. Ekologiya 0(3):28-40.

Kryuchkov V. 1991b. Maximal anthropogenic loading and condition of northern ecosystems. Soviet Journal of Ecology 22(3):155-166.

Kryuchkov V. 1993. Extreme anthropogenic loads and the northern ecosystem condition. Ecological Applications 3(4):622-630.

Kumar A, Mohan M. 1986. Kerosene poisoning. Indian Pediatr 23:178-179.

Lacey P, Lestz S. 1991. Failure analysis of fuel injection pumps from generator sets fueled with Jet A-1. Southwest Research Int San Antonio, TX. Belvoir Fuels and Lubricants Research Facility.

*Lam WK, Du YX. 1988. Environmental inhaled agents and their relation to lung cancer. In: Loke J, ed. Pathophysiology and treatment of inhalation injuries: Lung Biology in Health and Disease, Vol. 34. New York, NY: Marcel Dekker, 423-451.

*Lamey SC, Hesbach PA, White KD. 1991. Liquid fuel analyses using high-performance liquid chromatography and gas chromatography-mass spectroscopy. Energy and Fuels 5:222-226.

*Larson RA, Bott TL, Hunt LL, et al. 1979. Photooxidation products of a fuel oil and their antimicrobial activity. Environmental Science and Technology 13(8):965-969.

*Larson RA, Hunt LL, Blankenship DW. 1977. Formation of toxic products from a \#2 fuel oil by photooxidation. Environmental Science and Technology 11(5):492-496.

Lashley P, St. John M. 1991. A review of accidental-poisoning in barbados - A new perspective( 19811985). Annuals of Tropical Paediatrics 11(2):149-153.

*Latimer JS, Hoffman EJ, Hoffman G, et al. 1990. Sources of petroleum hydrocarbons in urban runoff. J Water Air Soil Pollut 52(1-2):1-21.

Laurent P, Guyotjeannin C, Thin D. 1967. [Apropos of occupation diseases of workers who clean fuel oil boilers (2).] Arch Ma1 Prof 28(10):789-792. (French)

Laursen H, Hansen A, Sheardown M. 1993. Cerebrovascular permeability and brain edema after cortical photochemical infarcts in the rat. Acta Neuropathologica 86(4):378-385.

Lazner J. 1970. Summer poison hazards for young children. Med J Aust 2(23):1098. 
Leaderer BP, Zagraniski RT, Berwick M, et al. 1986. Assessment of exposure to indoor air contaminant from combustion sources: Methodology and application. Am J Epidemiol 124(2):275-289.

Leary J, Biemann K, Braun A, et al. 1984. Chemical and toxicologic characterization of No. 2 fuel oil and its combustion products at different smoke numbers. American Chemical Society (ACS), 187th National Meeting 8-13 Apr 1984 St. Louis, MO.

Leary JA, Bieman K, Lafleur AL, et al. 1987. Chemical and toxicological characterization of residential oil burner emissions: I. Yields and chemical characterization of extractables from combustion of no. 3 fuel oil at different Bacharach smoke numbers and firing cycles. Environ Health Perspect 73:223-234.

Lebowitz H, Brusick D, Matheson D, et al. 1979. Commonly used fuels and solvents evaluated in a battery of short-term bioassays [Abstract]. Environ Mutagen 1:172-173.

*Lee L, Agwall M, Delfino J, et al. 1992. Partitioning of Polycyclic aromatic-hydrocarbons from diesel fuel imo water. Environmental Science and Technology 26(11):2104-2110.

Lee ML, Prado GP, Howard JB, et al. 1977. Source identification of urban airborne polycyclic aromatic hydrocarbons by gas chromatographic mass spectrometry and high resolution mass spectrometry. Biomed Mass Spectrom 4(3):182-185.

*Lesnik R, Kligman L, Kligman A. 1992. Agents that cause enlargement of sebaceous glands in hairless mice. Arch Dermatol Res 284(2):100-105.

Lewis SC, King RW, Cragg ST, et al. 1984. Skin carcinogenic potential of petroleum hydrocarbons: II. Crude oil, distillate fractions and chemical class subfractions. In: MacFarland HN, Holdsworth CE, MacGregot JA, et al., eds. Advances in modern environmental toxicology. Vol. VI: Applied toxicology of petroleum hydrocarbons. Princeton, NJ: Princeton Scientific Publishers, Inc.

Lewtas J. 1993. Complex mixtures of air pollutants: Characterizing the cancer risk of polycyclic organic matter. Environmental Health Perspectives 100:211-218.

Lewtas J, Claxton L, Mumford J, et al. 1993. Bioassay of complex mixtures of indoor air pollutants. IARC Sci Pub1 109:85-95.

*Lieberman S, Inman S, Theriault G. 1993. Laser-induced fluorescence over optical fibers for real time in situ measurement of petroleum hydrocarbons in seawater. Naval Command, Control and Ocean Surveillance Center San Diego, Ca.

Lillienberg L, Hogstedt B, Jarvholm B, et al. 1992. Health effects at tank cleaners. American Industrial Hygiene Association 53(6):375-380.

*Lindquist R, Nilsson B, Eklund G, et al. 1991. Acute leukemia in professional drivers exposed to gasoline and diesel. Eur J Haematol 47(2):98-103.

Lipfert F, DePhillips M, Moskowitz P. 1992. Air toxics from heavy oil production and consumption. Brookhaven National Lab Lipton, NY. 
Lipfert F, DePhillips M, Moskowitz P. 1992. Air toxics from heavy oil production and consumption. Brookhaven National lab Department of Energy, Washington DC.

Lewtas J. 1989. Toxicology of complex mixtures of indoor air pollutants. Annu Rev Pharmacol and Toxicol 29:415-439.

*Liss-Suter D, Villaume JE, Goldstein FJ. 1978. A literature review - problem definition studies on selected toxic chemicals. Volume 8: Environmental aspects of diesel fuels and fog oils SGF no. 1 and SGF no. 2 and smoke screens generated from them. Philadelphia, PA: Franklin Institute Research Laboratories. Final report. Contract no. DAMD 17-77-C-7020. AD A056021.

*Litovitz T, Greene AE. 1988. Health implications of petroleum distillate ingestion, Occup Med 3(3):555-568.

*Litz N, Blume H-P. 1989. [Behaviour of organic chemicals in soils and a prognosis after a contamination.] Z Kulturtechnik Landentwicklung 30(6):355-364. (German)

Lizasa T, Moniki S, Bauer B, et al. 1993. Invasive tumors derived from xenotransplanted, immortalized human cells after in vivo exposure to chemical carcinogens. Carcinogenesis 14(9):17891794.

*Lock S, Dalbey W, Schmoyer R, et al. 1984. Chemical characterization and toxicologic evaluation of airborne mixtures: Inhalation toxicology of diesel fuel obscurant aerosol in Sprague-Dawley rats. Final report, phase 3: Subchronic exposures. Oak Ridge, TN: Oak Ridge National Laboratory. ORNL/TM9403.

Lockard JM, Prater JW, Viau CJ, et al. 1982. Comparative study of the genotoxic properties of Eastern and Western U.S. shale oils, crude petroleum, and coal-derived oil. Mutat Res 102(3):221-235.

Lollar RM. 1980. Are carcinogens a chronic health hazard in the tannery workplace? JALCA 75:510525.

Lomer C, Teman R, Gosonou I, et al. 1993. Field infection of zonocerus-variegatus following application of an oil-based formulation of metarhizium-flavoviride conidia. Biocontrol Science and Technology 3(3):337-346.

Lupulescu A. 1973. Electron microscopic autoradiography of 3H-kerosene in human epidermis: 13th annual meeting of American Society for Cell Biology. Journal of Cell Biology 59(2).

*Lupulescu AP, Birmingham DJ. 1975. Effect of lipid solvents on protein, DNA, and collagen synthesis in human skin: An electron microscopic autoradiographic study. J Invest Dermatol 65(5):419422.

*Lupulescu AP, Birmingham DJ. 1976, Effect of protective agent against lipid-solvent-induced damages: Ultrastructural and scanning electron microscopial study of human epidermis. Arch Environ Health 31(1):33-36.

*Lupulescu AP, Birmingham DJ, Pinkus H. 1973. An electron microscopic study of human epidermis after acetone and kerosene administration. J Invest Dermatol 60(1):33-45. 
*MacKerron CB, Kiesche ES. 1988. After the Ashland spill, more regulations? Chemical Week $142(1,2): 19-20$.

*MacNamara BGP. 1968. The treatment of poisoning in children. West Indian Med J 17(3):166-171.

MacNaughton MG, Uddin DE. 1984. Toxicology of mixed distillate and high-energy synthetic fuels. Adv Mod Env Toxicol 7:121-132.

Macys D, Carpenter R, Risher J, et al. 1992. Results of a workshop on health effects of crude oil exposures related to operation desert storm Final report 14-15 Feb. 1991. MainTech Environmental Technology, Inc Dayton OH.

*Mahdi AH. 1988. Kerosene poisoning in children in Riyadh. J Trap Pediatr 34(6)316-318.

Mahlman M. 1991. Dangerous and cancer-causing properties of products and chemicals in the oil refining and petrochemical industry, part XII. Human health and environmental hazards. In MA Mehlman, ed., Advances in Modern Environmental Toxicology, Vol XIX Health and Risks from Exposure to Complex Mixtures and Air Toxic Chemicals, Princeton Scientific Publishing CO, Inc., Princeton, New Jersey, 99- 116.

Maier H, Devries N, Show G. 1991. Occupational factors in the aetiology of head and neck cancer. Clin Otolaryngol Allied Sci 16(4):406-412.

*Majeed HA, Bassyouni H, Kalaawy M, et al. 1981. Kerosene poisoning in children: A clinicoradiological study of 205 cases. Ann Trop Pediatr 1(2):123-130.

*Mann MD, Pirie DJ, Wolfsdorf J. 1977. Kerosene absorption in primates. J Pediatr 91(3):495-498.

*Martin JH, Siebert AJ, Loehr RC. 1991. Estimating oil and grease content of petroleum-contaminated soil. Journal of Environmental Engineering 117(3):291-299.

Mattie DR, Alden CL, Newell TK, et al. 1991. A 90-day continuous vapor inhalation toxicity study of JP-8 jet fuel followed by 20 or 21 months of recovery in Fischer 244 rats and C57BL/6 mice. Toxicol Pathol 19(2):77-87.

McGill WB, Rowe11 MJ. 1980. Determination of oil content of oil contaminated soil. Sci Total Environ 14:245-253.

McKee R, Freeman J. 1993. Dermal carcinogenicity studies of petroleum-derived materials. In RGM Wang, JB Knaak, HI Maiback, eds., Health Risk Assessment: Dermal and Inhalation Exposure and Absorption of Toxicants CRC Press, Ann Arbor MI, 263-274.

*McKee RH, Amoruso MA, Freeman JJ, Przygoda RT. 1994. Evaluation of the genetic toxicity of middle distillate fuels. Exxon Biomedical Services, Inc., East Millstone, NJ.

McKee RH, Kapp RW Jr, Ward DP. 1985. Evaluation of the systemic toxicity of coal liquefaction-derived materials following repeated dermal exposure in the rabbit. J Appl Toxicol 5(6):345-351. 
McKee RH, Nicolich MJ, Scala Ra, et al. 1990. Estimation of epidermal carcinogenic potency. Fundamental and Applied Toxicology. 15:230-328.

McKee RH, Pasternak SJ, Traul KA. 1987a. Developmental toxicity of EDS recycle solvent and fuel oil. Toxicology 46(2):205-215.

*McKee RH, Plutnick RT, Przygoda RT. 1989. The carcinogenic and initiating and promoting properties of a lightly refined paraffinic oil. Fundam Appl Toxicol 12(4):748-756.

McKee RH, Plutnick RT, Traul KA. 1987b. Assessment of the potential reproductive and subchronic toxicity of EDS coal liquids in Sprague-Dawley rats. Toxicology 46(3):267-280.

Melia RJW, Chinn S, Rona RJ. 1990. Short communication: Indoor levels of $\mathrm{NO}_{2}$ associated with gas cookers and kerosene heaters in inner city areas of England. Atmos Environ 24B(1):177-180.

*Midkiff CR Jr, Washington WD. 1972. Gas chromatographic determination of traces of accelerants in physical evidence. J Assoc Off Anal Chem 55(4):840-845.

*Mille G, Guiliano M, Reymond H, et al. 1985. Analysis of hydrocarbons by Fourier transform infrared spectroscopy. Int J Environ Anal Chem 21(3):239-260.

Millner GC, Nye AC, James RC. 1992. Human health based soil cleanup guidelines for diesel fuel No. 2. In: Kostecki PT, Calabrese EJ. Contaminated Soils-Diesel Fuel Contamination. Lewis Publishers. Ann Arbor, MI.

Mintz AA. 1966. Furniture polish intoxication. South Med J 59:1010-1014.

Mishad MM. 1969. Kerosene poisoning. Ain Shams Medical Journal 20(2)125-128.

Mitsue R, Okuyama S, Fujimura Y. 1991. Determination of the blend composition ratio of gasoline to kerosene by multivariate analysis. Bunseki Kagaku 40:389-394.

*Molden A. 1992. Collision results in fuel-oil spill in South-African waters. Marine Pollution Bulletin 24(6):281.

Mijller L, Torndal UB, Eriksson LC, et al. 1989. The air pollutant 2-nitrofuran as initiator and promoter in a liver model for chemical carcinogenesis. Carcinogenesis 10(3):435-440.

Mommsen S, Aagard J. 1984. Occupational exposures as risk indicator of male bladder carcinoma in a predominantly rural area. Acta Radio1 23(2-3):147-152.

Moore WS, Hyland JL, Melzian BD, et al. 1978. Technique for removal of dissolved and dispersed hydrocarbons from bioassay effluents. Environ Sci Technol 12(5):595-596.

*Morrison I, Sprague P. 1976. Kerosene pneumonia: Its incidence in Perth and case history of a recent fatality. Australas Radio1 20(2):118-121.

*Morrison H, Semenciw R, Morrison D, et al. 1992. Brain cancer and farming in western Canada. Neuroepidemiology 11:267-276. 
*Morrison H, Semenciw R, Wilkins K, et al. 1994. Non-Hodgkin's lymphoma and agricultural practices in the prairie provinces of Canada. Stand J Work Environ Health 20(1):42-47.

Morrow P, Muhle H, Memelstein R. 1991. Chronic inhalation study findings as a basis for proposing a new occupational dual exposure limit. J Am Coll Toxicol 10(2):279.

*Mosconi G, Migliori M, Greco V, et al. 1988. Kerosene "bums": A new case. Contact Dermatitis 19(4):314-315.

*Mumford JL, Williams RW, Walsh DB, et al. 1991. Indoor air pollutants from unvented kerosene heater emissions in mobile homes: Studies on particles, semivolatile organics, carbon monoxide, and mutagenicity. Environ Sci Technol 25(10):1732-1738.

Muralidhara, Krishnakumari MK. 1980. Acute oral toxicity of some petroleum fractions used in pesticidal formulations to albino rats [Abstract]. Indian J Biochem Biophys 18(4):149-150.

"Muralidhara, Krishnakumari MK, Ramesh HP, et al. 1982. Toxicity of some petroleum fractions used in pesticidal emulsions to albino rats. J Food Sci Technol 19(6):260-262.

*Mushrush G, Mose D, Sullivan K. 1994. Soil vapor and ground water analysis from a recent oil spill. Bulletin of Environmental Contamination and Toxicology 52(1):31.

Narasimhan MJ, Ganla VG. 1967. Experimental studies on kerosene poisoning. Acta Pharmacol Toxicol 25(2):214-224.

*NAS/NRC. 1989. Biological markers in reproductive toxicology. National Academy of Sciences/National Research Council. Washington, DC: National Academy Press, 15-35.

*NATICH. 1991. National Air Toxics Information Clearinghouse. Data base report on state, local, and EPA air toxics activities. U.S. Environmental Protection Agency, Office of Air Quality Planning and Standards, Washington, DC. August 13, 1991.

Nethercott JR, Lawrence M. 1983. The effect of the guinea pig maximization protocol on the irritant response to deodorized kerosene: The excited skin syndrome. Contact Dermatitis 9(6):439-443.

*Newton J, Rothman B, Walker F. 1991. Separation and determination of diesel contaminants in various fish products by capillary gas chromatography. Journal of the Association of Official Analytical Chemists 74(6):968-990.

*Ng RC, Darwish H, Stewart DA. 1974. Emergency treatment of petroleum distillate and turpentine ingestion. Can Med Assoc J 111:537-538.

Nhachi C, Kasilo 0. 1994. Household chemicals poisoning admissions in Zimbabwe main urban centers. Human and Experimental Toxicology 13(2):69-72.

Nicholson A. 1975. Quantitative analysis of fuel oils and gasoline in drinking water by gas chromatography. First chemical congress of the north american continent [abst]. American Chemical Society Washington, DC. 
Nieman GF, Clark WR, Wax SD, et al. 1980. The effect of smoke inhalation on pulmonary surfactant. Ann Surg 191(2):171-181.

NIOSH. 1975. Environmental injury and repair of epidermis. Cincinnati, OH: National Institute for Occupational Safety and Health.

*NIOSH. 1992. NIOSH pocket guide to chemical hazards. Cincinnati, OH: National Institute for Occupational Safety and Health. DHHS(NIOSH) publication no. 90-1 17.

*NIOSH. 1994. Manual of analytical methods. 4th ed. Eller PM, ed. Cincinnati, OH: National Institute for Occupational Safety and Health. Publication no. 94-113, Method 1550.

Nitschke IA, Traynor GW, Wadach JB, et al. 1985. Indoor air quality, infiltration and ventilation in residential buildings. Albany, NY: New York State Energy Research and Development Authority. Document no. PB89-165500.

*Noa M, Illnait J. 1987a. Changes in the aorta of guinea pigs exposed to kerosene. Acta Morphologica Hungarica 35(1-2):59-69.

Noa M, Illnait J. 1987b. Induction of aortic plaques in guinea pigs by exposure to kerosene. Arch Environ Health 42:3 1-36.

Noa M, Sanabria J. 1984. Tracheal ultrastructure in kerosene treated guinea pigs: A preliminary report. Allergol Immunopathol 12( 1):33-36.

Noa M, Illait J, Gonzalez R. 1985. Cytologic and biochemical changes in pulmonary washings of guinea pigs exposed to kerosene. Allergol Immunopathol 13(3):193-196.

*NOAA. 1982. Effects from residual and no. 2 fuel oils on intertidal infauna recovery rate. Seattle, WA: National Oceanic and Atmospheric Administration, Office of Marine Pollution Assessment. Document no. PB83-152298.

*NOES. 1992. National Occupational Exposure Survey. Cincinnati, OH: U.S. Department of Health and Human Services, Public Health Service, Centers for Disease Control, National Institute for Occupational Safety and Health, Division of Surveillance, Hazard Evaluations and Field Studies.

*Nouri L, Al-Rahim IS. 1970. Kerosene poisoning in children. Postgrad Med .I 46(532):71-75.

*Nouri LA, Sordelli DO, Cerquetti MC, et al. 1983. Pulmonary clearance of Sta hylococcus a eus and plasma angiotensin-converting enzyme activity in hydrocarbon pneumonitis. Pediatr Res 17(8):657661 .

*NTP/NIH. 1986. National toxicology program technical report series no. 310: Toxicology and carcinogenesis studies of marine diesel fuel and JP-5 navy fuel in $\mathrm{B} 6 \mathrm{C} 3 \mathrm{Fl}$ mice (dermal studies). Research Triangle Park, NC: National Toxicology Program/National Institutes of Health. NIH publication no. 86-2566.

Nussinsovitch M, Amir J, Arsano I. 1992. Chemical pneumonia and dermatitis caused by kerosene. Clinical Pediatrics 31(9):574. 
Nylander G, Berg K. 1991. Mutagenicity study of urine from smoking and non-smoking road tanker drivers. Int Arch Occup Environ Health 63(4):229-232.

*OHM/TADS. 1985. Oil and Hazardous Materials/Technical Assistance Data System. Baltimore, MD: Chemical Information Systems, Inc. December, 1985.

Ohnishi Y, Kinouchi T, Manabe Y, et al. 1985. Nitro compounds in environmental mixtures and foods. Environ Sci Res 32(4):195-204.

Okamori K, Tanaka S, Hashimoto Y. 1991. Transport of soil particles an pollutants to the ocean and their concentration distribution in the marine atmosphere. A study of marine aerosols collected on board the antarctic observation ship "Shirase". Nippon Kagaku Kaishi 6:759-765.

*Olson MJ, Johnson JT, Reidy CA. 1990. A comparison of male rat and human urinary proteins: Implications for human resistance to hyaline droplet nephropathy. Toxicol Appl Pharmacol 102:524536.

*OSHA. 1989a. Air contaminants. Occupational Safety and Health Administration. Code of Federal Regulations. 29 CFR 1910.1000.

*OSHA. 1989b. Air contaminants. Occupational Safety and Health Administration. Federal Register 54:2920-2960.

O’Sullivan BP. 1983. Carbon monoxide poisoning in an infant exposed to a kerosene heater. J Pediatr 103(2):249-251.

*Oviatt C, Frithsen J, Gearing J, et al. 1982. Low chronic additions of no. 2 fuel oil: Chemical behavior, biological impact and recovery in a simulated estuarine environment. Mar Ecol Prog Ser 9:121-136.

Oxenford JL, McGeorge LJ, Jenniss SW. 1989. Determination of practical quantitation levels for organic compounds in drinking water. J Am Water Works Assoc 81(4):149-154.

Palma-Carlos AG. 1975. [Diseases caused by inhalation of organic dusts.] Allergol Immunopathol 3(5):339-356. (Spanish)

*Panson RD, Winek CL. 1980. Aspiration toxicity of ketones. Clin Toxicol 17(2):271-317.

Papini RPG. 1991. 'Is all that's blistered burned?' . . . a case of kerosene contact burns. Bums 17:415416.

*Parker GA, Bogo V, Young RW. 1981. Acute toxicity of conventional versus shale-derived JP-5 jet fuel: Light microscopic, hematologic, and serum chemistry studies. Toxicol Appl Pharmacol 57(3):302-317.

* Partanen T, Heikkila P, Hemberg S, et al. 1991. Renal cell cancer and occupational exposure to chemical agents. Scan J Work Environ Health 17(4):231-239.

Patterson A. 1993. Hand dermatitis in a hand cleanser salesman. Contact Dermatitis 28(2):119-120. 
Perrone H, Passero MA. 1983. Hydrocarbon aerosol pneumonitis in an adult. Arch Intern Med 143(8):1607-1608.

*Pharr D, McKenzie J, Hickman A. 1992. Fingerprinting petroleum contamination using synchronous scanning fluorescence spectroscopy. Ground Water 30(4):484-489.

Phillips RD, Cockrell BY. 1984. Effect of certain light hydrocarbons on kidney function and structure in male rats. In: Mehlman MA, Hemstreet GP III, Thorpe JJ, et al., eds. Advances in modern environmental toxicology: Volume VII. Renal effects of petroleum hydrocarbons. Princeton, NJ: Princeton Scientific Publishers.

*Porter HO. 1990. Aviators intoxicated by inhalation of JP-5 fuel vapors. Aviat Space Environ Med 61(7):654-656.

Power A, Mathys G. 1992. Characterization of distillate fuel sediment molecules-functional-group derivatization. Fuel 71(8):903908.

Presley LA. 1979. Evaluation of a portable gas chromatograph for arson analysis: Column selection. Arson Anal News1 3(5):18-34.

Prince R. 1993. Petroleum spill bioremediation in marine environments. Critical Reviews in Microbiology 19(4):217-242.

Puranen A, Matila M. 1992. Exhaust emissions from work machinery in finland. Environ Int 18(5):467-476.

Qaryoute SM. 1984. Skin ulceration induced by kerosene injection. Ann Plast Surg 12(4):361-363.

Ragland KW, Andren AW, Manchester JB. 1985. Emissions from unvented kerosene heaters. Sci Total Environ 46:171-179.

* Rahimtula AD, Payne JF, Martins I. 1982. Hydrocarbon-based oils as inducers of cutaneous aryl hydrocarbon hydroxylase. Toxicol Lett 10(2-3):213-217.

Rahimtula AD, O'Brien PJ, Payne JF. 1984. Induction of xenobiotic metabolism in rats on exposure to hydrocarbon-based oils. Adv Mod Toxicol 6:7 1-79.

Rai UC, Singh TSK. 1980. Cardio-pulmonary changes in mongrel dogs after exposure to kerosene smoke. Indian J Exp Biol 18(11):1263-1266.

Raiyani C, Shah S, Desai N, et al. 1993. Characterization and problems of indoor pollution due to cooking stove smoke. Atmos Environ Part A Gen Top 27(11):1643-1655.

* Rao GS, Pandya KP. 1980. Hepatic metabolism of heme in rats after exposure to benzene, gasoline, and kerosene. Arch Toxicol 46(3-4):313-317.

Rao GS, Kannan K, Goel SK, et al. 1984. Subcutaneous kerosene toxicity in albino rats. Environ Res 35(2):516-530. 
*Raymond RL, Hudson JO, Jamison VW. 1975. Assimilation of oil by soil bacteria. Proceeding of the American Petroleum Institute, Refining Department 54:429-455.

*Raymond RL, Hudson JO, Jamison VW. 1976. Oil degradation in soil. Appl Environ Microbial 31(4):522-535.

*Regnier ZR, Scott BF. 1975. Evaporation rates of oil components. Environmental Science \& Technology 9(5):469-472.

*Reidenberg MM, Powers DV, Sevy RW, et al. 1964. Acute renal failure due to nephrotoxins. Am J Med Sci 247125-29.

Reish D. 1993. Effects of metals and organic compounds on survival and bioaccumulation in two species of marine gammaridean amphipod, together with a summary of toxicological research on the group. Journal of Natural History 27(4):781-794.

Rice D, Seltenrich C, Spies R, et al. 1993. Seasonal and annual distribution of organic contaminants in marine sediments from elkhom slough moss landing harbor and nearshore monterey bay california. Environmental Pollution 82( 1):79-91.

Ring R, Nelson JD. 1966. Hydrocarbon pneumonitis in rats: Comparison of mineral seal oil, furniture polish, and kerosene toxicities with an evaluation of gastric lavage. Arch Environ Health 13(6):749-752.

Richardson JA, Pratt-Thomas HR. 1951. Toxic effects of varying doses of kerosene administered by different routes. Am J Med Sci 221:531-536.

*Riss A, Schweisfurth R. 1987. [The degradation of fuel oil via denitrification: Effect of nitrate concentration.] Vom Wasser 68: 111-123. (German)

Rissmiller R. 1983. Kerosene heaters: A new burn threat to children. Clin Pediatr 22(3):203.

Ritchie IM, Oatman LA. 1983. Residential air pollution from kerosene heaters. J Air Pollut Control Assoc 33(9):879-880.

Rodriquez de la Vega A, Casaco A, Garcia M, et al. 1990. Kerosene-induced asthma. Ann Allergy 64(4):362-363.

*Rosenblatt D, Montemagno C. 1992. Criteria for evaluating the health risk remaining after bioremediation of a buried mass of diesel fuel No. 2. Department of Energy Washington, DC.

Rothman N, Emmett EA. 1988. The carcinogenic potential of selected petroleum-derived products. Occup Med 3(3):475-489.

Roudabush RL, Terhaar CJ, Fassett DW, et al. 1965. Comparative acute effects of some chemicals on the skin of rabbits and guinea pigs. Toxicol Appl Pharmacol 7(4):559-565.

*Rowe LD, Dollahite JW, Camp BJ. 1973. Toxicity of two crude oils and of kerosine to cattle. J Am Vet Med Assoc 162(1):61-66. 
*RTECS. 1992. Registry of Toxic Effects of Chemical Substances. U.S. Department of Health and Human Services, National Institute for Occupational Safety and Health, Washington, DC.

* Runion HE. 1988. Occupational exposures to potentially hazardous agents in the petroleum industry. Occupational Medicine: State of the Art Reviews 3(3):431-444.

Rushton L. 1993. A 39-year follow-up of the U.K. oil refinery and distribution center studies: Results for kidney cancer and leukemia. Environ Health Perspect Supplements 101 (Suppl. 6):77-84.

Ryan PB, Spengler JD, Letz R. 1983. The effects of kerosene heaters on indoor pollutant concentrations: A monitoring and modeling study. Atmos Environ 17(7): 1339- 1345.

Sagai M, Saito H, Ichinose T, et al. 1993. Biological effects of diesel exhaust particles I. In vitro production of superoxide and in vivo toxicity in mouse. Free Radic Biol Med 14(1):37-47.

*Saksena PN. 1969. Kerosine oil poisoning in children. Indian Med Assoc 52(4):169-171.

Samet JM, Marbury MC, Spengler JD. 1987. Health effects and. sources of indoor air pollution: Part I. Am Rev Respir Dis 136(6):1486-1508.

Sanabria J, Noa M, Casaco A, et al. 1984. [Morphological changes in the respiratory system of guinea pigs after kerosine aerosol administration.] Allergol Immunopathol 12(3):213-215. (Spanish)

*Santhanakrishnan BR, Chithra S. 1978. Accidental kerosene poisoning in infants and children. Indian J Pediatr 45(367):265-273.

Sarker AK, Ghosh S, Batik K. 1990. A study of accidental poisoning (in children) in a rural medical college hospital of West Bengal. Indian J Public Health 34(3):159-162.

Salthouse R. 1992. Making Clean Gasoline: The Effect on Jet Fuels. Logistics Management Inst Bethesda, MD.

Sas P, Sharan P, Axena S. 1992. Kerosene abuse by inhalation and ingestion. American Journal of Psychiatry 149(5):710.

Sawhney CP. 1989. Flame burns involving kerosene pressure stoves in India. Bruns 15(6):362-364.

*Sax NI, Lewis RJ, Sr. 1989. Dangerous properties of industrial materials. 7th ed. New York, NY: Van Nostrand Reinhold.

Scharf SM, Prinsloo I. 1982. Pulmonary mechanics in dogs given different doses of kerosene intratracheally. Am Rev Respir Dis 126(4)695-700.

Scharf SM, Heimer D, Goldstein J. 1981. Pathologic and physiologic effects of aspiration of hydrocarbons in the rat. Am Rev Respir Dis 124(5):625-629.

*Scherr P, Hutchinson G, Neiman R. 1992. Non-Hodgkin's GB lymphoma and occupational exposure. Cancer Res 52(19):5503-5509. 
Schreiner CA. 1983. Petroleum and petroleum products: A brief review of studies to evaluate reproductive effects. Adv Mod Env Toxicol 3:29-45.

*Schultz TW, Epler JL, Witschi H, et al. 1981. Health effects research in oil shale development. Oak Ridge National Laboratory report no. ORNL/TM-8034. Oak Ridge, TN: Oak Ridge National Laboratory.

Selden A, Ahlborg G, Jr. 1991. Mortality and cancer morbidity after exposure to military aircraft fuel. Aviat Space Environ Med 62(8):789-794.

*Semenciw R, Al E. 1993. Multiple myeloma mortality. J of Occup Med 35(6):557-561.

*Sengupta R, Fondekar S, Alagarsamy R. 1993. State of Oil Pollution in the Northern Arabian Sea after the 1991 Gulf Oil Spill. Marine Pollution Bulletin 27:85-91.

Senz G, Pingitore N. 1991. Characterization of hydrocarbon contaminated areas by multivariate statistical analysis: Case studies. Environ Monit Assess 17(2-3):281-302.

Sexton K, Webber LM, Hayward SB, et al. 1986. Characterization of particle composition, organic vapor constituents, and mutagenicity of indoor air pollutant emissions. Environment International $12: 351-362$.

Sharma V, Ansari M, Razdan R. 1993. Use of kerosene lamp containing synthetic pyrethroids to repel mosquitoes. Indian Journal of Malariology 30(3):169-176.

Shen J, Martha R. 1992. Changes in acute toxicity during on-site bioremediation of soil contaminated by no. 2 fuel oil. 92nd General Meeting of the American Society for Microbiology 92:355.

*Shirkey HC. 1971. Treatment of petroleum distillate ingestion. Mod Treat 8(3):580-592.

Siemiatycki J, Dewar R, Nadon L, et al. 1987. Associations between several sites of cancer and twelve petroleum-derived liquids. Stand J Work Environ Health 13(6):493-504.

Singh H, Chugh J, Shembesh A, et al. 1992. Management of Accidental Kerosene Ingestion. Ann Trop Paediatr 12(1):105-109.

* Singh S, Narang A, Walia BN, et al. 1981. Accidental poisoning in children: Ten years experience. Indian Pediatr 18(3):163-166.

*Skisak C. 1991. The role of chronic acanthosis and subacute inflammation in tumor promotion in CD-1 mice by petroleum middle distillates. Toxicol Appl Pharmaol 109(3):399-411.

Skyberg K, Ronneberg A, Kamoy JI, et al. 1986. Pulmonary fibrosis in cable plant workers exposed to mist and vapor of petroleum distillates. Environ Res 40(2):261-273.

Smuin D, Crutcher J. 1991. Applicability of environmental laws to the remedial investigation and cleanup of a site at Naval Air Station Fallon, Nevada. Hazrap: Navy remedial action investigation feasibility study. Oak Ridge National Laboratory TN. 
*Soczo ER, Staps JJM. 1988. Review of biological soil treatment techniques in the Netherlands. In: Wolf K, van den Brink WJ, Colon FJ, eds. Contaminated soil '88: Second International Netherlands Organization for Applied Scientific Research/Federal Ministry of Research and Technology Conference, Hamburg, West Germany, April 11-15, 1988. Boston, MA: Kluwer Academic Publishers, 663-670.

Squire, Al. E. 1978. Pathology of Laboratory Animals. Springer-Verlag, NY, 1068-1069.

*St. John MA. 1982. Kerosene poisoning in children in Barbados. Ann Trop Paediatr 2(1):37-40.

Stainken D. 1975. Preliminary observations on mode of accumulation of no. 2 fuel oil by soft shell clam. 1975 Conference on Prevention and Control of Oil Pollution San Francisco, California.

Starek A. 1980a. [The influence of kerosene hydrocarbons on the activity of acid hydrolases of lymphocytes in rats.] Folia Med Cracov 22(3-4):385-392. (Polish)

Starek A. 1980b. [The influence of kerosene hydrocarbons on the activity of acid hydrolases of neutrophils and serum in rats.] Folia Med Cracov 22(3-4):375-384. (Polish)

Starek A. 1983. [Some biological effects of chronic exposure to kerosine hydrocarbons.] Med $\mathrm{Pr}$ 34(5-6):451-454. (Polish)

Starek A. 1988. [The effect of kerosene hydrocarbons on microsomal monooxygenases activity in rat liver.] Folia Med Cracov 29(3-4):161-170. (Polish)

Starek A, Czosnek-Dabros E. 1982. [Functional alterations in the liver and kidneys of rats following acute poisoning with kerosine hydrocarbons and Mentor 28.1 Bromatol Chem Toksykol 15(4):259-265. (Polish)

Starek A, Golba W. 1984. [Determination of kerosene vapors in air by gas chromatography.] Med $\mathrm{Pr}$ 35(5):373-378. (Polish)

Starek A, Kaminski M. 1981. [Toxicity of certain petroleum derivatives used as dielectrics in electromachining: IV. Morphologic and cytoenzymic changes in lungs and disorders of acid-base equilibrium in rats chronically exposed to kerosene hydrocarbons.] Med Pr 32(2):69-81. (Polish)

Starek A, Kaminski M. 1982. [Toxicity of certain petroleum derivatives used as dielectrics in electromachining: V. Morphological, cytoenzymic, and biochemical changes in the liver of rats chronically exposed to kerosine hydrocarbons.] Med Pr 33(5-6):239-253. (Polish)

*Starek A, Vojtisek M. 1986. Effects of kerosene hydrocarbons on tissue metabolism in rats. Pol J Pharmacol Pharm 38(5-6):461-469.

Starek A, Fiema L, Cembala D, et al. 1975. [Comparing toxicity of certain oil products used as dielectrics in electroerosive working: I. Acute and subacute toxicity.] Med Pr 26(3):219-230. (Polish)

Starek A, Plewka A, Kaminski M, et al. 1988. [The effect of kerosene hydrocarbons and phenobarbital on the microsomal electron transport chain in rat liver.] Folia Med Cracov 29(1-2):49-57. (Polish) 
*State of Alaska. 1989. Alaska water quality standards. Juneau, AL: Alaska Administrative Code, Water Quality Standards, Amended 12/89. Alaska Title 18, Chapter 70.

*State of Arkansas. 1991. Regulation no. 2 as amended water quality standards for surface waters of the State of Arkansas. Little Rock, AK: Water Quality Standards for Surface Waters of the State of Arkansas.

*State of Florida. 1992. Florida Water Quality Standards 1992. Tallahassee, FL: Florida Water Quality Standards 17.-3.

*State of Nebraska. 1990. Nebraska water quality standards 1990. Lincoln, NE: Nebraska Water Quality Standards for Surface Waters of the State, revised effective /29/88. Nebraska State, Title 117.

*State of New York. 1989. New York public drinking water standards. Albany, NY: New York Public Drinking Water Standards, Code Revision.

* State of South Dakota. 1989. South Dakota water quality standards 1989. Bismarck, SD: South Dakota Surface Water Quality Standards, 2/89. Chapter 74:04:02.

* State of Wyoming. 1990. Wyoming water quality rules and regulations. Cheyenne, WY: Wyoming Water Quality Standards. Cheyenne, WY: Wyoming Department of Environmental Quality, Water Quality Standards for Wyoming Surface Waters, Chapter I.

Staudemayer H, Selner J, Buhr M. 1993. Double-blind provocation chamber challenges in 20 patients presenting with multiple chemical sensitivity. Regul Toxicol Pharmacol 18(1):44-53.

Steadman B, Farag A, Bergman H. 1991. Exposure-related patterns of biochemical indicators in rainbow trout exposed to no. 2 fuel oil. Environ Toxicol Chem 10(3):365-374.

*Steele RW, Conklin RH, Mark HM. 1972. Corticosteroids and antibiotics for the treatment of fulminant hydrocarbon aspiration. JAMA 219( 11): 1434-1437.

Stenzel H, Rodicker H. 1991. Results of substance groups and structural groups analysis of petroleum fractions and their application in estimating the correlation for predicting properties. Chemische Technik 43:344-346.

Stewart PA, Lee JS, Marano DE, et al. 1991. Retrospective cohort mortality study of workers at an aircraft maintenance facility: II. Exposures and their assessment. Br J Int Med 48(8):531-537.

*STORET. 1992. Storage and Retrieval Database. Washington, DC: U.S. Environmental Protection Agency, Office of Water.

*Strand J, Cullinan V, Crecelius E, et al. 1992. Fate of bunker-c fuel in Washington costal habitats following the december 1988 Nestucca oil spill. Northwest Science 66:1-14.

*Strayer RF, Edwards NT, Walton BT, et al. 1983. Potential terrestrial fate and effects on soil biota of a coal liquification product spill. Environmental Toxicology and Chemistry 2(2):217-224.

*Stutz DR, Janusz SJ. 1988. Hazardous materials injuries: A handbook for pre-hospital care. 2nd ed. Beltsville, MD: Bradford Communications Corporation, 360-361. 
* Subcommittee on Accidental Poisoning. 1962. Co-operative kerosene poisoning study: Evaluation of gastric lavage and other factors in the treatment of accidental ingestion of petroleum distillate products. Pediatrics 648-674.

Sun X. 1991. Heating fuels and respiratory diseases in the risks of female lung cancer. Chin J Oncol 13(6):413-415.

Swader N. 1975. Persistence \& effects of light fuel oil in soil. 1975 Conference on Prevention and Control of Oil Pollution San Francisco, California.

*Tagami H, Ogino A. 1973. Kerosine dermatitis: Factors affecting skin irritability to kerosine. Dermatologica 146(2):123-131.

*Tal A, Aviram M, Bar-Ziv J, et al. 1984. Residual small airways lesions after kerosene pneumonitis in early childhood. Eur J Pediatr 142(4): 117-120.

Tandon J, Kalra A, Sahu S, et al. 1993. Profile of accidents in children. Indian Pediatr 30(6):765-769.

*Teal J, Farrington J, Burns K, et al. 1992. The West Falmouth oil spill after 20 years fate of fuel oil compounds and effects on animals. Mar Pollut Bull 24(12):607-614.

*Teal JM, Burns K, Farrington JW. 1978. Analyses of aromatic hydrocarbons in intertidal sediments resulting from two spills of no. 2 fuel oil in Buzzards Bay, Massachusetts. Journal of Fisheries Research Board - Canada 35(5):510-520.

Temple WA, Ferry DG. 1988. Solvent exposures and risk assessment. In: Richardson ML, ed. Risk assessment of chemicals in the environment: Third European Conference, Guilford, England, UK, July 11-14, 1988. London, England: Royal Society of Chemistry, 222-241.

*Theobald N. 1988. Rapid preliminary separation of petroleum hydrocarbons by solid-phase extraction cartridges. Anal Chim Acta 204(1-2):135-144.

Thilly WG, Longwell J, Andon BM. 1983. General approach to the biological analysis of complex mixtures. Environ Health Perspect 48:129- 136.

*Thomas DH, Delfino JJ. 1991a. A gas-chromatographic/chemical indicator approach to assessing ground water contamination by petroleum products. Ground Water Monitoring Review 11(4):90-100.

Thomas DH, Delfino JJ. 1991b. Analytical methods and chemical indicators for assessing groundwater contamination by petroleum products [Abstract]. Abs Pap Am Chem Sot 201(1):Envr 40.

Thurston GD, Spengler JD. 1985. A quantitative assessment of source contributions to inhalable particulate matter pollution in metropolitan Boston. Atmos Environ 19(1):9-25.

Tichenor BA, Sparks LA, White JB, et al. 1990. Evaluating sources of indoor air pollution. J Air Waste Manage Assoc 40(4):487-492. 
Todaro A, Bronsato R, Buratti M, et al. 1991. Acute exposure to vanadium-containing dusts: the health effects and biological monitoring in a group of workers employed in boiler maintenance. Med Lav 82(2):142-147.

Tokiwa H, Nakagawa R, Horikawa K. 1985. Mutagenic/carcinogenic agents in indoor pollutants: The dinitropyrenes, generated by kerosene heaters and fuel gas and liquefied petroleum gas burners. Mutat Res 157(1):39-47.

Tokiwa H, Nakagawa R, Horikawa K, et al. 1987. The nature of the mutagenicity and carcinogenicity of nitrated, aromatic compounds in the environment. Environ Health Perspect 73: 191-199.

*Tominaga S, Itoh K. 1985. Relationship between parental smoking and respiratory diseases of three year old children. Tokai J Exp Clin Med 10(4):395-399.

*Toriyama S, Shimada H, Arakawa H, et al. 1991. An estimate of source contribution of atmospheric aerosols in Toyama Prefecture by chemical mass balance method. Nippon Kagaku Kaishi N5:454-464.

*TRI90. 1992. Toxic Chemical Release Inventory. National Library of Medicine, National Toxicology Information Program, Bethesda, MD.

Truffa O Montalenti P. 1969. [Acute pneumopathy and jaundice caused by accidental ingestion of kerosene.] Minerva Med 60(30):1403-1406. (Italian)

*Tu K, Knutson E, George A. 1991. Indoor Radon Progeny aerosol size measurements in urban, suburban, and rural regions. Aerosol Science and Technology 15:170-178.

Tucker WG. 1987. Characterization of emissions from combustion sources: Controlled studies. Atmos Environ 21(2):281-284.

*Upreti RK, Das M, Shanker R. 1989. Dermal exposure to kerosene. Vet Hum Toxicol 31(1):16-20. Uri N, Day K. 1992. The Dieselization of American Agriculture. International Journal of Energy Research 16:129-137.

Urmey W, Scharf S, Song P, et al. 1980. Effects of interstitial fluid on lung mechanics in the rat. Federation of American Societies for Experimental Biology 64th Annual Meeting Anahiem, California.

Vernon A, Church T, Patterson C, et al. 1992. Continental origin and industrial sources of trace-metals in the northwest atlantic troposphere. Journal of Atmospheric Chemistry 14:339-351.

Vernot EH, Drew RT, Kane ML. 1990a. Acute toxicological evaluation of hydrosulfurized kerosine. Acute Toxic Data 1(1):31-32.

Vernot EH, Drew RT, Kane ML. 1990b. Acute toxicological evaluation of jet fuel A. J Am Co11 Toxicol Part B 1(2):29-30.

Vernot EH, Drew RT, Kane ML. 1990c. Acute toxicologic evaluation of \#6 fuel oil. Acute Toxic Data 1(2):137. 
*Vernot EH, Drew RT, Kane ML. 1990d. Acute toxicological evaluation of straight run kerosene. J Am Co11 Toxicol Part B 1(1):30-31.

Viegi G, Paoletti P, Carrozzi L, et al. 1989a. Adverse health effects of exposure to indoor pollutants in young non-smokers from a general population sample of North Italy. Am Rev Respir Dis 13(4 part 2):A563.

Viegi G, Paoletti P, Carrozzi L, et al. 1989b. Effects of indoor pollutants on respiratory symptoms and lung function of a general population sample in North Italy. In: Proceedings of the Air and Waste Management Association 82nd Annual Meeting and Exhibition, Anaheim, CA, June 25-30, 1989. Pittsburgh, PA: Air and Waste Management Association, 1-1 1.

*Wade TL, Quinn JG. 1980. Incorporation, distribution, and fate of saturated petroleum hydrocarbons in sediments from a controlled marine ecosystem. Marine Environmental Research 3(1):15-34.

*Walker JD, Colwell RR. 1975. Some effects of petroleum on estuarine and marine microorganisms. Can J Microbial 21(3):305-313.

*Walker JD, Petrakis L, Colwell RR. 1976. Comparison of the biodegradability of crude and fuel oils. Can J Microbial 22(4):598-602.

Wallace L. 1992. Recent field studies of personal and indoor exposures to environmental pollutants. Ann New York Acad Sci 641:7-16.

Walton B, Buchanan M. 1980. Teratogenic effects of fuel oils on insects developing in contaminated substrates. Second Chemical Congress of the North American Continent San Francisco, California.

*Waring JI. 1933. Pneumonia in kerosene poisoning. Am J Med Sci 185:325-330.

Watts R, McGuire P. 1992. Emergency Services to Conduct Laboratory Research Concerning Appropriate Additions at NAS Patuxent River Fuel Farm In situ Bioreclamation. Nevada Univ, Reno Dept of Civil Engineering Reno Nevada.

*Westerholm R, Egebaeck K. 1991. Impact of fuels on diesel exhaust emissions. A chemical and biological characterization. National Environmental Protection Agency Solna, Sweden.

*WHO. 1991. Indoor air quality: Combustion products. Environmental Technology 12:829-831.

Wickramanayake G, Arther M, Pollack A, et al. 1992. Removal of Aqueous Phase Petroleum Products in Groundwater by Aeration. Battelle Columbus Labs OH.

Weil CS, Condra NI. 1977. Experimental carcinogenesis of pyrolysis fuel oil. Am Ind Hyg Assoc J 38(12):730-733.

*Williams UP, Kiceniuk JW, Fancey LL, et al. 1989. Tainting and depuration of taint by lobsters (Homarus americanus) exposed to water contaminated with a no. 2 fuel oil: Relationship with aromatic hydrocarbon content in tissue. J Food Sci 54(2):240-243. 
*Williams U, Kiceniuk J, Fancey L, et al. 1991. Tainting and Depuration of Taint by Lobsters Homarus-Americanus exposed to water contaminated with a no. 2 fuel oil relationship with aromatic hydrocarbon content in tissue. J Food Sci 54(2):240-243.

*Wilson AL, Harrer RD, Holtz DR. 1978. Hydrocarbon emissions from fixed-roof storage tanks. Proceeding of the 71st Annual Meeting of the Air Pollution Control Association 1:78-8.3.

*Witschi HP, Smith LH, Frome EL. 1987. Skin tumorigenic potential of crude and refined coal liquids and analogous petroleum products. Fundamental and Applied Toxicology. 9:297-303.

*Wolfe BM, Brodeur AE, Shields JB. 1970. The role of gastrointestinal absorption of kerosene in producing pneumonitis in dogs. J Pediatr 76(6):867-873.

Wolff GT, Korsog PE. 1985. Estimates of the contributions of sources to inhalable particulate concentrations in Detroit. Atmos Environ 19(9): 1399-1409.

Wolfsdorf J. 1976. Experimental kerosene pneumonitis in primates: Relevance to the therapeutic management of childhood poisoning. Clin Exp Pharmacol Physiol 3(6):539-544.

*Wolfsdorf J, Kundig H. 1972. Kerosene poisoning in primates. S Afr Med J 46(20):619-621.

*Wolfsdorf J, Kundig H. 1974. Dexamethasone in the management of kerosene pneumonia. Pediatrics 53(1):86-90.

Wolfsdorf J, Paed D. 1976. Kerosene intoxication: An experimental approach to the etiology of the CNS manifestations in primates. J Pediatr 88(6):1037-1040.

Woodring JL, Duffy TL, Davis JT, et al. 1985. Measurements of combustion product emission factors of unvented kerosene heaters. An Ind Hyg Assoc J 46(7):350-356.

Worfley P, Vaughan T, Davis S, et al. 1992. A case-control study of occupational risk factors for laryngeal cancer. British Journal of Industrial Medicine 49(12): 837-844.

*Yamaguchi S, Yamamoto H, Mizukoshi R, et al. 1992. Rapid chemical diagnosis of kerosene ingestion by NMR. Clinical Chemistry. 38(4):593.

Yamanaka S, Maruoka S. 1984. Mutagenicity of the extract recovered from airborne particles outside and inside a home with an unvented kerosine heater. Atmos Environ 18(7):1485-1487.

Yamanaka S, Hirose H, Takada S. 1979. Nitrogen oxides emissions from domestic kerosene-fired and gas-fired appliances. Atmos Environ 13(3):407-412.

*Yaron B, Sutherland P, Galin T, et al. 1989. Soil pollution by petroleum products: II. Adsorption-desorption of "kerosene" vapors on soils. Journal of Contaminant Hydrology 4:347-358.

Yokoyana Y, Bitta H, Maeda K, et al. 1985. What interaction does indoor nitrogen dioxide have on the effect of the automobile exhaust. Tokai J Exp Clin Ned 10(4):379-384. 
Zeiger E, Anderson B, Haworth S, et al. 1987. Salmonella mutagenicity tests: 3. Results from the testing of 255 chemicals. Environ Mutagen 9 (Suppl 9):1-110.

*Zheng J, Quinn JG. 1988. Petroleum hydrocarbon contamination of ground water in Tiverton, Rhode Island, USA. Chin J Oceanol Limnol 6(4):367-375.

*Zheng W, Blot WJ, Shu X, et al. 1992. Risk factors for oral and pharyngeal cancer in Shanghai, with emphasis on diet. Cancer Epidemiol Biomarkers Prev 1:441-448.

*Zieserl E. 1979. Hydrocarbon ingestion and poisoning. Compr Ther 5(6):35-42.

*Zucker AR, Berger S, Wood LD. 1986. Management of kerosene-induced pulmonary injury. Crit Care Med 14(4):303-304.

Zucker AR, Berger S, Becker CJ, et al. 1987. Effects of PEEP on kerosene induced pulmonary edema. Am Rev Respir Dis 135(4 Part 2):A428.

Zucker AR, Wood LDH, Curet-Scott M, et al. 1991. Partial lung bypass reduces pulmonary edema induced by kerosene aspiration in dogs. J Crit Care 6(1):29-35). 



\section{GLOSSARY}

Acute Exposure -- Exposure to a chemical for a duration of 14 days or less, as specified in the Toxicological Profiles.

Adsorption Coefficient $\left(\mathbf{K}_{\mathbf{o c}}\right)$-- The ratio of the amount of a chemical adsorbed per unit weight of organic carbon in the soil or sediment to the concentration of the chemical in solution at equilibrium.

Adsorption Ratio (Kd) -- The amount of a chemical adsorbed by a sediment or soil (i.e., the solid phase) divided by the amount of chemical in the solution phase, which is in equilibrium with the solid phase, at a fixed solid/solution ratio. It is generally expressed in micrograms of chemical sorbed per gram of soil or sediment.

Bioconcentration Factor (BCF) -- The quotient of the concentration of a chemical in aquatic organisms at a specific time or during a discrete time period of exposure divided by the concentration in the surrounding water at the same time or during the same period.

Cancer Effect Level (CEL) -- The lowest dose of chemical in a study, or group of studies, that produces significant increases in the incidence of cancer (or tumors) between the exposed population and its appropriate control.

Carcinogen -- A chemical capable of inducing cancer.

Ceiling Value -- A concentration of a substance that should not be exceeded, even instantaneously.

Chronic Exposure -- Exposure to a chemical for 365 days or more, as specified in the Toxicological Profiles.

Ct -- A means of expressing concentration as a convenient mechanism for establishing an exposure mechanism. Specifically, it is the product of airborne concentration of aerosolized diesel fuel $(\mathrm{mg} / \mathrm{m} 3)$ and duration of exposure (hours).

Developmental Toxicity -- The occurrence of adverse effects on the developing organism that may result from exposure to a chemical prior to conception (either parent), during prenatal development, or postnatally to the time of sexual maturation. Adverse developmental effects may be detected at any point in the life span of the organism.

Embryotoxicity and Fetotoxicity -- Any toxic effect on the conceptus as a result of prenatal exposure to a chemical; the distinguishing feature between the two terms is the stage of development during which the insult occurred. The terms, as used here, include malformations and variations, altered growth, and in utero death.

EPA Health Advisory -- An estimate of acceptable drinking water levels for a chemical substance based on health effects information. A health advisory is not a legally enforceable federal standard, but serves as technical guidance to assist federal, state, and local officials. 
Immediately Dangerous to Life or Health (IDLH) -- The maximum environmental concentration of a contaminant from which one could escape within 30 min without any escape-impairing symptoms or irreversible health effects.

Intermediate Exposure -- Exposure to a chemical for a duration of 15-364 days, as specified in the Toxicological Profiles.

Immunologic Toxicity -- The occurrence of adverse effects on the immune system that may result from exposure to environmental agents such as chemicals.

$\underline{\text { In vitro }}$-- Isolated from the living organism and artificially maintained, as in a test tube.

$\underline{\text { In vivo }}$-- Occurring within the living organism.

Lethal Concentration $_{(\mathbf{L O})}\left(\mathbf{L C}_{\mathbf{L O}}\right)$-- The lowest concentration of a chemical in air which has been reported to have caused death in humans or animals.

Lethal Concentration $_{(50)}\left(\mathbf{L C}_{\mathbf{5 0}}\right)$-- A calculated concentration of a chemical in air to which exposure for a specific length of time is expected to cause death in $50 \%$ of a defined experimental animal population.

Lethal Dose $\mathbf{L}_{(\mathbf{L})}\left(\mathbf{L D}_{\mathbf{L} 0}\right)$-- The lowest dose of a chemical introduced by a route other than inhalation that is expected to have caused death in humans or animals.

Lethal Dose $_{(\mathbf{5 0})}\left(\mathbf{L D}_{\mathbf{5 0}}\right)$-- The dose of a chemical which has been calculated to cause death in $50 \%$ of a defined experimental animal population.

Lethal Time $_{(50)},\left(\mathbf{L T}_{\mathbf{5 0}}\right)$-- A calculated period of time within which a specific concentration of a chemical is expected to cause death in $50 \%$ of a defined experimental animal population.

Lowest-Observed-Adverse-Effect Level (LOAEL) -- The lowest dose of chemical in a study, or group of studies, that produces statistically or biologically significant increases in frequency or severity of adverse effects between the exposed population and its appropriate control.

Malformations -- Permanent structural changes that may adversely affect survival, development, or function.

Minimal Risk Level -- An estimate of daily human exposure to a dose of a chemical that is likely to be without an appreciable risk of adverse noncancerous effects over a specified duration of exposure.

Mutagen -- A substance that causes mutations. A mutation is a change in the genetic material in a body cell. Mutations can lead to birth defects, miscarriages, or cancer.

Neurotoxicity -- The occurrence of adverse effects on the nervous system following exposure to chemical.

No-Observed-Adverse-Effect Level (NOAEL) -- The dose of chemical at which there were no statistically or biologically significant increases in frequency or severity of adverse effects seen 
between the exposed population and its appropriate control. Effects may be produced at this dose, but they are not considered to be adverse.

Octanol-Water Partition Coefficient $\left(\mathbf{K}_{\mathbf{o w}}\right)$-- The equilibrium ratio of the concentrations of a chemical in noctanol and water, in dilute solution.

Permissible Exposure Limit (PEL) -- An allowable exposure level in workplace air averaged over an 8-hour shift.

$\mathbf{q}_{1}{ }^{*}$-- The upper-bound estimate of the low-dose slope of the dose-response curve as determined by the multistage procedure. The $\mathrm{q}_{1}{ }^{*}$ can be used to calculate an estimate of carcinogenic potency, the incremental excess cancer risk per unit of exposure (usually $\mu \mathrm{g} / \mathrm{L}$ for water, $\mathrm{mg} / \mathrm{kg} / \mathrm{day}$ for food, and $\mu \mathrm{g} / \mathrm{m}^{3}$ for air).

Reference Dose (RfD) -- An estimate (with uncertainty spanning perhaps an order of magnitude) of the daily exposure of the human population to a potential hazard that is likely to be without risk of deleterious effects during a lifetime. The RfD is operationally derived from the NOAEL (from animal and human studies) by a consistent application of uncertainty factors that reflect various types of data used to estimate RfDs and an additional modifying factor, which is based on a professional judgment of the entire database on the chemical. The RfDs are not applicable to nonthreshold effects such as cancer.

Reportable Quantity (RQ) -- The quantity of a hazardous substance that is considered reportable under CERCLA. Reportable quantities are (1) 1 pound or greater or (2) for selected substances, an amount established by regulation either under CERCLA or under Sect. 311 of the Clean Water Act. Quantities are measured over a 24-hour period.

Reproductive Toxicity -- The occurrence of adverse effects on the reproductive system that may result from exposure to a chemical. The toxicity may be directed to the reproductive organs and/or the related endocrine system. The manifestation of such toxicity may be noted as alterations in sexual behavior, fertility, pregnancy outcomes, or modifications in other functions that are dependent on the integrity of this system.

Short-Term Exposure Limit (STEL) -- The maximum concentration to which workers can be exposed for up to 15 min continually. No more than four excursions are allowed per day, and there must be at least $60 \mathrm{~min}$ between exposure periods. The daily TLV-TWA may not be exceeded.

Target Organ Toxicity -- This term covers a broad range of adverse effects on target organs or physiological systems (e.g., renal, cardiovascular) extending from those arising through a single limited exposure to those assumed over a lifetime of exposure to a chemical.

Teratogen -- A chemical that causes structural defects that affect the development of an organism.

Threshold Limit Value (TLV) -- A concentration of a substance to which most workers can be exposed without adverse effect. The TLV may be expressed as a TWA, as a STEL, or as a CL.

Time-Weighted Average (TWA) -- An allowable exposure concentration averaged over a normal 8-hour workday or 40-hour workweek. 
Toxic Dose $\left(\mathbf{T D}_{\mathbf{5 0}}\right)$-- A calculated dose of a chemical, introduced by a route other than inhalation, which is expected to cause a specific toxic effect in $50 \%$ of a defined experimental animal population.

Uncertainty Factor (UF) -- A factor used in operationally deriving the RfD from experimental data. UFs are intended to account for (1) the variation in sensitivity among the members of the human population, (2) the uncertainty in extrapolating animal data to the case of human, (3) the uncertainty in extrapolating from data obtained in a study that is of less than lifetime exposure, and (4) the uncertainty in using LOAEL data rather than NOAEL data. Usually each of these factors is set equal to 10 . 


\section{APPENDIX A}

\section{USER'S GUIDE}

\section{Chapter 1}

\section{Public Health Statement}

This chapter of the profile is a health effects summary written in nontechnical language. Its intended audience is the general public especially people living in the vicinity of a hazardous waste site or substance release. If the Public Health Statement were removed from the rest of the document, it would still communicate to the lay public essential information about the substance.

The major headings in the Public Health Statement are useful to find specific topics of concern. The topics are written in a question and answer format. The answer to each question includes a sentence that will direct the reader to chapters in the profile that will provide more information on the given topic.

\section{Chapter 2}

\section{Tables and Figures for Levels of Significant Exposure (LSE)}

Tables (2-1, 2-2, and 2-3) and figures (2-1 and 2-2) are used to summarize health effects by duration of exposure and end point and to illustrate graphically levels of exposure associated with those effects. All entries in these tables and figures represent studies that provide reliable, quantitative estimates of No-Observed-Adverse-Effect Levels (NOAELs), Lowest-Observed-Adverse-Effect Levels (LOAELs) for Less Serious and Serious health effects, or Cancer Effect Levels (CELs). In addition, these tables and figures illustrate differences in response by species, Minimal Risk Levels (MRLs) to humans for noncancer end points, and EPA's estimated range associated with an upper-bound individual lifetime cancer risk of 1 in 10,000 to 1 in 10,000,000. The LSE tables and figures can be used for a quick review of the health effects and to locate data for a specific exposure scenario. The LSE tables and figures should always be used in conjunction with the text.

The legends presented below demonstrate the application of these tables and figures. A representative example of LSE Table 2-1 and Figure 2-1 are shown. The numbers in the left column of the legends correspond to the numbers in the example table and figure.

\section{LEGEND}

\section{See LSE Table 2-1}

(1). Route of Exposure One of the first considerations when reviewing the toxicity of a substance using these tables and figures should be the relevant and appropriate route of exposure. When sufficient data exist, three LSE tables and two LSE figures are presented in the document. The three LSE tables present data on the three principal routes of exposure, i.e., inhalation, oral, and dermal (LSE Table 2-1, 2-2, and 2-3, respectively). LSE figures are limited to the inhalation (LSE Figure 2-1) and oral (LSE Figure 2-2) routes.

(2). Exposure Duration Three exposure periods: acute (14 days or less); intermediate (15 to 364 days); and chronic (365 days or more) are presented within each route of exposure. In this example, an inhalation study of intermediate duration exposure is reported. 
(3). Health Effect The major categories of health effects included in LSE tables and figures are death, systemic, immunological, neurological, developmental, reproductive, and cancer. NOAELs and LOAELs can be reported in the tables and figures for all effects but cancer. Systemic effects are further defined in the "System" column of the LSE table.

(4). Key to Figure Each key number in the LSE table links study information to one or more data points using the same key number in the corresponding LSE figure. In this example, the study represented by key number 18 has been used to define a NOAEL and a Less Serious LOAEL (also see the two "18r" data points in Figure 2-1).

(5). Species The test species, whether animal or human, are identified in this column. Species

(6). Exposure Frequency/Duration The duration of the study and the weekly and daily exposure regimen are provided in this column. This permits comparison of NOAELs and LOAELs from different studies. In this case (key number 18), rats were exposed to [substance $\mathrm{x}$ ] via inhalation for 13 weeks, 5 days per week, for 6 hours per day.

(7). System This column further defines the systemic effects. These systems include: respiratory, cardiovascular, gastrointestinal, hematological, musculoskeletal, hepatic, renal, and dermal/ocular. "Other" refers to any systemic effect (e.g., a decrease in body weight) not covered in these systems. In the example of key number 18, one systemic effect (respiratory) was investigated in this study.

(8). NOAEL A No-Observed-Adverse-Effect Level (NOAEL) is the highest exposure level at which no harmful effects were seen in the organ system studied. Key number 18 reports a NOAEL of $3 \mathrm{ppm}$ for the respiratory system which was used to derive an intermediate exposure, inhalation MRL of $0.005 \mathrm{ppm}$ (see footnote "b").

(9). LOAEL A Lowest-Observed-Adverse-Effect Level (LOAEL) is the lowest exposure level used in the study that caused a harmful health effect. LOAELs have been classified into "Less Serious" and "Serious" effects. These distinctions help readers identify the levels of exposure at which adverse health effects first appear and the gradation of effects with increasing dose. A brief description of the specific end point used to quantify the adverse effect accompanies the LOAEL. The "Less Serious" respiratory effect reported in key number 18 (hyperplasia) occurred at a LOAEL of $10 \mathrm{ppm}$.

(10). $\quad$ Reference The complete reference citation is given in Chapter 8 of the profile.

(11). CEL A Cancer Effect Level (CEL) is the lowest exposure level associated with the onset of carcinogenesis in experimental or epidemiological studies. CELs are always considered serious effects. The LSE tables and figures do not contain NOAELs for cancer, but the text may report doses which did not cause a measurable increase in cancer.

(12). Footnotes Explanations of abbreviations or reference notes for data in the LSE tables are found in the footnotes. Footnote " $b$ " indicates the NOAEL of 3 ppm in key number 18 was used to derive an MRL of $0.005 \mathrm{ppm}$.

\section{LEGEND}

\section{See LSE Figure 2-1}

LSE figures graphically illustrate the data presented in the corresponding LSE tables. Figures help the reader quickly compare health effects according to exposure levels for particular exposure duration, 


\begin{tabular}{|c|c|c|c|c|c|c|c|c|}
\hline \multirow[b]{2}{*}{$\begin{array}{l}\text { Key to } \\
\text { figure }\end{array}$} & \multirow[b]{2}{*}{ Species } & \multirow{2}{*}{$\begin{array}{l}\text { Exposure } \\
\text { frequency/ } \\
\text { duration }\end{array}$} & \multirow[b]{2}{*}{ System } & \multirow[b]{2}{*}{$\begin{array}{l}\text { NOAEL } \\
(\mathrm{ppm})\end{array}$} & \multicolumn{3}{|c|}{ LOAEL (effect) } & \multirow[b]{2}{*}{ Reference } \\
\hline & & & & & $\begin{array}{c}\text { Less serious } \\
\text { (ppm) }\end{array}$ & & $\begin{array}{l}\text { Serious } \\
\text { (ppm) }\end{array}$ & \\
\hline & 5 & 6 & 7 & 8. & 9 & & & 10 \\
\hline 18 & Rat & $\begin{array}{l}13 \mathrm{wk} \\
5 \mathrm{~d} / \mathrm{wk} \\
6 \mathrm{hr} / \mathrm{d}\end{array}$ & Resp & $3^{\mathrm{b}}$ & 10 (hyperplasia) & & & $\begin{array}{l}\text { Nitschke et al. } \\
1981\end{array}$ \\
\hline $\begin{array}{l}\text { CHRONIC } \\
\text { Cancer }\end{array}$ & EXPOSURE & & & & & $\frac{11}{1}$ & & \\
\hline 38 & Rat & $\begin{array}{l}18 \mathrm{mo} \\
5 \mathrm{~d} / \mathrm{wk} \\
7 \mathrm{hr} / \mathrm{d}\end{array}$ & & & & 20 & $\begin{array}{l}\text { (CEL, multiple } \\
\text { organs) }\end{array}$ & Wong et a1. 1982 \\
\hline 39 & Rat & $\begin{array}{l}89-104 \text { wk } \\
5 \mathrm{~d} / \mathrm{wk} \\
6 \mathrm{hr} / \mathrm{d}\end{array}$ & & & & 10 & $\begin{array}{l}\text { (CEL, Iung tumors, } \\
\text { nasal tumors) }\end{array}$ & NTP 1982 \\
\hline 40 & Mouse & $\begin{array}{l}79-103 \mathrm{wk} \\
5 \mathrm{~d} / \mathrm{wk} \\
6 \mathrm{hr} / \mathrm{d}\end{array}$ & & & & 10 & $\begin{array}{l}\text { (CEL, lung tumors, } \\
\text { hemangiosarcomas) }\end{array}$ & NTP 1982 \\
\hline
\end{tabular}

a The number corresponds to entries in Figure 2-1.

II: $\rightarrow$ b Used to derive an intermediate inhalation Minimal Risk Level (MRL) of $5 \times 10^{-3}$ ppm; dose adjusted for intermittent exposure and divided by an uncertainty factor of 100 (10 for extrapolation from animal to humans, 10 for CEL = cancer effect level; $\mathrm{d}=\mathrm{day}(\mathrm{s}) ; \mathrm{hr}=\mathrm{hour}(\mathrm{s}) ; \mathrm{LOAEL}=$ lowest-observed-adverse-effect level; mo = month(s); NOAEL =
no-observed-adverse-effect level; Resp = respiratory; wh = week $(\mathrm{s})$ 


\section{SAMPLE}

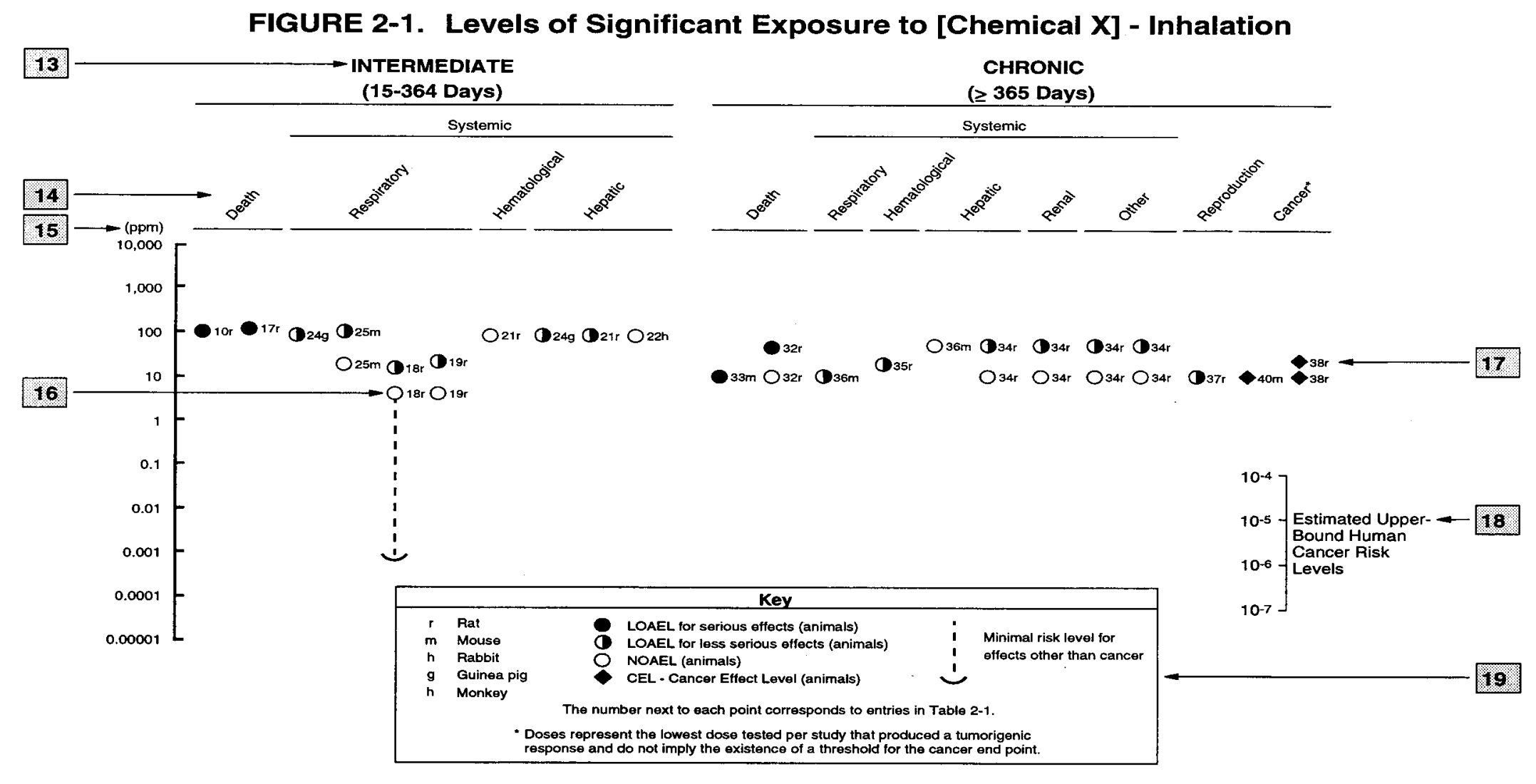


(13). Exposure Duration The same exposure periods appear as in the LSE table. In this example, health effects observed within the intermediate and chronic exposure periods are illustrated.

(14). Health Effect These are the categories of health effects for which reliable quantitative data exist. The same health effects appear in the LSE table.

(15). Levels of Exposure Exposure levels for each health effect in the LSE tables are graphically displayed in the LSE figures. Exposure levels are reported on the log scale "y" axis. Inhalation exposure is reported in $\mathrm{mg} / \mathrm{m}^{3}$ or ppm and oral exposure is reported in $\mathrm{mg} / \mathrm{kg} / \mathrm{day}$.

(16). NOAEL In this example, 18r NOAEL is the critical end point for which an intermediate inhalation exposure MRL is based. As you can see from the LSE figure key, the open-circle symbol indicates a NOAEL for the test species (rat). The key number 18 corresponds to the entry in the LSE table. The dashed descending arrow indicates the extrapolation from the exposure level of $3 \mathrm{ppm}$ (see entry 18 in the Table) to the MRL of $0.005 \mathrm{ppm}$ (see footnote " $\mathrm{b}$ " in the LSE table).

(17). CEL Key number 38r is one of three studies for which Cancer Effect Levels (CELs) were derived. The diamond symbol refers to a CEL for the test species (rat). The number 38 corresponds to the entry in the LSE table.

(18). Estimated Upper-Bound Human Cancer Risk Levels This is the range associated with the upper-bound for lifetime cancer risk of 1 in 10,000 to 1 in 10,000,000. These risk levels are derived from EPA's Human Health Assessment Group's upper-bound estimates of the slope of the cancer dose response curve at low dose levels $\left(\mathrm{q}_{1}{ }^{*}\right)$.

(19). Key to LSE Figure The Key explains the abbreviations and symbols used in the figure.

\section{Chapter 2 (Section 2.4)}

\section{Relevance to Public Health}

The Relevance to Public Health section provides a health effects summary based on evaluations of existing toxicological, epidemiological, and toxicokinetic information. This summary is designed to present interpretive, weight-of-evidence discussions for human health end points by addressing the following questions.

1. What effects are known to occur in humans?

2. What effects observed in animals are likely to be of concern to humans?

3. What exposure conditions are likely to be of concern to humans, especially around hazardous waste sites?

The section discusses health effects by end point. Human data are presented first, then animal data. Both are organized by route of exposure (inhalation, oral, and dermal) and by duration (acute, intermediate, and chronic). In vitro data and data from parenteral routes (intramuscular, intravenous, subcutaneous, etc.) are also considered in this section. If data are located in the scientific literature, a table of genotoxicity information is included. 
The carcinogenic potential of the profiled substance is qualitatively evaluated, when appropriate, using existing toxicokinetic, genotoxic, and carcinogenic data. ATSDR does not currently assess cancer potency or perform cancer risk assessments. MRLs for noncancer end points if derived, and the end points from which they were derived are indicated and discussed in the appropriate section(s).

Limitations to existing scientific literature that prevent a satisfactory evaluation of the relevance to public health are identified in the Identification of Data Needs section.

\section{Interpretation of Minimal Risk Levels}

Where sufficient toxicologic information was available, MRLs were derived. MRLs are specific for route (inhalation or oral) and duration (acute, intermediate, or chronic) of exposure. Ideally, MRLs can be derived from all six exposure scenarios (e.g., Inhalation - acute, -intermediate, -chronic; Oral acute, -intermediate, - chronic). These MRLs are not meant to support regulatory action, but to acquaint health professionals with exposure levels at which adverse health effects are not expected to occur in humans. They should help physicians and public health officials determine the safety of a community living near a substance emission, given the concentration of a contaminant in air or the estimated daily dose received via food or water. MRLs are based largely on toxicological studies in animals and on reports of human occupational exposure.

MRL users should be familiar with the toxicological information on which the number is based. Section 2.4, "Relevance to Public Health," contains basic information known about the substance. Other sections such as 2.6, "Interactions with Other Chemicals" and 2.7, "Populations that are Unusually Susceptible" provide important supplemental information.

MRL users should also understand the MRL derivation methodology. MRLs are derived using a modified version of the risk assessment methodology used by the Environmental Protection Agency (EPA) (Barnes and Dourson 1988; EPA 1989a) to derive reference doses (RfDs) for lifetime exposure.

To derive an MRL, ATSDR generally selects the end point which, in its best judgement, represents the most sensitive human health effect for a given exposure route and duration. ATSDR cannot make this judgement or derive an MRL unless information (quantitative or qualitative) is available for all potential effects (e.g., systemic, neurological, and developmental). In order to compare NOAELs and LOAELs for specific end points, all inhalation exposure levels are adjusted for $24 \mathrm{hr}$ exposures and all intermittent exposures for inhalation and oral routes of intermediate and chronic duration are adjusted for continuous exposure (i.e., 7 days/week). If the information and reliable quantitative data on the chosen end point are available, ATSDR derives an MRL using the most sensitive species (when information from multiple species is available) with the highest NOAEL that does not exceed any adverse effect levels. The NOAEL is the most suitable end point for deriving an MRL. When a NOAEL is not available, a Less Serious LOAEL can be used to derive an MRL, and an uncertainty factor of (1, 3 , or 10) is employed. MRLs are not derived from Serious LOAELs. Additional uncertainty factors of $(1,3$, or 10$)$ are used for human variability to protect sensitive subpopulations (people who are most susceptible to the health effects caused by the substance) and $(1,3$, or 10) are used for interspecies variability (extrapolation from animals to humans). In deriving an MRL, these individual uncertainty factors are multiplied together. Generally an uncertainty factor of 10 is used; however, the MRL Workgroup reserves the right to use uncertainty factors of $(1,3$, or 10) based on scientific judgement. The product is then divided into the adjusted inhalation concentration or oral dosage selected from the study. Uncertainty factors used in developing a substance-specific MRL are provided in the footnotes of the LSE Tables. 


\section{APPENDIX B}

\section{ACRONYMS, ABBREVIATIONS, AND SYMBOLS}

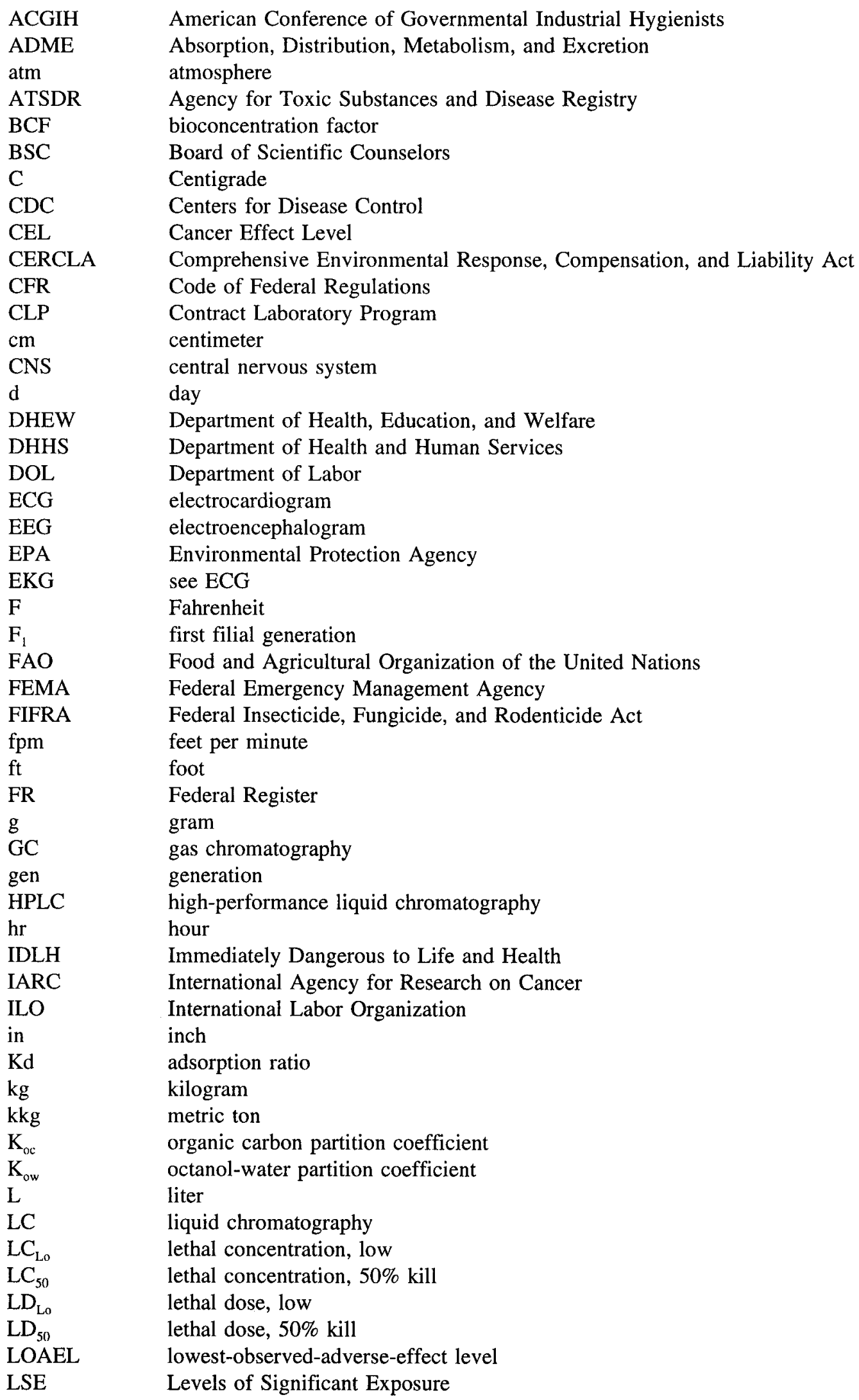




\begin{tabular}{|c|c|}
\hline $\mathrm{m}$ & meter \\
\hline $\mathrm{mg}$ & milligram \\
\hline $\min$ & minute \\
\hline $\mathrm{mL}$ & milliliter \\
\hline $\mathrm{mm}$ & millimeter \\
\hline $\mathrm{mmHg}$ & millimeters of mercury \\
\hline mmol & millimole \\
\hline mo & month \\
\hline mppcf & millions of particles per cubic foot \\
\hline MRL & Minimal Risk Level \\
\hline MS & mass spectrometry \\
\hline NIEHS & National Institute of Environmental Health Sciences \\
\hline $\mathrm{NIOSH}$ & National Institute for Occupational Safety and Health \\
\hline $\begin{array}{l}\text { NIOSHTIC } \\
\text { ng }\end{array}$ & $\begin{array}{l}\text { NIOSH's Computerized Information Retrieval System } \\
\text { nanogram }\end{array}$ \\
\hline $\mathrm{nm}$ & nanometer \\
\hline $\begin{array}{l}\text { NHANES } \\
\text { nmol }\end{array}$ & $\begin{array}{l}\text { National Health and Nutrition Examination Survey } \\
\text { nanomole }\end{array}$ \\
\hline NOAEL & no-observed-adverse-effect level \\
\hline NOES & National Occupational Exposure Survey \\
\hline NOHS & National Occupational Hazard Survey \\
\hline NPL & National Priorities List \\
\hline NRC & National Research Council \\
\hline NTIS & National Technical Information Service \\
\hline NTP & National Toxicology Program \\
\hline OSHA & Occupational Safety and Health Administration \\
\hline PEL & permissible exposure limit \\
\hline $\mathrm{pg}$ & picogram \\
\hline pmol & picomole \\
\hline PHS & Public Health Service \\
\hline PMR & proportionate mortality ratio \\
\hline $\mathrm{ppb}$ & parts per billion \\
\hline ppm & parts per million \\
\hline ppt & parts per trillion \\
\hline REL & recommended exposure limit \\
\hline RfD & Reference Dose \\
\hline $\begin{array}{l}\text { RTECS } \\
\text { sec }\end{array}$ & $\begin{array}{l}\text { Registry of Toxic Effects of Chemical Substances } \\
\text { second }\end{array}$ \\
\hline SCE & sister chromatid exchange \\
\hline SIC & Standard Industrial Classification \\
\hline SMR & standard mortality ratio \\
\hline STEL & short term exposure limit \\
\hline STORET & STORAGE and RETRIEVAL \\
\hline TLV & threshold limit value \\
\hline TSCA & Toxic Substances Control Act \\
\hline TRI & Toxics Release Inventory \\
\hline TWA & time-weighted average \\
\hline U.S. & United States \\
\hline UF & uncertainty factor \\
\hline $\mathrm{yr}$ & year \\
\hline $\begin{array}{l}\text { WHO } \\
\text { wk }\end{array}$ & $\begin{array}{l}\text { World Health Organization } \\
\text { week }\end{array}$ \\
\hline$>$ & greater than \\
\hline$\geq$ & greater than or equal to \\
\hline
\end{tabular}


APPENDIX B

$\begin{array}{ll}= & \text { equal to } \\ < & \text { less than } \\ \leq & \text { less than or equal to } \\ \% & \text { percent } \\ \alpha & \text { alpha } \\ \beta & \text { beta } \\ \delta & \text { delta } \\ \gamma & \text { gamma } \\ \mu \mathrm{m} & \text { micron } \\ \mu \mathrm{g} & \text { microgram }\end{array}$

\#U.S. GOVERMAENT PRINTING OFFICE: 638-643 